Cochrane Database of Systematic Reviews

\title{
Interventions to improve adherence to lipid-lowering medication
} (Review)

van Driel ML, Morledge MD, Ulep R, Shaffer JP, Davies P, Deichmann R

van Driel ML, Morledge MD, Ulep R, Shaffer JP, Davies P, Deichmann R.

Interventions to improve adherence to lipid-lowering medication.

Cochrane Database of Systematic Reviews 2016, Issue 12. Art. No.: CD004371.

DOI: 10.1002/14651858.CD004371.pub4.

www.cochranelibrary.com 
TABLE OF CONTENTS

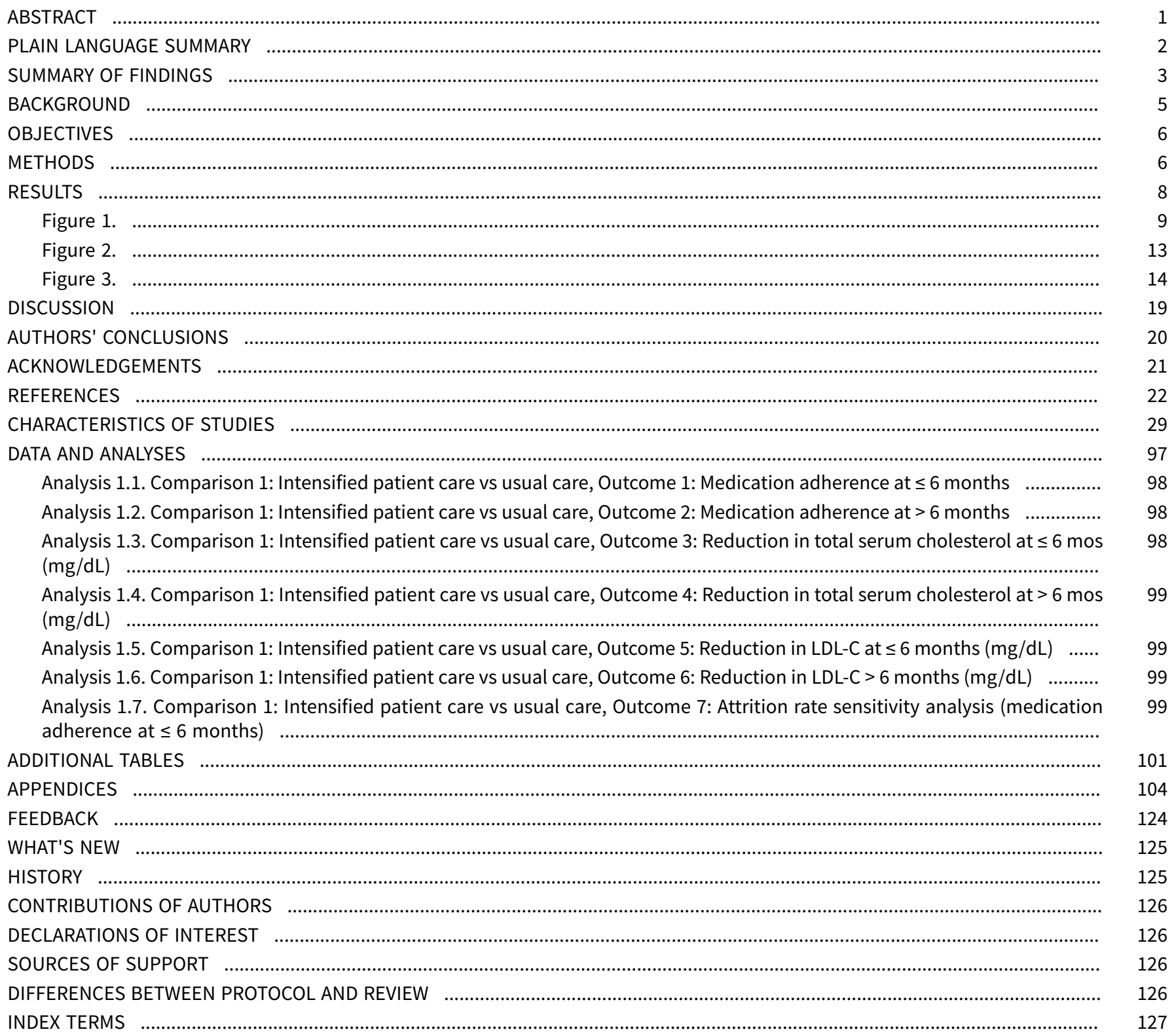


[Intervention Review]

\section{Interventions to improve adherence to lipid-lowering medication}

Mieke L van Driel1,2, Michael D Morledge³, Robin Ulep³, Johnathon P Shaffer ${ }^{3}$, Philippa Davies ${ }^{4}$, Richard Deichmann 5

1Primary Care Clinical Unit, Faculty of Medicine, The University of Queensland, Brisbane, Australia. 2Department of Public Health and Primary Care, Ghent University, Ghent, Belgium. ${ }^{3}$ Ochsner Clinical School, School of Medicine, The University of Queensland, New Orleans, USA. ${ }^{4}$ Population Health Sciences, Bristol Medical School, University of Bristol, Bristol, UK. ${ }^{5}$ Department of Internal Medicine, Ochsner Health System, New Orleans, USA

Contact: Mieke L van Driel, m.vandriel@uq.edu.au.

Editorial group: Cochrane Heart Group.

Publication status and date: Edited (no change to conclusions), published in Issue 3, 2021.

Citation: van Driel ML, Morledge MD, Ulep R, Shaffer JP, Davies P, Deichmann R. Interventions to improve adherence to lipid-lowering medication. Cochrane Database of Systematic Reviews 2016, Issue 12. Art. No.: CD004371. DOI: 10.1002/14651858.CD004371.pub4.

Copyright (c 2016 The Cochrane Collaboration. Published by John Wiley \& Sons, Ltd.

\section{A B S T R A C T}

\section{Background}

Lipid-lowering drugs are widely underused, despite strong evidence indicating they improve cardiovascular end points. Poor patient adherence to a medication regimen can affect the success of lipid-lowering treatment.

\section{Objectives}

To assess the effects of interventions aimed at improving adherence to lipid-lowering drugs, focusing on measures of adherence and clinical outcomes.

\section{Search methods}

We searched the Cochrane Central Register of Controlled Trials (CENTRAL), MEDLINE, Embase, PsycINFO and CINAHL up to 3 February 2016, and clinical trials registers (ANZCTR and ClinicalTrials.gov) up to 27 July 2016. We applied no language restrictions.

\section{Selection criteria}

We evaluated randomised controlled trials of adherence-enhancing interventions for lipid-lowering medication in adults in an ambulatory setting with a variety of measurable outcomes, such as adherence to treatment and changes to serum lipid levels. Two teams of review authors independently selected the studies.

\section{Data collection and analysis}

Three review authors extracted and assessed data, following criteria outlined by the Cochrane Handbook for Systematic Reviews of Interventions. We assessed the quality of the evidence using GRADEPro.

\section{Main results}

For this updated review, we added 24 new studies meeting the eligibility criteria to the 11 studies from prior updates. We have therefore included 35 studies, randomising 925,171 participants. Seven studies including 11,204 individuals compared adherence rates of those in an intensification of a patient care intervention (e.g. electronic reminders, pharmacist-led interventions, healthcare professional education of patients) versus usual care over the short term (six months or less), and were pooled in a meta-analysis. Participants in the intervention group had better adherence than those receiving usual care (odds ratio (OR) 1.93, 95\% confidence interval (CI) 1.29 to $2.88 ; 7$ studies; 11,204 participants; moderate-quality evidence). A separate analysis also showed improvements in long-term adherence rates (more than six months) using intensification of care (OR 2.87, 95\% Cl 1.91 to 4.29; 3 studies; 663 participants; high-quality evidence). Analyses of the effect on total cholesterol and LDL-cholesterol levels also showed a positive effect of intensified interventions over both short- and long-term follow-up. Over the short term, total cholesterol decreased by a mean of $17.15 \mathrm{mg} / \mathrm{dL}$ (95\% Cl 1.17 to 33.14; 4 studies; 430 participants; low- 
quality evidence) and LDL-cholesterol decreased by a mean of $19.51 \mathrm{mg} / \mathrm{dL}$ (95\% Cl 8.51 to 30.51; 3 studies; 333 participants; moderatequality evidence). Over the long term (more than six months) total cholesterol decreased by a mean of $17.57 \mathrm{mg} / \mathrm{dL}$ (95\% Cl 14.95 to 20.19 ; 2 studies; 127 participants; high-quality evidence). Included studies did not report usable data for health outcome indications, adverse effects or costs/resource use, so we could not pool these outcomes. We assessed each included study for bias using methods described in the Cochrane Handbook for Systematic Reviews of Interventions. In general, the risk of bias assessment revealed a low risk of selection bias, attrition bias, and reporting bias. There was unclear risk of bias relating to blinding for most studies.

\section{Authors' conclusions}

The evidence in our review demonstrates that intensification of patient care interventions improves short- and long-term medication adherence, as well as total cholesterol and LDL-cholesterol levels. Healthcare systems which can implement team-based intensification of patient care interventions may be successful in improving patient adherence rates to lipid-lowering medicines.

\section{PLAIN LANGUAGE SUMMARY}

\section{Interventions to improve people's drug-taking behaviour with lipid-lowering drugs}

\section{Review question}

Which interventions help improve people's ability to take lipid-lowering medications more regularly?

\section{Background}

Lipid-lowering therapy has been shown to decrease the risk of both heart attacks and strokes. However, taking these medications as prescribed has not been as high as one would wish. In the past, several methods have been tried to improve the rate at which people take these lipid-lowering treatments. Previous Cochrane Reviews have not shown a clear benefit of any particular method. We have updated our review to see if any new methods in this digital age have been tested as ways of improving these rates.

\section{Search}

Our search included the 11 studies identified from previous versions in 2004 and 2010. We conducted an updated search of the same electronic databases on 3 February 2016, and we searched clinical trials registers up to 27 July 2016.

\section{Study characteristics}

The people included in the studies were adults over 18 years of age in outpatient settings, for whom lipid-lowering therapy was recommended. We now include 35 studies covering 925,171 participants in this review.

\section{Key results}

Of the 35 included studies, 16 compared interventions categorised as 'intensified patient care' versus usual care. These interventions included electronic reminders, pharmacist-led interventions, and healthcare professional education to help people better remember to take their medications. These types of interventions when compared to standard care demonstrated significantly better adherence rates both over the short term (up to and including six months) as well as the long term (longer than six months). Additionally, cholesterol levels were better over both long- and short-term periods in those offered the intervention, compared to those receiving usual care.

\section{Quality of the evidence}

We considered only randomised controlled trials for this review. Given the nature of the interventions, it was not possible to keep participants unaware of which group they were in. However, analysis of other forms of bias indicated that generally the studies were at low risk of bias. We assessed the evidence for the outcomes using the GRADE system, and rated it as high quality for long-term adherence (more than six months) and for reduction in total cholesterol, and moderate quality for short-term medication adherence (up to six months) and for LDL-cholesterol levels. For the outcome total cholesterol levels at less than six months follow-up, we downgraded the evidence to low quality. 


\begin{tabular}{|c|c|c|c|c|c|}
\hline \multicolumn{6}{|c|}{ Summary of findings table for the comparison of 'intensified patient care' vs 'usual care } \\
\hline \multicolumn{6}{|c|}{ Intensified patient care vs usual care } \\
\hline \multicolumn{6}{|c|}{$\begin{array}{l}\text { Patient or population: People receiving lipid-lowering medications } \\
\text { Setting: Ambulatory } \\
\text { Intervention: Intensified patient care } \\
\text { Comparison: Usual care }\end{array}$} \\
\hline \multirow[t]{2}{*}{ Outcomes } & \multicolumn{2}{|c|}{ Anticipated absolute effects ${ }^{\star}(95 \% \mathrm{Cl})$} & \multirow{2}{*}{$\begin{array}{l}\text { Relative effect } \\
(95 \% \mathrm{CI})\end{array}$} & \multirow{2}{*}{$\begin{array}{l}\text { № of participants } \\
\text { (studies) }\end{array}$} & \multirow{2}{*}{$\begin{array}{l}\text { Quality of the evi- } \\
\text { dence } \\
\text { (GRADE) }\end{array}$} \\
\hline & Risk with usual care & Risk with Intensified patient care & & & \\
\hline \multirow{2}{*}{$\begin{array}{l}\text { Medication adherence } \\
\text { at } \leq 6 \text { months }\end{array}$} & Study population & & \multirow{2}{*}{$\begin{array}{l}\text { OR } 1.93 \\
(1.29 \text { to } 2.88)\end{array}$} & \multirow{2}{*}{$\begin{array}{l}11,204 \\
\text { (7 RCTs) }\end{array}$} & \multirow{2}{*}{$\begin{array}{l}\oplus \oplus \oplus \ominus \\
\text { MODERATE } 1\end{array}$} \\
\hline & 456 per 1,000 & $\begin{array}{l}618 \text { per } 1,000 \\
(519 \text { to } 707)\end{array}$ & & & \\
\hline \multirow{2}{*}{$\begin{array}{l}\text { Medication adherence } \\
\text { at }>6 \text { months }\end{array}$} & \multicolumn{2}{|l|}{ Study population } & \multirow{2}{*}{$\begin{array}{l}\text { OR } 2.87 \\
(1.91 \text { to } 4.29)\end{array}$} & \multirow{2}{*}{$\begin{array}{l}663 \\
\text { (3 RCTs) }\end{array}$} & \multirow{2}{*}{$\begin{array}{l}\oplus \oplus \oplus \oplus \\
\mathrm{HIGH}\end{array}$} \\
\hline & 705 per 1,000 & $\begin{array}{l}873 \text { per } 1,000 \\
(820 \text { to } 911)\end{array}$ & & & \\
\hline $\begin{array}{l}\text { Reduction in LDL-C at } \leq \\
6 \text { months }(\mathrm{mg} / \mathrm{dL})\end{array}$ & $\begin{array}{l}\text { The mean reduction in } \\
\mathrm{LDL}-\mathrm{C} \text { at } \leq 6 \text { months }(\mathrm{mg} / \\
\mathrm{dL}) \text { was } 0\end{array}$ & $\begin{array}{l}\text { The mean reduction in } L D L-C \text { at } \leq 6 \text { months } \\
(\mathrm{mg} / \mathrm{dL}) \text { in the intervention group was } 19.51 \\
\text { greater ( } 8.51 \text { greater to } 30.51 \text { greater) }\end{array}$ & - & $\begin{array}{l}333 \\
\text { (3 RCTs) }\end{array}$ & $\begin{array}{l}\oplus \oplus \oplus \ominus \\
\text { MODERATE } 1\end{array}$ \\
\hline $\begin{array}{l}\text { Reduction in total } \\
\text { serum cholesterol at } \leq \\
6 \text { months }(\mathrm{mg} / \mathrm{dL})\end{array}$ & $\begin{array}{l}\text { The mean reduction in to- } \\
\text { tal serum cholesterol at } \leq \\
6 \mathrm{mos}(\mathrm{mg} / \mathrm{dL}) \text { was } 0\end{array}$ & $\begin{array}{l}\text { The mean reduction in total serum choles- } \\
\text { terol at } \leq 6 \text { months }(\mathrm{mg} / \mathrm{dL}) \text { in the intervention } \\
\text { group was } 17.15 \text { greater }(1.17 \text { greater to } 33.14 \\
\text { greater) }\end{array}$ & - & $\begin{array}{l}430 \\
(4 \mathrm{RCTS})\end{array}$ & $\begin{array}{l}\oplus \oplus \odot \odot \\
\text { LOW } 1,2\end{array}$ \\
\hline $\begin{array}{l}\text { Reduction in total } \\
\text { serum cholesterol at }> \\
6 \operatorname{mos}(\mathrm{mg} / \mathrm{dL})\end{array}$ & $\begin{array}{l}\text { The mean reduction in to- } \\
\text { tal serum cholesterol at }> \\
6 \text { months }(\mathrm{mg} / \mathrm{dL}) \text { was } 0\end{array}$ & $\begin{array}{l}\text { The mean reduction in total serum choles- } \\
\text { terol at }>6 \text { months }(\mathrm{mg} / \mathrm{dL}) \text { in the intervention } \\
\text { group was } 17.57 \text { greater }(14.95 \text { greater to } 20.19 \\
\text { greater) }\end{array}$ & - & $\begin{array}{l}127 \\
(2 \mathrm{RCTs})\end{array}$ & $\begin{array}{l}\oplus \oplus \oplus \oplus \\
\mathrm{HIGH}\end{array}$ \\
\hline
\end{tabular}

${ }^{\star}$ The risk in the intervention group (and its $95 \%$ confidence interval) is based on the assumed risk in the comparison group and the relative effect of the intervention (and its $95 \% \mathrm{Cl})$.

Cl: Confidence interval; OR: Odds ratio; 
High quality: We are very confident that the true effect lies close to that of the estimate of the effect

Moderate quality: We are moderately confident in the effect estimate: The true effect is likely to be close to the estimate of the effect, but there is a possibility that it is sub-

stantially different

Low quality: Our confidence in the effect estimate is limited: The true effect may be substantially different from the estimate of the effect

Very low quality: We have very little confidence in the effect estimate: The true effect is likely to be substantially different from the estimate of effect

1Downgraded due to heterogeneity

2Downgraded due to wide confidence interval 


\section{B A C K G R O U N D}

Despite compelling evidence about the effectiveness of lipidlowering drugs and the introduction of clear guidelines, lipidlowering therapy is still underused (Rosenson 2015). Recent recommendations by the American College of Cardiology/ American Heart Association are expected to significantly increase the number of individuals for whom statin therapy is indicated (ACC/AHA Guidelines 2013). Lack of adherence and high rates of discontinuation have been shown to be important factors in failing treatment when looking both at high cholesterol levels and at morbidity in terms of recurrent myocardial infarction (Blackburn 2005; Cheng 2004; Wei 2002).

\section{Description of the condition}

High cholesterol is one of the top 10 risk factors that account for more than one-third of all deaths worldwide (WHO Report 2002). It is an important risk factor for cardiovascular disease (CVD), estimated to cause $18 \%$ of CVD and $56 \%$ of ischaemic heart disease (WHO Report 2002). There is compelling evidence for the effectiveness of lipid-lowering drugs in reducing both lipid levels and the risk of heart attacks and strokes (Baigent 2005). Elevated serum concentrations of total cholesterol (TC), low-density lipoprotein (LDL) and total triglycerides (TRG) are associated with increased risk of coronary heart disease (CHD), whereas highdensity lipoproteins (HDL) or a low TC to HDL ratio appear to be protective. Lipid-lowering medications (hypolipidaemics) for the treatment of hyperlipidaemia include statins, fibrates and anionexchange resins. Statins, in particular, have been shown in large randomised controlled trials to be effective in preventing CHD events and in reducing overall mortality (4S 1994; Athyros 2002a; Downs 1998; LIPID 1998; MRC/BHF 2002; Sacks 1996; Shepherd 1995). Fibrates and anion-exchange resins achieved reductions in CHD events, but showed a non-significant increase in non-coronary mortality (Downs 1998). Statins are therefore recommended as first-line therapy, whereas fibrates and anion-exchange resins can be considered as second-line therapy and also in combination with statins (SIGN 2007).

Recommendations about drug treatments vary from country to country. In the UK, treatment with statins for secondary prevention is indicated in people with clinical evidence of CVD to reduce further ischaemic events. For primary prevention of CVD, lipidlowering medication is recommended in asymptomatic adults who have a $20 \%$ or greater risk of developing CVD in the next 10 years (NICE 2014; SIGN 2007). A combination of statins, blood pressurelowering drugs and low-dose aspirin is recommended by the World Health Report (WHO Report 2002) for secondary prevention of CVD, as this could cut death and disability rates from CVD by more than 50\%. A meta-analysis confirmed an approximately linear relationship between the absolute reduction in LDL-cholesterol and the proportional reductions in the incidence of coronary and major vascular events (Baigent 2005). Statin therapy resulted in a $19 \%$ proportional reduction in CHD deaths per $\mathrm{mmol} / \mathrm{L}$ LDLcholesterol reduction. It can safely reduce the five-year incidence of cardiovascular events largely irrespective of the initial lipid profile, relating the absolute benefit mainly to an individual's absolute risk of such events and the absolute reduction in LDL-cholesterol achieved (Baigent 2005). In England, 7000 myocardial infarctions and 2500 strokes could be avoided each year if individuals at high risk, who are not taking medication, received lipid-lowering treatment (Primatesta 2000). These figures show the impact of lipid-lowering drugs on public health and thus the importance of the acceptance of and adherence to medication by the public.

\section{Description of the intervention}

Adherence is defined as the extent to which people take medication as prescribed. Since the landmark publication by Sackett 1976, it has been the focus of research over the last three decades (Vermeire 2001). Adherence can either be intentional or non-intentional, and is determined by a variety of factors such as lack of knowledge, denial, adverse effects, poor memory and adverse attitudes to treatment. Reliable indicators of adherent behaviour have not been found to date and demographic factors such as age, sex or social class have been shown to be poor predictors of adherence (Vermeire 2001). The importance of the person's agreement (Lewis 2003) and the significance of their role within the doctor-patient relationship have been emphasised, which has led to replacing the term 'compliance' with more patient-centred synonyms such as 'adherence' and 'concordance' (Lewis 2003; Marinker 1997; Mullen 1997). The treatment of a symptomless condition such as hyperlipidaemia signifies a particular challenge to both doctor and patient. It has been difficult to identify the scope of the problem, as adherence rates from hyperlipidaemia trials show considerable variation, ranging from $37 \%$ to $80 \%$, depending on factors such as study population, background morbidity, classes of drugs, duration of follow-up and adherence-measuring methods (Tsuyuki 2001). Epidemiological data show that target cholesterol concentrations are achieved in fewer than $50 \%$ of people receiving cholesterollowering drugs and that only one in four people continue taking medication in the long term (Benner 2002; Primatesta 2000). Not surprisingly, primary prevention trials appear to have higher discontinuation rates than secondary prevention trials, which indicates a relationship between adherence and awareness of illness (Tsuyuki 2001). This was confirmed in a population-based study involving elderly people, where $60 \%$ of people prescribed a statin for acute coronary syndrome gave up treatment within two years, compared to $75 \%$ of those without coronary disease (Jackevicius 2002).

A wide range of interventions to improve adherence to medication have been studied (Brown 2011; Costa 2015). They can focus on the person, the drug regimen, the physician or the health system (delivery of medication). Patient education and empowerment is important, as people adhere less to drugs or treatments if they do not understand why they need to take them (Brown 2011). Simplification of the drug regimen may assist, as adherence is inversely related to the number of drugs the person is taking (Pasina 2014), and especially complex dosing schedules are at risk. Interventions focused on physicians advocate good communication and a patient-centred approach (Brown 2011), which could include appropriate follow-up and support. Systembased approaches could include pharmacist involvement and (automated) patient reminder systems.

\section{How the intervention might work}

A number of systematic reviews looking at adherence-enhancing interventions have been published in the Cochrane Library. Nieuwlaat 2014 identified effective ways to improve medication adherence for a variety of medical conditions in widely differing populations. Adherence to short-term drug treatment was improved by written information, personal phone calls and counselling. For long-term treatments, no simple intervention 
and only some complex ones led to some improvement in health outcomes (Nieuwlaat 2014). Schroeder 2004 focused on medications for controlling blood pressure and reported enhanced adherence by reducing the number of daily doses. Patient support and education interventions improved adherence to antiretroviral therapy when targeting practical medication management skills aimed at individuals rather than groups (Rueda 2006). In the treatment of type 2 diabetes, it was concluded that nurse-led interventions, home aids, diabetes education and pharmacy-led interventions do not show significant effects (Vermeire 2005). Another review concluded that reminder packaging increased the proportion of people taking their medications, but the effect was not large (Mahtani 2011).

\section{Why it is important to do this review}

The indication for prescribing lipid-lowering drugs has changed substantially over the last 20 years (ACC/AHA Guidelines 2013; Baigent 2005). With evidence to suggest that effectiveness of statins occurs irrespective of initial lipid level, greater numbers of people are being actively prescribed lipid-lowering agents. Observational studies have shown that adherence to lipid-lowering drugs is poor, with people taking their medication only $60 \%$ of the time in a one-year period (Avorn 1998). There is strong evidence that adherence diminishes over time in people who are being treated as part of a primary or secondary prevention strategy (Benner 2002; Jackevicius 2002). The consequence of inadequate adherence to lipid-lowering therapy is substantial. In secondary prevention, inadequate adherence is associated with an increase in recurrent myocardial infarction and all-cause mortality (Wei 2002). For these reasons, it is important that clinically effective and costeffective strategies to improve adherence are found for primary and secondary prevention of cardiovascular disease in the community. The findings of our review can be integrated into clinical practice guidelines and assist clinicians in making a difference to patient outcomes. This update of previous reviews, published in 2004 and updated in 2010 (Schedlbauer 2004; Schedlbauer 2010), assessed interventions designed to help people take their lipid-lowering medication in an ambulatory care setting, taking into account new and emerging evidence.

\section{OB JECTIVES}

To assess the effects of interventions aimed at improving adherence to lipid-lowering drugs, focusing on measures of adherence and clinical outcomes.

\section{METHODS}

\section{Criteria for considering studies for this review}

\section{Types of studies}

Randomised controlled trials (RCTs), of parallel-group or cross-over design, that used individual or cluster randomisation.

\section{Types of participants}

All adults (over 18 years of age) who were prescribed lipid-lowering medication for primary or secondary prevention of cardiovascular disease in ambulatory care settings.

\section{Types of interventions}

Interventions of any type intended to increase adherence to selfadministered lipid-lowering medication versus usual care or no intervention.

This included, but was not exclusive to, interventions such as:

1. simplification of drug regimen;

2. patient education and information;

3. intensified patient care (increased follow-up, sending out reminders, etc.);

4. complex behavioural approaches (increasing motivation by arranging group sessions, giving out rewards, etc.);

5. decision support systems (computer-based information systems aimed at support of decision-making);

6. administrative improvements (audit, documentation, computers, co-payments);

7. large-scale pharmacy-led automated telephone intervention.

\section{Types of outcome measures}

\section{Primary outcomes}

Methods of measuring adherence continue to be widely variable and remain controversial. We identify three categories of adherence assessment, and have included them in this review:

1. Indirect measures of adherence (e.g. pill count, prescription refill rate, electronic monitoring);

2. Subjective measures of adherence (e.g. person's self-report in diaries, interviews);

3. Direct measures of adherence (tracer substances in blood or urine).

\section{Secondary outcomes}

We have also included the following outcome measures, in addition to adherence measures:

1. Physiological indicators (e.g. total cholesterol);

2. Health outcome indications (e.g. quality of life, morbidity, mortality);

3. Adverse effects;

4. Implications for costs (impact of intervention on economic outcomes, economic evaluation).

In the literature, physiological indicators, health outcomes and adverse effects have been used as proxy measures for adherence. We included these studies only if those indicators were reported in association with adherence outcomes (see Characteristics of included studies).

\section{Search methods for identification of studies \\ Electronic searches \\ Previous searches}

The 2010 version of this review included searches of the Cochrane Central Register of Controlled Trials (CENTRAL) (the Cochrane Library 2008, Issue 1), MEDLINE (January 2000 to March 2008), Embase (January 1998 to March 2008), PsycINFO (1972 to March 2008) and CINAHL (January 1982 to March 2008). CENTRAL 
incorporates all controlled trials from Embase and MEDLINE, except in the most recent years. We used an appropriate RCT filter for MEDLINE (Dickersin 1994) and Embase (Lefebvre 1996). Details of the previous search strategies are in Appendix 1 and Appendix 2.

\section{Latest Searches}

For this updated review we included the studies from the previously published review (Schedlbauer 2010; search date 31 March 2008). We updated the search terms to increase the sensitivity of the searches. We applied these changes and reran the searches from database inception. We subsequently applied limits to entry dates or equivalent to all databases except CENTRAL, to identify only those records which had been added to the databases since the last search in 2008.

We ran the most recent database search on 3 February 2016 and included the following databases:

- CENTRAL in the Cochrane Library (Issue 1, 2016)

- MEDLINE (Ovid, 1946 to January Week 32016 )

- Embase (Ovid, 1980 to Week 5 2016)

- PsycINFO (Ovid, 1806 to January Week 4 2016)

- CINAHL Plus with Full Text (EBSCO, 1937 to 3 February 2016).

We also searched clinical trials registers (www.anzctr.org.au/ and ClinicalTrials.gov) up to 27 July 2016, using the following search terms: "statin", "adherence", "compliance", "intervention".

We updated the RCT filters for MEDLINE and Embase according to the latest recommendations in the Cochrane Handbook (Lefebvre 2011), and applied adaptations of it to the other databases, except for CENTRAL. Details of the latest search strategies are in Appendix 3. We applied no language restrictions.

\section{Searching other resources}

We sought additional studies through scrutinising the reference lists of identified eligible studies.

\section{Data collection and analysis}

\section{Selection of studies}

Three review authors (JS, MM, and RU) selected studies independently by assessing titles and abstracts. We obtained fulltext articles of potentially relevant studies. Following this initial screening, the three review authors (JS, MM, RU) selected trials independently by applying predetermined inclusion criteria. We included a trial if it met all of our inclusion criteria. The review authors discussed disagreements and resolved them, with recourse to MVD and RD when necessary. We used a spreadsheet to identify and extract studies in duplicate.

\section{Data extraction and management}

We extracted study outcome data using a predefined data collection tool that had been developed by one of the review authors (MVD). The form had been developed and piloted on a random sample of three studies and refined appropriately. For this updated version of the review, we conducted the 'Risk of bias' assessment for all included studies with Review Manager 5. Three review authors (JS, MM, and RU) extracted data from the newlyselected studies, with a second author checking the extracted data for accuracy.

\section{Assessment of risk of bias in included studies}

We performed 'Risk of bias' assessment using the Cochrane 'Risk of bias' tool in the Cochrane Handbook of Systematic Reviews of Interventions (Higgins 2011). We assessed the following 'Risk of bias' categories:

- selection bias (by assessing the method of random number generation and the process of allocation concealment);

- performance and detection bias (blinding of participants, providers and outcomes assessors);

- attrition bias (by assessing how incomplete data were managed); and

- reporting bias (by assessing whether all intended outcomes were reported).

See Risk of bias in included studies. We rated each of the studies as 'high risk', 'low risk' or 'unclear risk' for each of these risk of bias domains. We also took into consideration the method used to measure adherence, as some methods are more likely to be biased than others (see Characteristics of included studies). For instance, medication refill data are likely to measure adherence more objectively than manual pill counts, even if outcome assessors are not blinded to group allocation. We applied a judgement of 'unclear risk' to blinding where participant and physician were not blinded. We applied a judgement of 'unclear risk' to blinding where outcome assessors were not blinded. We also applied a judgement of 'unclear risk' to any risk assessment when information was not provided or if there was insufficient information to permit a judgement.

\section{Measures of treatment effect}

For dichotomous data, we reported the results as odds ratios (ORs) with 95\% confidence intervals (Cls). For continuous data, we reported the mean difference (MD) with standard deviation (SD) of pre- and post-measurements. For serum cholesterol, we report values in $\mathrm{mg} / \mathrm{dL}$. We converted cholesterol values reported as $\mathrm{mmol} / \mathrm{L}$ to $\mathrm{mg} / \mathrm{dL}$, using the formula: $1 \mathrm{mmol} / \mathrm{l}=38.66976 \mathrm{mg} /$ dL.

\section{Unit of analysis issues}

The unit of analysis in our meta-analysis was the participant; however, if this was not the case, such as in cluster-randomised trials, we planned to make adjustment for clustering in the pooled analysis following the guidelines in the Cochrane Handbook (Higgins 2011).

\section{Dealing with missing data}

If data for analysis were missing, we attempted to obtain information from authors. If no additional data were provided by the authors we used available-case analysis, which includes analysis of the available data only (thus ignoring the missing data), assuming that the data were missing at random.

\section{Assessment of heterogeneity}

We used the data analysis tools in Review Manager 5 for the assessment of heterogeneity, which is indicated in the forest plots measuring the treatment effect. We assessed heterogeneity by first assessing the comparability of the included studies in terms of population, setting and outcomes (face value or "clinical" heterogeneity). We considered pooling only studies that 
were sufficiently similar from a clinical perspective. We assessed statistical heterogeneity by calculating the $\mathrm{Chi}^{2}$ statistic (with $\mathrm{P}$ value $<0.10$ as level of significance) and the $1^{2}$ statistic.

We used 12 thresholds as described in the Cochrane Handbook as a rough guide to interpretation as follows (Higgins 2011), and used $40 \%$ as a cut-off value for important heterogeneity, which means that we considered an 12 under $40 \%$ heterogeneity as low:

- $0 \%$ to $40 \%$ : might not be important;

-30\% to $60 \%$ : may represent moderate heterogeneity;

- $50 \%$ to $90 \%$ : may represent substantial heterogeneity;

- $75 \%$ to $100 \%$ : considerable heterogeneity.

\section{Assessment of reporting biases}

If we suspected reporting bias, we contacted the authors to request missing data. As the number of studies available for meta-analysis was fewer than 10 we did not investigate publication bias by means of a funnel plot.

\section{Data synthesis}

We grouped the studies according to the type of intervention. In the absence of an existing standard classification for such interventions, the review authors agreed upon a classification based on the pragmatic focus of the intervention. For instance, we considered interventions related to the medication regimen separate from the behavioural approaches involving doctors or other healthcare professionals. We identified seven types of interventions and reported them separately:

1. Simplification of drug regimen;

2. Patient education and information;

3. Intensified patient care;

4. Complex behavioural approaches;

5. Decision support systems;

6. Administrative improvements; and

7. Pharmacy-led interventions.

'Usual care' was not defined as a separate intervention. We compared outcomes for each comparison independently, and performed pooling of data and meta-analysis where possible. We chose a per-protocol analysis, as intention-to-treat analysis would yield misleading results by not showing an effect in many of these studies due to the pragmatic nature of the study designs. We pooled data by using the random-effects model. We also performed a fixedeffect model analysis if we assessed statistical heterogeneity as low $(12<40 \%)$. We used dichotomous outcomes for analysis of medication adherence, and continuous outcomes for analysis of clinical markers.

We included the cross-over trial (Brown 1997) from the previous version of this review. However, we classified this study as a simplification of drug regimen intervention and could not perform pooling of data and meta-analysis. Thus, we did not include it in our meta-analysis for intensified patient care versus usual care.

\section{Subgroup analysis and investigation of heterogeneity}

We did not plan any subgroup analyses for this review.

\section{Sensitivity analysis}

We performed sensitivity analysis for the pooled results by removing the studies that contributed to heterogeneity and comparing the overall outcome estimate. We also compared the results of pooling with a random-effects model to those using a fixed-effect model when statistical heterogeneity was low $(12<40 \%$, see Assessment of heterogeneity), in order to assess the robustness of the effect estimate. We performed sensitivity analysis for the impact of high attrition on the overall study outcome by removing the studies with high attrition (> 20\%).

\section{Summary of findings and assessment of the certainty of the evidence}

We created a Summary of findings table using the following outcomes - medication adherence, reduction in LDL-C and reduction in total serum cholesterol. We used the five GRADE considerations (study limitations, consistency of effect, imprecision, indirectness and publication bias) to assess the quality of a body of evidence as it relates to the studies which contribute data to the meta-analyses for the prespecified outcomes (Guyatt 2008). We used methods and recommendations described in Section 8.5 and Chapter 12 of the Cochrane Handbook for Systematic Reviews of Interventions (Higgins 2011) using GRADEpro software (https://gradepro.org/). We justified all decisions to downgrade the quality of studies using footnotes.

\section{RE S U L T S}

\section{Description of studies}

\section{Results of the search}

The search for the original 2004 review of this topic retrieved 2380 articles from all sources (Schedlbauer 2004). Eight studies met all inclusion criteria and were analysed. The search for the first update in 2010 (Schedlbauer 2010) identified three additional studies from the 4227 screened records.

The updated search in January 2015 retrieved 6785 articles from all sources. After de-duplication, we reviewed 5768 titles. Of these references, we excluded 5734 studies by identifying titles and abstracts which did not meet the study criteria for inclusion. We added 16 new studies to the 2010 review. The updated search in February 2016 retrieved 6719 articles from all sources. We reviewed these articles and excluded those which, on the basis of title and abstracts, did not meet the study criteria for inclusion. We added five new studies. One study that was previously excluded was reconsidered and included (Choudhry 2011). We reviewed three other studies also identified in previous searches and originally excluded, and these are awaiting classification (Johnson 2006; Harrison 2015; Lee 2006).

The search in the clinical trials registers retrieved eight references. We identified and included two additional studies (Gujral 2014; PILL 2011) and included two others as ongoing studies (ACTRN12616000422426; ACTRN12616000233426). We identified the protocol of another ongoing study in the 2016 search (Thom 2014).

We summarise the search results in Figure 1. 
Figure 1. Study flow diagram.

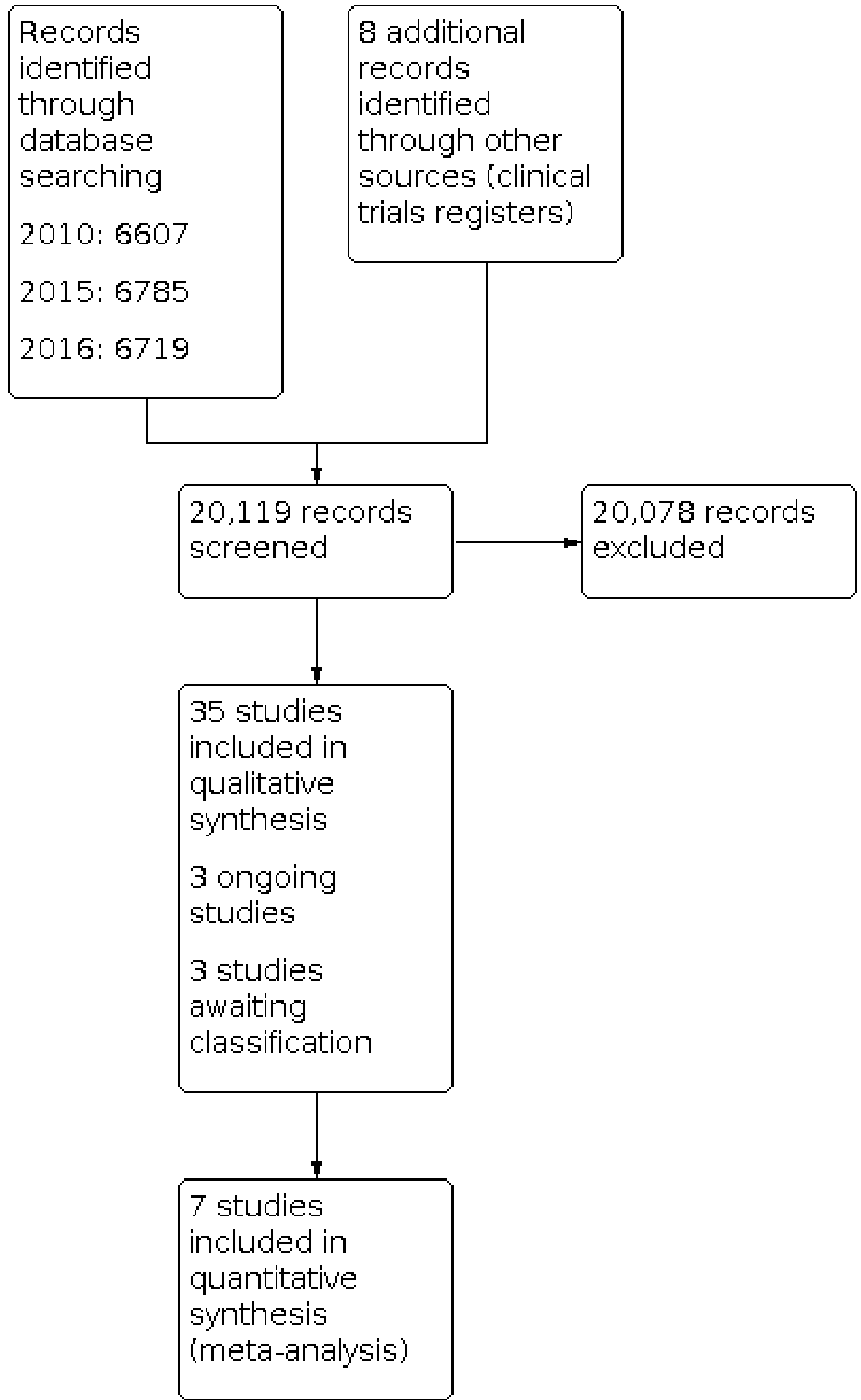




\section{Included studies}

This review includes 35 references to 35 studies. The study sizes varied from 30 (Faulkner 2000) to 861,894 (Fischer 2014) with a total of 919,316 participants included in the review. Most trials included both men and women. Two trials included only men (Brown 1997; Schectman 1994). Mean age ranged from 49 to 76.5 years and was not reported in three studies (Fang 2015; Poston 1998; Powell 1995). There was great variation in the types of participants, setting, medication, interventions used and outcomes measured. This is described in more detail in the Characteristics of included studies table. Among the included studies, one study (Brown 1997) was identified as a cross-over trial and five studies (Aslani 2010; Choudhry 2011; Poston 1998; Tamblyn 2009; Vrijens 2006) as cluster-RCTs.

See Characteristics of included studies.

\section{Interventions}

We stratified interventions into groups on pragmatic grounds, as generally accepted categories do not exist. We identified seven main groups:

1. Drug regimen simplification (Brown 1997; Castellano 2014; Patel 2015; PILL 2011; Selak 2014; Sweeney 1991; Thom 2013);

2. Patient education and information (Gujral 2014; Park 2013; Poston 1998; Powell 1995; Willich 2009);

3. Intensified patient care with reminders via mail, telephone and hand-held pill devices (Aslani 2010; Derose 2012; Eussen 2010; Fang 2015; Faulkner 2000; Goswami 2013; Guthrie 2001; Ho 2014; Kardas 2013; Ma 2010; Márquez 2004; Márquez 2007; Nieuwkerk 2012; Schectman 1994; Vrijens 2006; Wald 2014);

4. Complex behavioural approaches, group sessions (Márquez 1998; Pladevall 2014);

5. Decision support systems (Kooy 2013);

6. Administrative improvements (Choudhry 2011; Tamblyn 2009);

7. Large-scale pharmacy-led automated telephone intervention (Fischer 2014); Vollmer 2014).

Drug regimen simplification was described as using a formulation (e.g. slow release) that could be given twice rather than four times a day (Brown 1997; Sweeney 1991), or a fixed dose formulation such as a 'polypill' or other (Castellano 2014; Patel 2015; PILL 2011; Selak 2014; Thom 2013).

Patient education and information was in the form of educative text messages delivered to participants (Park 2013), a 'Program Kit', including a videotape, information booklet, and newsletter (Poston 1998), videotapes mailed to participants (Powell 1995), or a pack containing a videotape, an educational leaflet, details of the free phone patient helpline and website, and labels with a reminder to take study medication, in addition to regular personalised letters and phone calls (Willich 2009). In Gujral 2014 the community pharmacist reviewed the participant monthly when they collected their prescriptions, and at three and six months the pharmacist had a longer discussion with the participant, tailored to their assessed medication beliefs.

Intensified patient care was delivered by different healthcare providers. Interventions involving pharmacists included counselling visits at the pharmacy (Eussen 2010), phone calls by a pharmacist (Faulkner 2000), pharmacist-led voice messaging (educational and medication refill reminder calls) (Ho 2014), a computer-based tracking system and a series of co-ordinated patient-centred pharmacist-delivered telephone counselling contacts (Ma 2010), and review by the participants' pharmacist and a 'beep-card' to remind the participant of the dosing time (Vrijens 2006). Nurses were involved in two studies: counselling from a nurse and an adherence tip sheet (Goswami 2013), and multifactorial risk-factor counselling by a nurse practitioner (Nieuwkerk 2012). Doctor-led counselling was delivered in two studies as counselling and advice about the disease, medicine, medicine use, adherence and lifestyle measures (Aslani 2010), counselling every eight weeks (Kardas 2013). Other interventions included automated telephone calls followed by letters (Derose 2012), telephone reminders and reminder postcards (Guthrie 2001), telephone call reminders (Márquez 2004), a calendar reminder (Márquez 2007), telephone calls (Schectman 1994), and text messages using an automated computer programme (Wald 2014) or sent live (Fang 2015).

Complex behavioural approaches were used by Márquez 1998 and consisted of a group session of 90 minutes for a maximum of 15 participants at a time, educating them about hypercholesterolaemia, followed by monthly letters written by the same clinician who delivered the group sessions with reinforcing messages. Pladevall 2014 used medication adherence information given by physicians and motivational interviewing by trained staff (nurses, pharmacists).

Decision support systems consisted of an electronic reminder device (ERD) that started beeping every day at the same time until the participant switched it off (Kooy 2013).

Administrative improvements: in Tamblyn 2009 the physician was provided with the participant's drug profile which included the total costs of medications dispensed each month, the amount of out-of-pocket expenditure paid by the participant, a graphic representation of unfilled prescriptions, and days of drug supply for each medication. Then at each visit the participant's adherence was calculated and if treatment adherence was less than $80 \%$, the physician received an alert to check with the participant. In Choudhry 2011 medication co-payments for participants in the intervention group were waived at the point of care (i.e. pharmacy), whereas participants in the control group continued to pay their usual copayments when refilling their prescriptions.

Large-scale pharmacy-led automated telephone intervention was delivered entirely by the pharmacy in Fischer 2014. In the first intervention, the 'automated intervention' participants received automated phone calls on days three and seven to remind them that their prescription was ready for them to pick up if the prescription had been processed by the pharmacy but the participant had not collected it. In the subsequent 'live intervention' a pharmacist or technician called participants who had not collected their prescription despite the reminders. The calls aimed to better understand why participants were not taking their medication and to counsel them regarding appropriate medication use. Vollmer 2014 used automated Interactive Voice Recognition (IVR) Calls to participants when they were due or overdue for a refill. Speech-recognition technology was used in these calls to educate participants about their medications. 


\section{Medication}

The lipid-lowering medications used to treat hyperlipidaemia in most trials were statins (3-hydroxy-3-methyl-glutaryl-coenzyme A (HMG-CoA) reductase inhibitors) (Castellano 2014; Choudhry 2011; Derose 2012; Eussen 2010; Fang 2015; Faulkner 2000; Fischer 2014; Goswami 2013; Gujral 2014 Guthrie 2001; Ho 2014; Kardas 2013; Kooy 2013; Ma 2010; Márquez 1998; Márquez 2004; Márquez 2007; Nieuwkerk 2012; Park 2013; Patel 2015; PILL 2011; Pladevall 2014; Poston 1998; Powell 1995; Selak 2014; Tamblyn 2009; Thom 2013; Vollmer 2014; Vrijens 2006; Wald 2014; Willich 2009). Anionexchange resins or bile acid sequestrants were used in five trials (Faulkner 2000; Pladevall 2014; Schectman 1994; Sweeney 1991; Wald 2014). Niacin or nicotinic acid were used in three trials (Brown 1997; Pladevall 2014; Schectman 1994). Two trials used a combined medication regimen (Faulkner 2000; Schectman 1994), and two trials did not specify a lipid-lowering medication (Aslani 2010; Tamblyn 2009). Drug therapy was most commonly started after study allocation; only eight studies included participants who were already taking lipid-lowering medication (Castellano 2014; Fischer 2014; Pladevall 2014; Poston 1998; Powell 1995; Selak 2014; Vollmer 2014; Wald 2014).

\section{Cardiovascular risk}

Most studies included in this review enrolled participants at high risk of suffering a cardiovascular event, where lipid-lowering medication was used for primary prevention, whether or not serum cholesterol levels were high (Aslani 2010; Brown 1997; Choudhry 2011; Derose 2012; Eussen 2010; Goswami 2013; Guthrie 2001; Kardas 2013; Kooy 2013; Márquez 1998; Márquez 2004; Márquez 2007; PILL 2011; Selak 2014; Sweeney 1991; Tamblyn 2009; Wald 2014). Nine trials included participants with pre-existing cardiovascular pathology, thus taking medication for secondary prevention (Castellano 2014; Choudhry 2011; Fang 2015; Faulkner 2000; Gujral 2014; Ho 2014; Ma 2010; Park 2013; Vollmer 2014). The remaining studies looked at people on medication for both primary and secondary prevention (Nieuwkerk 2012; Patel 2015; Pladevall 2014; Poston 1998; Powell 1995; Schectman 1994; Thom 2013; Vrijens 2006; Willich 2009). One study (Fischer 2014) identified people at a community pharmacy and did not indicate whether the medication was for primary or secondary prevention.

\section{Settings}

Twelve of the included trials took place in primary care (Castellano 2014; Guthrie 2001; Kardas 2013; Márquez 1998; Márquez 2004; Márquez 2007; Patel 2015; PILL 2011; Selak 2014; Tamblyn 2009; Wald 2014; Willich 2009). In six studies participants were followed up in secondary care (Brown 1997; Fang 2015; Faulkner 2000; Goswami 2013; Nieuwkerk 2012; Park 2013), and three studies took place in both settings (Ma 2010; Sweeney 1991; Thom 2013). Other settings were community pharmacies (Aslani 2010; Eussen 2010; Fischer 2014; Gujral 2014; Kooy 2013; Poston 1998; Vrijens 2006), healthcare system (Derose 2012; Pladevall 2014), health maintenance organisation (Choudhry 2011; Powell 1995; Vollmer 2014), and Veterans Affairs medical centres (Ho 2014; Schectman 1994). Trials were set geographically in the USA (15 trials), Netherlands (four trials), Australia (three trials), Spain (three trials), Canada (two trials), England (two trials), Poland (one trial), New Zealand (one trial), India (one trial), China (one trial), Ireland (one trial), and Belgium (one trial). The FOCUS, ORBITAL and PILL trials were conducted across several countries. FOCUS: Argentina, Paraguay, Italy, Spain (Castellano 2014); ORBITAL:
Germany, Denmark, Switzerland, and Greece (Willich 2009); PILL: Australia, Brazil, India, Netherlands, New Zealand, United Kingdom, United States (PILL 2011).

\section{Follow-up}

Follow-up times ranged from no follow-up to 24 months of followup. Most studies achieved their end point outcomes at nine months beginning at three-month intervals. The frequency of the intervention varied, ranging from one single contact up to 12 (see Characteristics of included studies table).

\section{Outcome measures}

The methods used to measure adherence included selfreport, Medication Adherence Report Scale (MARS), time to discontinuation, medication possession ratio (MPR), proportion of days covered (PDC), continuous multiple interval (CMI), Medication Event Monitoring System (MEMS), drug profile review, prescription refill rate, prescription abandonment, and pill count. Self-report was assessed by asking participants if they had taken their medication as prescribed and how many doses they missed over a given time period (Choudhry 2011; Guthrie 2001, Nieuwkerk 2012; Patel 2015; Poston 1998; Selak 2014; Wald 2014). The MARS questionnaire was used in two studies (Aslani 2010; Gujral 2014). Time to discontinuation of lipid-lowering medication was used by three studies (Eussen 2010; Kooy 2013; Schectman 1994). MPR is defined as the number of days on medication after study enrolment divided by the number of days between the first fill and the last refill plus the day's supply of last refill. MPR was used in six studies (Eussen 2010; Goswami 2013; Gujral 2014; Kardas 2013; Poston 1998; Powell 1995). PDC was used in three studies (Goswami 2013; Ho 2014; Vollmer 2014). CMI, the ratio of days supply obtained to total days between refill records, was based on pharmacy records from one study (Ma 2010). MEMS is an electronic system of standard pill bottles with microprocessors in the cap that record the timing and frequency of bottle openings, providing detailed and reliable outcome measures at low risk of bias. MEMS was used in three trials (Márquez 2007; Park 2013; Vrijens 2006). Drug profile review by a physician on each visit with study participants was used in one study (Tamblyn 2009). Prescription refill rates were used by seven studies, where refill information was obtained from pharmacies (Derose 2012; Faulkner 2000; Kooy 2013; Pladevall 2014; Poston 1998; Powell 1995; Schectman 1994). Prescription abandonment was used in one study (Fischer 2014). Manual pill counting was performed in seven trials (Brown 1997; Castellano 2014; Faulkner 2000; Márquez 1998; Márquez 2004; PILL 2011; Sweeney 1991). Counting pills is a measure vulnerable to participant manipulation, and one author attempted to increase the reliability of this method by performing unexpected visits to participants' homes for pill counts (Márquez 1998). In another study, pills were not counted in the participant's view in order to avoid influencing their subsequent adherent behaviour (Faulkner 2000). The different methods of measuring adherence was one of the main obstacles in comparing results from the studies, which was further complicated by the fact that some authors used more than one method to measure adherence during their trials.

The report of percentage of mean compliance was considered as the most valid description of compliant behaviour and is reported in the tables of included studies as a main outcome measure, providing the opportunity of comparison between the studies. Other outcome measures reported were: thresholds to define 
compliant behaviour, i.e. the proportion of participants taking more than $80 \%$ of the prescribed medication; discontinuation rates; absolute risk reduction; relative risk reduction; and number needed to intervene in order to save one non-adherent behaviour (see Characteristics of included studies table).

Serum lipids consisting of total cholesterol, HDL, LDL and triglycerides are physiological indicators of participant compliance that were the most frequently reported outcome in the following trials: Aslani 2010; Brown 1997; Castellano 2014; Eussen 2010; Faulkner 2000; Ho 2014; Ma 2010; Márquez 1998; Márquez 2004; Márquez 2007; Nieuwkerk 2012; Patel 2015; PILL 2011; Pladevall 2014; Selak 2014; Sweeney 1991; Thom 2013; Vollmer 2014; Wald 2014; Willich 2009. Some trials began with a 'start-up' phase where participants were either taking medication (Brown 1997) or following a diet (Sweeney 1991) before baseline blood samples were taken; the majority of the trials took baseline blood samples immediately after recruitment. Other reported outcome measures included side effects experienced (Brown 1997; Castellano 2014; Márquez 1998; Patel 2015; PILL 2011; Schectman 1994; Thom 2013; Willich 2009), participant satisfaction (Park 2013), and self-reported lifestyle measures (Aslani 2010; Guthrie 2001; Nieuwkerk 2012;
Sweeney 1991). None of the studies provided data on morbidity or mortality as additional outcome measures.

\section{Commercial sponsorship}

Authors declared some form of funding by drug companies in Brown 1997; Derose 2012; Eussen 2010; Goswami 2013; Gujral 2014; Guthrie 2001; Nieuwkerk 2012; Patel 2015; PILL 2011; Poston 1998; Powell 1995; Schectman 1994; Sweeney 1991; Vrijens 2006; Wald 2014; Willich 2009.

\section{Excluded studies}

We excluded 62 studies after review (see Characteristics of excluded studies). The most common reason for exclusion was that the study was not aimed at improving adherence. One article was a study description without any outcomes and appeared to be the same as Thom 2013, which we included for analysis; however, the two studies had different trial registration numbers.

\section{Risk of bias in included studies}

The results of the 'Risk of bias' analysis are shown in Figure 2; Figure 3. 
Figure 2. Methodological quality summary: review authors' judgements about each methodological quality item for each included study.

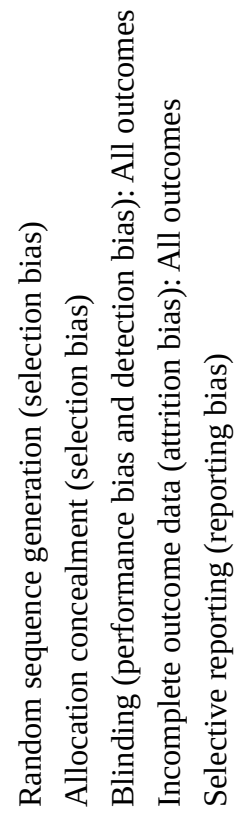

Aslani 2010

Brown 1997

Castellano 2014

Choudhry 2011

Derose 2012

Eussen 2010

Fang 2015

Faulkner 2000

Fischer 2014

Goswami 2013

Gujral 2014

Guthrie 2001

Ho 2014

Kardas 2013

Kooy 2013

Ma 2010

Márquez 1998

Márquez 2004

Márquez 2007

Nieuwkerk 2012

Park 2013

Patel 2015

PILL 2011

Pladevall 2014

Poston 1998

Powell 1995

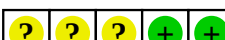


Figure 2. (Continued)

\begin{tabular}{|c|c|c|c|c|c|}
\hline Powell 1995 & $?$ & $?$ & + & + & + \\
\hline chectman 1994 & $?$ & $?$ & + & + & + \\
\hline Selak 2014 & + & + & $?$ & + & + \\
\hline Sweeney 1991 & $?$ & $?$ & $?$ & + & + \\
\hline Tamblyn 2009 & + & + & - & $?$ & + \\
\hline Thom 2013 & + & + & $?$ & + & + \\
\hline Vollmer 2014 & + & + & $?$ & + & + \\
\hline Vrijens 2006 & $?$ & $?$ & $?$ & + & + \\
\hline Wald 2014 & + & $?$ & $?$ & + & + \\
\hline Willich 2009 & + & + & $?$ & + & + \\
\hline
\end{tabular}

\section{Figure 3. Risk of bias graph: review authors' judgements about each risk of bias item presented as percentages across all included studies.}

\begin{tabular}{rl|} 
Random sequence generation (selection bias) & \\
Allocation concealment (selection bias) & \\
Blinding (performance bias and detection bias): All outcomes & \\
Incomplete outcome data (attrition bias): All outcomes & \\
Selective reporting (reporting bias) & \\
\hline$\square$ Low risk of bias & $0 \% \quad 50 \%$ \\
\hline
\end{tabular}

\begin{abstract}
Allocation
We rated 11 studies at 'unclear risk' for random sequence generation, as they did not provide sufficient information to make a judgement (Aslani 2010; Brown 1997; Gujral 2014; Guthrie 2001; Kardas 2013; Márquez 1998; Poston 1998; Powell 1995; Schectman 1994; Sweeney 1991; Vrijens 2006). We assessed 24 studies at 'low risk' for random sequence generation, as they reported using a computer-generated allocation process, telephone allocation, or allocation by a statistician who was not involved in conducting the study (Castellano 2014; Choudhry 2011; Derose 2012; Eussen 2010; Fang 2015; Faulkner 2000; Fischer 2014; Goswami 2013; Ho 2014; Kooy 2013; Ma 2010; Márquez 2004; Márquez 2007; Nieuwkerk 2012; Park 2013; Patel 2015; PILL 2011; Pladevall 2014; Selak 2014; Tamblyn 2009; Thom 2013; Vollmer 2014; Wald 2014; Willich 2009). We rated none of the studies at 'high risk' for random sequence generation.
\end{abstract}

We assessed 14 studies at 'unclear risk' for allocation concealment, as they did not report sufficient information to allow judgement. (Aslani 2010; Brown 1997; Choudhry 2011; Faulkner 2000; Goswami 2013; Guthrie 2001; Kardas 2013; PILL 2011; Poston 1998; Powell 1995; Schectman 1994; Sweeney 1991; Vrijens 2006; Wald 2014) We rated 20 studies at 'low risk' for allocation concealment as this was adequately described and deemed appropriate (Castellano 2014; Derose 2012; Eussen 2010; Fang 2015; Fischer 2014; Ho 2014; Kooy 2013; Ma 2010; Márquez 1998; Márquez 2004; Márquez 2007;
Nieuwkerk 2012; Park 2013; Patel 2015; Pladevall 2014; Selak 2014; Tamblyn 2009; Thom 2013; Vollmer 2014; Willich 2009). In Gujral 2014 allocation was not concealed as reported in the protocol of the study (ACTRN12611000322932), so we judged this to be at 'high risk' for allocation concealment.

\section{Blinding}

One study (Tamblyn 2009) had a single-blinded study design and was rated as 'high risk'. Physicians and participants were blind to the outcome assessed, but not to the intervention in this study. We assessed 28 studies as being at 'unclear risk', as they had an unblinded, open-label study design or did not report open-label design (Aslani 2010; Brown 1997; Castellano 2014; Choudhry 2011; Eussen 2010; Fang 2015; Faulkner 2000; Fischer 2014; Goswami 2013; Gujral 2014; Guthrie 2001; Ho 2014; Kardas 2013; Kooy 2013; Ma 2010; Márquez 2004; Márquez 2007; Nieuwkerk 2012; Park 2013; Patel 2015; Pladevall 2014; Poston 1998; Selak 2014; Sweeney 1991; Thom 2013; Vollmer 2014; Vrijens 2006; Wald 2014). Five studies at low risk stated a method where investigators and participants were blind to the outcome and intervention (Derose 2012; Márquez 1998; PILL 2011; Powell 1995; Schectman 1994). Blinding participants to the intervention they were receiving and blinding key study personnel including physicians was often not possible, given the nature of the intervention. Most trials did not report blinding of those assessing the outcome 'adherence'. 


\section{Incomplete outcome data}

We judged two studies (Gujral 2014; Guthrie 2001) as being at 'high risk' for attrition bias, due to a high rate of attrition in return of a survey tool (Guthrie 2001) or high attrition (31.5\%) at the primary end point after 12 months follow-up (Gujral 2014). We rated six studies as being at 'unclear risk' due to variable rates of study attrition (Brown 1997; Goswami 2013; Márquez 1998; Pladevall 2014; Tamblyn 2009) or not reporting on attrition (Derose 2012). We judged the other studies as being at 'low risk', as they reported minimal to no loss to follow-up.

\section{Selective reporting}

All included studies reported on all intended outcomes, as assessed by comparing the Methods section with the Results section or with the available protocol.

\section{Effects of interventions}

See: Summary of findings 1 Summary of findings table for the comparison of 'intensified patient care' vs 'usual care'

\section{Types of interventions}

The trials in this review aimed to increase adherence to lipidlowering medication by applying one of the following seven intervention categories. In order to determine study similarities, we created a grid into which we placed studies with similar interventions and comparators. We then further grouped those studies which we found to have both similar interventions and comparators, according to similar outcome measures. In grouping the studies in this manner, we found that there were sufficient studies to conduct a meta-analysis among those studies comparing such interventions with usual care (see Table 1).

\section{Drug regimen simplification vs usual care}

Seven studies attempted to simplify the drug regimen (Brown 1997; Castellano 2014; Patel 2015; PILL 2011; Selak 2014; Sweeney 1991; Thom 2013). Two studies (Brown 1997; Sweeney 1991) used a regimen with reduction of daily dosing, whereas the other five studies used a fixed-dose combination or 'polypill' regimen (Castellano 2014; Patel 2015; PILL 2011; Selak 2014; Thom 2013).

We were unable to pool data, as the study publications provided insufficient data, so we describe the results for each of the individual studies below.

Medication adherence - Reducing medication intake from four times to twice daily improved mean medication intake by $11 \%$ (96\% in the intervention group vs $85 \%$ in the control group; $\mathrm{P}=$ $0.01 ; n=29$ ) (Brown 1997). Drug modification, by administering colestyramine bars instead of powder to make intake easier, did not decrease the adherence rate $(91.8 \%$ in the intervention group vs $94.8 \%$ in the control group; $P>0.05 ; n=83$ ) (Sweeney 1991).

In the five studies that used a fixed-dose combination (FDC) or polypill, four out of five studies showed better adherence with the polypill compared with the separate dosing regimens.

In Castellano 2014, the polypill group showed improved adherence compared with the group receiving separate medications after nine months of follow-up: $50.8 \%$ vs $41 \%$; $P=0.019$ (for the intentionto-treat population) and $65.7 \%$ vs $55.7 \% ; \mathrm{P}=0.012$ (for the perprotocol population); $\mathrm{n}=458$ (per-protocol population).
In Patel 2015 participants in the polypill-based strategy showed greater use of treatment compared to those receiving separate medications after a median of 18 months ( $70 \%$ vs $47 \%$; risk ratio (RR) 1.49, 95\% confidence interval (Cl) 1.30 to 1.72 ; $\mathrm{P}<0.0001$; number needed to treat for an additional beneficial outcome (NNTB) 4 ( $95 \% \mathrm{Cl} 3$ to 7$) ; \mathrm{n}=623$ ).

In the PILL 2011 study, discontinuation rates were $23 \%$ in the polypill group vs $18 \%$ in the placebo group ( $R R 1.33,95 \% \mathrm{Cl} 0.89$ to $2.00 ; P=0.2 ; n=373$.

In Selak $2014(n=513)$ adherence was greater with the FDC than with usual care at 12 months ( $81 \%$ vs $46 \%$; RR $1.75,95 \% \mathrm{Cl} 1.52$ to 2.03; $\mathrm{P}<0.001 ;$ NNTB 3, $95 \% \mathrm{Cl} 2$ to 4). Adherence specifically for the statins was not different in the FDC group ( $94 \%$ vs $89 \% ; P=0.06$ ).

In Thom 2013 using FDC improved adherence vs usual care (86\% vs $65 \%$; RR $1.33,95 \% \mathrm{Cl} 1.26$ to $1.41 ; \mathrm{P}<0.001 ; \mathrm{n}=1921$ ).

Total serum cholesterol - Brown 1997 demonstrated low-/highdensity lipoprotein (LDL/HDL) change from means of 215/46 mg/ $\mathrm{dl}$ at baseline, to $94 / 59 \mathrm{mg} / \mathrm{dl}$ after run-in, to $85 / 52 \mathrm{mg} / \mathrm{dl}$ after eight months of controlled-release niacin, and to $98 / 56 \mathrm{mg} / \mathrm{dl}$ after eight months of regular niacin (regular niacin vs controlled-release niacin, $\mathrm{P}<0.005 /<0.05)$. The target of $\mathrm{LDL}<100 \mathrm{mg} / \mathrm{dl}$ was achieved at eight months by $83 \%$ of these participants with controlledrelease niacin and by $52 \%$ with regular niacin $(P<0.01)$.

In Sweeney 1991, total cholesterol decreased by $16 \%$ in the bar group and $17 \%$ in the powder group $(P<0.01)$. LDL-cholesterol decreased by $28 \%$ and $29 \%$ in the bar and powder groups respectively $(P<0.01)$. There was no change in $\mathrm{HDL}$ cholesterol. Triglycerides increased in both groups, by $29 \%$ in the bar group and by $25 \%$ in the powder group. There was no difference between bar and powder in the effect on blood lipids.

In the five studies that used a FDC or polypill, two out of five studies found a reduction in LDL-cholesterol levels with the polypill as compared with the separate dosing regimens (PILL 2011; Thom 2013).

Castellano 2014 did not find a difference in mean low-density lipoprotein cholesterol levels $(89.9 \mathrm{mg} / \mathrm{dl}$ vs $91.7 \mathrm{mg} / \mathrm{dl}$ ) between the groups receiving the polypill or the three drugs administered separately.

In Patel 2015 there was no difference in total cholesterol levels in the polypill-based strategy compared to those receiving separate medications after a median of 18 months $(0.08 \mathrm{mmol} / \mathrm{l}, 95 \% \mathrm{Cl} 0.06$ to $0.22 ; \mathrm{P}=0.26$ ).

The PILL 2011 study found a reduction in LDL-cholesterol of 0.8 $\mathrm{mmol} / \mathrm{L}, 95 \% \mathrm{Cl} 0.6$ to 0.9 in favour of the group that was given the polypill.

Selak 2014 did not find any difference in LDL-cholesterol levels between the FDC group and the control group (difference -0.05 $\mathrm{mmol} / \mathrm{L}(-0.20$ vs $-0.15,95 \% \mathrm{Cl}-0.17$ to $0.08 ; \mathrm{P}=0.46))$.

Thom 2013 found a difference in LDL-cholesterol in favour of the FDC group (difference $-4.2 \mathrm{mg} / \mathrm{dL}, 95 \% \mathrm{Cl}-6.6$ to $-1.9 \mathrm{mg} / \mathrm{dL}$; $\mathrm{P}<$ 0.001 ) at the end of the study. 
Blood pressure - In the studies that used a FDC or polypill, three out of five studies found a reduction in systolic blood pressure (SBP) with the intervention groups as compared with the separate dosing regimens (PILL 2011; Selak 2014; Thom 2013). Brown 1997 and Sweeney 1991 do not report effects on blood pressure.

Castellano 2014 did not find a difference in mean SBP $(129.6 \mathrm{mmHg}$ vs $128.6 \mathrm{~mm} \mathrm{Hg}$ ) between the groups receiving the polypill or the three drugs administered separately.

In Patel 2015 there was no difference in SBP in the polypill-based strategy compared to those receiving separate medications after a median of 18 months ( $1.5 \mathrm{mmHg}, 95 \% \mathrm{Cl} 4.0$ to 1.0 ; $\mathrm{P}=0.24$ ).

The PILL 2011 study found a reduction in SBP of $9.9 \mathrm{mmHg}, 95 \% \mathrm{Cl}$ 7.7 to 12.1 in favour of the group that was given the polypill.

Selak 2014 showed reductions in SBP $(-2.6 \mathrm{mmHg}, 95 \% \mathrm{Cl}-4.0$ to $-1.1 \mathrm{mmHg} ; \mathrm{P}<0.001)$ in the FDC group vs the usual care group.

Thom 2013 showed reduction of SBP $(-2.6 \mathrm{mmHg}, 95 \% \mathrm{Cl}-4.0$ to $-1.1 \mathrm{mmHg}$ ) in the FDC group compared with the usual care group at the end of the study.

\section{Adverse events -}

Castellano 2014 did not find a difference in number of adverse events between the groups receiving the polypill or the three drugs administered separately ( $35.4 \%$ vs $32.5 \%$, respectively).There were 21 reported serious adverse events (6.0\%) in the polypill group vs 23 (6.6\% in the control group). There was 1 death in each group $(0.3 \%$ vs $0.3 \%)$.

In Patel 2015 there was at least one serious adverse event reported in $46.3 \%$ of participants in the polypill group vs $40.7 \%$ in the usual care group $(P=0.16)$.

The PILL 2011 study 58\% in the polypill group reported adverse events compared with $42 \%$ in the control group $(P=0.001)$ The authors report that the side effects were known side effects of the medication contained in the polypill. Four serious adverse events were reported in each group (polypill group: chest pain, newly diagnosed Type 2 diabetes, removal of wisdom teeth, syncope; placebo group: syncope,

depression, transient ischaemic attack, hip fracture). No deaths, major vascular events, major bleeds or episodes of gastrointestinal ulceration were reported.

In Selak 2014 the number of participants with serious adverse events was not different between groups (fixed dose combination 99 vs usual care $93, P=0.56)$. Four deaths occurred in the group with fixed dose combination and 6 in the usual care group $(P=0.75)$.

Thom 2013 showed no significant differences in serious adverse events $(5 \%$ in the foxed dose combination group and 3.5\% in the usual care group $(P=0.09)$ between the groups. Seventeen deaths occurred in the fixed dose combination group vs 15 in the usual care group $(P=0.72)$.

\section{Patient education and information vs usual care}

Five studies including 8116 participants intended to improve medication adherence by improving patient information and eduction. No consistent improvement was found (Gujral 2014; Park 2013; Poston 1998; Powell 1995; Willich 2009).
Medication adherence - Pharmacist-mediated information and postal backups, where videotapes, booklets and newspapers were handed out by the local pharmacist followed by educational newsletters sent by post, successfully improved adherence in people who had started taking statins within 60 days before recruitment into the study, but did not improve adherence in those who had been taking statins for more than 60 days before recruitment into the study (Poston 1998). In participants who had started taking statins within 60 days before recruitment into the study, the increase in adherence was 13\% (92\% in intervention group vs $79 \%$ in control group; $P \leq 0.005$ ). In participants who had been taking statins for more than 60 days before recruitment into the study, adherence to long-term therapy was not improved (92\% vs $91 \%$; $P$ value reported as non-significant but not based on a correct interaction test).

Another study applied a less personal approach, by sending out videotapes to members of a health maintenance organisation who were known to have a pharmacy claim for statins (Powell 1995), not increasing adherence rates $(73 \%$ in intervention group vs $70 \%$ in control group; $P>0.05 ; n=568)$.

Medication Event Monitoring Systems (MEMS) revealed that those who received text messages for antiplatelets had a higher percentage of correct doses taken $(\mathrm{t}(36)=2.5 ; \mathrm{P}=0.02)$, percentage number of doses taken $(t(31)=2.8 ; P=0.01)$, and percentage of prescribed doses taken on schedule $(t(37)=2.6 ; P=0.01 ; n=84)$. Text message response rates were higher for antiplatelets ( $M=90.2 \%$; SD $=9)$ than statins $(M=83.4 \% ; S D=15.8)(t(26)=3.1 ; P=0.005)$. Selfreported adherence revealed no differences among groups (Park 2013).

In another study, participants received a starter pack containing a videotape, an educational leaflet, details of the free-phone patient helpline and website, and labels with a reminder to take study medication. Participants also received regular personalised letters and phone calls throughout the study. The compliance-enhancing programme was only effective in statin-naïve participants at three and six months, but had no overall effect over 12 months ( $80 \%$ vs $76 \%$ and $78 \%$ vs $73 \% ; P<0.01 ; n=6872$ ) (Willich 2009).

In Gujral 2014 participants in the intervention group received education from the pharmacists tailored to identified misconceptions and beliefs about their medication. However, at the end of the study (after 12 months) there was no difference in adherence: $29 \%$ of the participants in the intervention group were non-adherent compared with $25 \%$ in the control group $(P=0.605$; $\mathrm{n}=137)$.

Total serum cholesterol - Willich 2009 reports that at month $12,2231(68.2 \%)$ of participants on rosuvastatin plus compliance initiatives and rosuvastatin alone - $2152(68.4 \%)$ were reported as achieving LDL-cholesterol < $115 \mathrm{mg} / \mathrm{dl}(\mathrm{P}=0.97)$, and 1894 (57.6\%) of participants on rosuvastatin plus compliance initiatives and 1837 $(57.9 \%)$ on rosuvastatin alone reported achieving total cholesterol $<190 \mathrm{mg} / \mathrm{dl} ; \mathrm{P}=0.8732 ; \mathrm{n}=6872$.

\section{Intensified patient care vs usual care}

Sixteen studies randomising 22,785 participants and reporting outcomes on 13,602 participants, investigated the effect of intensified patient care. Reinforcing people to take their medication in the form of written postal material, telephone 
or other reminders was associated with improved adherence in 10 studies, with results from eight trials reaching statistical significance. There was a positive trend towards improvement in lipid levels in two studies (Márquez 2004; Márquez 2007).

Pooling of data for medication adherence at up to six months included Derose 2012; Eussen 2010; Faulkner 2000; Goswami 2013; Guthrie 2001; Márquez 2004; Márquez 2007. Pooling of data for medication adherence at more than six months included Faulkner 2000; Ho 2014;Vrijens 2006.

Of the 16 RCTs with an intensified patient care intervention, five studies used continuous instead of dichotomous outcomes or cumulative results, and could not be included in the pooled data for medication adherence (Aslani 2010; Fang 2015; Kardas 2013; Ma 2010; Nieuwkerk 2012). For Aslani 2010, low recruitment and high drop-out rate had a significant impact on the study power (reducing it to $44 \%$ ) to detect changes in adherence levels but study had sufficient power to detect a statistically and clinically significant difference in total cholesterol levels.

We could not include Schectman 1994 in the pooled data for medication adherence, as this study was very different from the other studies; the medications used, niacin and bile acid salts, had very low adherence due to side effects. In Faulkner 2000, for medication adherence at more than six months, outcome adherence with colestipol was much lower than with lovastatin, due to side effects, so we used lovastatin adherence for pooling of data. Wald 2014 could not be included in the pooled data as outcome measures included combined data from blood pressure and lipid-lowering medications.

\section{Medication adherence}

Sixteen studies report medication adherence for intensified vs usual care interventions (see Table 2); seven provided data for pooling of short-term adherence and three studies for long-term adherence. We describe the pooled results below, and report results for the studies that could not be pooled here.

In Aslani 2010 ( $n=97)$, Medication Adherence Report Scales showed no changes in medicine adherence scores, although intervention participants were less likely to take less than the prescribed dose after the first-time interval (main effect $\mathrm{F}_{2,178}=4.3 ; \mathrm{P}<0.05$; contrast $\left.F_{1,89}=5.7 ; P<0.05\right)$, and the intervention group reported that compared with the control group they were more liable to alter the dose of their medicine at the third reading compared to the second reading $\left(\mathrm{F}_{1,89}=4.97 ; \mathrm{P}<0.05\right)$.

In Kardas 2013, the intervention group received educational counselling at each visit (i.e. every eight weeks) and were also asked to adopt a routine evening activity of their choice for a reminder. Study arms differed in their level of adherence: mean \pm SD MPR was $95.4 \% \pm 53.7 \%$ and $81.7 \% \pm 31.0 \%$, for intervention and control groups respectively $(P<0.05 ; n=196)$.

Participants in the intervention group of Ma 2010 ( $n=559$ ) received five pharmacist-delivered telephone counselling calls post-hospital discharge. The continuous multiple interval (CMI) for statin medication use was 0.88 (SD 0.3) in the pharmacydelivered intervention (PI) (referring to the participant being $88 \%$ adherent to their statins medication), and 0.90 (SD 0.3) in the usual care condition ( $P=0.51$ ), leading to the conclusion that a pharmacist-delivered intervention aimed only at improving participant adherence is unlikely to positively affect outcomes.

Nieuwkerk $2012(\mathrm{n}=181)$ demonstrated that statin adherence was higher $(P<0.01)$ and anxiety was lower $(P<0.01)$ in the intervention group, which received nurse-led cardiovascular riskfactor counselling than in the routine-care group.

In Fang 2015 ( $n=271)$ participants who were randomised to the short message service (SMS) and those in the SMS + Micro Letter group had better cumulative adherence (lower Morisky Medication Adherence Scale scores) after six months than the phone group. The SMS + Micro Letter group had better cumulative adherence (lower Morisky Medication Adherence Scale scores) than the SMS-alone group.

\section{Pooling of the results}

We grouped the results into long-term adherence and shortterm outcomes. We defined short-term results as those outcomes measured at up to six months, and long-term outcomes as measured at more than six months. We then pooled results according to long-term or short-term outcomes. When it was not provided, we estimated the SD for the difference between means using the formula $\sigma_{d}=\operatorname{sqrt}\left(\sigma_{1} 2 / n_{1}+\sigma_{2} 2 / n_{2}\right)$. We estimated the SDs for Aslani 2010 and Faulkner 2000.

The forest plots in Analysis 1.1 and Analysis 1.2 both show pooled treatment effects of the intensification of patient care category of interventions when compared with usual care and using adherence measures as an outcome in both short-term and longterm measures. Forest plots in Analysis 1.4 show the pooled effect estimate for total cholesterol level over both short- and long-term follow-up.

We did not adjust the Aslani 2010 data for clustering as the expected clustering effect of patients within pharmacies in Australia is very low (Armour 2007).

\section{Medication adherence at $\leq 6$ months}

Pooling of data for medication adherence at up to six months using per-protocol analysis of dichotomous outcomes included seven studies involving 11,204 participants. There was considerable heterogeneity $\left(1^{2}=88 \%\right)$. Meta-analysis using a random-effects model estimated an odds ratio of $1.93(95 \% \mathrm{Cl} 1.29$ to $2.88 ; 7$ studies; 11,204 participants; moderate-quality evidence), favouring the intervention (Analysis 1.1). Removing the three studies with less intensive interventions that contributed to the heterogeneity (as is also apparent from the forest plot) from the pooled analysis (Derose 2012; Márquez 2004; Márquez 2007) resulted in an of OR 1.19 (95\% $\mathrm{Cl} 1.02$ to $1.39 ; \mathrm{I}^{2}=0 \%$ ), favouring the intervention. All but one study (Guthrie 2001) had low attrition rates. A sensitivity analysis excluding Guthrie 2001, which had very high attrition (only 35\% of surveys were returned to the investigators), resulted in an OR 2.22, $95 \% \mathrm{Cl} 1.41$ to 3.49 (Analysis 1.7). The conclusions remained unaltered (Summary of findings 1 ).

\section{Medication adherence at $>6$ months}

Pooling of data for medication adherence at more than six months using per-protocol analysis of dichotomous outcomes included three studies involving 663 participants. The studies were homogeneous $\left(1^{2}=0 \%\right)$. Meta-analysis using a random-effects model estimated an odds ratio of 2.87 ( $95 \% \mathrm{Cl} 1.91$ to 4.29 ; 3 studies; 
663 participants; high-quality evidence), favouring the intervention (Analysis 1.2). Using a fixed-effect model did not alter the estimate $(\mathrm{OR}=2.87,95 \% \mathrm{Cl} 1.92$ to 4.30$)$ nor the conclusions.

Although Vrijens 2006 contributes 59\% of the weighting, the estimate remains robust if this study is removed: the result is OR $3.82,95 \% \mathrm{Cl} 2.03$ to $7.18 ; \mathrm{I}^{2}=0 \%$, favouring the intervention, and hence the overall conclusion remained unchanged (Summary of findings 1).

Total serum cholesterol and low-density lipoprotein cholesterol - From the 16 RCTs that used intensified patient care, five studies (Derose 2012; Goswami 2013; Guthrie 2001; Schectman 1994; Vrijens 2006) did not use lipid levels as an outcome measure.

Eussen 2010 reported adjusted levels of total cholesterol at three months, but did not report the raw data for inclusion in the metaanalysis. Kardas 2013 also reported a decrease in total cholesterol, LDL, and triglycerides with constant HDL, but it did not include any raw data except for baseline measures. Ma 2010 did not provide baseline or change scores and cholesterol data included participants not receiving lipid-lowering medications. However, no other studies reported the same time point for comparison. Nieuwkerk 2012 was not included, as the lipid level data were compiled as an average of three time points: three months, nine months, and 18 months. Ho 2014 could not be included in the pooled data as cholesterol data included participants not taking lipid-lowering medications. Means and SD were pooled and compared for Aslani 2010; Faulkner 2000; Márquez 2004; Márquez 2007 at up to six-month time points. Additionally, the means and SD were compared for Aslani 2010 and Faulkner 2000 at more than six months.

The studies that we could not pool are described here.

Eussen 2010 reported a significant decline in mean total cholesterol and LDL-cholesterol levels in those receiving pharmaceutical care. Total cholesterol and LDL-cholesterol decreased by a mean of 17.2 $\mathrm{mg} / \mathrm{dL}, 95 \% \mathrm{Cl} 12.3$ to 22.0 , and $9.47 \mathrm{mg} / \mathrm{dL}, 95 \% \mathrm{Cl} 5.02$ to 13.9 respectively. Three months after initiating statin therapy $65 \%$ of participants achieved a target LDL-cholesterol level of $\leq 115 \mathrm{mg} / \mathrm{dL}$. The intervention appeared to have a sustained effect, given the fact that at six and 12 months after treatment, these percentages were $72 \%$ and $77 \%$ respectively.

Kardas 2013 reported that both the control and intervention groups had decreases in total cholesterol, LDL-cholesterol, and triglycerides, with a relatively constant level of HDL-cholesterol. At the end of the 48-week follow-up period, the two groups showed no differences in these lipid parameters.

In a study of 689 individuals, Ma 2010 found no differences in those receiving the pharmacist-delivered intervention versus usual care. Sixty-five per cent of individuals achieved a goal LDL-cholesterol of $<100 \mathrm{mg} / \mathrm{dl}$ in the intervention group versus $65 \%(P=0.29)$. After 12 months there were no differences in total cholesterol, LDL-cholesterol, HDL-cholesterol, or triglycerides between the two groups.

Nieuwkerk 2012 found that the LDL-cholesterol was lower in the intensified patient care group when compared to the routine-care group during follow-up in primary prevention participants, but not in secondary prevention participants.
Wald 2014 found no differences in serum cholesterol $(4.20 \mathrm{mmol} /$ $\mathrm{L}$ versus $4.21 \mathrm{mmol} / \mathrm{L}$ total cholesterol and $2.29 \mathrm{mmol} / \mathrm{L}$ versus $2.22 \mathrm{mmol} / \mathrm{L} \mathrm{LDL}$-cholesterol) between the Text and No-text groups respectively.

\section{Pooling of the results}

\section{Reduction in total serum cholesterol $(\mathrm{mg} / \mathrm{dL})$ at $\leq 6$ months:}

Pooling of data for total serum cholesterol at up to six months using per-protocol analysis of continuous outcomes included four studies with 430 participants. There was considerable heterogeneity $\left(\mathrm{I}^{2}\right.$ $=89 \%$ ). Meta-analysis using a random-effects model produced a mean difference (MD) of $17.15,95 \% \mathrm{Cl} 1.17$ to 33.14 ; 4 studies; 430 participants; low-quality evidence, favouring the intervention (Analysis 1.3). Removing the studies that contributed most to the heterogeneity from the pooled analysis resulted in $\mathrm{MD} 3.79,95 \% \mathrm{Cl}$ -2.42 to $10.00 ; I^{2}=18 \%$, favouring the intervention but not reaching statistical significance. The smaller reductions in the Aslani 2010 study may have been related to the fact that participants were being treated for hyperlipidaemia at the time and were already on therapy, whereas in Márquez 2004; Márquez 2007; Faulkner 2000, participants were relatively statin-naïve and either had therapy initiated or intensified, which would account for a greater initial decline in lipid levels. We used mean difference here as it has a more direct clinical meaning and is easier to interpret compared to the standardised mean difference (SMD). Also, using SMD did not change the conclusion of the analysis (Summary of findings 1)

\section{Reduction in total serum cholesterol $(\mathrm{mg} / \mathrm{dL})$ at $>6$ months:}

Pooling of data for total serum cholesterol at up to six months using per-protocol analysis of continuous outcomes included two studies with 127 participants. The studies were homogeneous $\left(I^{2}=\right.$ $0 \%$ ). Meta-analysis using a random-effects model produced an MD of $17.57,95 \% \mathrm{Cl} 14.95$ to 20.19 ; 2 studies; 127 participants; highquality evidence, favouring the intervention (Analysis 1.4). Using a fixed-effect model did not change the overall estimate (Summary of findings 1 ).

\section{Reduction in LDL-cholesterol (mg/dL) at $\leq 6$ months:}

Pooling of data for low-density lipoprotein cholesterol at up to six months using per-protocol analysis of continuous outcomes included three studies with 333 participants. There was moderate heterogeneity $\left(\mathrm{I}^{2}=53 \%\right)$. Meta-analysis using a random-effects model produced a MD of $19.51,95 \% \mathrm{Cl} 8.51$ to $30.51 ; 3$ studies; 333 participants; moderate-quality evidence, favouring the intervention (Analysis 1.5). Removing the studies that contributed to the heterogeneity from the pooled analysis resulted in MD 9.00, $95 \% \mathrm{Cl}-3.57$ to 21.57 , favouring the intervention, but not reaching statistical significance (Summary of findings 1 ).

\section{Reduction in LDL-cholesterol $(\mathrm{mg} / \mathrm{dL})$ at $>6$ months:}

Pooling of data for LDL-cholesterol at more than six months using per-protocol analysis of continuous outcomes included one study with 30 participants. Meta-analysis using a random-effects model estimated a MD of $18.00,95 \% \mathrm{Cl} 5.12$ to 30.88 , favouring the intervention (Analysis 1.6) (Summary of findings 1).

\section{Complex behavioural approaches vs usual care}

Medication adherence - Only one trial (Márquez 1998) used a group behavioural approach, where participants initially 
attended small-group training followed by postal information. The adherence in the intervention group was no different from the control group ( $88.5 \%$ in intervention group versus $83.8 \%$ in control group, $\mathrm{P}>0.05 ; \mathrm{n}=108)$.

Total serum cholesterol - There were differences between intervention and control groups for TC, LDL and HDL. Compared final mean differences in the intervention groups vs the control groups were: $7.5 \mathrm{mg} / \mathrm{dl}$ reduction in mean TC $(P>0.05) ; 5.2 \mathrm{mg} / \mathrm{dl}$ reduction in mean LDL $(P>0.05), 2.1 \mathrm{mg} / \mathrm{dl}$ increase in mean HDL $(P>0.05)$, and $30 \mathrm{mg} / \mathrm{dl}$ reduction in mean triglyceride levels (TRG) $(P<0.05)$

\section{Decision support systems vs complex behavioural approaches}

Medication adherence - In Kooy 2013 ( $\mathrm{n}=108)$ the median PDC360 (25th - 75th percentile) was $90.0 \%(76.75-98.25)$ in the counselling/ERD group, $91.0 \%(76.00-99.00)$ in the ERD group and $87.5 \%$ (75.00 - 99.00) in the control group (ITT analysis). We found no differences in the median refill adherence. In Pladevall $2014(n=1692)$ there was no difference between participants in the study arms that received adherence information and motivational interviewing when compared with usual care.

Total serum cholesterol - This outcome was not reported in Kooy 2013. In Pladevall 2014 there were no differences in LDL-cholesterol levels between the different groups $(P=0.084)$.

\section{Administrative improvements vs usual care}

Medication adherence - In Tamblyn 2009 ( $n=2293)$ participants in the intervention group were more likely to have their drug profile reviewed compared to those in the control group (44.5\% vs $35.5 \%$; OR 1.46; $\mathrm{P}<0.001)$. Overall, however, there was no difference in the magnitude of the decline in adherence between the intervention and control group (mean -6.2 (intervention) vs -6.4 (control); $\mathrm{P}=$ 0.90). In Choudhry $2011(n=5855)$ rates of full adherence (defined as having a supply of medications available on at least $80 \%$ of days during follow-up) for statins were $41.9 \%$ in the usual care group and $49.3 \%$ in the full-coverage group (increase by 6.2 percentage points, $95 \% \mathrm{Cl} 3.9$ to 8.5 ); OR $1.36,95 \% \mathrm{Cl} 1.18$ to $1.56 ; \mathrm{P}<0.001$. Rates of adherence to other medications for which copayments remained the same were no different between the two study groups.

Total serum cholesterol - This outcome was not reported in Choudhry 2011 or Tamblyn 2009.

Costs - Choudhry 2011 evaluated costs related to the intervention and found that elimination of co-payments in the intervention group did not increase total spending for the health system (USD 66,008 for the full-coverage group and USD 71,778 for the usualcoverage group; relative spending $0.89,95 \% \mathrm{Cl} 0.50$ to 1.56 ; $\mathrm{P}=$ $0.68)$. Participants in the intervention group paid less for drugs and other services (relative spending $0.74,95 \% \mathrm{Cl} 0.68$ to $0.80 ; \mathrm{P}<$ 0.001).

\section{Large-scale pharmacy-led automated telephone intervention vs usual care}

Fischer 2014 ( $n=861,894)$ included two interventions on nearly a million participants, initiated by a commercial pharmacy dispensing medications. One intervention consisted of automated phone calls to participants on the third and seventh days after a prescription was processed but remained unpurchased. The other intervention was a live intervention which used calls from a pharmacist or technician to participants who still had not picked up their prescriptions after eight days. Data for analysis were obtained following the interventions being commercially conducted. Data were not recorded on whether pharmacists or technicians left a message or actually spoke with participants, or on the content of conversations. In Vollmer 2014 the intervention consisted of automated phone reminders using interactive voice recognition to participants when they were due or overdue for a refill. Participants in the enhanced study arm also received a letter if they were 60 to 89 days overdue. This study randomised 16,280 participants.

Medication adherence - Fischer 2014: For the automated intervention, the proportion of abandoned prescriptions was $4.2 \%$ in the intervention group and $4.5 \%$ in the control group $(P=0.23)$. For antihypertensives, the proportion of abandoned prescriptions was $3.7 \%$ in the intervention group and $4.1 \%$ in the control group $(P=0.06)$, whereas for antihyperlipidaemics the proportions were the same (6.0\%).

For the live intervention, the proportion of abandoned prescriptions was $36.9 \%$ in the intervention group and $41.7 \%$ in the control group, a difference of $4.8 \%(P<0.0001)$. The difference for antihypertensives was $6.9 \%(P<0.0001)$ but for antihyperlipidaemics was only $1.4(\mathrm{P}=0.25)$

In Vollmer 2014 ( $n=16,366)$ statin adherence increased for both intervention groups compared with usual care, but adherence was no different between the phone group and the enhance phone group. On average, adherence among the group that only received the phone calls was 2.2 percentage points higher than for usual care (95\% Cl 1.1 to 3.4), while the difference was $3.0,95 \% \mathrm{Cl} 1.9$ to 4.2 percentage points for the group that also received a reminder letter.

Total serum cholesterol - This outcome was not reported in Fischer 2014. In Vollmer 2014 a reduction in LDL-cholesterol levels was found among the participants receiving phone calls and a letter, compared to usual care (mean difference $-1.5,95 \% \mathrm{Cl}-2.7$ to -0.2 $\mathrm{mg} / \mathrm{dL} ; \mathrm{P}=0.019)$.

\section{ISC USSION}

\section{Summary of main results}

This updated systematic review identified new evidence to suggest that patient interventions which we grouped as intensified patient care may improve patient adherence to lipid-lowering therapy when compared to usual care. These types of interventions took the form of telephone reminders, calendar reminders, integrated multidisciplinary educational activities and pharmacistled interventions. The interventions appeared to be effective in improving medication adherence, both over the short term (up to six months) and the long term (more than six months). Physiologic outcome data in the form of cholesterol levels also demonstrated significant improvement over short-term and long-term periods. The effectiveness of these types of interventions was sustained even when we removed studies contributing to heterogeneity from the analysis.

Other types of interventions which we grouped as drug regimen simplification, complex behavioural approaches, decision support systems, administrative improvements, and a largescale pharmacy-led automated telephone intervention did not 
consistently show an overall improvement in adherence rates or other physiologic measures of adherence. Some outcomes were not measured in all studies and comparisons were made only where possible.

\section{Overall completeness and applicability of evidence}

The significant increase in research activity in this field has yielded more robust data from which to draw conclusions. In the studies classified as intensification of patient care, enough high-quality studies exist with similar outcomes where we noted significant trends favouring the interventions. The types of studies in this category included large groups of outpatients and would seem to be generalisable to other outpatient cohorts. Studies in the other categories could address the objectives of our meta-analysis, but given the relatively small number of comparable studies with similar interventions and outcome measures, no clear trends emerged.

The interventions in the intensified patient care group are of a type which is applicable to current practice. Many large healthcare systems are evaluating methods to improve the health of large populations of patients. Large-scale structural interventions noted in the intensified patient care group of interventions are generally feasible for these types of systems.

\section{Quality of the evidence}

The studies in this review investigate the impact of a wide range of interventions on adherence to lipid-lowering treatments. The nature of the majority of interventions implies that blinding of participants was not possible (e.g. interventions such as reminder phone calls or education sessions). As this is acceptable in a pragmatic context, we have not downgraded the evidence for lack of blinding. Studies demonstrating a fixed dose combination or 'polypill' placebo comparison are feasible, but we could not pool them in our review.

We assessed the quality of the pooled evidence using the GRADE classification for five pooled outcomes in the comparison of intensification of patient care vs usual care. We graded the evidence for the outcomes of long-term adherence (more than six months) and reduction in total cholesterol as being of high quality. We rated the short-term outcomes (up to six months) of patient adherence and LDL-cholesterol as being of moderate quality. We downgraded these outcomes by one level because of heterogeneity of the pooled data. We downgraded the short-term outcome of total serum cholesterol to low quality, due to heterogeneity and a wide confidence interval (imprecision).

The review authors independently reviewed data at various checkpoints, ensuring the selection of a series of rigorous studies. The review authors believe that systematic error did not threaten the validity of the results of the studies included in this review (see Risk of bias in included studies).

\section{Potential biases in the review process}

We have searched in several different databases, including trials registers, and we have handsearched reference lists in order to identify eligible studies. It is nevertheless still possible that we have missed relevant material. In addition, two review authors selected studies independently, thus minimising the risk of overlooking any. The updated searches in 2015 and 2016 retrieved a considerable number of new studies for inclusion, indicating that the topic is still being actively researched. In order to maintain the relevance of this review, we will therefore attempt to update our searches regularly. The evidence is quite consistent and robust and it may therefore be unlikely that a missed study could have changed our conclusions.

The diverse nature of the studied interventions and absence of a standard classification of interventions to improve medication adherence means that studies can be grouped in different ways. We have grouped the studies from the perspective of the health system/provider, as this has relevance to implementation strategies.

In the pooled analysis Analysis 1.3 the Aslani 2010 study was a clustered RCT, however we did not adjust for clustering as in Australia pharmacies do not serve specific populations. Patients generally purchase their medication from a number of different pharmacies. A study in a similar setting found a clustering effect of -0.006 , which justifies using uni-level analysis. It is possible that we have overestimated the effect of the intervention, however, it is unlikely that this will have influenced the conclusion.

\section{Agreements and disagreements with other studies or reviews}

The two previous versions of this review concluded that there were no reliable interventions that have been shown to improve adherence rates to lipid-lowering medications (Schedlbauer 2004; Schedlbauer 2010). However, this updated review which includes 24 additional studies indicates that interventions classified as intensification of patient care could improve both short-term and long-term adherence rates when compared to usual care.

An earlier systematic review (Muller-Nordhorn 2005), including 10 RCTs, found that interventions (ranging from postal reminders to coaching, delivered by nurses, pharmacists or physicians) was associated with a significant increase in patient adherence to statin therapy compared with the control group in four of the 10 RCTs. The remaining six RCTs found no significant difference in adherence. The authors conclude that "given the inconsistency of the findings and the limitations of certain study designs, RCTs with a large sample size are needed to further investigate the effectiveness of adherence-increasing interventions in patients with statin therapy." The most recent systematic review by Rash 2016, which includes 29 RCTs, pooled data for interventions labelled as 'simplification of drug regimen', 'provision of education', and 'multi-faceted interventions'. They conclude that all these types of interventions had a small positive effect on statin adherence, but that additional methodologically rigorous trials are needed.

\section{AUTHORS' CONCLUSIONS}

\section{Implications for practice}

High-quality evidence shows that intensification of patient care interventions improves long-term medication adherence and total cholesterol. Moderate-quality evidence shows that intensification of patient care interventions improves short-term medication adherence and LDL-cholesterol. The evidence for total cholesterol reduction in the short term is of low quality. Given the importance of statin therapy in both primary and secondary prevention, strategies to improve adherence rates should have significant benefit in those 
people for whom statin therapy is recommended. The interventions which were identified as successful in the intensification of patient care interventions typically involved strategies beyond what a single clinician could provide. Instead, healthcare delivery systems might be better equipped to deliver the types of interventions which have been shown to best improve adherence rates. Health system-related interventions which showed benefit involved strategies such as pharmacist-led interventions, multidisciplinary educational or counselling sessions, and automated reminders of various types. A combination of all of these types of interventions, along with an added focus on teamwork with the primary physician, also proved to be effective (Ho 2014). In these studies, effectiveness was generally demonstrated by improvements in both adherence rates and in lipid levels. The effect appeared durable and was significant over both short-term and longterm time periods. Healthcare systems which are able to involve teams of healthcare professionals in the implementation of such interventions may well be successful in decreasing the burden of cardiovascular disease in the populations whom they serve through improved adherence to statin medications.

The results of our meta-analysis must, however, be seen in the context of the healthcare system in which they were trialled. For instance, the pharmacy-led interventions are applicable in systems with a strong and well-structured medication delivery system through pharmacies, but will not be feasible in, for instance, low-income countries where drug dispensing is much less controlled or integrated into the healthcare system. Cultural and social context will also play a role and the impact of automated reminders delivered as text messages, for instance, will be less effective if patients' beliefs regarding their medicines have not been addressed.

it is important to acknowledge the wide diversity of control interventions that we have grouped as 'usual care', which is different in each setting. For instance, pharmacy usual care can include patient education in some settings but none at all in others. Likewise, usual care in the context of physiciandelivered interventions can also vary extensively. The results of our comparisons therefore need to be interpreted with caution.

\section{Implications for research}

Exploration of additional factors which influence adherence to drug therapy may help in identifying other targets for interventions.
These additional factors include knowledge, health beliefs, risk perception, memory, side effects of medication, costs of medication and inconvenience (Ebrahim 1998). The phenomenon of adherence is complex and it would seem reasonable for interventions to address this complexity with a more patientcentred approach. People's beliefs and preferences need to be acknowledged and incorporated into adherence-enhancing interventions (Marinker 1997). A combination of strategies including information, reminding, adherence reinforcement and emphasis on the person's perspective might lead to more effective strategies. In terms of the lipid-lowering drug class, the main focus should be on statins, as they have been shown to be the most potent lipid-lowering drugs (ACC/AHA Guidelines 2013; Baigent 2005). Other important aspects for future studies include valid methods for measuring adherence and assessing the effects on serum lipid levels. Long-term follow-up, of 12 months and more, will reveal a more realistic picture of adherence to lifelong treatment and allow for the evaluation of morbidity and costs. Finally, studies evaluating these types of interventions on other outcomes such as morbidity, mortality, quality of life and cost effectiveness would be very useful. Data relating to which interventions were the most cost-effective can provide guidance to healthcare systems.

\section{ACK NOWLEDGEMENTS}

We would like to acknowledge the important contributions by Knut Schroeder and Tim Peters, who were co-authors of the original review. Knut Schroeder conceived the original review and contributed to the screening of search results, data extraction and interpretation of data. Tim Peters was involved with the analysis of data and provided general advice on interpreting the data. Thanks to the authors of the original studies (BG Brown, E Bruckert, M Faulkner, E de Klerk, E Lesaffre, E Marquez-Contreras) and the updates (A Shedlbauer, P Davies, T Fahey) for their work which was included in this update.

We would like to thank the Cochrane Heart Group for the support they gave for the update of this review; Margaret Burke, Liz Bickerdike, and Nicole Martin in particular for their help with the literature search, and Zulian Liu from PenTAG for her help with the abstract selection. 


\section{RE F E R E N C E S}

\section{References to studies included in this review}

Aslani 2010 \{published data only\}10.1093/eurpub/ckq118

Aslani P, Rose G, Chen TF, Whitehead PA, Krass I. A community pharmacist delivered adherence support service for dyslipidaemia. European Journal of Public Health 2010;21(5):567-72.

\section{Brown 1997 \{published data only\}}

Brown BG, Bardsley J, Poulin D, Hillger LA, Dowdy A, Maher VM, et al. Moderate dose, three-drug therapy with niacin, lovastatin, and colestipol to reduce low-density lipoprotein cholesterol $<100 \mathrm{mg} / \mathrm{dl}$ in patients with hyperlipidemia and coronary artery disease. American Journal of Cardiology 1997;80(2):111-15.

Castellano 2014 \{published data only\}10.1016/

j.jacc.2014.08.021

Castellano JM, Gines S, Penalvo JL, Bansilal S, FernandezOrtiz A, Alvarez L, et al. A polypill strategy to improve adherence: results from the FOCUS Project. Journal of the American College of Cardiology 2014;64(20):2071-82. [DOI: 10.1016/ j.jacc.2014.08.021]

\section{Choudhry 2011 \{published data only\}10.1056/NEJMsa1107913}

Choudhry NK, Avorn J, Glynn RJ, Antman EM, Schneeweiss S, Toscano M, et al. Full coverage for preventive medications after myocardial infarction. New England Journal of Medicine 2011;365(22):2088-97.

\section{Derose 2012 \{published data only\}}

Derose SF, Green K, Marrett E, Tunceli K, Cheetham TC, Chiu VY, et al. Automated outreach to increase primary adherence to cholesterol-lowering medications. JAMA Internal Medicine 2013;173(1):38-43. [DOI: 10.1001/2013.jamainternmed.717]

\section{Eussen 2010 \{published data only\}10.1345/aph.1P281}

Eussen SR, Van der Elst ME, Klungel OH, Rompelberg CJ, Garssen J, Oosterveld MH, et al. A pharmaceutical care program to improve adherence to statin therapy: a randomized controlled trial. Annals of Pharmacotherapy 2010;44(12):1905-13.

\section{Fang 2015 \{published data only\}}

Fang R, Li X. Electronic messaging support service programs improve adherence to lipid-lowering therapy among outpatients with coronary artery disease: an exploratory randomised control study. Journal of Clinical Nursing 2015;25(5-6):664-71. [DOI: 10.1111/jocn.12988]

Faulkner 2000 \{published data only\}

Faulkner MA, Wadibia EC, Lucas BD, Hilleman DE. Impact of pharmacy counseling on compliance and effectiveness of combination lipid-lowering therapy in patients undergoing coronary artery revascularization: a randomized, controlled trial. Pharmacotherapy 2000;20(4):410-6.
Fischer 2014 \{published data only\}10.1097/

MLR.0000000000000247

Fischer MA, Choudhry NK, Bykov K, Brill G, Bopp G, Wurst AM, et al. Pharmacy-based interventions to reduce primary medication nonadherence to cardiovascular medications. Medical Care 2014;52(12):1050-4.

Goswami 2013 \{published data only\}

Goswami NJ, Dekoven M, Kuznik A, Mardekian J, Krukas MR, Liu LZ, et al. Impact of an integrated intervention program on atorvastatin adherence: a randomized controlled trial. International Journal of General Medicine 2013;6:647-55. [DOI: 10.2147/IJGM.S47518]

Gujral 2014 \{published data only\}10.1007/s11096-014-9993-y Gujral G, Winckel K, Nissen LM, Cottrell WN. Impact of community pharmacist intervention discussing patients' beliefs to improve medication adherence. International Journal of Clinical Pharmacy 2014;36(5):1048-58.

Guthrie 2001 \{published data only\}

Guthrie RM. The effects of postal and telephone reminders on compliance with pravastatin therapy in a national registry: results of the first myocardial infarction risk reduction program. Clinical Therapeutics 2001;23(6):970-80.

Ho 2014 \{published data only\}10.1001/

jamainternmed.2013.12944

Ho PM, Lambert-Kerzner A, Carey EP, Fahdi IE, Bryson CL, Melnyk SD, et al. Multifaceted intervention to improve medication adherence and secondary prevention measures after acute coronary syndrome hospital discharge: a randomized clinical trial. JAMA Internal Medicine 2014;174(2):186-93.

Kardas 2013 \{published data only\}

Kardas P. An education-behavioural intervention improves adherence to statins. Central European Journal of Medicine 2013;8(5):580-5.

Kooy 2013 \{published data only\}10.3389/fphar.2013.00069

Kooy MJ, Van Wijk BL, Heerdink ER, De Boer A, Bouvy ML. Does the use of an electronic reminder device with or without counseling improve adherence to lipid-lowering treatment? The results of a randomized controlled trial. Frontiers in Pharmacology 2013;4:69.

\section{Ma 2010 \{published data only\}10.1155/2010/383281}

Ma YS, Ockene IS, Rosal MC, Merriam PA, Ockene JK, Gandhi PJ. Randomized trial of a pharmacist-delivered intervention for improving lipid-lowering medication adherence among patients with coronary heart disease. Cholesterol 2010;2010:383281. [DOI: 10.1155/2010/383281]

\section{Márquez 1998 \{published data only\}}

Márquez Contreras E, Casado Martínez JJ, López de Andrés M, Corés Prieto E, López Zamorano JM, Moreno García JP, et al. Therapeutic compliance in dyslipidemias. A trial of the efficacy of health education. Atencion Primaria 1998;22(2):79-84. 
Márquez 2004 \{published data only\}

Márquez Contreras E, Casado Martínez JJ, Corchado Albalat Y, Chaves Gonzalez R, Grandio A, Losada Velasco C, et al. Efficacy of an intervention to improve therapy compliance in lipaemia cases. Atencion Primaria 2004;33(8):15.

\section{Márquez 2007 \{published data only\}}

Márquez Contreras E, Casado Martínez JJ, Motero Carrasco J, Martín de Pablos JL, Chaves Gonzales R, Losada Ruiz C, et al. Therapy compliance in cases of hyperlipaemia, as measured through electronic monitors. Is a reminder calendar to avoid forgetfulness effective? Atencion Primaria 2007;39(12):661-8.

Nieuwkerk 2012 \{published data only\}10.1016/

j.amjcard.2012.04.045

Nieuwkerk PT, Nierman MC, Vissers MN, Locadia M, GreggersPeusch P, Knape LPM, et al. Intervention to improve adherence to lipid-lowering medication and lipid-levels in patients with an increased cardiovascular risk. American Journal of Cardiology 2012;110(5):666-72.

Park 2013 \{published data only\}10.1016/j.pec.2013.10.027

Park LG, Howie-Esquivel J, Chung ML, Dracup K. A text messaging intervention to promote medication adherence for patients with coronary heart disease: A randomized controlled trial. Patient Education and Counseling 2013;94(2):261-8.

Patel 2015 \{published data only\}10.1177/2047487314530382 Patel A, Cass A, Peiris D, Usherwood T, Brown A, Jan S, et al. A pragmatic randomized trial of a polypill-based strategy to improve use of indicated preventive treatments in people at high cardiovascular disease risk. European Journal of Preventive Cardiology 2015;22(7):920-30.

PILL 2011 \{published data only\}10.1371/journal.pone.0019857 PILL Collaborative Group. An international randomised placebo-controlled trial of a four-component combination pill ("Polypill') in people with raised cardiovascular risk. PLOS One 2011;6(5):e19857.

Pladevall 2014 \{published data only\}10.1177/0145721714561031 Pladevall M, Divine G, Wells KE, Resnicow K, Williams LK. A randomized controlled trial to provide adherence information and motivational interviewing to improve diabetes and lipid control. Diabetes Educator 2015;41(1):136-46.

\section{Poston 1998 \{published data only\}}

Poston J, Loh E, Dunham W. The medication use study. Canadian Pharmaceutical Journal 1998;131(10):31-8.

Powell 1995 \{published data only\}

Powell KM, Edgren B. Failure of educational videotapes to improve medication compliance in a health maintenance organization. American Journal of Health-System Pharmacy 1995;52(20):2196-9.

\section{Schectman 1994 \{published data only\}}

Schectman G, Hiatt J, Hartz A. Telephone contacts do not improve adherence to niacin or bile acid sequestrant therapy. Annals of Pharmacotherapy 1994;28(1):29-35.
Selak 2014 \{published data only\}10.1136/bmj.g3318

Selak V, Elley CR, Bullen C, Crengle S, Wadham A, Rafter N, et al. Effect of fixed dose combination treatment on adherence and risk factor control among patients at high risk of cardiovascular disease: randomised controlled trial in primary care. $B M J$ 2014;348:g3318.

Sweeney 1991 \{published data only\}

Sweeney ME, Fletcher BJ, Rice CR, Berra KA, Rudd CM, Fletcher GF, et al. Efficacy and compliance with cholestyramine bar versus powder in the treatment of hyperlipidemia. American Journal of Medicine 1991;90(4):469-73.

Tamblyn 2009 \{published data only\}

Tamblyn R, Reidel K, Huang A, Taylor L, Winslade N, Bartlett G, et al. Increasing the detection and response to adherence problems with cardiovascular medication in primary care through computerized drug management systems: a randomized controlled trial. Medical Decision Making 2009;30(2):176-88

Thom 2013 \{published data only\}

Thom S, Poulter N, Field J, Patel A, Prabhakaran D, Stanton A, et al. Effects of a fixed-dose combination strategy on adherence and risk factors in patients with or at high risk of CVD (UMPIRE). JAMA 2013;310(9):918-29.

\section{Vollmer 2014 \{published data only\}}

Vollmer WM, Owen-Smith AA, Tom JO, Laws R, Ditmer DG, Smith $\mathrm{DH}$, et al. Improving adherence to cardiovascular disease medications with information technology. American Journal of Managed Care 2014;20(11 Spec No. 17):SP502-10.

Vrijens 2006 \{published data only\}

Vrijens B, Belmans A, Matthys K, De Klerke E, Lesaffre E. Effect of intervention through a pharmaceutical care program on patient adherence with prescribed once-daily atorvastatin. Pharmacoepidemiology and Drug Safety 2006;15(2):115-21.

Wald 2014 \{published data only\}10.1371/journal.pone.0114268

Wald DS, Bestwick JP, Raiman L, Brendell R, Wald NJ. Randomised trial of text messaging on adherence to cardiovascular preventive treatment (INTERACT Trial). PLOS ONE 2014;9(12):e114268.

\section{Willich 2009 \{published data only\}}

Willich SN, Englert H, Sonntag F, Voller H, Meyer-Sabellek W, Wegscheider K, et al. Impact of a compliance program on cholesterol control: results of the randomized ORBITAL study in 8108 patients treated with rosuvastatin. European Journal of Cardiovascular Prevention and Rehabilitation 2009;16(2):180-7.

\section{References to studies excluded from this review}

Allen 2000 \{published data only\}

Allen JK. Cholesterol management: an opportunity for nurse case managers. Journal of Cardiovascular Nursing 2000;14(2):50-8. 
Anon 2002 \{published data only\}

Anonymous. Is alternate day dosing more cost-effective? Pharmaceutical Journal 2002;269(7224):706.

\section{Athyros 2002b \{published data only\}}

Athyros VG, Mikhailidis DP, Papageorgiou AA, Mercouris BR, Athyrou VV, Symeonidis AN, et al. Attaining United KingdomEuropean Atherosclerosis Society low-density lipoprotein cholesterol guideline target values in the GREek Atorvastatin and Coronary-heart-disease Evaluation (GREACE) study. Current Medical Research and Opinion 2002;18(8):499-502.

\section{Becker 1998 \{published data only\}}

Becker DM, Raqueno JV, Yook RM, Kral BG, Blumenthal RS, Moy TF, et al. Nurse-mediated cholesterol management compared with enhanced primary care in siblings of individuals with premature coronary disease. Archives of Internal Medicine 1998;158(14):1533-9.

\section{Bogden 1997 \{published data only\}}

Bogden PE, Koontz LM, Williamson P, Abbott RD. The physician and pharmacist team. An effective approach to cholesterol reduction. Journal of General Internal Medicine 1997;12(3):158-64. [MEDLINE: 9100140]

\section{Bruckert 1999 \{published data only\}}

Bruckert E, Simonetta C, Giral P. Compliance with fluvastatin treatment characterization of the noncompliant population within a population of 3845 patients with hyperlipidemia: CREOLE Study Team. Journal of Clinical Epidemiology 1999;52(6):589-94.

\section{Burkett 1990 \{published data only\}}

Burkett PA, Southard DR, Herbert WG, Walberg J. Frequent cholesterol feedback as an aid in lowering cholesterol levels. Journal of Cardiopulmonary Rehabilitation 1990;10(4):141-6. [EMBASE: 1990218703]

\section{Casebeer 1999 \{published data only\}}

Casebeer LL, Klapow JC, Centor RM, Stafford MA, RenkI LA, Mallinger AP, et al. An intervention to increase physicians' use of adherence-enhancing strategies in managing hypercholesterolemic patients. Academic Medicine 1999;74(12):1334-9.

\section{Coates 1982 \{published data only\}}

Coates TJ, Jeffery RW, Slinkard LA. Frequency of contact and monetary reward in weight loss, lipid change, and blood pressure reduction with adolescents. Behavior Therapy 1982;13(2):175-85.

\section{DeBusk 1994 \{published data only\}}

DeBusk RF, Miller NH, Superko HR, Dennis CA, Thomas RJ, Lew HT, et al. A case-management system for coronary risk factor modification after acute myocardial infarction. Annals of Internal Medicine 1994;120(9):721-9.

\section{Diabetes 2000 \{published data only\}}

Diabetes Prevention Program Research Group. The Diabetes Prevention Program: baseline characteristics of the randomized cohort. Diabetes Care 2000;23(11):1619-29.

\section{Diwan 1995 \{published data only\}}

Diwan VK, Wahlstrom R, Tomson G, Beermann B, Sterky G, Eriksson B. Effects of "group detailing" on the prescribing of lipid-lowering drugs: a randomized controlled trial in Swedish primary care. Journal of Clinical Epidemiology 1995;48(5):705-11.

\section{Dobs 1994 \{published data only\}}

Dobs AS, Masters RB, Rajaram L, Stillman FA, Wilder LB, Margolis S, et al. A comparison of education methods and their impact on behavioral change in patients with hyperlipidemia. Patient Education and Counseling 1994;24(2):157-64.

Dunham 2000 \{published data only\}

Dunham DM, Stewart RD, Laucka PV. Low-density-lipoprotein cholesterol in patients treated by a lipid clinic versus a primary care clinic. American Journal of Health-System Pharmacy 2000;57(24):2285-6.

\section{Ellis 2000 \{published data only\}}

Ellis SL, Carter BL, Malone DC, Billups SJ, Okano GJ, Valuck RJ, et al. Clinical and economic impact of ambulatory care clinical pharmacists in management of dyslipidemia in older adults: the IMPROVE study. Impact of Managed Pharmaceutical Care on Resource Utilization and Outcomes in Veterans Affairs Medical Centers. Pharmacotherapy 2000;20(12):1508-16.

\section{Eriksson 1998 \{published data only\}}

Eriksson M, Hadell K, Holme I, Walldius G, Kjellstrom T. Compliance with and efficacy of treatment with pravastatin and cholestyramine: a randomized study on lipid-lowering in primary care. Athereosclerosis 1997;134:55.

* Eriksson M, Hadell K, Holme I, Walldius G, Kjellstrom T. Compliance with and efficacy of treatment with pravastatin and cholestyramine: A randomized study on lipid-lowering in primary care. Journal of Internal Medicine 1998;243(5):373-80.

Frances 2001 \{published data only\}

Frances CD, Alperin P, Adler JS, Grady D. Does a fixed physician reminder system improve the care of patients with coronary artery disease? A randomized controlled trial. Western Journal of Medicine 2001;175(3):165-6.

\section{Fretheim 2006 \{published data only\}}

Fretheim A, Oxman AD, Havelsrud K, Treweek S, Kristoffersen DT, Bjorndal A. Rational prescribing in primary care (RaPP): a cluster randomized trial of a tailored intervention. PLoS Medicine / Public Library of Science 2006;3(6):e134.

\section{Friedman 1998 \{published data only\}}

Friedman RH. Automated telephone conversations to assess health behavior and deliver behavioral interventions. Journal of Medical Systems 1998;22(2):95-102.

\section{Gaede 1999 \{published data only\}}

Gaede P, Vedel P, Parving HH, Pedersen O. Intensified multifactorial intervention in patients with type 2 diabetes mellitus and microalbuminuria: the Steno type 2 randomised study. Lancet 1999;353(9153):617-22. 


\section{Gaede 2003 \{published data only\}}

Gaede P, Vedel P, Larsen N, Jensen GV, Parving HH, Pedersen O. Multifactorial intervention and cardiovascular disease in patients with type 2 diabetes. New England Journal of Medicine 2003;348(5):383-93.

Hae 2007 \{published data only\}

Hae MC. Impact of patient financial incentives on participation and outcomes in a statin pill-splitting program. American Journal of Managed Care 2007;13(6):298-304.

\section{Ives 1993 \{published data only\}}

Ives DG, Kuller LH, Traven ND. Use and outcomes of a cholesterol-lowering intervention for rural elderly subjects. American Journal of Preventive Medicine 1993;9(5):274-81. [MEDLINE: 94079785]

\section{Jafari 2003 \{published data only\}}

Jafari M, Ebrahimi R, Ahmadi-Kashani M, Balian H, Bashir M. Efficacy of alternate-day dosing versus daily dosing of atorvastatin. Journal of Cardiovascular Pharmacology and Therapeutics 2003;8(2):123-6.

\section{Jiang 2007 \{published data only\}}

Jiang X, Sit JW, Wong TK. A nurse-led cardiac rehabilitation programme improves health behaviours and cardiac physiological risk parameters: evidence from Chengdu, China. Journal of Clinical Nursing 2007;16(10):1886-97.

\section{Johannesson 1996 \{published data only\}}

Johannesson M, Borgquist L, Jonsson B, Lindholm LH. The cost effectiveness of lipid lowering in Swedish primary health care. The CELL Study Group. Journal of Internal Medicine 1996;240(1):23-9.

\section{Jolly 1998 \{published data only\}}

Jolly K, Bradley F, Sharp S, Smith H, Mant D. Follow-up care in general practice of patients with myocardial infarction or angina pectoris: initial results of the SHIP trial. Southampton Heart Integrated Care Project. Family Practice 1998;15(6):548-55. [MEDLINE: 99176682]

\section{Keyserling 1997 \{published data only\}}

Keyserling TC, Ammerman AS, Davis CE, Mok MC, Garrett J, Simpson R Jr. A randomized controlled trial of a physiciandirected treatment program for low-income patients with high blood cholesterol: the Southeast Cholesterol Project. Archives of Family Medicine 1997;6(2):135-45. [MEDLINE: 97229885]

\section{Kirkman 1994 \{published data only\}}

Kirkman MS, Weinberger M, Landsman PB, Samsa GP, Shortliffe EA, Simel DL, et al. A telephone-delivered intervention for patients with NIDDM. Effect on coronary risk factors. Diabetes Care 1994;17(8):840-6. [MEDLINE: 95044714]

\section{Kjelsberg 1990 \{published data only\}}

Kjelsberg MO. Mortality after $101 / 2$ years for hypertensive participants in the multiple risk factor intervention trial. Circulation 1990;82(5):1616-28.
Kulik 2013 \{published data only\}

Kulik A, Desai NR, Shrank WH, Antman EM, Glynn RJ, Levin R, et al. Full prescription coverage versus usual prescription coverage after coronary artery bypass graft surgery: analysis from the post-myocardial infarction free Rx event and economic evaluation (FREEE) randomized trial. Circulation 2013;128(Suppl 1):S219-S225.

Kuznar 2002 \{published data only\}

Kuznar W. Protocol helps drug adherence. Cardiology Review 2002;19(3):6

\section{Lee 2007 \{published data only\}}

Lee JK. How should we measure medication adherence in clinical trials and practice? Therapeutics and Clinical Risk Management 2007;3(4):2007.

Lesaffre $\mathbf{2 0 0 0}$ \{published data only\}

Lesaffre E, De Klerk E. Estimating the power of compliance Improving methods. Controlled Clinical Trials 2000;21(6):540-51.

Lin 2006 \{published data only\}

Lin EH, Katon W, Rutter C, Simon GE, Ludman EJ, Von Korff M, et al. Effects of enhanced depression treatment on diabetes selfcare. Annals of Family Medicine 2006;4(1):46-53

\section{Lindholm 1996 \{published data only\}}

Lindholm LH, Ekbom T, Dash C, Isacsson A, Schersten B. Changes in cardiovascular risk factors by combined pharmacological and nonpharmacological strategies: the main results of the CELL Study. Journal of Internal Medicine 1996;240(1):13-22.

Merriam 1997 \{published data only\} Merriam PA, Ockene IS, Hebert JR, Ma Y. A lipid trial tracking system. Journal of Public Health Management and Practice 1997;3(6):74-8

\section{Moher 2001 \{published data only\}}

Moher M, Yudkin P, Wright L, Turner R, Fuller A, Schofield T, et al. Cluster randomised controlled trial to compare three methods of promoting secondary prevention of coronary heart disease in primary care. BMJ 2001;322(7298):1338-42.

\section{Oi 1998 \{published data only\}}

Oi K, Komori H. Escape phenomenon with pravastatin during long-term treatment of patients with hyperlipidemia associated with diabetes mellitus. Current Therapeutic Research, Clinical and Experimental 1998;59(2):130-8.

Oosterhoff 2011 \{published data only\}

Oosterhof P, Van Boven JF, Visser ST, Hiddink EG, StuurmanBieze AG, Postma MJ, et al. Cost effectiveness of increasing statin adherence for secondary prevention in community pharmacies. Value in Health 2011;14:A379.

\section{Polack 2008 \{published data only\}}

Polack J, Jorgenson D, Robertson P. Evaluation of different methods of providing medication-related education to patients following myocardial infarction. Canadian Pharmacists Journal/ Revue des Pharmaciens du Canada 2008;141:241. 


\section{Rachmani 2002 \{published data only\}}

Rachmani R, Levi Z, Slavachevski I, Avin M, Ravid M. Teaching patients to monitor their risk factors retards the progression of vascular complications in high-risk patients with Type 2 diabetes mellitus: a randomized prospective study. Diabetic Medicine 2002;19(5):385-92.

\section{Rastam 1996 \{published data only\}}

Rastam L, Frick J-O. Nurses counseling for hypercholesterolemia: Efficient strategy in middle-aged men. Cardiovascular Risk Factors 1996;6(1):36-41.

\section{Rindone 1998 \{published data only\}}

Rindone JP, Hiller D, Arriola G. A comparison of fluvastatin 40 mg every other day versus $20 \mathrm{mg}$ every day in patients with hypercholesterolemia. Pharmacotherapy 1998;18(4):836-9. [MEDLINE: 98355406]

\section{Robin 2002 \{published data only\}}

Robin DM, Giordani PJ, Lepper HS, Croghan TW. Patient adherence and medical treatment outcomes: a meta-analysis. Medical Care 2002;40(9):794-811.

\section{Rodgers 2000 \{published data only\}}

Rodgers J. Pharmacological interventions in type 2 diabetes: the role of nurses. British Journal of Nursing 2000;9(13):866-70.

Rubenfire 2004 \{published data only\}

Rubenfire M, Impact of Medical Subspecialty on Patient Compliance to Treatment Study Group. Safety and compliance with once-daily niacin extended-release/lovastatin as initial therapy in the Impact of Medical Subspecialty on Patient Compliance to Treatment (IMPACT) study. American Journal of Cardiology 2004;94(3):306-11.

\section{Schectman 1996 \{published data only\}}

Schectman G, Wolff N, Byrd JC, Hiatt JG, Hartz A. Physician extenders for cost-effective management of hypercholesterolemia. Journal of General Internal Medicine 1996;11(5):277-86. [MEDLINE: 96338658]

\section{Scherwitz 1995 \{published data only\}}

Scherwitz LW, Brusis OA, Kesten D, Safian PA, Hasper E, Berg A, et al. Life style changes in patients with myocardial infarct in the framework of intramural and ambulatory rehabilitation-results of a German pilot study [Lebensstilanderung bei Herzinfarktpatienten im Rahmen der stationaren und ambulanten Rehabilitation--Ergebnisse einer deutschen Pilotstudie]. Zeitschrift fur Kardiologie 1995;84(3):216-21.

\section{Shaffer 1995 \{published data only\}}

Shaffer JW. Reducing low-density lipoprotein cholesterol levels in an ambulatory care system. Results of a multidisciplinary collaborative practice lipid clinic compared with traditional physician-based care. Archives of Internal Medicine 1995;155(21):2330-5.

\section{Simpson 2001 \{published data only\}}

Simpson SH, Johnson JA, Tsuyuki RT. Economic impact of community pharmacist intervention in cholesterol risk management: an evaluation of the study of cardiovascular risk intervention by pharmacists. Pharmacotherapy 2001;21(5):627-35.

\section{Toobert 2000 \{published data only\}}

Toobert DJ, Glasgow RE, Radcliffe JL. Physiologic and related behavioral outcomes from the women's lifestyle heart trial. Annals of Behavioural Medicine 2000;22(1):1-16.

\section{Tsuyuki 1999 \{published data only\}}

Tsuyuki RT, Johnson JA, Teo KK, Ackman ML, Biggs RS, Cave A, et al. Study of Cardiovascular Risk Intervention by Pharmacists (SCRIP): a randomized trial design of the effect of a community pharmacist intervention program on serum cholesterol risk. Annals of Pharmacotherapy 1999;33(9):910-9.

Tully 2000 \{published data only\}

Tully MP, Seston EM. Impact of pharmacists providing a prescription review and monitoring service in ambulatory care or community practice. Annals of Pharmacotherapy 2000;34(11):1320-31.

\section{Vale 2002 \{published data only\}}

Vale MJ, Jelinek MV, Best JD, Santamaria JD. Coaching patients with coronary heart disease to achieve the target cholesterol: a method to bridge the gap between evidence-based medicine and the "real world"--randomized controlled trial. Journal of Clinical Epidemiology 2002;55(3):245-52.

\section{Wahlstrom 1995 \{published data only\}}

Wahlstrom R, Tomson G, Diwan VK, Beermann B, Sterky G. Hyperlipidaemia in primary care - a randomized controlled trial on treatment information in Sweden: Design and methodology. Pharmacoepidemiology and Drug Safety 1995;4(2):75-90.

\section{Weymiller 2007 \{published data only\}}

Weymiller AJ. Helping patients with type 2 diabetes mellitus make treatment decisions: Statin choice randomized trial. Archives of Internal Medicine 2007;167(10):28

\section{Wright 2002 \{published data only\}}

Wright L. The specialist nurse in coronary heart disease prevention: Evidence for effectiveness. British Journal of Cardiology 2002;9 Suppl 3:S15-9.

Wu 2006 \{published data only\}

Wu JY, Leung WY, Chang S, Lee B, Zee B, Tong PCY, et al. Effectiveness of telephone counselling by a pharmacist in reducing mortality in patients receiving polypharmacy: Randomised controlled trial. BMJ 2006;333(7567):522-7.

Yigit 2004 \{published data only\}

Yigit F, Muderrisoglu H, Guz G, Bozbas H, Korkmaz ME, Ozin MB, et al. Comparison of intermittent with continuous simvastatin treatment in hypercholesterolemic patients with end stage renal failure. Japanese Heart Journal 2004;45(6):959-68.

\section{Yilmaz 2005 \{published data only\}}

Yilmaz MB, Pinar M, Naharci I, Demirkan B, Baysan O, Yokusoglu M, et al. Being well-informed about statin is associated with continuous adherence and reaching targets. Cardiovascular Drugs and Therapy 2005;19(6):437-40. 
Zermansky 2002 \{published data only\}

Zermansky AG, Petty DR, Raynor DK, Lowe CJ, Freemantle N, Vail A. Clinical medication review by a pharmacist of patients on repeat prescriptions in general practice: A randomised controlled trial. Health Technology Assessment 2002;6(20):76.

\section{References to studies awaiting assessment}

Harrison 2015 \{published data only\}

* Harrison TN, Green KR, Liu IA, Vansomphone SS, Handler J, Scott RD, et al. Automated outreach for cardiovascular-related medication refill reminders. Journal of Clinical Hypertension 2015;18(7):641-6. [DOI: 10.1111/jch.12723]

Reynolds K, Green KR, Vansomphone SS, Scott RD, Cheetham TC. Automated outreach for cholesterol-lowering medication refill reminders. European Heart Journal 2011;32(Abstract Suppl):230-1.

\section{Johnson 2006 \{published data only\}}

Johnson SS, Driskell MM, Johnson JL, Dyment SJ, Prochaska JO, Prochaska JM, et al. Transtheoretical model intervention for adherence to lipid-lowering drugs. Disease Management 2006;9(2):102-14.

\section{Lee 2006 \{published data only\}}

Lee JK. Effect of a pharmacy care program on medication adherence and persistence, blood pressure, and low-density lipoprotein cholesterol: a randomized controlled trial. JAMA 2006;296(21):2563-71.

\section{References to ongoing studies}

ACTRN12616000233426 \{published data only\}

ACTRN12616000233426. INtegrated combination Therapy, Electronic General practice support tool, phaRmacy led intervention And combination Therapy Evaluation (INTEGRATE): A pragmatic cluster randomised controlled trial. www.anzctr.org.au/Trial/Registration/TrialReview.aspx? id=370068 19th February 2016.

\section{ACTRN12616000422426 \{published data only\}}

ACTRN12616000422426. Text4Heart Partnership: a text messaging program to enhance self-management of cardiovascular disease. www.anzctr.org.au/Trial/Registration/ TrialReview.aspx?id=370398 1st April 2016.

\section{Thom 2014 \{published data only\}}

Thom S, Field J, Poulter N, Patel A, Prabhakaran D, Stanton A, et al. Use of a Multidrug Pill In Reducing cardiovascular Events (UMPIRE): rationale and design of a randomised controlled trial of a cardiovascular preventive polypill-based strategy in India and Europe. European Journal of Preventive Cardiology 2014;21:252-61.

\section{Additional references}

\section{S 1994}

Scandinavian Simvastatin Survival Study Group. Randomised trial of cholesterol lowering in 4444 patients with coronary heart disease: the Scandinavian Simvastatin Survival Study (4S). Lancet 1994;344(8934):1383-9.

\section{ACC/AHA Guidelines 2013}

Stone NJ, Robinson JG, Lichtenstein AH, Bairey Merz CN, Blum CB, et al. 2013 ACC/AHA Guideline on the Treatment of Blood Cholesterol to Reduce Atherosclerotic Cardiovascular Risk in AdultsA Report of the American College of Cardiology/ American Heart Association Task Force on Practice Guidelines. Circulation 2014;129(25 Suppl 2):s1-45.

\section{Armour 2007}

Armour C, Bosnic-Anticevich S, Brilliant M, Burton D, Emmerton L, Krass I, et al. Pharmacy Asthma Care Program (PACP) improves outcomes for patients in the community. Thorax 2007;62:496-592.

\section{Athyros 2002a}

Athyros VG, Papageorgiou AA, Mercouris BR, Athyrou VV, Symeonidis AN, Basayannis EO, et al. Treatment with atorvastatin to the National Cholesterol Educational Program goal versus 'usual' care in secondary coronary heart disease prevention. The GREek Atorvastatin and Coronary-heart-disease Evaluation (GREACE) study. Current Medical Research and Opinion 2002;18(4):220-8.

\section{Avorn 1998}

Avorn J, Monette J, Lacour A, Bohn RL, Monane M, Mogun $\mathrm{H}$, et al. Persistence of use of lipid-lowering medications. JAMA 1998;279(18):1458-62.

\section{Baigent 2005}

Baigent C, Keech A, Kearney PM, Blackwell L, Buck G, Pollicino C, et al, Cholesterol Treatment Trialists' (CTT) Collaborators. Efficacy and safety of cholesterol-lowering treatment: Prospective meta-analysis of data from 90 056 participants in 14 randomised trials of statins. Lancet 2005;366(9493):1267-78.

\section{Benner 2002}

Benner JS, Glynn RJ, Mogun H, Neumann PJ, Weinstein MC, Avorn J. Long-term persistence in use of statin therapy in elderly patients. JAMA 2002;288(4):455-61.

\section{Blackburn 2005}

Blackburn DF, Dobson RT, Blackburn JL, Wilson TW. Cardiovascular morbidity associated with nonadherence to statin therapy. Pharmacotherapy 2005;25(8):1035-43.

\section{Brown 2011}

Brown MT, Bussell JK. Medication adherence: WHO cares? Mayo Clinic Proceedings 2011;86(4):304-14.

\section{Cheng 2004}

Cheng CW, Woo K-S, Chan JC, Tomlinson B, You JH. Association between adherence to statin therapy and lipid control in Hong 
Kong Chinese patients at high risk of coronary heart disease. British Journal of Clinical Pharmacology 2004;58(5):528-35.

\section{Costa 2015}

Costa E, Giardini A, Savin M, Menditto E, Lehane E, Laosa O, et al. Interventional tools to improve medication adherence: review of literature. Patient Preference and Adherence 2015;9:1303-14.

\section{Dickersin 1994}

Dickersin K, Scherer R, Lefebvre C. Identifying relevant studies for systematic reviews. BMJ 1994;309(6964):1286-91.

\section{Downs 1998}

Downs JR, Clearfield M, Weis S, Whitney E, Shapiro DR, Beere PA, et al. Primary prevention of acute coronary events with lovastatin in men and women with average cholesterol levels: results of AFCAPS/TexCAPS. Air Force/Texas Coronary Atherosclerosis Prevention Study. JAMA 1998;279(20):1615-22.

\section{Ebrahim 1998}

Ebrahim S. Detection, adherence and control of hypertension for the prevention of stroke: a systematic review. Health Technology Assessment 1998;2(11):1-78. [www.hta.ac.uk/ project.asp?Pjtld=881]

\section{Guyatt 2008}

Guyatt GH, Oxman AD, Vist GE, Kunz R, Falck-Ytter Y, AlonsoCoello $P$, et al. GRADE: an emerging consensus on rating quality of evidence and strength of recommendations. BMJ 2008;336:924-6.

\section{Higgins 2011}

Higgins JPT, Green S, editor(s). Cochrane Handbook for Systematic Reviews of Interventions. Cochrane Handbook of Systemtic Reviess of Interventions Version 5.1.0 (updated March 2011). The Cochrane Collaboration, 2011. Available from handbook.cochrane.org.

\section{Jackevicius 2002}

Jackevicius CA, Mamdani M, Tu JV. Adherence with statin therapy in elderly patients with and without acute coronary syndromes. JAMA 2002;288(4):462-7.

\section{Lefebvre 1996}

Lefebvre C, McDonald S. Development of a sensitive search strategy for reports of randomized controlled trials in EMBASE. In: Paper presented at the Fourth International Cochrane Colloquium, 20-24 Oct 1996; Adelaide, Australia. 1996.

\section{Lefebvre 2011}

Lefebvre C, Manheimer E, Glanville J. Chapter 6: Searching for studies. In: Cochrane Handbook for Systematic Reviews of Interventions Version 5.1.0 (updated March 2011). The Cochrane Collaboration, 2011. Available from handbook.cochrane.org.

\section{Lewis 2003}

Lewis DK, Robinson J, Wilkinson E. Factors involved in deciding to start preventive treatment: qualitative study of clinicians' and lay people's attitudes. BMJ 2003;327(7419):841-5.

\section{LIPID 1998}

Long-Term Intervention with Pravastatin in Ischaemic Disease (LIPID) study group. Prevention of cardiovascular events and death with pravastatin in patients with coronary heart disease and a broad range of initial cholesterol levels. The Long-Term Intervention with Pravastatin in Ischaemic Disease (LIPID) Study Group. New England Journal of Medicine 1998;339(19):1349-57.

\section{Mahtani 2011}

Mahtani KR, Heneghan CJ, Glasziou PP, Perera R. Reminder packaging for improving adherence to selfadministered long-term medications. Cochrane Database of Systematic Reviews 2011, Issue 9. Art. No: CD005025. [DOI: 10.1002/14651858.CD005025.pub3]

\section{Marinker 1997}

Marinker M. From Compliance to Concordance: Towards Shared Goals in Medicine taking. London: Royal Pharmaceutical Society of Great Britain, 1997.

\section{MRC/BHF 2002}

Heart Protection Study Collaborative Group. MRC/BHF Protection Study of cholesterol lowering with simvastatin in 20536 high-risk individuals: a randomised placebo-controlled trial. Lancet 2002;360(9326):7-22.

\section{Mullen 1997}

Mullen PD. Compliance becomes concordance. BMJ 1997;314(7082):691-2.

\section{Muller-Nordhorn 2005}

Muller-Nordhorn J, Willich SN. Effectiveness of interventions to increase adherence to statin therapy. Disease Management of Health Outcomes 2005;13(2):72-82. [1173-8790/05/0002-0073/ $\$ 34.95 / 0]$

\section{NICE 2014}

National Institute for Health and Care Excellence (NICE). Cardiovascular Disease: risk assessment and reduction, including lipid modification. www.nice.org.uk/guidance/cg181 (accessed 18th December 2016).

\section{Nieuwlaat 2014}

Nieuwlaat R, Wilczynksi N, Navarro T, Hobson N, Jeffery R, Keepanasseril A, et al. Interventions for enhancing medication adherence. Cochrane Database of Systematic Reviews 2014, Issue 11. Art. No: CD000011. [DOI: 10.1002/14651858.CD000011.pub4]

\section{Pasina 2014}

Pasina L, Brucato AL, Falcone C, Cucchi E, Bresciani A, Sottocorno M, et al. Medication non-adherence among elderly patients newly discharged and receiving polypharmacy. Drugs \& Aging 2014;31(4):283-9. [DOI: 10.1007/s40266-014-0163-7]

\section{Primatesta 2000}

Primatesta P, Poulter NR. Lipid concentrations and the use of lipid lowering drugs: evidence from a national cross sectional survey. BMJ 2000;321(7272):1322-5. 


\section{Rash 2016}

Rash JA, Campbell DJ, Tonelli M, Campbell TS. A systematic review of interventions to improve adherence to statin medication: what do we know about what works? Preventive Medicine 2016;90:155-69. [DOI: 10.1016/j.ypmed.2016.07.006]

\section{Rosenson 2015}

Rosenson R, Kent ST, Brown TM, Farkouh ME, Levitan EB, Yun $\mathrm{H}$, et al. Underutilization of high-intensity statin therapy after hospitalization for coronary heart disease. Journal of the American College of Cardiology 2015;65(3):270-7.

\section{Rueda 2006}

Rueda S, Park-Wyllie LY, Bayoumi A, Tynan A-M, Antoniou T, Rourke $S$, et al. Patient support and education for promoting adherence to highly active antiretroviral therapy for HIV/AIDS. Cochrane Database of Systematic Reviews 2006, Issue 3. Art. No: CD001442. [DOI: 10.1002/14651858.CD001442.pub2]

\section{Sackett 1976}

Sackett DL, Haynes RB. Compliance with Therapeutic Regimens. Baltimore: John Hopkins University Press, 1976.

\section{Sacks 1996}

Sacks FM, Pfeffer MA, Moye LA, Rouleau JL, Rutherford JD, Cole TG, et al. The effect of pravastatin on coronary events after myocardial infarction in patients with average cholesterol levels. Cholesterol and Recurrent Events Trial investigators. New England Journal of Medicine 1996;335(14):1001-9.

\section{Schroeder 2004}

Schroeder K, Fahey T, Ebrahim S. Interventions for improving adherence to treatment in patients with high blood pressure in ambulatory settings. Cochrane Database of Systematic Reviews 2004, Issue 3. Art. No: CD004804. [DOI: 10.1002/14651858.CD004804]

\section{Shepherd 1995}

Shepherd J, Cobbe SM, Ford I, Isles CG, Lorimer AR, MacFarlane PW, et al. Prevention of coronary heart disease with pravastatin in men with hypercholesterolemia. West of Scotland Coronary Prevention Study Group. New England Journal of Medicine 1995;333(20):1301-07.

\section{SIGN 2007}

Scottish Intercollegiate Guidelines Network (SIGN). Risk estimation and the prevention of cardiovascular disease. A national clinical guideline.. Available at www.sign.ac.uk/pdf/ sign97.pdf 2007 (accessed 11th January 2009).

\section{Tsuyuki 2001}

Tsuyuki RT, Bungard TJ. Poor adherence with hypolipidemic drugs: a lost opportunity. Pharmacotherapy 2001;21(5):576-82.

\section{Vermeire 2001}

Vermeire E, Hearnshaw H, Van Royen P, Denekens J. Patient adherence to treatment: three decades of research. A comprehensive review. Journal of Clinical Pharmacy and Therapeutics 2001;26(5):331-42.

\section{Vermeire 2005}

Vermeire EIJJ, Wens J, Van Royen P, Biot Y, Hearnshaw H, Lindenmeyer $\mathrm{A}$. Interventions for improving adherence to treatment recommendations in people with type 2 diabetes mellitus. Cochrane Database of Systematic Reviews 2005, Issue 2. Art. No: CD003638. [DOI: 10.1002/14651858.CD003638.pub2]

\section{Wei 2002}

Wei L, Wang J, Thompson P, Wong S, Struthers AD, MacDonald TM. Adherence to statin treatment and readmission of patients after myocardial infarction: a six year follow up study. Heart (British Cardiac Society) 2002;88(3):229-33.

\section{WHO Report 2002}

World Health Organization. The World Health Report 2002 - Reducing risks, promoting healthy life. Available at www.who.int/whr/2002/en/whr02_en.pdf?ua=1 2002 (accessed 18th December 2016).

\section{References to other published versions of this review Schedlbauer 2003}

Schedlbauer A, Schroeder K. Interventions to improve adherence to lipid lowering medication. Cochrane Database of Systematic Reviews 2003, Issue 2. Art. No: CD004371. [DOI: 10.1002/14651858.CD004371]

\section{Schedlbauer 2004}

Schedlbauer A, Schroeder K, Peters TJ, Fahey T. Interventions for improving adherence to lipid lowering medication. Cochrane Database of Systematic Reviews 2004, Issue 4. Art. No: CD004371. [DOI: 10.1002/14651858.CD004371.pub2]

\section{Schedlbauer 2010}

Schedlbauer A, Davies P, Fahey T. Interventions to improve adherence to lipid lowering medication. Cochrane Database of Systematic Reviews 2010, Issue 3. Art. No: CD004371. [DOI: 10.1002/14651858.CD004371.pub3]

* Indicates the major publication for the study

CHARACTERISTICS OF STUDIES

Characteristics of included studies [ordered by study ID]

Aslani 2010

\section{Study characteristics}


Aslani 2010 (Continued)

Methods
Parallel cluster-randomised controlled clinical trial

Randomisation ratio: 1:1

Equivalence design: 2-sided confidence interval

Open-label

\begin{tabular}{ll}
\hline Participants & N recruited $=142$ \\
& N randomised $=97$ (49 control, 48 intervention) \\
& N reported outcomes $=97$ \\
& Mean age 58 years (CI 55.2 to 60.8$)$ for the intervention and 63.6 years (CI 60.1 to 67.1$)$ for the control \\
& group. \\
& INCLUSION CRITERIA \\
& "At least 18 years old, able to fluently speak and read English, taking a lipid-lowering medicine for at \\
& least 1 month prior to enrolment in the study." \\
& EXCLUSION CRITERIA \\
& Not reported \\
& COUNTRY/SETTING: Australia \\
& STUDY PERIOD: Not reported
\end{tabular}

Interventions

Number of study centres: 38 community pharmacies

\section{INTERVENTION GROUP}

In addition to routine care, participants received individualised adherence support service delivered at $\mathrm{t}=1,2,3,4$ (baseline and 3,6,9 months) to address issues identified from a questionnaire and come up with appropriate interventions recorded on data sheets. Interventions included counselling and advice about the disease, medicine, medicine use, adherence and lifestyle measures.

\section{CONTROL GROUP}

Received routine care from pharmacist (blood lipid levels measured and reported to participant, participant completed the questionnaire)

\section{Outcomes}

\section{TIME OF OUTCOME MEASUREMENTS}

"Repeated measures (baseline $(t=1)$, post-intervention at 3-monthly intervals $(t=2,3,4))$."

PRIMARY OUTCOMES: lipid levels using Accutrend GC, participant adherence to therapy using MARS Medication Adherence Report Scale

SECONDARY OUTCOME: lifestyle measures - potential factors affecting lipid levels.

Notes

Commercial funding/non-commercial funding/other funding: "This project has been funded by the Australian Government Department of Health and Ageing as part of the Third Community Pharmacy Agreement, administered by the Pharmacy Guild of Australia." Participating pharmacists received reimbursement for every completed participant.

Stated aim for study: "This study aimed to evaluate the impact of a community pharmacist-delivered adherence support service on patients' adherence and total cholesterol levels."

\section{Risk of bias}


Aslani 2010 (Continued)

\begin{tabular}{|c|c|c|}
\hline Bias & Authors' judgement & Support for judgement \\
\hline $\begin{array}{l}\text { Random sequence genera- } \\
\text { tion (selection bias) }\end{array}$ & Unclear risk & Not reported \\
\hline $\begin{array}{l}\text { Allocation concealment } \\
\text { (selection bias) }\end{array}$ & Unclear risk & Not reported \\
\hline $\begin{array}{l}\text { Blinding (performance } \\
\text { bias and detection bias) } \\
\text { All outcomes }\end{array}$ & Unclear risk & Unblinded open-label study \\
\hline $\begin{array}{l}\text { Incomplete outcome data } \\
\text { (attrition bias) } \\
\text { All outcomes }\end{array}$ & Low risk & $\begin{array}{l}\text { "A comparison of the demographics of patients who stayed in the study and } \\
\text { those who dropped out, showed that they were mostly similar. Cross tabula- } \\
\text { tion using Fishers Exact Test (two-sided) found that there were differences be- } \\
\text { tween the two groups on only one variable" }\end{array}$ \\
\hline $\begin{array}{l}\text { Selective reporting (re- } \\
\text { porting bias) }\end{array}$ & Low risk & All outcomes reported \\
\hline
\end{tabular}

\section{Brown 1997}

\section{Study characteristics}

\begin{tabular}{|c|c|}
\hline Methods & $\begin{array}{l}\text { Cross-over randomised controlled clinical trial } \\
\text { Randomisation ratio: 1:1 } \\
\text { Equivalence design: 2-sided confidence interval } \\
\text { Open-label }\end{array}$ \\
\hline Participants & $\begin{array}{l}\text { N recruited = } 31 \\
\text { N randomised = } 31 \text { (cross-over - both groups received intervention) } \\
\text { N reported outcomes = } 29 \\
\text { Mean age } 49 \pm 7 \text { yrs } \\
\text { INCLUSION CRITERIA } \\
\text { "All were men less than or equal to } 65 \text { years old at high risk for future cardiac events by virtue of: }(1) \text { an } \\
\text { elevated apoprotein B greater than or equal to } 125 \mathrm{mg} / \mathrm{dl},(2) \text { at least } 1 \text { coronary lesion greater than or } \\
\text { equal to } 50 \% \text { stenosis or } 2 \text { lesions greater than or equal to } 30 \% \text { stenosis, as documented in the base- } \\
\text { line angiogram, and ( } 3 \text { ) a family history of premature cardiovascular events. All patients signed an ap- } \\
\text { proved written consent form." } \\
\text { EXCLUSION CRITERIA } \\
\text { Not reported } \\
\text { COUNTRY/SETTING: USA } \\
\text { STUDY PERIOD: Not reported }\end{array}$ \\
\hline
\end{tabular}

Interventions Number of study centres: 1


Brown 1997 (Continued)

"All patients received the 3-drug regimen listed above (niacin, lovastatin 20mg BD, colestipol 10g BD), using regular niacin, for 12 months, with dosage adjustment to a target cholesterol of 150 to $175 \mathrm{mg} / \mathrm{dl}$, and to minimize side effects."

INTERVENTION (2) AND CONTROL (1) GROUP at 12 months:

"At 12 months, patients were randomly assigned to:

(1) continue with regular niacin at a dosage identical to that established in the 12 month dose-finding period, or

(2) change to polygel controlled-release niacin at that daily dosage, but given twice rather than 4 times/ day."

INTERVENTION AND CONTROL GROUP at 20 months:

"At 20 months, groups (1) and (2) were reversed (crossover)."

"This regimen continued for 8 more months. Just before the clinic visit at 28 months, patients completed a mail-in questionnaire comparing the 2 niacin preparations in terms of a variety of possible side effects and specifying which of the 2 preparations they preferred. After 30 months, all these drugs were discontinued and a postdrug follow-up evaluation was performed 6 weeks later."

Outcomes

TIME OF OUTCOME MEASUREMENTS

"Plasma very low-density lipoprotein (VLDL), LDL, and HDL cholesterol and triglycerides, apolipoprotein $B$, and aspartate aminotransferase were measured at baseline and every 4 months at the Northwest Lipid Research Laboratory. At entry (before treatment), at 6 months, 12 months, 20 months, 28 months, and 6 weeks after stopping the triple-drug regimen, the lipid and clinical laboratory determinations listed in Table II were obtained. HDL2 and HDL3 cholesterol were measured at baseline, at 1 and 2 years, and at 6 weeks after discontinuing therapy."

PRIMARY OUTCOME: lipid levels

SECONDARY OUTCOMES: compliance, side effects

Notes

Commercial funding/non-commercial funding/other funding: "The pharmaceutical supplies were provided by Merck Research Laboratories, Inc., West Point, Pennsylvania; Upjohn Co., Inc., and Upsher-Smith Inc., Minneapolis, Minnesota. This study was supported in part by grants from the National Heart, Lung, and Blood Institute and National Institutes of Health, Bethesda, Maryland; in part by the University of Washington Clinical Research Center (NIH \#RR31), Seattle, Washington; and in part by a grant from the John L. Locke, Jr. Charitable Trust, Seattle, Washington."

Stated aim for study: "To identify a regimen that is effective among such hyperlipidemic coronary disease patients (usually meets $</-100 \mathrm{mg} / \mathrm{dl}$ target), is well tolerated, and is realistic, we have employed and evaluated a 3-drug combination with niacin, lovastatin, and colestipol, in moderate doses in such patients. Furthermore, we have objectively compared a polygel controlled-release niacin (Upsher-Smith, Minneapolis) with regular niacin used in this regimen in a randomized, crossover trial design."

\section{Risk of bias}

\begin{tabular}{lll}
\hline Bias & Authors' judgement & Support for judgement \\
\hline $\begin{array}{l}\text { Random sequence genera- } \\
\text { tion (selection bias) }\end{array}$ & Unclear risk & Not reported \\
\hline $\begin{array}{l}\text { Allocation concealment } \\
\text { (selection bias) }\end{array}$ & Unclear risk & Not reported \\
\hline $\begin{array}{l}\text { Blinding (performance } \\
\text { bias and detection bias) }\end{array}$ & Unclear risk & Unblinded open-label study \\
\hline
\end{tabular}


Brown 1997 (Continued)

All outcomes

Incomplete outcome data Unclear risk
(attrition bias)
(attrition bias)

All outcomes

$\begin{array}{lll}\text { Selective reporting (re- } \quad \text { Low risk } & \text { All outcomes reported } \\ \text { porting bias) }\end{array}$
porting bias)

Castellano 2014

\section{Study characteristics}

\begin{tabular}{|c|c|}
\hline Methods & $\begin{array}{l}\text { Parallel randomised controlled clinical trial } \\
\text { Randomisation ratio: 1:1 } \\
\text { Equivalence design: 2-sided confidence interval } \\
\text { Open-label }\end{array}$ \\
\hline Participants & $\begin{array}{l}\text { N recruited = } 695 \\
N \text { randomized = } 695 \text { ( } 345 \text { control, } 350 \text { intervention) } \\
\text { N reported outcomes = } 695 \text { included for intention-to-treat analysis, but only } 458 \text { completed all visits for } \\
\text { per protocol analysis } \\
\text { Mean age for Phase } 1 \text { is } 64 \pm 11 \text { years (not reported for Phase 2) } \\
\text { INCLUSION CRITERIA } \\
\text { Participants previously included in Phase } 1 \text { (cross-sectional study of FOCUS) but not in Phase } 2 \text { (ran- } \\
\text { domised controlled trial of FOCUS) } \\
\text { EXCLUSION CRITERIA } \\
\text { Secondary dyslipidaemia, contraindication to any of the components of the polypill, participation in } \\
\text { another trial, previous percutaneous transluminal coronary angioplasty with a drug eluting stent with- } \\
\text { in the previouS year, severe congestive heart failure (New York Heart Association functional class III to } \\
\text { IV), serum creatinine > } 2 \text { mg/dl, any condition limiting life expectancy < } 2 \text { years, and pregnancy or pre- } \\
\text { menopause } \\
\text { COUNTRY/SETTING: Argentina, Brazil, Italy, Paraguay, and Spain } \\
\text { STUDY PERIOD: January } 2011 \text { to January } 2014\end{array}$ \\
\hline
\end{tabular}

Interventions

Number of study centres: 63 outpatient clinics in Argentina, Paraguay, Italy and Spain

\section{INTERVENTION GROUP}

FDC polypill containing aspirin $100 \mathrm{mg}$, simvastatin $40 \mathrm{mg}$, and rampiril at 3 different doses: $2.5,5$, or 10 mg given once daily

\section{CONTROL GROUP}

Received aspirin, simvastatin, and ramipril as 3 separate drugs given once daily

Outcomes

\section{TIME OF OUTCOME MEASUREMENTS}

Participants were followed at 1,4 , and 9 months 
PRIMARY OUTCOME: percentage of participants taking medication adequately at 9 months in each arm assessed by attendance at the final 9-month visit and the Morisky-Green questionnaire (MAQ) and pill count methods, simultaneously.

SECONDARY OUTCOMES: risk factor control in each study arm (BP and lipid LDL-cholesterol levels at months 1 and 9), incidence of adverse events (including death, reinfarction, and rehospitalisation for any $\mathrm{CV}$ cause), rate of treatment withdrawal, tolerability, and quality of life, economic end points (medical and nonmedical costs data not shown)

Notes
the text that the FOCUS trial "provided both the polypill group and the control group with free medica-
tions."
Stated aim for study: "This randomized trial aims to analyze the impact of a polypill strategy on adher-
ence in post-MI patients."

\section{Risk of bias}

\begin{tabular}{|c|c|c|}
\hline Bias & Authors' judgement & Support for judgement \\
\hline $\begin{array}{l}\text { Random sequence genera- } \\
\text { tion (selection bias) }\end{array}$ & Low risk & $\begin{array}{l}\text { "a central electronic randomization service assigned participants to } 1 \text { of } 2 \\
\text { arms" }\end{array}$ \\
\hline $\begin{array}{l}\text { Allocation concealment } \\
\text { (selection bias) }\end{array}$ & Low risk & See above \\
\hline $\begin{array}{l}\text { Blinding (performance } \\
\text { bias and detection bias) } \\
\text { All outcomes }\end{array}$ & Unclear risk & $\begin{array}{l}\text { Unblinded but "pill count enabled a more objective assessment of adherence } \\
\text { during the trial" }\end{array}$ \\
\hline $\begin{array}{l}\text { Incomplete outcome data } \\
\text { (attrition bias) } \\
\text { All outcomes }\end{array}$ & Low risk & $\begin{array}{l}78 \text { participants ( } 43 \text { intervention, } 35 \text { control) were lost to follow-up, } 27 \text { partici- } \\
\text { pants ( } 14 \text { intervention, } 13 \text { control) discontinued the medications due to an ad- } \\
\text { verse effect }\end{array}$ \\
\hline $\begin{array}{l}\text { Selective reporting (re- } \\
\text { porting bias) }\end{array}$ & Low risk & All outcomes reported \\
\hline
\end{tabular}

Choudhry 2011

\section{Study characteristics}

Parallel cluster-randomised controlled clinical trial
Equivalence design: 2-sided confidence interval
Open-label
Randomisation occurred at the level of plan sponsor (i.e. the employer, union, government, or associa-
tion that sponsors a particular benefits package) so that all eligible employees of a given plan sponsor
received the same coverage after randomisation

\footnotetext{
Participants $\mathrm{N}$ recruited $=6768$ (13.5\% excluded because plan sponsors declined to participate)

$\mathrm{N}$ randomised $=5855$ (2845 intervention, 3010 control)

$\mathrm{N}$ reported outcomes $=5216$

Mean age 53.6 years, $75 \%$ of participants were men
} 
Choudhry 2011 (Continued)

\author{
INCLUSION CRITERIA: \\ - patients discharged after myocardial infarction \\ - patients receiving medical and prescription drug benefits through Aetna, a large commercial insurer \\ in the United States
}

EXCLUSION CRITERIA:

Not stated

COUNTRY/SETTING: USA

STUDY PERIOD: "We planned to recruit 7500 patients over a 1.5-year period and to follow them for a minimum of 1 year in order to achieve a power of $90 \%$ to detect a between-group difference of $20 \%$ in the relative risk of the primary outcome. Because of slower-than anticipated enrollment, the trial steering committee accepted a recommendation from the independent data and safety monitoring committee that equivalent power could be obtained if a total of 1000 primary outcome events were to occur. The steering committee then adapted the trial by extending enrollment by 15 months and reducing minimum follow-up to 3 months."

End of study was 30 November 2010.

Interventions INTERVENTION GROUP:

Pharmacy benefits for participants in the full-coverage group were changed so that they had no cost sharing for any brand-name or generic statin, betablocker, angiotensin-converting-enzyme (ACE) inhibitor, or angiotensin-receptor blocker (ARB) for every prescription after randomisation. All copayments and co-insurance were waived at the point of care (i.e. the pharmacy), as was any contribution to a participant's deductible.

CONTROL GROUP:

Usual copayment arrangements

Outcomes PRIMARY OUTCOME: first major vascular event or revascularisation SECONDARY OUTCOMES: rates of medication adherence: by calculating the mean medication possession ratio (number of days a participant had a supply of each medication class available) divided by the number of days of eligibility for that medication; ratios were multiplied by 100 to generate absolute adherence percentages. "We also calculated the proportion of patients who had full adherence (defined as a medication possession of $\geq 80 \%$ ) to each and to all three study medication classes throughout follow-up.", total major vascular events or revascularisation, the first major vascular event, health expenditures

The median duration of follow-up after randomisation was 394 days (interquartile range, 201 to 663)

Notes All outcomes reported as ITT with GEE to adjust for clustering

Funding: "Supported by unrestricted research grants from Aetna and the Commonwealth Fund to Brigham and Women's Hospital."

COI: all authors report receiving funding from healthcare funds and pharmaceutical companies

\title{
Risk of bias
}

\begin{tabular}{lll}
\hline Bias & Authors' judgement & Support for judgement \\
\hline $\begin{array}{l}\text { Random sequence genera- } \\
\text { tion (selection bias) }\end{array}$ & Low risk & "use of a random-number generator" \\
\hline $\begin{array}{l}\text { Allocation concealment } \\
\text { (selection bias) }\end{array}$ & Unclear risk & not reported \\
\hline
\end{tabular}


Choudhry 2011 (Continued)
Blinding (performance
Unclear risk
not reported
bias and detection bias)
All outcomes

$\begin{array}{ll}\begin{array}{l}\text { Incomplete outcome data } \quad \text { Low risk } \\ \text { (attrition bias) }\end{array} & \begin{array}{l}\text { "A total of } 133 \text { patients (4.7\%) in the full-coverage group and } 151 \text { (5.0\%) in the } \\ \text { usual-coverage group lost insurance eligibility between the time of hospital } \\ \text { All outcomes } \\ \text { discharge and randomization, so data from these patients were not included } \\ \text { in the follow-up analyses." }\end{array}\end{array}$

Selective reporting (re- Low risk all outcomes reported
porting bias)

\title{
Study characteristics
}

Methods

\author{
Parallel randomised controlled clinical trial \\ Randomisation ratio: 1:1 \\ Equivalence design: 2-sided confidence interval \\ Open-label
}

\section{Participants}

$\mathrm{N}$ recruited $=28,750$ (based on mean numbers for 10 -week recruitment in weekly batches)

$\mathrm{N}$ randomised $=5216$ (2610 control, 2606 intervention)

$\mathrm{N}$ reported outcomes $=5216$

Mean age 56.1 years, $50.6 \%$ of participants were women

INCLUSION CRITERIA

"We identified a group of patients who were prescribed a statin as a new medication. A new medication was operationalized as a prescription for a statin or combination drug containing a statin and no record of such a drug dispensed within 365 days before the index prescription date. Participants were limited to those with 1 or more years of membership from the prescription date and no gap in enrolment more than 30 days during the past year. An age limit of 24 years and older at the time of the prescription was required because of infrequent statin prescriptions in younger individuals and controversial use of statins early in life. Members who had no record of the statin prescription being filled at a health plan pharmacy after 1 to 2 weeks were considered nonadherent and eligible for the study."

\section{EXCLUSION CRITERIA}

Not reported

COUNTRY/SETTING: USA

STUDY PERIOD: April to June 2010

Interventions

Number of study centres: Kaiser Permanente Southern California, an integrated healthcare system at 14 medical centres and 197 medical offices

\section{INTERVENTION GROUP}

"The intervention group received automated telephone calls followed 1 week later by letters for continued nonadherence."

CONTROL GROUP 


\section{Outcomes TIME OF OUTCOME MEASUREMENTS}

The time frame for intervention was guided by prior work. In these analyses, $18.4 \%$ of new statin prescriptions remained unfilled after 12 weeks. Among those who filled their prescription, $82.2 \%$ to $90.1 \%$ did so by 1 to 2 weeks after the prescription date. With a plan to conduct the intervention in weekly batches, it was determined that contact 1 to 2 weeks after the prescription date was a practical time frame for initiating outreach.

PRIMARY OUTCOME: dispensation of a statin ("The primary outcome was dispensation of a statin between the first telephone call (day 0 , the randomization day) and up to 2 weeks after delivery of the letter.")

SECONDARY OUTCOME: refills at intervals up to 1 year

Notes

Commercial funding/non-commercial funding/other funding: This research was supported by grants from Merck Sharp \& Dohme Corp, a subsidiary of Merck \& Co Inc, Whitehouse Station, New Jersey.

Stated aim for the study: "We performed a randomized controlled trial to evaluate an automated system to decrease primary nonadherence to statins for lowering cholesterol."

Conflict of Interest Disclosures: Ms Marrett is an employee of Merck. Dr Tunceli is an employee of Merck and owns stock in the company.

\section{Risk of bias}

\begin{tabular}{|c|c|c|}
\hline Bias & Authors' judgement & Support for judgement \\
\hline $\begin{array}{l}\text { Random sequence genera- } \\
\text { tion (selection bias) }\end{array}$ & Low risk & $\begin{array}{l}\text { "A study programmer used computer-generated random numbers to sort par- } \\
\text { ticipants into the intervention and control groups in equal proportion (day 0)" }\end{array}$ \\
\hline $\begin{array}{l}\text { Allocation concealment } \\
\text { (selection bias) }\end{array}$ & Low risk & See above \\
\hline $\begin{array}{l}\text { Blinding (performance } \\
\text { bias and detection bias) } \\
\text { All outcomes }\end{array}$ & Low risk & "Assignment was concealed from study investigators and analysts" \\
\hline $\begin{array}{l}\text { Incomplete outcome data } \\
\text { (attrition bias) } \\
\text { All outcomes }\end{array}$ & Unclear risk & $\begin{array}{l}\text { Mean numbers were given for recruitment data in } 10 \text { weekly batches } \\
\text { Attrition was not reported }\end{array}$ \\
\hline $\begin{array}{l}\text { Selective reporting (re- } \\
\text { porting bias) }\end{array}$ & Low risk & All outcomes reported \\
\hline
\end{tabular}

\section{Eussen 2010}

\section{Study characteristics}

$\begin{array}{ll}\text { Methods } & \text { Parallel randomised controlled clinical trial } \\ & \text { Randomisation ratio: } 1: 1 \\ & \text { Equivalence design: } 2 \text {-sided confidence interval } \\ & \text { Open-label }\end{array}$


Eussen 2010 (Continued)

Participants

$\mathrm{N}$ recruited $=1016$ signed informed consent

$\mathrm{N}$ randomised $=1016$ (513 control group, 503 intervention group)

$\mathrm{N}$ reported outcomes $=899$ (460 control, 439 intervention)

Mean age: $60.1 \pm 11.3$ (control) and $60.2 \pm 10.9$ (intervention)

INCLUSION CRITERIA

New users of statins age 18 and above

"New users were defined as those who had not filled a prescription for statins in the preceding 6 months, verified by the pharmacist through a patient record check."

\section{EXCLUSION CRITERIA}

Not reported

COUNTRY/SETTING: The Netherlands

STUDY PERIOD: "Study enrollment started in September 2004 and was completed in March 2006."

\section{CONTROL GROUP}

"Patients in the control group were provided usual care, consisting of verbal and written drug information according to the standard protocol in the pharmacies. Patients in the usual care group did not receive lipid measurements or counselling sessions."

\section{INTERVENTION GROUP}

"Patients in the intervention (pharmaceutical care) group were invited to visit the pharmacy for 5 individual counselling visits, each lasting 10-15 minutes. Counseling visits were scheduled at first prescription, at second prescription (after 15 days), and at subsequent refill dates at 3, 6, and 12 months after the start of statin therapy."

\section{Outcomes}

\section{TIME OF OUTCOME MEASUREMENTS}

"At 3, 6, and 12 months, total cholesterol, high-density lipoprotein cholesterol, and triglyceride levels were measured from fasting fingerstick whole blood samples using Cholestech LDX Analyzers (Cholestech Corp., Hayward, CA) and low-density lipoprotein cholesterol (LDL-C) was estimated by the Friedewald formula.21 Measured lipid levels and treatment goals were recorded on a wallet card that was kept by all patients to monitor their progress in lowering lipid levels. In addition, medication adherence was assessed via unused pill counts, and the association between adherence and lipid levels was discussed to encourage patients to adhere to the prescribed dosing regimen."

PRIMARY OUTCOMES: adherence in terms of time to discontinuation and medication possession ratio (MPR), lipid levels the National Institute for Public Health and the Environment (RIVM). The Division of Pharmacoepidemiology and Clinical Pharmacology employing Mr. Eussen, Dr. Klungel, Dr. de Boer, and Dr. Bouvy has received unrestricted funding for pharmacoepidemiologic research from GlaxoSmithKline, Novo Nordisk, the private/public funded Top Institute Pharma (www.tipharma.nl, includes co-funding from universities, government, and industry), the Dutch Medicines Evaluation Board, and the Dutch Ministry of Health. The funding source had no role in the study design; in the collection, management, analysis, or interpretation of the data; in the writing of the manuscript; or in the decision to submit the manuscript for publication."

Stated aim for study: "To implement and assess the effectiveness of a community pharmacy-based pharmaceutical care program developed to improve patients' adherence to statin therapy." 
Eussen 2010 (Continued)

Risk of bias

\begin{tabular}{|c|c|c|}
\hline Bias & Authors' judgement & Support for judgement \\
\hline $\begin{array}{l}\text { Random sequence genera- } \\
\text { tion (selection bias) }\end{array}$ & Low risk & $\begin{array}{l}\text { "Once the informed consent form was received, each participant was random- } \\
\text { ly assigned to either the intervention or control group by a procedure that was } \\
\text { built into the computer system and used a set of random numbers in a 1:1 ra- } \\
\text { tio" }\end{array}$ \\
\hline $\begin{array}{l}\text { Allocation concealment } \\
\text { (selection bias) }\end{array}$ & Low risk & See above \\
\hline $\begin{array}{l}\text { Blinding (performance } \\
\text { bias and detection bias) } \\
\text { All outcomes }\end{array}$ & Unclear risk & Unblinded "open-label study" \\
\hline $\begin{array}{l}\text { Incomplete outcome data } \\
\text { (attrition bias) } \\
\text { All outcomes }\end{array}$ & Low risk & $\begin{array}{l}\text { "A total of } 1016 \text { subjects were enrolled in the trial, } 513(50 \%) \text { of whom were } \\
\text { randomized to the pharmaceutical care group and } 503(50 \%) \text { to the usual care } \\
\text { group (Figure } 1) \text {. A total of } 117 \text { patients were excluded because no pharmacy } \\
\text { dispensing data were available for these subjects, due to mismatch between } \\
\text { data from the electronic records and the handwritten study entry forms. Thus, } \\
899 \text { patients ( } 439 \text { in the pharmaceutical care group and } 460 \text { in the usual care } \\
\text { group) were eligible for analysis. Of the patients in the pharmaceutical care } \\
\text { group, } 62(14 \%) \text { did not attend any follow-up counselling session, whereas } 29 \\
\text { ( } 7 \%), 43(10 \%) \text {, and } 305(69 \%) \text { patients attended 3, } 4 \text {, and all } 5 \text { counselling ses- } \\
\text { sions, respectively." }\end{array}$ \\
\hline $\begin{array}{l}\text { Selective reporting (re- } \\
\text { porting bias) }\end{array}$ & Low risk & All outcomes reported \\
\hline
\end{tabular}

Fang 2015

Study characteristics

\begin{tabular}{|c|c|}
\hline \multirow[t]{4}{*}{ Methods } & Randomised controlled clinical trial (RCT) \\
\hline & Randomisation ratio: 1:1:1 \\
\hline & Equivalence design: (2-sided confidence interval) \\
\hline & Open-label \\
\hline \multirow[t]{6}{*}{ Participants } & $\mathrm{N}$ recruited $=596$ \\
\hline & $\mathrm{N}$ randomized $=280$ (95 SMS, $92 \mathrm{SMS}+\mathrm{ML}, 93$ phone) \\
\hline & $\mathrm{N}$ reported outcomes $=271$ \\
\hline & Mean age not reported; $68 \%$ - $70 \%$ men \\
\hline & INCLUSION CRITERIA \\
\hline & $\begin{array}{l}\text { "All study participants had CAD diagnoses of chronic stable angina consistent with the criteria of the } \\
\text { Chinese Medical Association of Cardiovascular Disease guide ( } 2007 \text { edition). Their case histories includ- } \\
\text { ed a history of angina, together with dual-source computed tomography or angiography examinations } \\
\text { that revealed coronary artery stenosis of } 75 \% \text { or more. All patients were prescribed oral beta blockers, } \\
\text { angiotensin-converting enzyme inhibitors (ACEIs), nitrates or lipid-lowering drugs to be taken at differ- } \\
\text { ent times according to their doctors' suggestion. Statins were taken once daily in the evening because }\end{array}$ \\
\hline
\end{tabular}


Fang 2015 (Continued)

lipid metabolism by the human body is fastest at night. All patients functioned independently in their daily lives and were able to receive SMS and ML communications via mobile phone."

\section{EXCLUSION CRITERIA}

"The exclusion criteria were as follows: (1) nonconformance with the diagnostic standards for chronic stable angina established by the Chinese Medical Association of Cardio- vascular Epidemiology, (2) history of mental illness, (3) infection, fever, operation, serious heart failure, respiratory failure or acute stroke in the prior month and (4) inability to use a mobile phone that accepts SMS."

COUNTRY/SETTING: China

STUDY PERIOD: March-December 2013

Interventions
CONTROL GROUP
Phone
"The phone group received a telephone call once a month to remind them of their medication schedule
and upcoming appointments."
INTERVENTION GROUPS
SMS
"The SMS group received medication reminders and educational materials via SMS."
SMS +ML
"The SMS + ML group received medication reminders via SMS and educational materials via a Micro
Letter (ML). We built a public ML platform, from which we regularly released CAD-related information,
including the hazards and methods of preventing hyperlipidaemia, the role, scope, usage, method of
use, and side effects of lipid-lowering drugs and other related information. Patients in the SMS + ML
group had open access to all information on the ML platform."

Outcomes "We used the four-item dichotomous Morisky Medication Adherence Scale (MMAS) to assess drug compliance. Scaled scores were determined by digitally tabulating responses as yes (1) or no (0). Scores ranged from $0-4$. A score of 0 indicated good compliance, scores of 1 and 2 indicated fair to medium compliance, and scores of 3 and 4 indicated poor compliance."

PRIMARY OUTCOME: medication adherence, phone (reference)

\begin{tabular}{|c|c|}
\hline \multirow[t]{2}{*}{ Notes } & Commercial funding/non-commercial funding/other funding: Funding not reported \\
\hline & $\begin{array}{l}\text { Stated aim for study: "To compare drug adherence to lipid-lowering therapy among outpatients with } \\
\text { coronary artery disease who received information via short message service, via short message service } \\
\text { and Micro Letter, or via phone only." }\end{array}$ \\
\hline
\end{tabular}

\section{Risk of bias}

\begin{tabular}{lll}
\hline Bias & Authors' judgement & Support for judgement \\
\hline $\begin{array}{l}\text { Random sequence genera- } \\
\text { tion (selection bias) }\end{array}$ & Low risk & $\begin{array}{l}\text { "Participants were randomised into three groups, SMS (n = 95), SMS + ML (n = } \\
92), \text { and phone }(\mathrm{n}=93), \text { by a computer-generated random number table." }\end{array}$ \\
\hline $\begin{array}{ll}\text { Allocation concealment } \\
\text { (selection bias) }\end{array}$ & Low risk & See above \\
\hline $\begin{array}{l}\text { Blinding (performance } \\
\text { bias and detection bias) }\end{array}$ & Unclear risk & Unblinded open-label study
\end{tabular}


Fang 2015 (Continued)

All outcomes

Incomplete outcome data Low risk (attrition bias)

All outcomes
"During the study period, nine of the 280 enrolled subjects withdrew from the study, including four from the SMS group, two from the SMS + ML group, and three from the phone group. Reasons for withdrawal included unwillingness to complete the test $(n=6)$ and personal issues $(n=3)$. The overall response rate of the study was $9678 \%(271 / 280)$."
Selective reporting (re-
Low risk
All outcomes reported

porting bias)

Faulkner 2000

\section{Study characteristics}

\begin{tabular}{ll}
\hline Methods & Parallel randomised controlled clinical trial \\
& Randomisation ratio: 1:1 \\
& Equivalence design: 2-sided confidence interval \\
& Open-label \\
\hline
\end{tabular}

Participants

$\mathrm{N}$ recruited $=30$

$\mathrm{N}$ randomised $=30$ (15 control group, 15 intervention group)

$\mathrm{N}$ reported outcomes $=30$

Mean age: $61 \pm 12$ (control group) and $64 \pm 12$ (intervention group)

INCLUSION CRITERIA

"Patients who had undergone coronary artery bypass graft (CABG) surgery or percutaneous transluminal coronary angioplasty (PTCA) in the previous 7-30 days were eligible. Patients had to have a baseline fasting LDL above $130 \mathrm{mg} / \mathrm{dl}$. They had to be able to read, understand, and speak English, and to have a telephone in their home. Written informed consent was obtained from each participant."

\section{EXCLUSION CRITERIA}

"Exclusion criteria were serum transaminase levels greater than 2 times the upper limit of normal; concomitant therapy with cyclosporine, warfarin, or erythromycin; and a history of significant gastrointestinal disease, including gastroesophageal reflux disease, peptic ulcer disease, Crohn's disease, and ulcerative colitis."

COUNTRY/SETTING: university-affiliated tertiary care hospital in Omaha, Nebraska, USA

STUDY PERIOD: Not reported

"While still hospitalized, all patients were prescribed lovastatin (Mevacor) $20 \mathrm{mg} / \mathrm{day}$ at bedtime and colestipol (Colestid) $5 \mathrm{~g}$ twice/day. All patients received dietary instruction before the start of drug therapy."

\section{CONTROL GROUP}

No telephone contact

INTERVENTION GROUP 
Faulkner 2000 (Continued)

"A pharmacist telephoned patients at their home every week for 12 weeks. To ensure consistency in the information requested of the patients, the same pharmacist was involved in each patient contact and a standard set of questions was asked. Emphasis was placed on the importance of therapy in reducing the risk of recurrent cardiac events. Patients were questioned about when and where prescriptions were filled, how they paid for their prescriptions, potential side effects, overall well-being, and specific reasons for noncompliance when applicable."

\begin{tabular}{|c|c|}
\hline \multirow[t]{3}{*}{ Outcomes } & TIME OF OUTCOME MEASUREMENTS \\
\hline & $\begin{array}{l}\text { "Lipid profiles were measured at baseline, at } 6 \text { and } 12 \text { weeks after starting therapy, and at } 1 \text { and } 2 \text { years } \\
\text { after enrolment. Compliance was determined by pill and packet counts (not performed within the pa- } \\
\text { tient's view) at the } 6 \text { - and } 12 \text {-week clinic visits. To assess long-term compliance, pharmacies at which } \\
\text { patients filled their prescriptions were contacted at } 1 \text { and } 2 \text { years to document refill information." }\end{array}$ \\
\hline & PRIMARY OUTCOMES: lipid levels, compliance - pill and packet counts and refill records \\
\hline \multirow[t]{2}{*}{ Notes } & Commercial funding/non-commercial funding/other funding: Not reported \\
\hline & $\begin{array}{l}\text { Stated aim for study: "we assessed the impact of personalized telephone follow-up on the rate of com- } \\
\text { pliance in high-risk, hypercholesterolemic patients receiving combination drug therapy." }\end{array}$ \\
\hline
\end{tabular}

\section{Risk of bias}

\begin{tabular}{lll}
\hline Bias & Authors' judgement & Support for judgement \\
\hline $\begin{array}{l}\text { Random sequence genera- } \\
\text { tion (selection bias) }\end{array}$ & Low risk & $\begin{array}{l}\text { "Patients were randomized to telephone contact or no telephone contact us- } \\
\text { ing a computer-generated list of random numbers" }\end{array}$ \\
\hline $\begin{array}{l}\text { Allocation concealment } \\
\text { (selection bias) }\end{array}$ & Unclear risk & Not reported \\
\hline $\begin{array}{l}\text { Blinding (performance } \\
\text { bias and detection bias) } \\
\text { All outcomes }\end{array}$ & Unclear risk & Unblinded open-label study \\
\hline $\begin{array}{l}\text { Incomplete outcome data } \\
\text { (attrition bias) } \\
\text { All outcomes }\end{array}$ & Low risk & None of the 30 participants enrolled in the study were lost to follow-up \\
\hline $\begin{array}{l}\text { Selective reporting (re- } \\
\text { porting bias) }\end{array}$ & Low risk & All outcomes reported \\
\hline
\end{tabular}

\section{Fischer 2014}

\section{Study characteristics}

\begin{tabular}{ll}
\hline Methods & Parallel randomised controlled clinical trial \\
& Randomisation ratio: 1:100 automated intervention; 1:40 live intervention \\
& Equivalence design: (2-sided confidence interval) \\
& Open-label
\end{tabular}

Participants Automated Intervention

$\mathrm{N}$ recruited $=861,894$ 
Fischer 2014 (Continued)

$\mathrm{N}$ randomised $=861,894$ (852,612 control, 9282 intervention $)$

$\mathrm{N}$ reported outcomes $=861,894$

Live Intervention

$\mathrm{N}$ recruited $=124,131$

$\mathrm{N}$ randomised $=124,131$ (121,155 control, 2976 intervention)

$\mathrm{N}$ reported outcomes $=124,131$

INCLUSION CRITERIA

All "Patients with newly prescribed cardiovascular medications received at CVS community pharmacies."

\section{EXCLUSION CRITERIA}

"A prescription was considered new if there were no claims in the same therapeutic class 6 months before the index date. Patients without at least 6 months of eligibility before the index date were excluded unless they had another prescription that satisfied the inclusion criteria."

COUNTRY/SETTING: USA

STUDY PERIOD: January 2008 to December 2010

Interventions
"Control group
"Control patients received usual care."
"Patients received automated phone calls on days 3 and 7 after the prescription was processed but re-
mained unpurchased. The calls reminded patients that their prescription was ready and encouraged
them to pick it up."
Live Intervention
"Identified patients who had not purchased a prescription 8 days after it was bottled, even after receiv-
ing automated calls on days 3 and 7 . A pharmacist or technician called these patients to better under-
stand barriers to medication adherence and provide counselling and solutions to encourage appropri-
ate medication use. Messaging included education about the importance of treatment, suggestions
about lower cost options when relevant, and efforts to engage and motivate patients to adhere to ther-
apy."

Outcomes PRIMARY OUTCOMES: proportion of abandoned prescriptions

Notes

\section{Publication details}

Commercial funding/non-commercial funding/other funding: "The research was funded by the National Association of Chain Drug Stores Foundation. Study design, conduct, and reporting were determined independently by the research team."

\section{Stated aim for study}

"To determine whether 2 pharmacy-based interventions could decrease PMN." (Primary medication nonadherence)

\section{Risk of bias}

Bias Authors' judgement Support for judgement


Fischer 2014 (Continued)

Random sequence genera- Low risk "Patients with randomly selected birthdays served as the control population" tion (selection bias)

\begin{tabular}{lll}
\hline $\begin{array}{l}\text { Allocation concealment } \\
\text { (selection bias) }\end{array}$ & Low risk & See above \\
\hline $\begin{array}{l}\text { Blinding (performance } \\
\text { bias and detection bias) }\end{array}$ & Unclear risk & Unblinded open-label study \\
All outcomes & &
\end{tabular}

Incomplete outcome data Low risk All randomised participants' outcome reported
(attrition bias)

All outcomes

Selective reporting (re- Low risk All outcomes reported
porting bias)

Goswami 2013

\title{
Study characteristics
}

\begin{tabular}{ll}
\hline Methods & Parallel randomised controlled clinical trial \\
& Randomisation ratio: 1:1 \\
& Equivalence design: 2 -sided confidence interval \\
& Open-label
\end{tabular}

Participants

\author{
$\mathrm{N}$ recruited $=500$ \\ $\mathrm{N}$ randomised $=500$ (125 control group, 375 intervention group) \\ $\mathrm{N}$ reported outcomes $=208$ (53 control group, 155 intervention group) - eligible for analysis
}

"Among the control group, the average age was 67.8 years, compared with 69.5 years for the intervention group. The sex distribution was predominantly male for both groups ( $67.9 \%$ of the controls and $58.7 \%$ of the intervention group)."

\section{INCLUSION CRITERIA}

"All subjects had to satisfy inclusion criteria to be considered eligible for participation by one of the ten participating physicians of the practice's study team: (1) be older than 21 years of age and, on the basis of clinical assessment by his or her physician, a candidate for statin therapy; (2) have received a first prescription for atorvastatin after study initiation at the practice, including patients who were new to the practice and returning practice patients (new versus continuing atorvastatin patients were deciphered by requiring claims activity 6 months before and after the index date); and (3) provide a personally signed and dated informed consent document indicating that the participant (or a legally acceptable representative) had been informed of all pertinent aspects of the study."

\section{EXCLUSION CRITERIA}

"Patients were excluded from the study if they were unwilling to participate in the adherence counseling or unwilling to give a written informed consent document."

\section{COUNTRY/SETTING: USA}

STUDY PERIOD: "The target sample was enrolled in the study from March 2010 through May 2011." 
Goswami 2013 (Continued)

Interventions

Number of study centres: Prairie Heart Cardiovascular Consultants in Illinois

\section{INTERVENTION GROUP}

"All patients randomized to the intervention group were provided adherence counseling from a nurse (via a 5-10-minute discussion), and an adherence tip sheet. Patients in the intervention group were also given the opportunity to enroll in the My HeartWise ${ }^{T M}$ Program, 24 a 12-week guide to managing cholesterol (included monthly mailing of educational materials). The practice physicians also had the discretion to provide eligible patients in the intervention group with a copay relief card (usable with commercial payers, not Medicare)."

\section{CONTROL GROUP}

"The control group received usual care, with no additional adherence counseling or tip sheet."

$\mathrm{t}=3,6,9,12$ months since index date

PRIMARY OUTCOME: adherence to atorvastatin using PDC (proportion of days covered) and MPR (medication possession ratio)

SECONDARY OUTCOME: persistence with the index therapy over the 6-month post-index period

\section{Notes}

Commercial funding/non-commercial funding/other funding:" This study was sponsored by Pfizer, Inc."

Conflict of Interest: "NJG is a speaker for The Medicines Company, Medtronic, and Boston Scientific and is the medical director for SynvaCor. MDK and MRK are employees of IMS Health, which was a paid consultant to Pfizer in connection with the development of this article. AK, JM, LZL, and JV are employees of Pfizer, Inc, and own stock in Pfizer, Inc."

Stated aim for study: "This trial evaluated the effectiveness of an integrated intervention program that included a 3-to-5-minute nurse counseling session, copay relief cards, and a monthly newsletter on adherence to atorvastatin treatment."

Limitations:

1) "As the control group's adherence was initially high, there was little room for improvement as a result of the intervention. The large number of continuing users at this particular cardiology practice group could explain the high adherence rate observed in this study, which in turn could partially explain the lack of a significant impact due to the intervention. The literature confirms that new users often exhibit lower adherence rates as compared with continuing users."

2) "The frequency with which discount cards were given to control patients was not tracked. However, because many of the patients were older than 65 years of age, the impact of discount cards was likely limited, as Medicare patients did not qualify to receive them."

\section{Risk of bias}

\begin{tabular}{lll}
\hline Bias & Authors' judgement & Support for judgement \\
\hline $\begin{array}{l}\text { Random sequence genera- } \\
\text { tion (selection bias) }\end{array}$ & Low risk & $\begin{array}{l}\text { "Eligible patients were randomized using a telephone randomization system } \\
\text { to one of two groups: an intervention group and a control group (with a pa- } \\
\text { tient ratio of 3:1 intervention:control)" }\end{array}$ \\
\hline $\begin{array}{l}\text { Allocation concealment } \\
\text { (selection bias) }\end{array}$ & Unclear risk & Not reported \\
\hline $\begin{array}{l}\text { Blinding (performance } \\
\text { bias and detection bias) } \\
\text { All outcomes }\end{array}$ & Unclear risk & Unblinded open-label study \\
\hline
\end{tabular}


Goswami 2013 (Continued)

Incomplete outcome data Unclear risk (attrition bias)

All outcomes
"The study initially included 500 patients ( 125 control patients and 375 patients who received the adherence intervention). After matching with the LRx database, 97 controls and 319 intervention patients remained eligible for analysis. However, only 93 controls and 300 intervention patients actually had any LRx claims available for analysis during the study window. Of this group, 57 controls and 180 intervention patients had an atorvastatin prescription after enrollment in the study, which served as the index date. After applying the study requirement of claims activity 6 months before and after the index date, only 53 controls (seven new users [first atorvastatin prescription after randomization] and 46 continuing users [evidence of atorvastatin prescription within 6 months prior to randomization]) and 155 intervention patients (14 new users and 141 continuing users) remained eligible for analysis (Figure 1)."

Selective reporting (re- Low risk All outcomes reported

porting bias)

Gujral 2014

Study characteristics

Methods

Parallel randomised controlled clinical trial

Randomisation ratio: 1:1

Equivalence design: 2-sided confidence interval

Open-label

Participants

$\mathrm{N}$ recruited $=640$

$\mathrm{N}$ randomised $=200$ (100 control, 100 intervention)

$\mathrm{N}$ reported outcomes $=137$ (72 intervention group and 65 control group) at 12 months

Mean age of participants in the intervention group was 58.4 (SD 11.3) and in the control group 60.4 (SD 11.0 ) years; respectively $77 \%$ and $80 \%$ men.

\section{INCLUSION CRITERIA}

"The study population was a convenience sample of patients admitted to the coronary care unit, cardiology ward or general medical wards with a documented diagnosis of STelevated MI or Non-ST-elevated MI."

"Participation in the study required patients to nominate and attend one community pharmacy for the study period."

From protocol: 18 - 85 years old

\section{EXCLUSION CRITERIA}

Not reported in paper but from protocol:

- People whose primary language is other than English (LOTE)

- Children and/or young people (i.e. < 18 years)

- People with an intellectual or mental impairment

- Aboriginal and/or Torres Strait Islander peoples

- Women who are pregnant

COUNTRY/SETTING: Queensland, Australia 
Gujral 2014 (Continued)

STUDY PERIOD: Enrolment from October 2009 to August 2010

Interventions INTERVENTION GROUP: "In the intervention group the community pharmacist reviewed the patient monthly when they collected their prescriptions, to assess if they were getting their MI medicines dispensed and whether they were experiencing any problems with their MI medicines. At 3 and 6 months, the pharmacist had a longer discussion with the patient tailored to their medication beliefs provided by the researcher from the repertory grid interview."

CONTROL GROUP: " Patients in the control group did not have their medication beliefs communicated to their community pharmacist by the researcher. The community pharmacists for patients in the control group were asked to provide the patient with usual care when they collected their prescription medications."

Outcomes PRIMARY OUTCOMES: medication non-adherence at 12 months

SECONDARY OUTCOMES: medication non-adherence at 6 months and changes in adherence and medication beliefs between 6 to 12 months.

"Medication adherence was measured in two ways. A medication possession ratio (MPR) was determined from prescriptions filled by the patient over the study period for the lipid lowering agent and ACE-I/ARB or beta-blocker (if they were not prescribed an ACE-I/ARB)."

"Patients were categorised as non-adherent based on the MPR of the lipid lowering drug."

"Medication beliefs were elicited .... using the repertory grid technique and the BMQ Specific at the 6 and 12 month interviews."

After discharge from hospital participants were followed for 12 months and participated in 3 interviews with the researcher (face-to-face at $5-6$ weeks, by telephone at 6 and 12 months).

Notes

Funding: "This work was supported by the Pharmacy Board of Queensland Research Grants Program 2008, Brisbane, Queensland. The Pharmacy Board had no input in the research design, methodology or results. The ideas expressed in this manuscript are those of the authors and are not intended to represent the position of the Board or members of the Board."

\section{Risk of bias}

\begin{tabular}{lll}
\hline Bias & Authors' judgement & Support for judgement \\
\hline $\begin{array}{l}\text { Random sequence genera- } \\
\text { tion (selection bias) }\end{array}$ & Unclear risk & $\begin{array}{l}\text { "Patients were randomly assigned into the pharmacy intervention or control } \\
\text { group using block randomisation." }\end{array}$ \\
& $\begin{array}{l}\text { From protocol:..."predetermined randomisation sequence.." "Will use an Ex- } \\
\text { cel data base to generate a permuted block randomisation sequence to ensure } \\
\text { equal numbers of participants in both groups." }\end{array}$
\end{tabular}

\begin{tabular}{|c|c|c|}
\hline $\begin{array}{l}\text { Allocation concealment } \\
\text { (selection bias) }\end{array}$ & High risk & $\begin{array}{l}\text { "Patients were randomly assigned into the pharmacy intervention or control } \\
\text { group using block randomisation." }\end{array}$ \\
\hline
\end{tabular}

From protocol: "Allocation was not concealed."

\begin{tabular}{lll}
\hline $\begin{array}{l}\text { Blinding (performance } \\
\text { bias and detection bias) } \\
\text { All outcomes }\end{array}$ & Unclear risk & Not blinded \\
\hline $\begin{array}{l}\text { Incomplete outcome data } \\
\begin{array}{l}\text { (attrition bias) } \\
\text { All outcomes }\end{array}\end{array}$ & High risk & attrition $31.5 \%(137 / 200$ analysed at primary endpoint) \\
\hline
\end{tabular}

Selective reporting (re- Low risk $\quad$ All outcomes reported
porting bias)


Guthrie 2001

\section{Study characteristics}

\begin{tabular}{ll}
\hline Methods & Parallel randomised controlled clinical trial \\
& Randomisation ratio: $1: 1$ \\
& Equivalence design: 2 -sided confidence interval \\
& Open-label
\end{tabular}

\section{Participants}

$N$ recruited $=13,100$

$\mathrm{N}$ randomised $=13,100$ (2765 control, 10335 intervention)

$\mathrm{N}$ reported outcomes $=4548$ (3635 in intervention group, 913 in control group) - returned 6-month patient survey forms

Mean age 57.9 years (intervention group), 58.3 years (control group)

INCLUSION CRITERIA

"Patients with risk scores $\sim 4$ on a scale of -1 to +16 for men and -1 to +17 for women on the First Heart Attack Risk Test were considered to be at increased risk for a first $\mathrm{MI}$ and suitable for enrollment in the registry program. An elevated total cholesterol level despite dietary interventions was an additional inclusion criterion."

\section{EXCLUSION CRITERIA}

"Previous MI, current therapy with a 3-hydroxy-3-methylglutaryl coenzyme A reductase inhibitor (i.e., statin), as well as membership in a federally funded health care program (except Medicare or plans for federal employees) constituted exclusion criteria. Medicaid patients were excluded in accordance with federal regulations prohibiting participation of such patients in programs involving prescription writing. Women of childbearing potential were similarly excluded from participation in the registry."

\section{COUNTRY/SETTING: USA}

STUDY PERIOD: December 1997 to December 1998

\section{INTERVENTION GROUP}

"Individuals randomized to the intervention group received telephone reminders at weeks 2 and 8 , as well as reminder postcards at week 4, to reinforce these messages about coronary risk reduction. Each of these communications stressed the importance of following the physician's instructions and taking medications as prescribed. These reminders were issued by a national program-coordinating center. Reminder postcards were also mailed to both groups at 4 and 5 months after enrollment. Physicians completed follow-up evaluation forms after patient visits, which were scheduled according to their normal practices."

CONTROL GROUP

Usual care

\section{Outcomes}

\section{TIME OF OUTCOME MEASUREMENTS}

"At 3 and 6 months or study discontinuation, registry participants completed patient-survey forms concerning compliance with care and mailed these to the program-coordinating center."

PRIMARY OUTCOME: compliance 
Commercial funding/non-commercial funding/other funding: "This registry was funded by Bristol-Myers Squibb Co, Princeton, New Jersey." "For professional services and administrative activities conducted in association with the First MI Risk Reduction Program, each participating physician received an honorarium of $\$ 500$ from the registry sponsor."

Stated aim for study: "The purpose of the First Myocardial Infarction (MI) Risk Reduction Program, an open-label drug registry involving mainly primary-care patients at increased risk of a first MI, was to examine the effects of postal and telephone reminders, as well as demographic and other baseline characteristics, on patient self-reported compliance with pravastatin treatment."

\section{Risk of bias}

\begin{tabular}{|c|c|c|}
\hline Bias & Authors' judgement & Support for judgement \\
\hline $\begin{array}{l}\text { Random sequence genera- } \\
\text { tion (selection bias) }\end{array}$ & Unclear risk & Not reported \\
\hline $\begin{array}{l}\text { Allocation concealment } \\
\text { (selection bias) }\end{array}$ & Unclear risk & Not reported \\
\hline $\begin{array}{l}\text { Blinding (performance } \\
\text { bias and detection bias) } \\
\text { All outcomes }\end{array}$ & Unclear risk & Unblinded "open-label" study \\
\hline $\begin{array}{l}\text { Incomplete outcome data } \\
\text { (attrition bias) } \\
\text { All outcomes }\end{array}$ & High risk & $\begin{array}{l}\text { "-35\% of the total number of patients enrolled who returned patient survey } \\
\text { forms to the national program coordinating center at } 6 \text { months" }\end{array}$ \\
\hline $\begin{array}{l}\text { Selective reporting (re- } \\
\text { porting bias) }\end{array}$ & Low risk & All outcomes reported \\
\hline
\end{tabular}

Ho 2014

\section{Study characteristics}

\begin{tabular}{ll}
\hline Methods & Parallel randomised controlled clinical trial \\
& Randomisation ratio: $1: 1$ \\
& Equivalence design: 2 -sided confidence interval \\
& Open-label not reported \\
\hline Participants & N recruited $=253$ patients \\
& N reported outcomes = 241 participants) (119 control, 122 intervention) \\
& Mean age 64 yrs, 98\% men \\
& INCLUSION CRITERIA \\
& "Patients admitted with ACS as the primary reason for hospital admission and used the VA for their usu- \\
& al care" \\
& EXCLUSION CRITERIA
\end{tabular}


Ho 2014 (Continued)

“1) patients admitted for primary non-cardiac diagnosis who developed ACS as a secondary condition

2) planned discharge to nursing home or skilled nursing facility

3) irreversible, noncardiac medical condition likely to affect 6-month survival or inability to execute study protocol

4) lack of telephone or cell phone

5) VA not a primary source of care in the future

6) fill medications at non-VA pharmacy

7) pregnancy"

COUNTRY/SETTING: 4 Department of Veterans Affairs (VA) medical centers (Denver, Colorado; Little Rock, Arkansas; Seattle,Washington; and Durham, NorthCarolina), USA

STUDY PERIOD: "Recruitment began July 1, 2010, in Denver and Seattle; September 1, 2010, in LittleRock; and July 1, 2011, in Durham."

Interventions

Number of study centres: 4 "Department of Veterans Affairs medical centers located in Denver (CO), Seattle (WA), Durham (NC), and Little Rock (AK)"

\section{INTERVENTION GROUP}

"standard ACS hospital discharge instructions, a discharge medication list, and educational information about cardiac medications" and "1) pharmacist-led medication reconciliation and tailoring, 2) patient education, 3) collaborative care between pharmacist and a patient's primary care clinician and/or cardiologist, and 4) 2 types of voice messaging (educational and medication refill reminder calls)"

\section{CONTROL GROUP}

"standard ACS hospital discharge instructions, a discharge medication list, and educational information about cardiac medications"

TIME OF OUTCOME MEASUREMENTS: 12 -month clinic visit
PRIMARY OUTCOMES: "Proportion of patients adherent to medication regimens based on a mean pro-
portion of days covered (PDC) greater than 0.80 in the year after hospital discharge using pharmacy re-
fill data for 4 cardioprotective medications (clopidogrel, B-blockers, statins, and ACEI/ARB)"
SECONDARY OUTCOMES: "Proportion of patients reaching blood pressure goals $(<140 / 90 \mathrm{mmHg})$ and
LDL-C goals $(<100 \mathrm{mg} / \mathrm{dL})$ at 12 months"

Notes Commercial funding/non-commercial funding/other funding:

"This study was funded by a Veterans Health Administration Health Service Research \& Development Investigator Initiated Award. Dr. Bosworth was supported by a senior career scientist award."

Stated aim for study: "To test a multifaceted intervention to improve adherence to cardiac medications"

\section{Risk of bias}

\begin{tabular}{lll}
\hline Bias & Authors' judgement & Support for judgement \\
\hline $\begin{array}{l}\text { Random sequence genera- } \\
\text { tion (selection bias) }\end{array}$ & Low risk & $\begin{array}{l}\text { "Eligible patients with ACS were randomized using blocked randomization } \\
\text { stratified by study site in a 1:1 ratio to INT or UC" }\end{array}$ \\
\hline $\begin{array}{l}\text { Allocation concealment } \\
\text { (selection bias) }\end{array}$ & Low risk & $\begin{array}{l}\text { "The allocation sequence was concealed until a patient consented to partic- } \\
\text { ipate and was generated centrally using the graphical user interface imple- } \\
\text { mented for the study" }\end{array}$ \\
\hline \hline
\end{tabular}


Ho 2014 (Continued)
Blinding (performance
Unclear risk
Not reported
bias and detection bias)
All outcomes

\begin{tabular}{lll}
\hline $\begin{array}{l}\text { Incomplete outcome data } \\
\text { (attrition bias) } \\
\text { All outcomes }\end{array}$ & Low risk & "Of 253 patients, 241 (95.3\%) completed the study (122 in INT and 119 in UC)" \\
\hline $\begin{array}{l}\text { Selective reporting (re- } \\
\text { porting bias) }\end{array}$ & Low risk & All outcomes reported \\
\hline
\end{tabular}

Kardas 2013

\section{Study characteristics}

\begin{tabular}{ll}
\hline Methods & Parallel randomised controlled clinical trial \\
& Randomisation ratio: $1: 1$ \\
& Equivalence design: (2-sided confidence interval) \\
& Open-label
\end{tabular}

Participants
$\begin{aligned} & \text { N recruited }=198 \\ & \text { N randomised }=198 \text { (89 control, } 107 \text { intervention }) \\ & \text { N reported }=196\end{aligned}$

Mean age $59.6 \pm 9.1$ years, $75.5 \%$ women

\section{INCLUSION CRITERIA}

Outpatients with untreated hyperlipidaemia (total cholesterol $\geq 250 \mathrm{mg} / \mathrm{dL}$ ) aged $40-80$ years $(59.6 \pm$ 9.1 years) were enrolled

\section{EXCLUSION CRITERIA}

Mental illness, dependence on other people's care, and/or medication taking, being at risk of not completing the study due to alcoholism, psychoactive substance abuse, homelessness etc., porphyria, unstable angina, NYHA class III or IV heart failure, acute infections, liver disease (cirrhosis), or significantly elevated transaminases (level $\geq 3$ times above the normal values), allergy to simvastatin, or any other known contraindications to its use, pregnancy, and lactation.

COUNTRY/SETTING: primary care centers in Poland

STUDY PERIOD: Not reported

CONTROL GROUP
All patients who were enrolled in the study were prescribed simvastatin at the initial dose of 20 mg to
be taken once daily in the evening
INTERVENTION GROUP
Intervention group received counselling every 8 weeks and were instructed to adopt routine evening
activity as a reminder


Kardas 2013 (Continued)

Outcomes
PRIMARY OUTCOME: adherence expressed as Medication Possession Ratio, calculated as the proportion of the number of days during which the participant was in possession of simvastatin, over the total number of days of the follow-up period.

\title{
Notes
}

\section{Risk of bias}

\begin{tabular}{lll}
\hline Bias & Authors' judgement & Support for judgement \\
\hline $\begin{array}{l}\text { Random sequence genera- } \\
\text { tion (selection bias) }\end{array}$ & Unclear risk & Not reported \\
\hline $\begin{array}{l}\text { Allocation concealment } \\
\text { (selection bias) }\end{array}$ & Unclear risk & Not reported \\
\hline $\begin{array}{l}\text { Blinding (performance } \\
\text { bias and detection bias) } \\
\text { All outcomes }\end{array}$ & Unclear risk & Unblinded open-label study \\
\hline $\begin{array}{l}\text { Incomplete outcome data } \\
\text { (attrition bias) } \\
\text { All outcomes }\end{array}$ & Low risk & 2 participants lost to attrition \\
\hline $\begin{array}{l}\text { Selective reporting (re- } \\
\text { porting bias) }\end{array}$ & Low risk & All outcomes reported \\
\hline
\end{tabular}

Kooy 2013

\section{Study characteristics}

\begin{tabular}{ll}
\hline Methods & Parallel randomised controlled clinical trial \\
& Randomisation ratio: 1:1:1 \\
& Equivalence design: (2-sided confidence interval) \\
& Open-label \\
\hline
\end{tabular}

\section{Participants}

\author{
$\mathrm{N}$ recruited $=399$ \\ $\mathrm{N}$ randomised = 399 (134 control, 134 intervention-1, 131 intervention-2) \\ $\mathrm{N}$ reported outcomes $=381$ \\ Mean age 76.5 (SD 6.3), $44.1 \%$ men \\ INCLUSION CRITERIA \\ $\leq 65$ years old (Mean age 76.5 )
}

"We included patients who had started statins at least one year prior to inclusion and were non-adherent in the year prior to inclusion (refill rate between 50 and $80 \%$ )."

\section{EXCLUSION CRITERIA}

"We excluded patients who were not personally responsible for their medication intake or who received their medication in a dosing aid, patients with a life expectancy of less than 6 months and patients younger than 65 years. Life expectancy is difficult to assess but this assessment was based on 
Kooy 2013 (Continued)

personal knowledge about the patient and the prescription of drugs used in the palliative phase. Patients who had switched to a different statin in the 540 days before the inclusion date were also excluded."

COUNTRY/SETTING: The Netherlands

STUDY PERIOD: Patients recruited between January 2008 and March 2008

Interventions
Counseling with ERD group (1)
"The pharmacist sent patients a written invitation and a follow up phone call was made 14 days after
the written invitation. The intervention consisted of two elements: the first and most important ele-
ment was the application of the stages of change model in non-adherence counseling. The second ele-
ment was the Electronic Reminder Device (ERD)."
"The 10-min counseling session by the pharmacist consisted of five phases. The patient received feed-
back on their previous drug dispensing data (1). Patients were asked if they were aware that they were
non-adherent and reasons for non-adherence were discussed (2). Patients were informed about the
benefits of statin use (3), received an ERD to help them with medication taking (4) and were informed
that after one year they would be invited for a follow-up visit (5). The ERD is a medication reminder de-
vice that starts beeping every day at the same time until the patient switches it off. Patients can adjust
the time."

ERD group (2)

"Patients received the ERD by mail with a written instruction about the use of the device."

Control group (3)

"Patients in the control group received usual care. In the Netherlands usual care entails: at the start of therapy, patients receive written and spoken information about the therapy and medication. After about 2 weeks, the patient should return for the first refill. The patient is then asked about his or her experience, concerns and need for information. Patients who use a statin for more than a year do not receive counselling on a regular basis."

Outcomes

"The pre-specified primary outcome was refill adherence to statins based on pharmacy dispensing records. Refill adherence was assessed by calculating the proportion of days covered of the 360 days following the index date by dividing the total days' supply by the number of days of study participation [PDC360 (Hess et al., 2006)]."

PRIMARY OUTCOME: refill adherence

SECONDARY OUTCOME: discontinuation

Notes Publication details

Commercial funding/non-commercial funding/other funding: "This trial was funded by Utrecht University."

\section{Stated aim for study}

"The aim of this study was to assess the effectiveness of an electronic reminder device (ERD) with or without counselling to improve refill adherence and persistence for statin treatment in non-adherent patients."

\section{Risk of bias}

\section{Bias}

Authors' judgement Support for judgement

Random sequence genera- Low risk tion (selection bias)
"Patients were randomized into one of three groups: the Counseling with ERD group, the ERD group (with written instruction) or the control group (usual 
Kooy 2013 (Continued)

care) in a 1:1:1 ratio using a computer generated random number sequence. Patients were randomized in blocks based on baseline medication adherence (above or below 65\%) and age [above or below 75 using the minimization method with equal weights assigned to both categories (Scott et al., 2002; Heritier et al., 2005)]."

\begin{tabular}{lll}
\hline $\begin{array}{l}\text { Allocation concealment } \\
\text { (selection bias) }\end{array}$ & Low risk & See above \\
\hline $\begin{array}{l}\text { Blinding (performance } \\
\text { bias and detection bias) } \\
\text { All outcomes }\end{array}$ & Unclear risk & Unblinded "open-label study" \\
\hline $\begin{array}{l}\text { Incomplete outcome data } \\
\text { (attrition bias) }\end{array}$ & Low risk & $\begin{array}{l}\text { "A total of } 399 \text { patients considered eligible by the pharmacists were random- } \\
\text { ly assigned to one of the two intervention groups or the control group. Two pa- } \\
\text { tients were excluded because they did not fill any prescription after the selec- } \\
\text { tion date. A total of } 16 \text { patients were excluded because they started receiving } \\
\text { medication weekly after the index date." }\end{array}$ \\
\hline
\end{tabular}

Selective reporting (re- Low risk $\quad$ All outcomes reported
porting bias)

\section{Study characteristics}

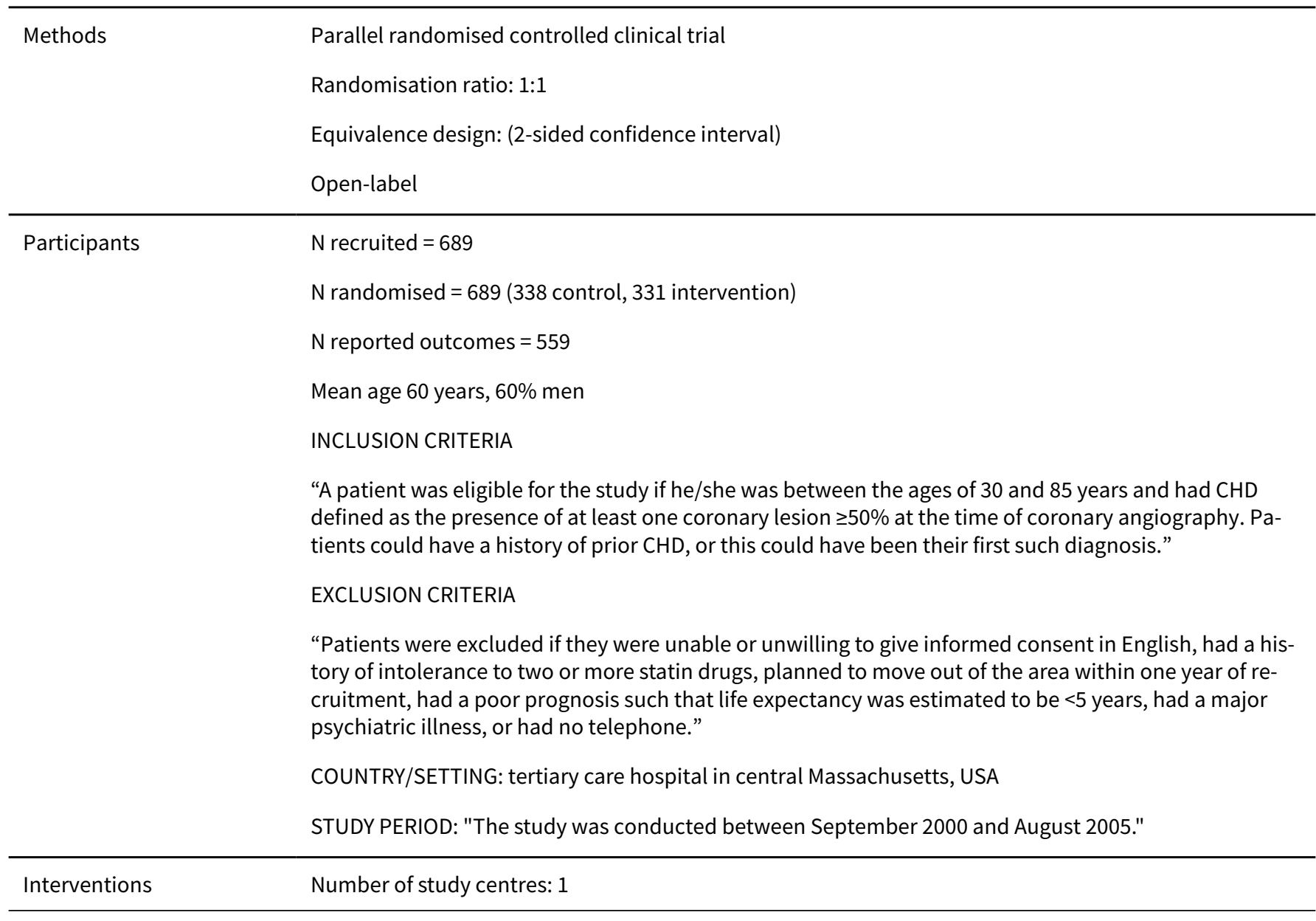


Ma 2010 (Continued)

\title{
INTERVENTION GROUP
}

"In this two-condition randomized clinical trial, the intervention condition included: (1) a computer-based tracking system designed to facilitate follow-up of patients who were initially seen for a CHD clinical event at UMass Memorial Medical Center (UMMMC); (2) an initial inpatient contact and a series of coordinated patient-centered pharmacist-delivered telephone counseling contacts to improve adherence to prescribed medications."

\section{CONTROL GROUP}

"The UC condition consisted of normal clinical care as determined by the patient's provider."

\section{Outcomes}

\begin{abstract}
"The primary outcome evaluated at one year included percentage of patients with a serum low-density lipoprotein cholesterol (LDL-C) level $<100 \mathrm{mg} / \mathrm{dl}$; the secondary outcome included the proportion of prescribed statin medication taken by patients as measured by a continuous multiple-interval (CMA) based on pharmacy records. The CMA is the ratio of days supply obtained to total days between refill records [22]. Other secondary outcomes evaluated at one year included the proportion of patients prescribed ACE inhibitor and beta-blocker medication. Adherence to these medications was also measured by CMA."
\end{abstract}

PRIMARY OUTCOME: LDL-C $<100 \mathrm{mg} / \mathrm{dl}$

SECONDARY OUTCOMES: adherence with statin medication

Notes Publication details

Commercial funding/non-commercial funding/other funding: "The project described was supported by Award Number R01 HL66786-01 to Dr. Ira S. Ockene from the National Heart, Lung, and Blood Institute (NHLBI)."

\section{Stated aim for study}

"The overall goal of this study was to implement and evaluate the effects of a pharmacist-delivered intervention (PI) designed to improve LDL-C goal attainment according to the NCEP ATP-III Guidelines and prescribed lipid-lowering medi- cation adherence in patients with known CHD."

\section{Risk of bias}

\begin{tabular}{lll}
\hline Bias & Authors' judgement & Support for judgement \\
\hline $\begin{array}{l}\text { Random sequence genera- } \\
\text { tion (selection bias) }\end{array}$ & Low risk & $\begin{array}{l}\text { "The patient was the unit of randomization and analysis. Randomization was } \\
\text { conducted by a statistician who was not involved with the intervention. The } \\
\text { study was conducted between September } 2000 \text { and August 2005. The Institu- } \\
\text { tional Review Boards of the University of Massachusetts Medical School ap- } \\
\text { proved all subject recruitment, intervention, and data collection procedures." }\end{array}$ \\
\end{tabular}

\begin{tabular}{ll}
\hline $\begin{array}{l}\text { Allocation concealment } \\
\text { (selection bias) }\end{array}$ & Low risk above
\end{tabular}

\begin{tabular}{lll}
\hline $\begin{array}{l}\text { Blinding (performance } \\
\text { bias and detection bias) }\end{array}$ & Unclear risk & Unblinded "open-label study" \\
$\begin{array}{ll}\text { All outcomes } \\
\text { Incomplete outcome data } \quad \text { Low risk }\end{array}$ & $\begin{array}{l}351 \text { to the intervention condition. A total of } 559 \text { ( } 81 \%) \text { had complete pharmacy } \\
\text { (attrition bias) } \\
\text { All outcomes }\end{array}$
\end{tabular}

\begin{tabular}{|c|c|c|}
\hline $\begin{array}{l}\text { Selective reporting (re- } \\
\text { porting bias) }\end{array}$ & Low risk & All outcomes reported \\
\hline
\end{tabular}


Márquez 1998

\section{Study characteristics}

\begin{tabular}{ll}
\hline Methods & Parallel randomised controlled clinical trial \\
& Randomisation ratio: 1:1 \\
& Equivalence design: 2-sided confidence interval \\
& Open-label
\end{tabular}

\section{Participants}

$\mathrm{N}$ recruited $=110$

$\mathrm{N}$ randomised $=110$ (55 control, 55 intervention)

$\mathrm{N}$ reported outcomes $=108$

Mean age years 55.7 (intervention group), 56.1 years (control group)

INCLUSION CRITERIA

a) outpatients of both sexes from 18 - 75 years old

b) diagnosed with new or uncontrolled hypercholesteraemia that can be treated according to the recommendation of the Spanish Society of Arteriosclerosis.

c) patients in whom pharmacological treatment of hypercholesteraemia is indicated by fluvastatin and can be initiated as new drug treatment

d) agree to participate in the study by written and verbal consent

\section{EXCLUSION CRITERIA}

a) patients who want to join the study to control their lipid levels or get lipid-lowering drugs

b) secondary hypercholesteraemia

c) patient is known to have side effects from statins

d) contraindicated for fluvastatin use or hypersensitive to fluvastatin

e) pregnant or breastfeeding women

f) patients in a pathological situation which could interfere with the study (i.e. disabled, alcoholic, drug user, chronic diseases)

g) unwilling to grant informed consent or poor co-operation is expected

h) patients who have participated in other studies from this investigation

i) having a cohabitant who is taking the same lipid-lowering medication used in the study

COUNTRY/SETTING: primary care centers in Spain

STUDY PERIOD: Patients enrolled between January and March 1997

Interventions Number of study centres: Primary Care setting

INTERVENTION GROUP

"HE (Health Education) was monitored by a) a group HE session and b) back-up letter sent to their homes."

CONTROL GROUP 
Márquez 1998 (Continued)

"received HE from their family doctor"

\begin{tabular}{l} 
Outcomes \\
TIME OF OUTCOME MEASUREMENTS: \\
Pill counts over 4 months \\
PRIMARY OUTCOME: compliance \\
SECONDARY OUTCOMES: lipid levels, adverse effects \\
\hline Notes \\
Commercial funding/non-commercial funding/other funding: Not reported \\
Stated aim for study: "To analyse the efficacy of Health Education (HE) through group session with \\
postal back-up in furthering compliance with therapy for Lipidemias."
\end{tabular}

\section{Risk of bias}

\begin{tabular}{|c|c|c|}
\hline Bias & Authors' judgement & Support for judgement \\
\hline $\begin{array}{l}\text { Random sequence genera- } \\
\text { tion (selection bias) }\end{array}$ & Unclear risk & Not reported \\
\hline $\begin{array}{l}\text { Allocation concealment } \\
\text { (selection bias) }\end{array}$ & Low risk & Randomisation performed blind \\
\hline $\begin{array}{l}\text { Blinding (performance } \\
\text { bias and detection bias) } \\
\text { All outcomes }\end{array}$ & Low risk & Generator and outcome assessor blinded to allocation \\
\hline $\begin{array}{l}\text { Incomplete outcome data } \\
\text { (attrition bias) } \\
\text { All outcomes }\end{array}$ & Unclear risk & 2 were excluded for having no measurement count tablets \\
\hline $\begin{array}{l}\text { Selective reporting (re- } \\
\text { porting bias) }\end{array}$ & Low risk & All outcomes reported \\
\hline
\end{tabular}

Márquez 2004

\section{Study characteristics}

\begin{tabular}{ll}
\hline Methods & Parallel randomised controlled clinical trial \\
& Radomisation ratio: $1: 1$ \\
& Equivalence design: (2-sided confidence interval) \\
\hline Participants & N recruited $=126$ \\
& N randomised $=126$ (63 control, 63 intervention) \\
& N reported outcomes $=115$ \\
& Mean age 57.7 (SD 8.7$)$ years, $51.3 \%$ women \\
INCLUSION CRITERIA & Outpatients of both sexes, aged between 18 and 75 years
\end{tabular}


Patients who, for the pharmacological treatment of hypercholesterolaemia this indicated the use of lipid-lowering pills, were recommended the use of simvastatin

Patients gave their consent to participate in this study

Patients requiring lipid-lowering medication treatment, as a function of the cardiovascular risk factors and presenting primary prevention, according to Spanish recommended by the Consensus guidelines for the control of blood cholesterol

\section{EXCLUSION CRITERIA}

Patients at baseline needed to control their lipid numbers with 2 or more lipid-lowering drugs

Present known cardiovascular disease

Secondary hypercholesterolaemia

Side effects and contraindications to the use of statins

Pregnant or lactating women

COUNTRY/SETTING: Spain

STUDY PERIOD: Recruitment between January and June 2001

\begin{tabular}{ll}
\hline Interventions & Number of study centres: 6 \\
& CONTROL GROUP \\
& "The control group ... received the doctor's normal treatment." \\
& INTERVENTION GROUP \\
& "The Intervention group ... received in addition a telephone call at 2 weeks, 2 months, and 4 months." \\
\hline Outcomes & PRIMARY OUTCOMES: adherence, serum lipids \\
& SECONDARY OUTCOMES: number needed to intervene in order to avoid 1 non-complier \\
\hline Notes & Aim: "To analyse the efficacy of the intervention through a telephone call about patients' compliance \\
with lipaemia therapy." \\
Funding: N/A \\
Conflicts: None stated \\
Language: Spanish
\end{tabular}

\section{Risk of bias}

\begin{tabular}{lll}
\hline Bias & Authors' judgement & Support for judgement \\
\hline $\begin{array}{l}\text { Random sequence genera- } \\
\text { tion (selection bias) }\end{array}$ & Low risk & Randomisation by providing numbers derived from tables by chance \\
\hline $\begin{array}{l}\text { Allocation concealment } \\
\text { (selection bias) }\end{array}$ & Low risk & Randomisation performed blind \\
\hline $\begin{array}{l}\text { Blinding (performance } \\
\text { bias and detection bias) } \\
\text { All outcomes }\end{array}$ & Unclear risk & Unblinded open-label study \\
\hline $\begin{array}{l}\text { Incomplete outcome data } \\
\text { (attrition bias) } \\
\text { All outcomes }\end{array}$ & Low risk & 11 out of 126 participants were excluded \\
\hline
\end{tabular}


Márquez 2004 (Continued)

Selective reporting (reporting bias)

Low risk All outcomes reported

Márquez 2007

\section{Study characteristics}

\begin{tabular}{ll}
\hline Methods & Parallel randomised controlled clinical trial \\
& Randomisation ratio: $1: 1$ \\
Equivalence design: (2-sided confidence interval)
\end{tabular}

\section{Participants}

$\mathrm{N}$ recruited $=220$

$\mathrm{N}$ randomised $=220$ (110 control, 110 intervention $)$

$\mathrm{N}$ reported outcomes $=186$

Mean age 60.62 years (SD $11 \mathrm{yrs}$ ), 59.6\% women

INCLUSION CRITERIA

Outpatients of both sexes, aged between 18 and 75 years

Patients who, for the pharmacological treatment of hypercholesterolaemia this indicated the use of lipid-lowering pills, were recommended the use of simvastatin

Patients gave their consent to participate in this study

Patients requiring lipid-lowering medication treatment, as a function of the cardiovascular risk factors and presenting primary prevention, according to Spanish recommended by the Consensus guidelines for the control of blood cholesterol

\section{EXCLUSION CRITERIA}

Patients at baseline needed to control their lipid numbers with 2 or more lipid-lowering drugs Present known cardiovascular disease

Secondary hypercholesterolaemia

Side effects and contraindications to the use of statins

Pregnant or lactating women

COUNTRY/SETTING: Spain

STUDY PERIOD: Recruitment between January and June 2006

Intervention group received calendar reminder of medication taking received at the time of first prescription

Outcomes PRIMARY OUTCOMES: adherence, serum lipids

SECONDARY OUTCOMES: number needed to intervene in order to avoid 1 non-complier

Notes

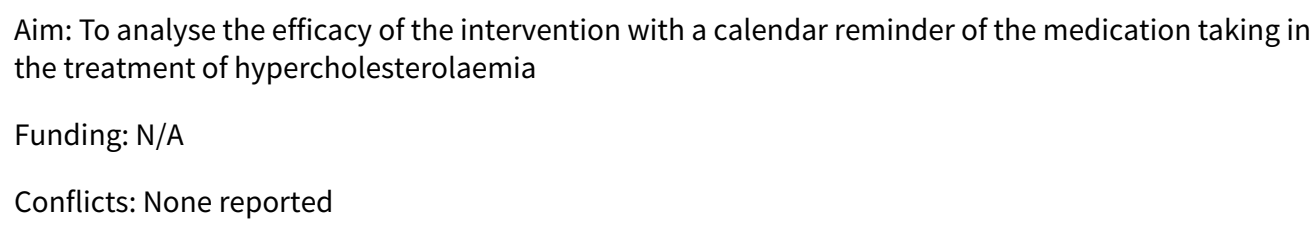


Márquez 2007 (Continued)

Language: Spanish

\section{Risk of bias}

\begin{tabular}{|c|c|c|}
\hline Bias & Authors' judgement & Support for judgement \\
\hline $\begin{array}{l}\text { Random sequence genera- } \\
\text { tion (selection bias) }\end{array}$ & Low risk & Randomisation by providing numbers derived from tables by chance \\
\hline $\begin{array}{l}\text { Allocation concealment } \\
\text { (selection bias) }\end{array}$ & Low risk & Randomisation performed blind \\
\hline $\begin{array}{l}\text { Blinding (performance } \\
\text { bias and detection bias) } \\
\text { All outcomes }\end{array}$ & Unclear risk & Unblinded open-label study \\
\hline $\begin{array}{l}\text { Incomplete outcome data } \\
\text { (attrition bias) } \\
\text { All outcomes }\end{array}$ & Low risk & 22 participants lost to follow-up \\
\hline $\begin{array}{l}\text { Selective reporting (re- } \\
\text { porting bias) }\end{array}$ & Low risk & All outcomes reported \\
\hline
\end{tabular}

Nieuwkerk 2012

\section{Study characteristics}

\begin{tabular}{ll}
\hline Methods & Parallel randomised controlled clinical trial \\
& Randomisation ratio: $1: 1$ \\
& Equivalence design: (2-sided confidence interval) \\
Open-label
\end{tabular}

Participants

$\mathrm{N}$ recruited $=201$

$\mathrm{N}$ randomised $=201$ (100 control, 101 intervention)

$\mathrm{N}$ reported outcomes $=181$

Mean age 49.2 years (SD 1.3) in routine care (RC) group and 48.9 years (SD 1.2) in extended care (EC) group, $60 \%$ men in RC and $59 \%$ men in EC

\section{INCLUSION CRITERIA}

"Patients (aged > 18 years) with indications for statin use (primary or secondary prevention of cardiovascular events)."

\section{EXCLUSION CRITERIA}

"Patients with severe fasting dyslipidemia (total cholesterol $>9.0 \mathrm{mmol} / \mathrm{L}$ or triglycerides $>4.0 \mathrm{mmol}$ / L) were excluded, as were those with fasting glucose $>7.0 \mathrm{mmol} / \mathrm{L}$. In addition, patients who had used statins for $>3$ months before inclusion, who had histories of drug and/or alcohol abuse, who were pregnant or breast-feeding, or who had life expectancies $<2$ years were excluded. In case patients had started statin therapy within 3 months, a washout period of 2 weeks was applied."

COUNTRY/SETTING: The Netherlands 
"All patients visited a study nurse practitioner at the Academic Medical Center in addition to their regular visits to their treating specialists. The baseline visit took place within 3 months after statin treatment had been indicated. Subsequent visits were scheduled after 3, 9, and 18 months."

CONTROL GROUP

Routine Care $(R C)$

"RC consisted of measuring body weight and blood pressure and performing a capillary lipid profile at each visit (Cholestech; Alere Health BV, Tilburg, The Netherlands). Initially, all patients received atorvastatin $10 \mathrm{mg}$, unless baseline cholesterol levels were severe and more aggressive therapy was needed. Dose escalation during the study period was allowed if deemed appropriate by the treating physician."

\section{INTERVENTION GROUP}

Extended Care (EC)

"In addition to RC, subjects in the EC group received multifactorial risk-factor counselling, during which the nurse practitioner explained the presence of unmodifiable risk factors, such as age, gender, and family history, and modifiable risk factors, such as lipid levels, diabetes mellitus, blood pressure, overweight, smoking habits, and physical activity. The study nurse was not blinded to the purpose of the study. The counselling focused on changing modifiable risk factors such as increasing medication adherence, reducing overweight, smoking cessation, and increasing physical activity. All obtained data were summarized in a personal risk-factor passport: a graphical presentation of the patient's calculated 10-year cardiovascular disease risk. It also showed the target risk that could be reached if all the patient's modifiable risk factors were optimally treated, as well as the standard age- and gender-related risk. Ten-year risk and target risk were calculated using the Framingham risk score. In addition, the riskfactor passport contained the most recent ultrasound image of the patient's carotid artery, as well as an example of a healthy and an unfavorable image of the carotid artery, which were both explained and discussed by the nurse practitioner. This risk-factor passport was updated during each follow-up visit."

Outcomes "The objective of the present study was to investigate if nurse-led multifactorial cardiovascular risk-
factor counselling would improve adherence to lipid-lowering medication and lipid levels without in-
creasing patients' anxiety compared to routine care (RC). We also investigated whether such an inter-
vention would result in a lower body mass index; lower blood pressure; improved intima-media thick-
ness (IMT) and flow-mediated dilatation (FMD); better quality of life (QoL), symptom scores, and beliefs
about medication; changed risk perception; and more smoking cessation compared with RC."

PRIMARY OUTCOMES: Serum LDL, adherence to lipid-lowering medication

SECONDARY OUTCOMES: BMI, BP, IMT, FMD, QoL, etc.

\section{Publication details}

Commercial funding/non-commercial funding/other funding: "This study was funded in part by Pfizer (Capelle aan den IJssel, The Netherlands)."

\section{Stated aim for study}

"The aim of this study was to investigate whether nurse-led cardiovascular risk-factor counseling could improve statin adherence and lipid levels without increasing patients' anxiety."

\section{Risk of bias}


Nieuwkerk 2012 (Continued)

Random sequence genera- Low risk "After inclusion, patients were randomly assigned to RC or extended care (EC), tion (selection bias) using a randomization computer program, to obtain an equal distribution of primary and secondary prevention patients, hospital origin, and gender in the 2 groups"

Allocation concealment $\quad$ Low risk See above
(selection bias)

Blinding (performance Unclear risk Unblinded "open-label study"
bias and detection bias)
All outcomes

All outcomes

Incomplete outcome data Low risk All randomised participants' outcomes reported
(attrition bias)

All outcomes

\begin{tabular}{ll}
\hline $\begin{array}{l}\text { Selective reporting (re- } \\
\text { porting bias) }\end{array}$ & Low risk \\
\hline
\end{tabular}

Park 2013

\section{Study characteristics}

\begin{tabular}{|c|c|}
\hline Methods & $\begin{array}{l}\text { Parallel randomised controlled clinical trial } \\
\text { Randomisation ratio: 1:1:1 } \\
\text { Superiority design: (2-sided confidence interval) } \\
\text { Open-label }\end{array}$ \\
\hline Participants & $\begin{array}{l}\text { N recruited = } 90 \\
\text { N randomised = } 90 \text { ( } 30 \text { control, } 30 \text { intervention-1, } 30 \text { intervention-2) } \\
\text { N reported outcomes = } 84 \\
\text { Mean age } 59.2 \text { years (SD 9.4, range } 35-83 \text { ), } 24 \% \text { women } \\
\text { INCLUSION CRITERIA } \\
\text { "Inclusion criteria were: (a) >/=21 years of age, (b) hospitalized for non-ST elevation MI, ST elevation MI, } \\
\text { or PCI, (c) prescribed an antiplatelet medication [thienopyridine class of ADP receptor inhibitors and/ } \\
\text { or a cyclooxygenase inhibitor (i.e., aspirin)], (d) prescribed a statin medication (HMG-CoA reductase in- } \\
\text { hibitors), (e) owned a mobile phone with text messaging capability, and (f) were able to speak, read, } \\
\text { and understand English." } \\
\text { EXCLUSION CRITERIA } \\
\text { "Exclusion criteria included: (a) cognitive impairment that limited ability to understand and complete } \\
\text { questionnaires, and (b) inability to operate a mobile phone." } \\
\text { COUNTRY/SETTING: USA } \\
\text { STUDY PERIOD: "Recruitment took place between April } 2012 \text { and March } 2013 \text { until the final sample size } \\
\text { was obtained." }\end{array}$ \\
\hline Interventions & $\begin{array}{l}\text { Number of study centres: } 1 \\
\text { Text Message Reminders + Text Message Education (1) }\end{array}$ \\
\hline
\end{tabular}


Park 2013 (Continued)

"Patients who received text messages (TM) for medication reminders and health education."

TM Education Alone (2)

"Patients who received TM for health education."

No TM (3)

"Patients who did not receive TM."

\section{Outcomes}

"First, data from the Medication Event Monitoring System (MEMS) provided four different indicators of adherence including: (1) total number of doses taken, (2) percentage of prescribed doses taken, (3) percentage of days correct number of doses were taken, and (4) percentage of doses taken on schedule. Second, the response rate to the TM medication reminders by the TM Reminders + TM Education group was to correspond to adherence. Third, medication adherence was assessed using the MMAS-8, a selfreport measure completed at baseline and at follow-up. The MMAS- 8 is a well-validated tool and correlates with other adherence measures such as medication refill rates and electronic monitoring devices (e.g., MEMS)."

"For the secondary aim, feasibility and patient satisfaction were assessed by successful execution of the intervention, patient participation, and by the Mobile Phone Use Questionnaire. The latter questionnaire was developed for the purpose of the study and sought to obtain patients' experience with using mobile phones for medication reminders and/or education."

PRIMARY OUTCOME: medication adherence

SECONDARY OUTCOME: feasibility and patient satisfaction

\section{Publication details}

Commercial funding/non-commercial funding/other funding: "Funding for research materials was provided by a grant from the Graduate Division of University of California, San Francisco and a scholarship from the UCSF/Hartford Center of Geriatric Nursing Excellence. CareSpeak Communications provided the use of the mobile Health manager platform, which is designed to improve medical therapy adherence using two-way text messaging."

\section{Stated aim for study}

"The primary aim was to compare medication adherence among three groups: (1) patients who received text messages (TM) for medication reminders and health education (TM Reminders + TM Education), (2) patients who received TM for health education (TM Education Alone), and (3) patients who did not receive TM (No TM). The secondary aim was to explore feasibility and patient satisfaction with mobile phone use to improve medication adherence among patients who received TM."

\section{Risk of bias}

\begin{tabular}{|c|c|c|}
\hline Bias & Authors' judgement & Support for judgement \\
\hline $\begin{array}{l}\text { Random sequence genera- } \\
\text { tion (selection bias) }\end{array}$ & Low risk & $\begin{array}{l}\text { "Group assignment was generated by random allocation sequence using } \\
\text { blocks of six that was prepared by a biostatistician. The PI assigned patients to } \\
\text { their groups by distributing envelopes in consecutive, numbered order." }\end{array}$ \\
\hline $\begin{array}{l}\text { Allocation concealment } \\
\text { (selection bias) }\end{array}$ & Low risk & $\begin{array}{l}\text { "Eligible patients opened sealed opaque envelopes that contained the assign- } \\
\text { ment to one of three groups (TM Reminders + TM Education, TM Education } \\
\text { Alone, or No TM)" }\end{array}$ \\
\hline $\begin{array}{l}\text { Blinding (performance } \\
\text { bias and detection bias) } \\
\text { All outcomes }\end{array}$ & Unclear risk & Unblinded "open-label study" \\
\hline $\begin{array}{l}\text { Incomplete outcome data } \\
\text { (attrition bias) }\end{array}$ & Low risk & $\begin{array}{l}\text { "Ninety patients were recruited to participate and completed baseline ques- } \\
\text { tionnaires; however, six patients withdrew or were lost to follow-up" }\end{array}$ \\
\hline
\end{tabular}


Park 2013 (Continued)

All outcomes

Selective reporting (re- Low risk $\quad$ All outcomes reported
porting bias)

Patel 2015

\section{Study characteristics}

\begin{tabular}{ll}
\hline Methods & Parallel randomised controlled clinical trial \\
& Randomisation ratio: $1: 1$ \\
& Equivalence design: 2 -sided confidence interval \\
& Open-label \\
\hline
\end{tabular}

Participants

$\mathrm{N}$ recruited $=731$

$\mathrm{N}$ randomised $=623$ (312 control, 311 intervention)

$\mathrm{N}$ reported outcomes $=623$

Median age: 63.4 years (intervention), 63.7 years (control)

INCLUSION CRITERIA

"Men and women aged 18 years at high CVD risk, defined as either established CVD (history of coronary, ischaemic cerebrovascular, or peripheral vascular disease) or an estimated five-year CVD risk of $15 \%$ (using the Framingham risk equation, including a 5\% increment for Aboriginal or Torres Strait Islander identification) were eligible. Each participant had to have, in their doctor's view, indications for all and no contraindications to any component of at least one of two polypills - version 1 (containing aspirin $75 \mathrm{mg}$, simvastatin $40 \mathrm{mg}$, lisinopril $10 \mathrm{mg}$, atenolol 50mg) or version 2 (containing aspirin $75 \mathrm{mg}$, simvastatin $40 \mathrm{mg}$, lisinopril $10 \mathrm{mg}$, hydrochlorothiazide $12.5 \mathrm{mg}) . "$

\section{EXCLUSION CRITERIA}

"Participants were excluded if it was felt clinically inappropriate to alter medications."

COUNTRY/SETTING: Australia

STUDY PERIOD: January 2010 - May 2012

Interventions Number of study centres: 33 Australian centers (12 Aboriginal Medical Services)

"Participants attended the primary healthcare centres for trial assessments at randomization and 12 month intervals thereafter. All participants were also reviewed one month post-randomization and at intervening six month intervals, but these could be conducted by telephone. BP and fasting lipids levels were obtained at baseline, 12 months, 24 months and the final visit (at 36 months)."

INTERVENTION GROUP - "polypill-based strategy received a polypill containing aspirin $75 \mathrm{mg}$, simvastatin $40 \mathrm{mg}$, lisinopril $10 \mathrm{mg}$ and either atenolol $50 \mathrm{mg}$ or hydrochlorothiazide $12.5 \mathrm{mg} "$

CONTROL GROUP - 'usual care' continued with separate medications and doses as prescribed by their doctor

Outcomes PRIMARY OUTCOMES: self-reported combination treatment use, systolic blood pressure and total cholesterol

SECONDARY OUTCOMES: "Secondary outcomes included self-reported combination treatment use at 12 months; combination treatment prescriptions at the study end; reasons for stopping cardiovascu- 
Patel 2015 (Continued)

lar medications; changes in lipid fractions; quality of life; serious adverse events; cardiovascular events (coronary heart disease, heart failure leading to death or hospitalization, cerebrovascular or peripheral arterial disease events); and renal events (new onset microalbuminuria (albumin:creatinine ratio $3.0-33.9 \mathrm{mg} / \mathrm{mmol}$ ), progression to macroalbuminuria (albumin:creatinine ratio $>33.9 \mathrm{mg} / \mathrm{mmol}$ ) or at least a $50 \%$ decrease in estimated glomerular filtration rate from baseline to a level $<60 \mathrm{ml} / \mathrm{min}$ per 1.73m2)."

Notes Commercial funding/non-commercial funding/other funding: "This work was supported by the National Health and Medical Research Council of Australia (grant numbers 457508, 571281 and 632810). The funder and Dr Reddy's Laboratories (who provided polypills free of charge for the trial) had no role in the study design, data collection and analysis, decision to publish, or preparation of the manuscript."

Stated aim for study: "Most individuals at high cardiovascular disease (CVD) risk worldwide do not receive any or optimal preventive drugs. We aimed to determine whether fixed dose combinations of generic drugs ('polypills') would promote use of such medications."

\section{Risk of bias}

\begin{tabular}{lll}
\hline Bias & Authors' judgement & Support for judgement \\
\hline $\begin{array}{l}\text { Random sequence genera- } \\
\text { tion (selection bias) }\end{array}$ & Low risk & $\begin{array}{l}\text { "Central, computer-based randomization to polypill based strategy or usual } \\
\text { care" }\end{array}$ \\
\hline $\begin{array}{l}\text { Allocation concealment } \\
\text { (selection bias) }\end{array}$ & Low risk & See above \\
\hline $\begin{array}{l}\text { Blinding (performance } \\
\text { bias and detection bias) } \\
\text { All outcomes }\end{array}$ & Unclear risk & Unblinded \\
\hline $\begin{array}{l}\text { Incomplete outcome data } \\
\text { (attrition bias) } \\
\text { All outcomes }\end{array}$ & Low risk & $\begin{array}{l}\text { "The study failed to recruit the numbers of participants originally planned as a } \\
\text { result of limited resources and was therefore under-powered to demonstrate } \\
\text { significant differences in BP and cholesterol." }\end{array}$ \\
\hline $\begin{array}{l}\text { Selective reporting (re- } \\
\text { porting bias) }\end{array}$ & Low risk & \begin{tabular}{l} 
All outcomes reported \\
\hline
\end{tabular}
\end{tabular}

PILL 2011

\section{Study characteristics}

\begin{tabular}{ll}
\hline Methods & Parallel randomised controlled clinical trial \\
& Randomisation ratio: 1:1:1 \\
& Equivalence design: 2 -sided confidence interval \\
Double-blinded
\end{tabular}

P recruited $=859$
N randomised $=378$ (189 in each arm)
N reported outcomes $=373$ (at 12 weeks)
Mean age 61.2 years (SD 7.2) in red heart pill (RHP) group and 61.6 years (SD 7.2) in placebo group
$81 \%$ men in RHP group and $80 \%$ men in placebo group


PILL 2011 (Continued)

\section{INCLUSION CRITERIA}

"..key eligibility criteria were raised cardiovascular risk together with no indication for or contraindication to treatment with component medicines in the polypill. Individuals were included if they were adults (18 years or older) with a cardiovascular disease (CVD) risk over 5 years of at least $7.5 \%$, determined by the Framingham risk function using data on age, gender, blood pressure, total cholesterol, HDL cholesterol, diabetes status and cigarette smoking status..."

"To be included, the participants had to have no contraindication to treatment with low-dose aspirin, angiotensin-converting enzyme (ACE) inhibitor, low-dose diuretic or statin; nor any indication or recommendation under local guidance for treatment with any of these medicines."

\section{EXCLUSION CRITERIA}

"Participants taking other antiplatelet, blood pressure lowering or cholesterol lowering medicines were also excluded, as were patients with diabetes mellitus or GFR \#30 ml/min/1.73 m2."

COUNTRY/SETTING: Trial was conducted in 7 countries - Australia $(n=21)$, Brazil $(n=8)$, India $(n=109)$, Netherlands $(n=102)$, New Zealand $(n=12)$, United Kingdom $(n=113)$ and United States $(n=13)$

STUDY PERIOD: 17 October 2008 to 22 December 2009

Interventions

INTERVENTION: Red Heart Pill (RHP, a polypill comprising a bilayered tablet containing aspirin $75 \mathrm{mg}$, lisinopril $10 \mathrm{mg}$, hydrochlorothiazide $12.5 \mathrm{mg}$ and simvastatin $20 \mathrm{mg}$ )

CONTROL: identical placebo.

"The use of concomitant open-label therapy was allowed at the discretion of the responsible clinician. Without the need to unblind, additional treatment with open-label therapy was permitted $-75 \mathrm{mg}$ aspirin; any beta-blocker, calcium channel blocker, angiotensin receptor blocker or alpha-blocker; $10-$ $20 \mathrm{mg}$ lisinopril and/or $12.5 \mathrm{mg}$ hydrochlorothiazide or $2.5 \mathrm{mg}$ bendrofluazide; $10-20 \mathrm{mg}$ simvastatin - if any of these treatments became indicated during the trial. If there was a need for higher doses of aspirin, ACE inhibitor, diuretic or simvastatin, these were provided as open label treatment and the trial treatment was stopped. Open-label fibrate (with the exception of gemfibrozil) could also be added, without the need to unblind or stop the trial treatment, provided that appropriate monitoring for rhabdomyolysis was instituted."

- change in systolic blood pressure (SBP),

- change in LDL-cholesterol

- tolerability (proportion who withdrew from trial treatment for any reason)

\section{SECONDARY OUTCOMES:}

- treatment adherence (\% of prescribed treatment according to pill counts, with participants asked to return all used blisters and unused trial treatment to study visits)

- diastolic blood pressure

- total cholesterol

- HDL cholesterol

- total cholesterol: HDL cholesterol ratio

- non-HDL cholesterol

- triglycerides,

- frequency of switching/adding open-label treatment

- estimated effects on CVD risk

Outcomes were assessed at 2, 6 and 12 weeks after randomisation

A post-study follow-up appointment 4 weeks after the final 12-week visit 
PILL 2011 (Continued)

Notes

\begin{abstract}
"Participants were recruited from 17 October 2008 to 22 December 2009. Regulatory delays in importing trial treatment were prolonged and recruitment was 22 participants less than intended, since the study medication expiry date was reached."

Commercial funding/non-commercial funding/other funding: "The trial was funded by The Wellcome Trust, the Health Research Council of New Zealand, the National Heart Foundation of New Zealand, the National Health and Medical Research Council of Australia, The Brazilian Ministry of Health (Projeto Hospitais de Excelencia) and the British Heart Foundation. The polypill and matching placebo were provided free of charge by Dr. Reddy's Laboratories, Hyderabad, India. None of these parties had any role in study design, data collection, data analysis, data interpretation, or writing of the report. The corresponding author had full access to all data in the study. The Steering Committee had final responsibility for the decision to submit for publication."
\end{abstract}

\title{
Risk of bias
}

Bias Authors' judgement Support for judgement

Random sequence genera- Low risk tion (selection bias)

"Study treatments were allocated using a central computer-based randomisation service at The Clinical Trials Research Unit, University of Auckland, accessible by Internet, using a minimisation algorithm including age, sex and centre."

\begin{tabular}{|c|c|c|}
\hline $\begin{array}{l}\text { Allocation concealment } \\
\text { (selection bias) }\end{array}$ & Unclear risk & "Eligible participants were randomised to the Red Heart Pill..." \\
\hline $\begin{array}{l}\text { Blinding (performance } \\
\text { bias and detection bias) } \\
\text { All outcomes }\end{array}$ & Low risk & $\begin{array}{l}\text { "Participants, research staff and and coordinating centre staff were all blinded } \\
\text { to the allocation." }\end{array}$ \\
\hline $\begin{array}{l}\text { Incomplete outcome data } \\
\text { (attrition bias) } \\
\text { All outcomes }\end{array}$ & Low risk & Outcomes reported for 373 of 378 participants (98.7\%) \\
\hline $\begin{array}{l}\text { Selective reporting (re- } \\
\text { porting bias) }\end{array}$ & Low risk & All outcomes reported \\
\hline
\end{tabular}

Pladevall 2014

\section{Study characteristics}

\begin{tabular}{ll}
\hline Methods & Parallel randomised controlled clinical trial \\
& Randomisation ratio: $1: 1: 1$ \\
& Equivalence design: 2 -sided confidence interval \\
& Open-label \\
\hline Participants & recruited $=3799$ \\
& N randomised $=1692(567$ usual care, 569 adherence information, 556 adherence information and mo- \\
& N reported outcomes $=1692$ \\
& Mean age 64.9 years $( \pm 11.5)$ in UC group, 63.3 yrs ( \pm 10.9$)$ in Al group, 64.5 years $( \pm 10.5)$ in Al+MI group \\
& $53 \%$ women in UC, $47 \%$ in Al and 48\% in Al+MI group \\
\hline
\end{tabular}


Pladevall 2014 (Continued)

\section{INCLUSION CRITERIA}

"age $\geq 18$ years, a member of the health plan with prescription drug coverage in both 2007 and $2008, \geq 1$ A1C measurement with the last value $\geq 7 \%, \geq 1 \mathrm{LDL}-\mathrm{C}$ measurement with the last value $\geq 100 \mathrm{mg} / \mathrm{dL}$, and $\geq 1$ prescription for both an oral diabetes medication and a lipid-lowering medication."

\section{EXCLUSION CRITERIA}

"Patients were not eligible to participate if they had been in hospice care or hospitalized $\geq 90$ days, if they were participating in any other study involving diabetes management or medication adherence, or if their primary care provider did not consent to be part of the study."

COUNTRY/SETTING: Michigan, USA

STUDY PERIOD: Patients recruited between July 1, 2007, and January 1, 2008

Number of study centres: Henry Ford health system in southeast Michigan and metropolitan Detroit
Arm $3-6$ adherence sessions: initial face-to-face or phone and subsequent 5 sessions via phone every
months
CONTROL GROUP - 'usual care'
Medication adherence information (AI) provided to their physician to discuss with participants
Medication Al and receive motivational interviewing (MI) provided directly to patients via an "adher-
ence clinic" of nurses and pharmacists (Al + MI)

Outcomes PRIMARY OUTCOMES: A1C and LDL-C levels at 18 months post-randomisation.

SECONDARY OUTCOMES: medication adherence using total days' supply of medication in 3 month period divided by number of days of observation from pharmacy claims.

Notes

Commercial funding/non-commercial funding/other funding: "This project was made possible through funding from the National Institute of Diabetes and Digestive and Kidney (R01DK064695 to Drs Pladevall and Williams), the National Institute of Allergy and Infectious Diseases (R01AI079139 to Dr Williams), and the National Heart Lung and Blood Institute (R01HL079055 and R01HL118267 to Dr Williams), National Institutes of Health and the Fund for Henry Ford Hospital (to Drs Pladevall and Williams)."

Stated aim for study: "The purpose of this study was to assess whether providing medication adherence information with or without motivational interviewing improves diabetes and lipid control."

Conflicts: None reported

Language: English

\section{Risk of bias}

\begin{tabular}{lll}
\hline Bias & Authors' judgement & Support for judgement \\
\hline $\begin{array}{l}\text { Random sequence genera- } \\
\text { tion (selection bias) }\end{array}$ & Low risk & $\begin{array}{l}\text { "2-step randomization process was used. A random number generator was } \\
\text { first used to randomly sort each participating physician's list of enrolled pa- } \\
\text { tients. The order of treatment arm assignment was then randomly selected for } \\
\text { each physician's patient list of participating patients." }\end{array}$ \\
\hline $\begin{array}{l}\text { Allocation concealment } \\
\text { (selection bias) }\end{array}$ & Low risk & See above \\
\hline $\begin{array}{l}\text { Blinding (performance } \\
\text { bias and detection bias) } \\
\text { All outcomes }\end{array}$ & Unclear risk & $\begin{array}{l}\text { Unblinded - "Because the study design involved interaction between the re- } \\
\text { search team, adherence clinic staff, and patients, none of these groups were } \\
\text { blinded to study arm assignment." }\end{array}$ \\
\hline
\end{tabular}


Pladevall 2014 (Continued)

\begin{tabular}{|c|c|c|}
\hline $\begin{array}{l}\text { Incomplete outcome data } \\
\text { (attrition bias) } \\
\text { All outcomes }\end{array}$ & Unclear risk & $\begin{array}{l}\text { "Patient participation in the } \mathrm{Al}+\mathrm{MI} \text { arm was low }(49 \%) \text { and limit the interpre- } \\
\text { tation of the study results. For individuals who were lost to follow-up ( } 57 \text { pa- } \\
\text { tients UC, } 69 \text { patients AI, } 54 \text { patients Al + MI), the last available values were car- } \\
\text { ried forward." }\end{array}$ \\
\hline $\begin{array}{l}\text { Selective reporting (re- } \\
\text { porting bias) }\end{array}$ & Low risk & All outcomes reported \\
\hline
\end{tabular}

Poston 1998

\section{Study characteristics}

\section{Methods}

Parallel cluster-randomised controlled clinical trial (54 pharmacies ( 26 intervention group/28 control groups))

Randomisation ratio: 1:1

P recruited $=455$
N randomised $=455$ (224 control, 231 intervention)
N reported outcomes $=455$
Mean age 60.8 (SD 11) years, $43.8 \%$ women
INCLUSION CRITERIA
"Each pharmacist was asked to invite patients presenting new or refill Mevacor, Zocor, Prinvil, or Va-
Sotec to participate in this study."
EXCLUSION CRITERIA
"Patients were excluded from this study if literacy was an issue, if they were visitors or indicated that
they would be out of the region for several months during the study or if their medication was formally
monitored on a daily basis."
COUNTRY/SETTING: Ontario, Canada
STUDY PERIOD: Not reported

Interventions

Number of study centres: 2

CONTROL GROUP

Medication refill records were obtained and both groups received follow-up telephone calls from pharmacy at 2, 5 and 8 months regarding medication behaviour and general demographics.

\section{INTERVENTION GROUP}

"Pharmacists in London (test site) also provided each patient with a VI Program Kit, which included a videotape, information booklet, and newsletter. Later patients would receive two additional newsletters."

Titration period: "Recruitment was initiated July 1996 and completed February 1997. Interviews were completed November 1997."

Outcomes Results were only presented in subgroup analysis: adherence

Notes

Aim: This study examined the "effectiveness of the Vital Interests Program on patient adherence to prescribed medications for hypertension, congestive heart failure, and raised cholesterol." 
Poston 1998 (Continued)

Funding: Merck Frosst Canada Incorporation

Conflicts: None reported

Language: English

\section{Risk of bias}

\begin{tabular}{lll}
\hline Bias & Authors' judgement & Support for judgement \\
\hline $\begin{array}{l}\text { Random sequence genera- } \\
\text { tion (selection bias) }\end{array}$ & Unclear risk & Cluster-Orandomisation \\
\hline $\begin{array}{l}\text { Allocation concealment } \\
\text { (selection bias) }\end{array}$ & Unclear risk & Not reported \\
\hline $\begin{array}{l}\text { Blinding (performance } \\
\text { bias and detection bias) } \\
\text { All outcomes }\end{array}$ & Unclear risk & Unblinded open-label study \\
\hline $\begin{array}{l}\text { Incomplete outcome data } \\
\text { (attrition bias) } \\
\text { All outcomes }\end{array}$ & Low risk & "Only 28 patients (2.8\%) completely withdrew from this study, 38 could not be \\
\hline $\begin{array}{l}\text { Selective reporting (re- } \\
\text { porting bias) }\end{array}$ & Low risk & contacted, and 9 patients died" \\
\hline
\end{tabular}

Powell 1995

\section{Study characteristics}

\begin{tabular}{ll}
\hline Methods & Parallel randomised controlled clinical trial \\
Randomisation ratio: $1: 1$ \\
Equivalence Design: (2-sided confidence interval) \\
\hline N recruited = 568 \\
N randomised = 568 (297 control, 271 intervention) \\
N reported outcomes = 568 \\
Mean age 55 years (range 20 - 97) in control group and 54 years (range 20 - 94) in the intervention group \\
68\% women in control group and 65\% in intervention group \\
INCLUSION CRITERIA \\
"The subjects were drawn from a large (500,000) midwestern member Health Maintenance Organiza- \\
tion; a member is a person receiving medical and prescription drug coverage through the plan." \\
EXCLUSION CRITERIA \\
Not reported \\
COUNTRY/SETTING: USA \\
STUDY PERIOD: Recruitment 1 July 1993 to 2 January 1994
\end{tabular}


Powell 1995 (Continued)

Interventions

Number of study centres: 1

\section{CONTROL GROUP}

Treatment before study: Standard care i.e. "Members with a pharmacy claim for benazepril, metopro-

lol, simvastatin, or transdermal estrogen"

\section{INTERVENTION GROUP}

"Subjects in the study group were mailed one of four videotape programs presenting information on the drugs prescribed and the inferred disease state. Refill data were collected over nine months."

Titration period:

"Enrollment occurred over a six-month period"

Outcomes
$\begin{aligned} & \text { Time of outcome measurements: "total number of days' supply of a medication obtained by a member } \\ & \text { during the study divided by the number of days between the time the subject was enrolled and April } 1, \\ & 1994 \text { or the date the member was terminated from the plan, whichever came first" } \\ & \text { PRIMARY OUTCOME: Medication-Possession Ratio ( } 80 \% \text { equals compliance) }\end{aligned}$
$\begin{aligned} & \text { Aim: "The objective of this study was to assess the value of mailed educational videotapes as a means } \\ & \text { of enhancing medication compliance" }\end{aligned}$
Funding: Ciba-Geigy Corporation and Merck \& Company
Conflicts: None reported
Language: English

\section{Risk of bias}

\begin{tabular}{|c|c|c|}
\hline Bias & Authors' judgement & Support for judgement \\
\hline $\begin{array}{l}\text { Random sequence genera- } \\
\text { tion (selection bias) }\end{array}$ & Unclear risk & "Members ... randomly assigned to a study group or a control group" \\
\hline $\begin{array}{l}\text { Allocation concealment } \\
\text { (selection bias) }\end{array}$ & Unclear risk & Not reported \\
\hline $\begin{array}{l}\text { Blinding (performance } \\
\text { bias and detection bias) } \\
\text { All outcomes }\end{array}$ & Low risk & $\begin{array}{l}\text { "The study group was told that the videotapes were part of a patient educa- } \\
\text { tion program but not that medication compliance was being assessed" }\end{array}$ \\
\hline $\begin{array}{l}\text { Incomplete outcome data } \\
\text { (attrition bias) } \\
\text { All outcomes }\end{array}$ & Low risk & Of 205 surveys mailed, 97 (47\%) were returned \\
\hline $\begin{array}{l}\text { Selective reporting (re- } \\
\text { porting bias) }\end{array}$ & Low risk & All outcomes reported \\
\hline
\end{tabular}

\section{Schectman 1994}

\section{Study characteristics}

$\begin{array}{ll}\text { Methods } & \text { Parallel randomised controlled clinical trial } \\ & \text { Randomisation ratio: } 1: 1\end{array}$




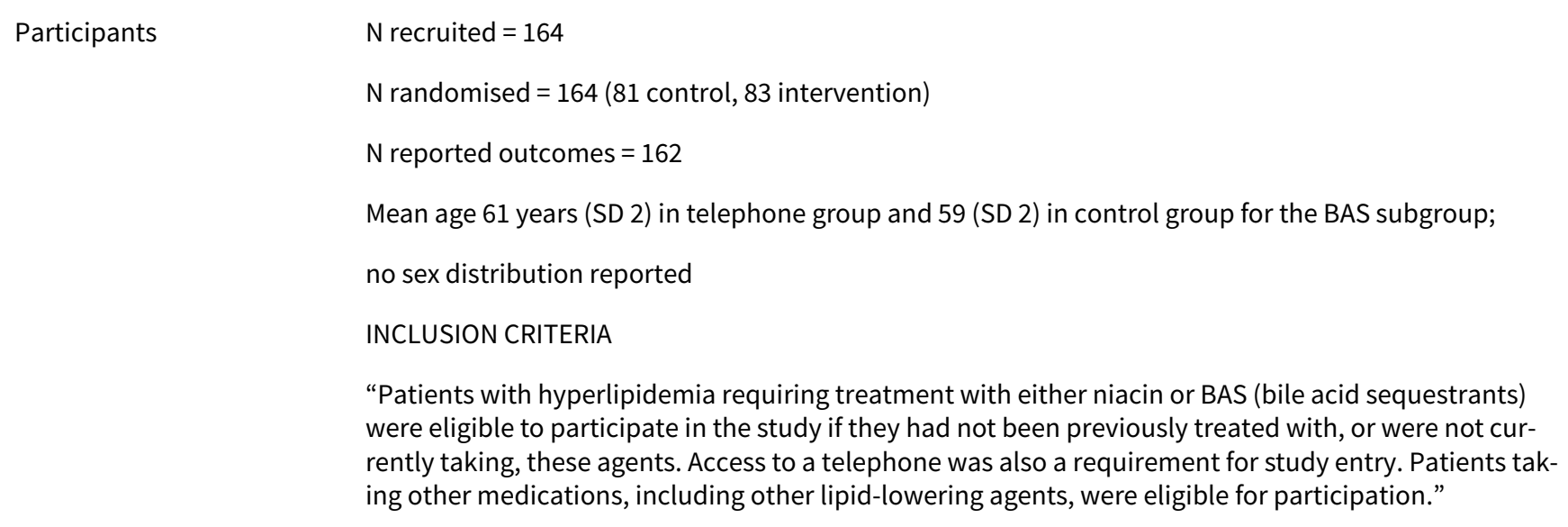

\section{EXCLUSION CRITERIA}

No additional exclusion criteria stated.

COUNTRY/SETTING: USA

STUDY PERIOD: September 1990 to September 1991

Interventions Number of study centres: 1 active lipid clinic

\section{INTERVENTION GROUP}

"Patients randomized to the telephone contact group received five telephone calls within one month after drug therapy was started."

CONTROL GROUP

"The control group received no telephone calls."

Outcomes

"The drug discontinuance rate was defined as the percentage of patients unable to continue therapy because of noxious adverse effects. Tolerance was calculated as one minus the drug discontinuance rate, and was defined as the ability of the patient to continue the medication, regardless of whether any adverse effects were experienced."

"Patient compliance was estimated by two different methods. First, patients were routinely asked at the clinical interview: "Patients often find it hard to take all of their medication without missing any doses. During the past week, how many doses of your medication have you missed?" The answer was recorded and then entered into the database. The second method employed a computerized check on the pharmacy prescription record. Because patients received all their medications on a monthly basis from the VAMC pharmacy, adherence was estimated by dividing the number of prescription refills by the duration of drug therapy."

PRIMARY OUTCOMES: drug discontinuation, adherence, final dosage

\section{Publication details}

Commercial funding/non-commercial funding/other funding: "This work was supported through HSR\&D Grant 77-33-05P from the Veterans Administration, and through a grant from the Squibb-Bristol Company."

\section{Stated aim for study}

"We conducted a prospective, randomized, controlled study to determine whether telephone contact by an allied healthcare professional could improve patient acceptability and adherence to drug therapy with nicotinic acid and BAS.“ 
Schectman 1994 (Continued)

Risk of bias

\begin{tabular}{|c|c|c|}
\hline Bias & Authors' judgement & Support for judgement \\
\hline $\begin{array}{l}\text { Random sequence genera- } \\
\text { tion (selection bias) }\end{array}$ & Unclear risk & $\begin{array}{l}\text { "Patients were randomized into two groups by the study coordinator: the tele- } \\
\text { phone contact group and the control group" }\end{array}$ \\
\hline $\begin{array}{l}\text { Allocation concealment } \\
\text { (selection bias) }\end{array}$ & Unclear risk & Not reported \\
\hline $\begin{array}{l}\text { Blinding (performance } \\
\text { bias and detection bias) } \\
\text { All outcomes }\end{array}$ & Low risk & $\begin{array}{l}\text { "Lipid clinic staff were not made aware of the group assignment, and were in- } \\
\text { structed not to ask patients on subsequent visits whether they had been tele- } \\
\text { phoned. Similarly, patients were instructed not to report that they had re- } \\
\text { ceived telephone contact unless specific interventions were performed neces- } \\
\text { sitating awareness of the staff." }\end{array}$ \\
\hline $\begin{array}{l}\text { Incomplete outcome data } \\
\text { (attrition bias) } \\
\text { All outcomes }\end{array}$ & Low risk & $\begin{array}{l}\text { "Two subjects prescribed BAS and randomized to telephone contact moved } \\
\text { shortly after randomization and did not attend subsequent clinic visits. These } \\
\text { subjects were withdrawn from the study and are not included in the data } \\
\text { analysis. Completing the study were } 102 \text { patients prescribed niacin and } 60 \text { pa- } \\
\text { tients prescribed BAS." }\end{array}$ \\
\hline $\begin{array}{l}\text { Selective reporting (re- } \\
\text { porting bias) }\end{array}$ & Low risk & All outcomes reported \\
\hline
\end{tabular}

Selak 2014

\section{Study characteristics}

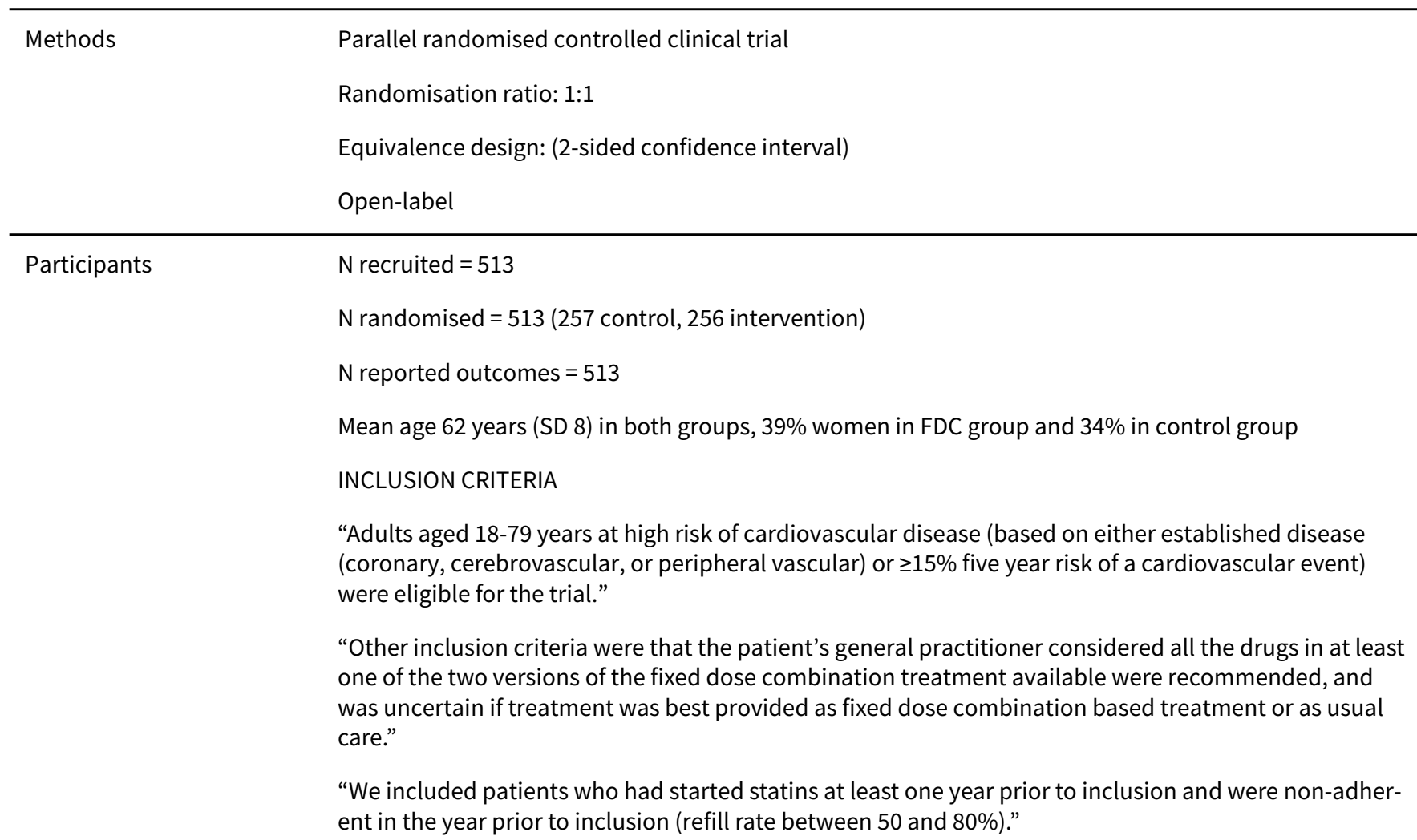


Selak 2014 (Continued)

\section{EXCLUSION CRITERIA}

"Exclusion criteria were contraindications to any of the components of the fixed dose combination, congestive heart failure, haemorrhagic stroke, active stomach or duodenal ulcer, receipt of an oral anticoagulant, concerns by the general practitioner about the risk to a patient of changing his or her cardiovascular disease drugs, impending alteration of a drug regimen for an important length of time (for example, planned coronary bypass graft operation), or the participant was unlikely to complete the trial or the trial procedures (for example, terminal illness)."

\section{COUNTRY/SETTING: New Zealand}

STUDY PERIOD: Randomisation between July 2010 and July 2012, follow-up concluded in August 2013

Interventions

Number of study centres: 54 general practices in the Auckland and Waikato regions of New Zealand.

CONTROL GROUP

"After randomisation, the participant's cardiovascular drugs were reviewed by their usual general practitioner (who was encouraged to manage the participants irrespective of treatment allocation in accordance with New Zealand cardiovascular disease risk assessment and management guidelines). Changes or additions to a cardiovascular drug regimen were at the discretion of the general practitioner, who remained the principal ongoing healthcare provider, including overseeing the use of fixed dose combination treatment where appropriate."

\section{INTERVENTION GROUP}

"General practitioners had the choice of two fixed dose combinations. Both contained aspirin $75 \mathrm{mg}$, simvastatin $40 \mathrm{mg}$, and lisinopril $10 \mathrm{mg}$, with atenolol $50 \mathrm{mg}$ additionally added to one combination and hydrochlorothiazide $12.5 \mathrm{mg}$ to the other. General practitioners could select the combination to use, change combinations, or discontinue treatment at any stage during the trial. There were no limitations on the use of any concomitant (including cardiovascular) drugs the general practitioners considered appropriate. Fixed dose combination treatment was prescribed according to the general practitioner's usual method."

Outcomes PRIMARY OUTCOME: Adherence

SECONDARY OUTCOME: mean change in LDL

Notes Publication details

Commercial funding/non-commercial funding/other funding: "The trial was funded by project grants from: New Zealand Health Research Council (06/582, 12/889), National Heart Foundation of New Zealand (1376), New Zealand Lotteries Grants Board (230904-310308), the Elsie Shrimpton Fund (University of Auckland), PHARMAC (New Zealand's Pharmaceutical Management Agency; A499735QA24208), Te Kupenga Hauora Māori (University of Auckland), Auckland regional district health boards (Auckland, Counties Manukau, and Waitemata; 12/889), the Faculty Research Development Fund (University of Auckland), and the Auckland Medical Research Foundation."

\section{Stated aim for study}

"The IMPACT (IMProving Adherence using Combination Therapy) trial was designed to evaluate whether fixed dose risk factors in people with established cardiovascular disease or at similarly high risk treated in primary care, where the majority of care for patients with vascular disease occurs."

\section{Risk of bias}

\begin{tabular}{lll}
\hline Bias & Authors' judgement & Support for judgement \\
\hline $\begin{array}{ll}\text { Random sequence genera- } \\
\text { tion (selection bias) }\end{array}$ & Low risk & $\begin{array}{l}\text { A central randomisation service randomly assigned (1:1) participants to fixed } \\
\text { dose combination based treatment or usual care. A minimisation algorithm in- } \\
\text { cluded the stratification factors: primary health organisation (these provide } \\
\text { business management and quality of care services to groups of general prac- }\end{array}$ \\
\end{tabular}


Selak 2014 (Continued)

tices), history of cardiovascular disease (yes or no), self-reported adherence to recommended drugs (antiplatelet, statin, and $\geq 2$ blood pressure-lowering drugs; yes or no), and ethnicity (indigenous Māori or non-Māori).

\begin{tabular}{|c|c|c|}
\hline $\begin{array}{l}\text { Allocation concealment } \\
\text { (selection bias) }\end{array}$ & Low risk & See above \\
\hline $\begin{array}{l}\text { Blinding (performance } \\
\text { bias and detection bias) } \\
\text { All outcomes }\end{array}$ & Unclear risk & Unblinded open-label study \\
\hline $\begin{array}{l}\text { Incomplete outcome data } \\
\text { (attrition bias) } \\
\text { All outcomes }\end{array}$ & Low risk & $\begin{array}{l}\text { "Between July } 2010 \text { and July 2012, we screened and randomised } 513 \text { (from } 91 \\
\text { general practitioners) of } 814 \text { potentially eligible patients invited by their doc- } \\
\text { tors to participate in the trial and who had provided written informed consent. } \\
\text { The median duration of follow-up was } 23 \text { months in both arms. Follow-up con- } \\
\text { cluded in August } 2013,12 \text { months after the last participant was randomised, as } \\
\text { planned. Primary outcome data were available for } 95-97 \% \text { of participants." }\end{array}$ \\
\hline $\begin{array}{l}\text { Selective reporting (re- } \\
\text { porting bias) }\end{array}$ & Low risk & All outcomes reported \\
\hline
\end{tabular}

Sweeney 1991

\section{Study characteristics}

\begin{tabular}{ll}
\hline Methods & Parallel randomised controlled clinical trial \\
& Randomisation ratio: $\sim 1: 1$ \\
& Equivalence design: (2-sided confidence interval) \\
& Open-label \\
\hline
\end{tabular}

Participants
N recruited $=98$
N randomised $=98$ (39 control, 49 intervention)
Mean age 55.3 years (SD 1.9) in the Bar group and 55.5 years (SD 1.8) in the Powder group
$49 \%$ men in the Bar group and $44 \%$ in the Powder group
INCLUSION CRITERIA

"Male and female subjects, 23 to 78 years of age, with hypercholesterolemia greater than the 90th percentile for LDL or total cholesterol were recruited."

\section{EXCLUSION CRITERIA}

"Subjects who had significant hypertriglyceridemia (more than $200 \mathrm{mg} / \mathrm{dL}$ ), major gastrointestinal disorders, intolerance to bile acid-binding resins, or metabolic disorders were excluded."

COUNTRY/SETTING: two sites: Emory Health Enhancement Program, Emory University in Atlanta, Georgia, and YMCA Cardiac Rehabilitation Center in Palo Alto, California, USA

STUDY PERIOD: Not reported

Interventions Number of study centres: 2


"After baseline medical history, physical examination, and comprehensive laboratory studies were obtained, all subjects were enrolled in a diet-only intervention phase utilizing the American Heart Association Step I diet for at least 6 weeks prior to randomization to medication. The diet composition was as follows: $15 \%$ protein, $55 \%$ carbohydrate, $30 \%$ fat, and $300 \mathrm{mg}$ or less of dietary cholesterol per day. Subjects were instructed in the diet by experienced dietitians at the beginning of this period, and blood lipid levels were measured every 2 weeks. Serum cholesterol levels were maintained to within $10 \%$ of previous values for at least two visits prior to randomization."

\section{INTERVENTION AND CONTROL GROUPS}

"Subjects who qualified were randomly assigned to receive cholestyramine powder (two 4-g packets, twice daily) or confectionery bars (two 4-g bars, twice daily). Medication was taken in the morning and evening within $1 / 2$ hour of a meal. Subjects had their choice of a mint- or maple-flavored bar, but were not permitted to switch flavors once the trial had begun. This comparative phase lasted for 8 weeks."

Outcomes

"Compliance to treatment was determined at each 2-week visit by counting the number of packets or bars not consumed and subtracting this from the amount of medication that had been dispensed. This number was divided by the amount that should have been consumed and multiplied by 100 , yielding percent compliances."

PRIMARY OUTCOMES: lipid changes, compliance

SECONDARY OUTCOMES: changes in haemodynamic data and body weight

Notes Publication details

"This work was supported by a research grant from Bristol-Myers U.S. Pharmaceutical Group."

\section{Stated aim for study}

"The purpose of the study was to compare the powder and the bar forms of cholestyramine to determine efficacy and patient compliance."

\section{Risk of bias}

\begin{tabular}{|c|c|c|}
\hline Bias & Authors' judgement & Support for judgement \\
\hline $\begin{array}{l}\text { Random sequence genera- } \\
\text { tion (selection bias) }\end{array}$ & Unclear risk & $\begin{array}{l}\text { "Subjects who qualified were randomly assigned to receive cholestyramine } \\
\text { powder (two 4-g packets, twice daily) or confectionery bars (two 4-g bars, } \\
\text { twice daily)" }\end{array}$ \\
\hline $\begin{array}{l}\text { Allocation concealment } \\
\text { (selection bias) }\end{array}$ & Unclear risk & Not reported \\
\hline $\begin{array}{l}\text { Blinding (performance } \\
\text { bias and detection bias) } \\
\text { All outcomes }\end{array}$ & Unclear risk & Unblinded open-label study \\
\hline $\begin{array}{l}\text { Incomplete outcome data } \\
\text { (attrition bias) } \\
\text { All outcomes }\end{array}$ & Low risk & $\begin{array}{l}\text { "Overall, five of } 39 \text { subjects taking powder and six of } 49 \text { subjects taking bar } \\
\text { prematurely discontinued the study. Of the five powder subjects, two were } \\
\text { noncompliant, one had an intercurrent illness after } 64 \text { days, one had an aller- } \\
\text { gic reaction after } 14 \text { days, and one experienced a syncopal episode of undeter- } \\
\text { mined etiology after } 14 \text { days of therapy. Two of the six bar subjects were non- } \\
\text { compliant, two experienced "heartburn" after approximately } 14 \text { days, one had } \\
\text { epigastric pain after } 13 \text { days, and one disliked the bar and discontinued thera- } \\
\text { py after } 5 \text { days. Eighty-three patients completed the study." }\end{array}$ \\
\hline
\end{tabular}

Selective reporting (re- Low risk $\quad$ All outcomes reported
porting bias)




\section{Study characteristics}

$\begin{array}{ll}\text { Methods } & \text { Parallel cluster-randomised controlled trial } \\ & \text { Block design with randomly-selected block sizes of 6, 8, and } 12 \\ \text { Equivalence design: (2-sided confidence interval) }\end{array}$

Participants

$\mathrm{N}$ recruited $=2293$

$\mathrm{N}$ randomised $=2293$ (1127 control, 1166 intervention)

$\mathrm{N}$ reported outcomes $=2293$

Mean age 73.2 yrs (SD 8.6) in control group, 73.0 yrs (SD 8.6) in intervention group and 73.1 yrs (SD 8.6) combined

$61.5 \%$ women

INCLUSION CRITERIA

"59 physicians and 15,486 patients in the MOXXI primary care research program (National EHR). 6372 patients had public drug insurance, and $2293(36.0 \%)$ of these patients had active lipid-lowering or antihypertensive drugs at the index visit."

"Patients were eligible for the study if they and their physicians had consented to participate in the MOXXI research program, they were insured with the provincial drug insurance program, and they had at least 1 active lipid-lowering or antihypertensive drug prescribed by the study physician in the 3 months prior to the index visit."

\section{EXCLUSION CRITERIA}

No specific exclusion criteria listed

COUNTRY/SETTING: Quebec, Canada

STUDY PERIOD: study started in April 2006

Interventions INTERVENTION GROUP

"In the intervention group, the primary care physician was provided with the drug profile: the patient's list of current prescribed and dispensed drugs, total costs of medications dispensed each month, the amount of out-of-pocket expenditures paid by the patient (deductibles and copayments), graphic representation of unfilled prescriptions, and days of drug supply for each medication, based on the start and end dates of dispensed medications. At each visit, patient adherence to lipid-lowering and antihypertensive drugs was calculated based on drugs dispensed in the past 3 months. If treatment adherence was less than $80 \%$, the physician received an alert to check for potential adherence problems."

\section{CONTROL GROUP}

"In the control group, the primary care physician had access only to the current list of prescribed and dispensed drugs and did not receive alerts when patient adherence was less than $80 \% . "$

Outcomes

"Each patient was followed for 6 months after the index visit to assess the primary (drug profile review, change in therapy) and secondary study outcomes (medication adherence)"

Notes

Aim: "To determine if a cardiovascular medication tracking and nonadherence alert system, incorporated into a computerized health record system, would increase drug profile review by primary care physicians, increase the likelihood of therapy change, and improve adherence with antihypertensive and lipid-lowering drugs." 
Tamblyn 2009 (Continued)

Funding: N/A

Conflicts: None reported

Language: English

\section{Risk of bias}

\begin{tabular}{lll}
\hline Bias & Authors' judgement & Support for judgement \\
\hline $\begin{array}{ll}\text { Random sequence genera- } \\
\text { tion (selection bias) }\end{array}$ & Low risk & $\begin{array}{l}\text { "Patients within a primary care physician's practice were randomized to the } \\
\text { intervention or control group." "The central database server conducted re- } \\
\text { al-time assessment of patent eligibility at the first visit after the start of the } \\
\text { study in April 2006, and eligible patients were randomized to intervention or } \\
\text { control groups using a randomized block design with randomly selected block } \\
\text { sizes of } 6,8, \text { and 12." }\end{array}$
\end{tabular}

\begin{tabular}{lll}
\hline $\begin{array}{l}\text { Allocation concealment } \\
\text { (selection bias) }\end{array}$ & Low risk
\end{tabular}

(selection bias)

\begin{tabular}{|c|c|c|}
\hline $\begin{array}{l}\text { Blinding (performance } \\
\text { bias and detection bias) } \\
\text { All outcomes }\end{array}$ & High risk & $\begin{array}{l}\text { Single-blinded study design; "Physicians and patients were blind to the out- } \\
\text { come assessed but not intervention status ... In particular, we suspect that } \\
\text { physicians were more vigilant" }\end{array}$ \\
\hline
\end{tabular}

Incomplete outcome data $\quad$ Unclear risk $\quad$ Not reported
(attrition bias)

All outcomes

Selective reporting (re- Low risk $\quad$ All outcomes reported
porting bias)

\section{Thom 2013}

\section{Study characteristics}

\begin{tabular}{ll} 
Methods & Parallel randomised controlled clinical trial \\
& Randomisation ratio: $1: 1$ \\
& Equivalence design: (2-sided confidence interval) \\
Open-label & \\
\hline $\mathrm{N}=2138$ screened \\
$\mathrm{N}=2004$ randomised (1002 control, 1002 intervention) \\
Participants 1921 reported outcomes for adherence \\
Mean Age 62.1 yrs (SD 10.4) in the FDC group and 61.6 yrs (SD 10.8) in the control group \\
$81.5 \%$ men in the FDC group and $82.3 \%$ in the control group \\
INCLUSION CRITERIA \\
"[Patients] aged 18 years or older with high cardiovascular risk, defined as either established CVD (his- \\
tory of coronary heart disease, ischemic cerebrovascular disease, or peripheral vascular disease) or an \\
estimated 5-year CVD risk of $15 \%$ or greater; the risk score included age, sex, SBP, ratio of total to high- \\
density lipoprotein cholesterol (HDL-C), diabetes, smoking, and a 5\% adjustment for people \\
from the Indian subcontinent"
\end{tabular}


Thom 2013 (Continued)

\section{EXCLUSION CRITERIA}

$\mathrm{N}=134$ excluded (62 - cardiovascular risk too low, 38 - medication switch contraidicated, 18 - clinically unstable, 11 - patient changed plans, 5 - other)

COUNTRY/SETTING: India; London, England; Dublin, Ireland; and Utrecht, the Netherlands

STUDY PERIOD: Randomization between July 2010 and July 2011

Interventions

Random assignment to a FDC strategy ( $n=1002$ ) containing either (1) $75 \mathrm{mg}$ aspirin, $40 \mathrm{mg}$ simvastatin, $10 \mathrm{mg}$ lisinopril, and $50 \mathrm{mg}$ atenolol or (2) $75 \mathrm{mg}$ aspirin, $40 \mathrm{mg}$ simvastatin, $10 \mathrm{mg}$ lisinopril, and 12.5 $\mathrm{mg}$ hydrochlorothiazide or to usual care $(\mathrm{n}=1002)$.

"Participants attended clinic visits for randomization, at 12 months, and at the end of the study. Telephone or clinic visits were conducted at 1 month, 6 months, and 18months. Self-reported adherence to all medications was recorded as the number of days medication was taken in the week prior to the visit (value between 0-7 days). During trial contacts, the research team asked about barriers to adherence, quality of life (measured using the self-administered EQ-5D questionnaire19), cardiovascular and other serious adverse events, and reasons for stopping cardiovascular medications."

Outcomes

PRIMARY OUTCOMES: "Primary outcomes included adherence to indicated medications (defined as taking the medication for at least 4 days during the week preceding the visit) at baseline and at the end of the trial and changes in SBP and LDL-C from baseline to the end of the trial."

SECONDARY OUTCOMES: "Secondary outcomes: 12 month adherence, reasons for stopping medications, quality of life, serious adverse events, and changes in total cholesterol, HDL-C, triglycerides, and creatinine from baseline to 12 months and end of study and cardiovascular events (including coronary heart disease, heart failure leading to death or hospital admission, and cerebrovascular or peripheral arterial disease events)"

Notes

Aim: "To assess whether FDC delivery of aspirin, statin, and 2 blood pressure-lowering agents vs usual care improves long-term adherence to indicated therapy and 2 major CVD risk factors, systolic blood pressure (SBP) and low-density lipoprotein cholesterol (LDL-C)."

Funding: "The project was funded by the European Commission Seventh Framework Programme (grant 241849). Dr. Reddy's Laboratories (Hyderabad, India) provided the FDCs and supported the trial start-up meetings in London and India."

Conflicts: None reported

Language: English

\section{Risk of bias}

\begin{tabular}{lll}
\hline Bias & Authors' judgement & Support for judgement \\
\hline $\begin{array}{ll}\text { Random sequence genera- } \\
\text { tion (selection bias) }\end{array}$ & Low risk & "Randomization to FDC or usual care was conducted in a 1:1 ratio and alloca- \\
& & $\begin{array}{l}\text { tion was stratified by site and by the presence or absence of established CVD } \\
\text { using a web-based clinical data management system (InForm; PhaseForward } \\
\text { Inc)" }\end{array}$
\end{tabular}

\begin{tabular}{lll}
\hline $\begin{array}{l}\text { Allocation concealment } \\
\text { (selection bias) }\end{array}$ & Low risk & See above \\
\hline $\begin{array}{l}\text { Blinding (performance } \\
\text { bias and detection bias) }\end{array}$ & Unclear risk & Unblinded open-label study \\
$\begin{array}{ll}\text { All outcomes } \\
\text { Incomplete outcome data }\end{array}$ & Low risk & "The trial had $90 \%$ power overall to detect difference. Estimates all assumed ... \\
$\begin{array}{l}\text { (attrition bias) } \\
\text { All outcomes }\end{array}$ & up to 10\% of patients having died or been lost to follow-up" \\
\hline
\end{tabular}


Thom 2013 (Continued)

Selective reporting (re- Low risk All outcomes reported
porting bias)

Vollmer 2014

\section{Study characteristics}

\begin{tabular}{ll}
\hline Methods & Randomised controlled clinical trial (RCT) \\
& Randomisation ratio: 1:1:1 \\
& Equivalence design: (2-sided confidence interval) \\
& Open label \\
\hline
\end{tabular}

Participants

$\mathrm{N}$ recruited $=45,051$

$\mathrm{N}$ randomised $=21,752$ (7255 control, 7247 IVR, 7250 IVR+) for all, 16,380 for statins, and 13,063 for ACEi/ ARB

$N$ reported outcomes: Statin adherence $=16,366$ and LDL levels $=13,776$

Mean age 63.6 yrs (SD 12.2), 53\% men

INCLUSION CRITERIA

$\geq 40$ years old (Mean age 63.6)

"Using each region's EMR, we identified participants 40 years and older with diabetes mellitus and/or cardiovascular disease (CVD), suboptimally $(<90 \%)$ adherent to a statin or ACEI/ARB during the previous 12 months, and due or overdue for a refill"

\section{EXCLUSION CRITERIA}

"We excluded only individuals with medical conditions that might contraindicate the use of these medications, such as medication allergies, liver failure, cirrhosis, rhabdomyolysis, end-stage renal disease, chronic kidney disease and those on KP's "do not contact" list."

COUNTRY/SETTING: 3 regions of the Kaiser Permanente (KP) health plan-Northwest (KPNW), Hawaii (KPH), and Georgia (KPG), USA

STUDY PERIOD: "Study enrollment began in December 2011 and continued through May 2012. Intervention and outcome assessment continued through November 2012."

Number of study centres: 3 regions of the Kaiser Permanente (KP) health plan-Northwest (KPNW), Hawaii (KPH), and Georgia (KPG)

\section{CONTROL GROUP}

"UC participants had access to the full range of usual services, including each region's normal education and care management outreach efforts to encourage statin and ACEI/ARB use."

\section{INTERVENTION GROUPS}

Interactive Voice Recognition (IVR) Calls

"VR participants received automated phone calls when they were due or overdue for a refill. The calls used speech-recognition technology to educate patients about their medications and help them refill prescriptions (we created separate "refill" and "tardy" calls). The flow of each call was determined by participants' responses; each call lasted 2 to 3 minutes. At randomization, IVR participants received a pamphlet explaining these calls. 
Vollmer 2014 (Continued)

Both call types offered a transfer to KP's automated pharmacy refill line. The tardy call also offered a transfer to a live pharmacist. With permission, obtained at the first successful call contact, the program left detailed messages on answering machines or with another household member."

\section{Enhanced IVR (IVR+)}

"In addition to IVR calls, participants in the IVR+ arm received a personalized re-minder letter if they were 60 to 89 days overdue and a live outreach call if they were $\geq 90$ days overdue, as well as EMR-based feedback to their primary care provider. IVR+ participants received additional materials, including a personalized health report with their latest BP and cholesterol levels, a pill organizer, and bimonthly mailings."

"We used a modified version of the Proportion of Days Covered (PDC),16 defined from pharmacy dis-
pensing records, for our primary measure. Because we were measuring adherence to chronic medica-
tions patients were known to be taking at randomization, we modified the PDC (mPDC) to include the
whole follow- up period as the denominator time frame rather than time from first dispensing.17 We
accounted for medication on hand at randomization and ignored any medication remaining at the end
of follow-up. We computed mPDCs separately for statins and ACEl/ARBs."

PRIMARY OUTCOMES: medication adherence

SECONDARY OUTCOMES: lipid Levels, blood pressure

Notes

Commercial funding/non-commercial funding/other funding: "This project was supported by grant number R01HS019341 from the Agency for Healthcare Research and Quality."

Stated aim for study: "Evaluate the utility of 2 electronic medical record (EMR)-linked, automated phone reminder interventions for improving adherence to cardiovascular disease medications."

\section{Risk of bias}

\begin{tabular}{|c|c|c|}
\hline Bias & Authors' judgement & Support for judgement \\
\hline $\begin{array}{l}\text { Random sequence genera- } \\
\text { tion (selection bias) }\end{array}$ & Low risk & $\begin{array}{l}\text { "Computer-generated randomization assignments were stratified by region } \\
\text { and blocked to assure balance across treatment arms" }\end{array}$ \\
\hline $\begin{array}{l}\text { Allocation concealment } \\
\text { (selection bias) }\end{array}$ & Low risk & See above \\
\hline $\begin{array}{l}\text { Blinding (performance } \\
\text { bias and detection bias) } \\
\text { All outcomes }\end{array}$ & Unclear risk & Unblinded open-label study \\
\hline $\begin{array}{l}\text { Incomplete outcome data } \\
\text { (attrition bias) } \\
\text { All outcomes }\end{array}$ & Low risk & 16,380 randomised for statins with adherence data for 16,366 at end of study \\
\hline $\begin{array}{l}\text { Selective reporting (re- } \\
\text { porting bias) }\end{array}$ & Low risk & All outcomes reported \\
\hline
\end{tabular}

Vrijens 2006

\section{Study characteristics}

Methods

Parallel cluster-randomised controlled clinical trial

Randomisation ratio: 1:1 
Vrijens 2006 (Continued)

Equivalence design: (2-sided confidence interval)

Open-label

Participants
N recruited = 429
N reported outcomes = 392
Mean age 61.9 yrs (SD 9.9) in the intervention group and 60.4 yrs (SD 10.2) in the control group
$55 \%$ men in the intervention group and 46\% in the control group
INCLUSION CRITERIA
"All patients, aged 18 years or above, who had been taking atorvastatin for at least 3 months, and who
had no contraindications to continuation of the treatment, could be included in the study provided
they usually got their medication in one of the pharmacies participating in the study."
EXCLUSION CRITERIA
None reported
COUNTRY/SETTING: Belgium
STUDY PERIOD: Patients enrolled between 13 February 2000 and 26 June 2002

Interventions Number of study centres: 35 pharmacies

"In each linguistic region, one district was randomized to deliver care as usual (control group), while in the other district a patient intervention through a pharmaceutical care program was implemented (intervention group)."

"The supportive intervention program consisted of review by the patients' pharmacist, jointly with the patient, of the electronically compiled dosing history, a 'beep-card' that reminds patient of the dosing time, and educational reminders. In the intervention group, the pharmacist delivered an educational message at each follow-up visit, updated the 'compliance passport' and analyzed, together with the patient, the electronically compiled dosing history of the past month/ 3 months."

Outcomes

"The primary outcome parameter is 'post-baseline adherence' to prescribed therapy defined for each patient as the proportion of days during which the MEMS record showed that the patient had opened the pill container. The estimation of this variable started from the second pharmacy visit until an arbitrary cut-off point of 300 days after inclusion. 'Baseline adherence' is estimated between inclusion and the second visit to the pharmacy.

Adherence can vary in many different ways over time. Summarizing the history in just one measure may hide important features of adherence patterns, especially potential changes over time. We captured the temporal evolution of daily adherence to study this clinically relevant aspect of dosing history data.

Further we found it useful to define persistence as the length of time between onset and discontinuation of treatment execution."

PRIMARY OUTCOMES: adherence, persistence

Notes Publication details

Commercial funding/non-commercial funding/other funding: "No conflict of interest was declared. Contract grant sponsor: Pfizer Belgium, Boulevard de la Plaine 17, BE 1050 Bruxelles-Ixelles, Belgium."

\section{Stated aim for study}


Vrijens 2006 (Continued)

"The objective of this study was to estimate the effect of a pharmaceutical care program on the adherence of once-daily atorvastatin treatment in patients with elevated cholesterol levels."

\section{Risk of bias}

Bias Authors' judgement Support for judgement

Random sequence genera- Unclear risk tion (selection bias)

\begin{abstract}
"In each linguistic region, one district was randomized to deliver care as usual (control group), while in the other district a patient intervention through a pharmaceutical care program was implemented (intervention group)"

"While we realize that there might be bias in the selection of the participating patients resulting three of the nine baseline variables being statistically significantly different between the two groups, the intervention effect remained significant in a multiple Cox regression analysis controlling for the baseline variables"
\end{abstract}

\begin{tabular}{lll}
\hline $\begin{array}{l}\text { Allocation concealment } \\
\text { (selection bias) }\end{array}$ & Unclear risk See above \\
\hline
\end{tabular}

\begin{tabular}{lll}
$\begin{array}{l}\text { Blinding (performance } \\
\text { bias and detection bias) } \\
\text { All outcomes }\end{array}$ & Unclear risk & \\
\hline $\begin{array}{l}\text { Incomplete outcome data } \\
\text { (attrition bias) }\end{array}$ & Low risk & $\begin{array}{l}\text { "Between } 13 \text { February } 2000 \text { and } 26 \text { June 2002, } 429 \\
\text { subjects were entered into the study, of whom } 37 \\
\text { did not visit the pharmacy: hence, a total of } 392 \text { subjects are included in the } \\
\text { ITT set, of whom } 194 \\
\text { attended pharmacies that employed adherence enhancing interventions and } \\
\text { 198 subjects had no intervention" }\end{array}$
\end{tabular}

\begin{tabular}{ll}
\hline $\begin{array}{l}\text { Selective reporting (re- } \\
\text { porting bias) }\end{array}$ & Low risk outcomes reported \\
\hline
\end{tabular}

\section{Study characteristics}

\begin{tabular}{ll}
\hline Methods & Parallel randomised controlled clinical trial \\
& Randomisation ratio: $1: 1$ \\
& Equivalence design: 2 -sided confidence interval \\
& Open-label not reported \\
\hline Participants & N recruited $=303$ \\
& N randomized $=303$ (152 control, 151 intervention) \\
& N reported outcomes $=301$ (151 control, 150 intervention) \\
& Median age 60 yrs (range $54-68)$ in the intervention group and 61 yrs $(49-69)$ in the control group \\
& $55 \%$ men in the intervention and $54 \%$ in the control group \\
INCLUSION CRITERIA
\end{tabular}


Wald 2014 (Continued)

"patients who owned a mobile telephone with text message capability and who had been prescribed blood pressure and/or lipid-lowering medication"

EXCLUSION CRITERIA

None reported

COUNTRY/SETTING: 7 primary care practices in London, UK

STUDY PERIOD: Patients enrolled between February 2012 and August 2013, participant follow-up was completed in March 2014

Number of study centres: 7 primary care practices in London
INTERVENTION GROUP
"Texts were sent daily for 2 weeks, alternate days for 2 weeks and weekly thereafter for 22 weeks (6
months overall), using an automated computer program."

CONTROL GROUP

No text reminders sent.

Outcomes TIME OF OUTCOME MEASUREMENTS: "At 6 months, use of medication was assessed." Cholesterol and blood pressure was also measured.

PRIMARY OUTCOMES: "Medication use at 6 months, exceeding $80 \%$ of the prescribed regimen. Medication use was usually determined by personal enquiry at clinic visits, or failing that, using general practice electronic prescription records. Patients were asked whether they had stopped taking their medication and if not, the number of days in the previous 28 days that medication had been missed."

SECONDARY OUTCOMES: "Secondary outcomes were i) the proportion of patients continuing their medication regardless of the number of days missed and ii) among those continuing, the proportion taking $>80 \%$ of their prescribed regimen." "Blood pressure measurements were taken at 6 months in patients on blood pressure lowering medication at randomization and similarly, serum cholesterol (total and LDL) in patients on cholesterol lowering medication at randomization."

Notes

Commercial funding/non-commercial funding/other funding: none reported

Stated aim for study: "to assess the value of text messaging as a means of improving medication adherence in patients receiving blood pressure and/or lipid-lowering treatment for the prevention of cardiovascular disease"

\section{Risk of bias}

Bias Authors' judgement Support for judgement

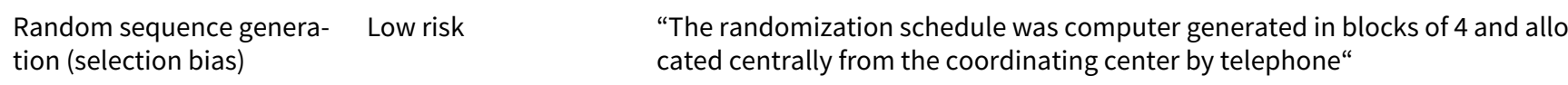

\begin{tabular}{lll}
\hline $\begin{array}{l}\text { Allocation concealment } \\
\text { (selection bias) }\end{array}$ & Unclear risk & Not reported \\
\hline $\begin{array}{l}\text { Blinding (performance } \\
\text { bias and detection bias) }\end{array}$ & Unclear risk & Not reported \\
All outcomes & \\
\hline
\end{tabular}

Incomplete outcome data Low risk "Two patients were lost to follow-up, providing data on 301 for analysis"
(attrition bias)
All outcomes


Wald 2014 (Continued)

Selective reporting (re- Low risk $\quad$ All outcomes reported
porting bias)

Willich 2009

\section{Study characteristics}

\begin{tabular}{ll}
\hline Methods & Parallel randomised controlled clinical trial \\
& Randomisation ratio: $1: 1$ \\
& Equivalence design: (2-sided confidence interval) \\
& Open-label
\end{tabular}

Participants

$\mathrm{N}$ recruited $=8108$

$\mathrm{N}$ randomised $=8108$ (4044 control, 4064 intervention)

$\mathrm{N}$ reported outcomes $=6872$

Mean age $60.8 \mathrm{yrs}$ (SD 10.41), 56.1\% men

INCLUSION CRITERIA

Low density lipoprotein cholesterol $($ LDL-C) $>115 \mathrm{mg} / \mathrm{dl}$ if statin-naïve or else $>125 \mathrm{mg} / \mathrm{dl}$

Participants were also required to have at least one of the following risk factors: history of CHD, other atherosclerotic disease, 10 -year CHD risk Z20\%, or diabetes

\section{EXCLUSION CRITERIA}

Fasting triglycerides $>400 \mathrm{mg} / \mathrm{dl}$ ( $4.5 \mathrm{mmol} / \mathrm{l})$; familial or secondary hypercholesterolaemia; active liver disease, defined as elevations of aspartate aminotransferase or alanine aminotransferase (ALT) Z1.5 upper limit of normal (ULN); creatine kinase greater than 3ULN; or unstable angina

\section{COUNTRY/SETTING: Germany}

STUDY PERIOD: Enrolment between April 2002 and February 2004

Interventions INTERVENTION GROUP

Participants in the intervention group received $10 / 20 \mathrm{mg}$ rosuvastatin in addition to a starter pack containing a videotape, an educational leaflet, details of the free phone patient helpline and website, and labels with a reminder to take study medication. Participants also received regular personalised letters and phone calls throughout the study.

CONTROL GROUP

The control group received $10 / \mathrm{m} 20$ rosuvastatin alone

Outcomes PRIMARY OUTCOMES: Long-term cumulative direct and indirect disease related costs associated with rosuvastatin treatment either with or without additional compliance programme at 12 and 36 months

SECONDARY OUTCOMES: Number (\%) of participants achieving 1998 European LDL-C and total cholesterol goals after 3, 6, and 12 months of therapy; number (\%) of participants increasing their dose of rosuvastatin at month 3; percentage change from baseline in lipids and lipoproteins; compliance with drug therapy (assessed by counting the number of pills returned by the patient at 6 and 12 months); and safety. 
Willich 2009 (Continued)

Notes

Aim: "To determine whether a compliance-enhancing program could increase the level of lipid control patients treated with rosuvastatin"

Funding: "This study was supported by a grant from AstraZeneca."

Conflicts: None reported

Language: English

\section{Risk of bias}

\begin{tabular}{|c|c|c|}
\hline Bias & Authors' judgement & Support for judgement \\
\hline $\begin{array}{l}\text { Random sequence genera- } \\
\text { tion (selection bias) }\end{array}$ & Low risk & $\begin{array}{l}\text { "For the 12-month intervention phase, consecutive patients were randomized } \\
1: 1 \text {, using a computer-generated randomization list, to receive rosuvastatin } 10 \\
\text { mg daily (manufacturer AstraZeneca GmbH, D-22876 Wedel, Germany) either } \\
\text { with or without a compliance program" }\end{array}$ \\
\hline $\begin{array}{l}\text { Allocation concealment } \\
\text { (selection bias) }\end{array}$ & Low risk & See above \\
\hline $\begin{array}{l}\text { Blinding (performance } \\
\text { bias and detection bias) } \\
\text { All outcomes }\end{array}$ & Unclear risk & Unblinded open-label study \\
\hline $\begin{array}{l}\text { Incomplete outcome data } \\
\text { (attrition bias) } \\
\text { All outcomes }\end{array}$ & Low risk & $\begin{array}{l}\text { "Assuming a } 20 \% \text { dropout rate, at least } 6608 \text { patients were required to be re- } \\
\text { cruited for } 90 \% \text { power" }\end{array}$ \\
\hline $\begin{array}{l}\text { Selective reporting (re- } \\
\text { porting bias) }\end{array}$ & Low risk & All outcomes reported \\
\hline
\end{tabular}

BAS bile acid sequestrants

BMI body mass index

BP blood pressure

CHD coronary heart disease

$\mathrm{COI}$ conflict of interest

FDC fixed-dose combination

FMD flow mediated dilatation

GEE generalised estimated equations

HDL-C high density lipoprotein cholesterol

IMT intima media thickness

ITT intention to treat

LDL-C low density lipoprotein cholesterol

MEMS Medication Event Monitoring System

MI myocardial infarction

RCT randomised controlled trial

SD standard deviation

SE standard error

TC total cholesterol

TRG triglycerides

Characteristics of excluded studies [ordered by study ID]

Study Reason for exclusion

Allen $2000 \quad$ Commentary, not RCT




\begin{tabular}{|c|c|}
\hline Study & Reason for exclusion \\
\hline Anon 2002 & Commentary, not RCT \\
\hline Athyros 2002b & Intervention not aimed at improving medication adherence \\
\hline Becker 1998 & $\begin{array}{l}\text { Intervention not aimed at improving medication adherence/ intervention aimed at improved pre- } \\
\text { scribing }\end{array}$ \\
\hline Bogden 1997 & Intervention not aimed at improving medication adherence \\
\hline Bruckert 1999 & $\begin{array}{l}\text { Inclusion criterion was patients NOT taking statin. Secondary analysis of an RCT, comparing char- } \\
\text { acteristics of compliant and non-compliant groups. }\end{array}$ \\
\hline Burkett 1990 & Intervention focused on diet. Taking statin was not an inclusion criterion. \\
\hline Casebeer 1999 & $\begin{array}{l}\text { Intervention not aimed at improving medication adherence/intervention aimed at influence physi- } \\
\text { cians' behaviour }\end{array}$ \\
\hline Coates 1982 & Intervention not aimed at improving medication adherence \\
\hline DeBusk 1994 & Study aimed at risk factor modification, not aimed at adherence to statins. \\
\hline Diabetes 2000 & Intervention not aimed at improving medication adherence \\
\hline Diwan 1995 & Intervention aimed at influence physicians' behaviour \\
\hline Dobs 1994 & Intervention not aimed at improving medication adherence \\
\hline Dunham 2000 & Study comparing different settings (primary care versus hospital) \\
\hline Ellis 2000 & Intervention not aimed at patient adherence \\
\hline Eriksson 1998 & $\begin{array}{l}\text { Intervention not aimed at improving medication adherence/adherence comparison of classes of } \\
\text { hypolipidemics }\end{array}$ \\
\hline Frances 2001 & Intervention not aimed at patient adherence \\
\hline Fretheim 2006 & Intervention not aimed at improving medication adherence \\
\hline Friedman 1998 & Intervention not aimed at medication adherence \\
\hline Gaede 1999 & Intervention not aimed at improving medication adherence \\
\hline Gaede 2003 & Intervention not aimed at improving medication adherence \\
\hline Hae 2007 & Intervention not aimed at improving medication adherence \\
\hline Ives 1993 & Intervention not aimed at improving medication adherence \\
\hline Jafari 2003 & No data available for adherence outcomes \\
\hline Jiang 2007 & Study not aimed at assessing adherence to statins \\
\hline Johannesson 1996 & Cost-effectiveness only, no adherence outcome reported \\
\hline Jolly 1998 & Not concerned with lipidaemia \\
\hline
\end{tabular}




\begin{tabular}{|c|c|}
\hline Study & Reason for exclusion \\
\hline Keyserling 1997 & Intervention not aimed at improving medication adherence \\
\hline Kirkman 1994 & Intervention not aimed at improving medication adherence \\
\hline Kjelsberg 1990 & Intervention not aimed at improving medication adherence \\
\hline Kulik 2013 & Inclusion limited only to post-MI patients \\
\hline Kuznar 2002 & Comment / no RCT design \\
\hline Lee 2007 & Aim of study was to compare different ways of measuring adherence \\
\hline Lesaffre 2000 & Not concerned with lipidaemia \\
\hline Lin 2006 & Not concerned with lipidaemia \\
\hline Lindholm 1996 & Intervention not aimed at improving medication adherence \\
\hline Merriam 1997 & Intervention not aimed at improving medication adherence \\
\hline Moher 2001 & Intervention aimed at influence prescribing \\
\hline Oi 1998 & No adherence outcome reported \\
\hline Oosterhoff 2011 & Meta-analysis \\
\hline Polack 2008 & Inclusion limited to only post-MI patients, limited sample \\
\hline Rachmani 2002 & Focus on diabetes treatment \\
\hline Rastam 1996 & Intervention not aimed at improving medication adherence \\
\hline Rindone 1998 & No adherence outcome reported \\
\hline Robin 2002 & Review \\
\hline Rodgers 2000 & Review \\
\hline Rubenfire 2004 & Intervention not aimed at improving medication adherence \\
\hline Schectman 1996 & Not all patients received drug treatment, adherence not outcome \\
\hline Scherwitz 1995 & Intervention not aimed at improving medication adherence \\
\hline Shaffer 1995 & Intervention not aimed at improving medication adherence \\
\hline Simpson 2001 & Intervention not aimed at improving medication adherence \\
\hline Toobert 2000 & Intervention not aimed at improving medication adherence \\
\hline Tsuyuki 1999 & Intervention not aimed at improving medication adherence \\
\hline Tully 2000 & No RCT design/ review \\
\hline
\end{tabular}




\begin{tabular}{ll}
\hline Study & Reason for exclusion \\
\hline Vale 2002 & $\begin{array}{l}\text { Study not aimed at improving adherence, but rather on cholesterol targets, no adherence outcome } \\
\text { reported }\end{array}$ \\
\hline Wahlstrom 1995 & $\begin{array}{l}\text { Intervention not aimed at improving medication adherence/intervention aimed at influence pre- } \\
\text { scribing }\end{array}$ \\
\hline Weymiller 2007 & Adherence outcome not reported \\
\hline Wright 2002 & Review \\
\hline Wu 2006 & Not concerned with lipidaemia \\
\hline Yigit 2004 & No ambulatory setting \\
\hline Yilmaz 2005 & Intervention not aimed at improving medication adherence \\
\hline Zermansky 2002 & Not concerned with lipidaemia \\
\hline
\end{tabular}

\section{Characteristics of studies awaiting classification [ordered by study ID]}

\section{Harrison 2015}

\begin{tabular}{ll}
\hline Methods & $\begin{array}{l}\text { "Participants were randomly assigned to either an automated telephone outreach or a control } \\
\text { group (usual care)." }\end{array}$ \\
\hline Participants & "The number randomized over 3 months was 15,254 in the control group and 15,356 in the out- \\
reach group." & "All participants were 18 years of age and older identified from a cardiovascular disease case-iden- \\
tification database. Participants had a prescription for a cholesterol-lowering agent overdue for re- & fill between 2 weeks and 6 weeks." \\
\hline Interventions & $\begin{array}{l}\text { "The outreach consisted of an automated telephone call that instructed the member to order a re- } \\
\text { fill for their overdue prescription by calling the number on their medication bottle or by using an } \\
\text { online refill system." }\end{array}$ \\
\hline "The primary outcome was refill rate at 2 weeks among the two groups. We further examined re- \\
fill rates at 2 weeks according to duration of being overdue (2 weeks to 4 weeks and 4 weeks to 6 \\
weeks)." \\
$\begin{array}{l}\text { Abstract only } \\
\text { Authors' conclusion: "This low-cost outreach intervention of automated prescription refill re- } \\
\text { minders resulted in a significant increase in refill rates. Further analyses will examine the relation- } \\
\text { ship between demographic and clinical factors and refill rates as well as mean cholesterol levels } \\
\text { and medication adherence and persistence in this population." }\end{array}$ \\
\hline Notes
\end{tabular}

\section{Johnson 2006}

$\begin{array}{ll}\text { Methods } & \text { "This study examined the effectiveness of a population-based, individualized Transtheoretical } \\ & \text { Model (TTM) expert system intervention to improve adherence and increase exercise and diet in a } \\ \text { randomized 18-month trial involving } 404 \text { adults." }\end{array}$


Johnson 2006 (Continued)

\begin{tabular}{ll} 
Participants & 404 adults \\
\hline Interventions & TTM vs usual care \\
\hline Outcomes & adherence \\
\hline Notes & $\begin{array}{l}\text { Authors conclusion: TTM expert system interventions can have a significant impact on entire popu- } \\
\text { lations for adherence. Results for dietary fat and exercise suggest covariation of treatment effects. }\end{array}$
\end{tabular}

Lee 2006

\begin{tabular}{ll} 
Methods & $\begin{array}{l}\text { After a 2-month run-in phase (measurement of baseline adherence, BP, and LDL-C), participants } \\
\text { entered a 6-month intervention phase (standardised medication education, regular follow-up } \\
\text { by pharmacists, and medications dispensed in time specific packs). Following the intervention } \\
\text { phase, participants were randomised to continued pharmacy care vs usual care for an additional } 6 \\
\text { months. }\end{array}$ \\
\hline Participants & 200 community-based people aged 65 years or older taking at least 4 chronic medications \\
\hline Interventions & $\begin{array}{l}\text { "Patients randomized to the pharmacy care group continued to meet with clinical pharmacists } \\
\text { every } 2 \text { months, as previously performed in phase } 1 \text { of the study, and were provided blister packed } \\
\text { medications and also continued medication education as needed." } \\
\text { "Usual care was defined as returning to their baseline (prestudy) status of medication provision; } \\
\text { however, medication education and blister-packed medications were not provided." }\end{array}$ \\
\hline Outcomes & $\begin{array}{l}\text { "Primary end point of the observation phase was change in the proportion of pills taken vs base- } \\
\text { line; secondary end points were the associated changes in BP and LDL-C. Primary end point of the } \\
\text { randomization phase was the between-group comparison of medication persistence." }\end{array}$ \\
\hline clinicaltrials.gov Identifier: NCT00393419
\end{tabular}

Characteristics of ongoing studies [ordered by study ID]

\section{ACTRN12616000233426}

Study name
INTEGRATE Study: A pragmatic cluster-randomised controlled trial of an integrated general prac-
tive medications among individuals at high cardiovascular risk

\begin{tabular}{ll}
\hline Methods & Randomised controlled trial \\
& Permuted block randomisation \\
& Open (masking not used)
\end{tabular}

Participants General Practice eligibility:

1. Not involved in other George Institute studies utilising HealthTracker.

2. Use of either Medical Director or Best Practice for electronic health record (EHR) management.

3. Exclusive use of these systems to record risk factors and prescribe drugs.

4. Agreement that all GPs and other designated staff are willing to use the integrated intervention. 
5. Agreement to encourage participants to fill prescriptions at a designated partner pharmacy and consider enrolment in the pharmacy adherence programme.

Pharmacy eligibility:

1. Use of an electronic dispensing software (FRED IT).

2. Agreement to stock and dispense the polypill formulations.

3. Agreement to conduct the pharmacy adherence programme.

Participant eligibility:

1. All adult patients (18 years) attending the GP will potentially be eligible to receive the HealthTracker intervention.

2. All adult patients who are recommended for the component medications according to current guidelines are eligible to be prescribed the polypill therapy.

3. All adult patients attending the paired pharmacy with a new prescription for a CVD prevention medication will be eligible to receive the pharmacy intervention.

Target sample size 4200

Interventions
70 Australian General Practice and Pharmacy pairs ( 35 intervention and 35 control) will be recruited.

Each GP/Pharmacy pair in the intervention group will be exposed to 3 interventions (HealthTracker, CVD polypills and PASS).

Each GP/pharmacy pair in the intervention arm will be encouraged to continue with the intervention for 18 months from the time the last practice is recruited (based on results from the TORPEDO study). At the end of this period, data will be collected from the GP/Pharmacy pairs in both study arms.

The integrated intervention comprises the following 3 elements: (1) HealthTracker, (2) availability of the Polypills and (3) Pharmacy Adherence Support Service (PASS).

(1) HealthTracker is an electronic decision support tool that aims to assist general practitioners in the management of cardiovascular disease (CVD) risk. It aims to promote best practice care by giving management advice to healthcare providers based on national guidelines. HealthTracker incorporates a single, extensively validated screening and management algorithm, based on a synthesis of recommendations from several guidelines for CVD, kidney disease and diabetes prevention and management. HealthTracker interfaces with Medical Director (MD) and Best Practice (BP), two clinical practice software systems that together comprise around $80 \%$ of general practice record systems in Australia. Data from the patient records in MD or BP pre-populate HealthTracker which then provides the GP point-of-care recommendations on optimal use of CVD risk preventive medications (including option of polypill), based on that patient's absolute CVD risk estimate.

(2) 8 CVD polypills will be available and they are:

(i) Name: PolyPill Hydroirb; Components: Hydrochlorothiazide (12.5 mg) + Irbesartan (150 mg) + atorvastatin $(40 \mathrm{mg})$

(ii) Name: PolyPill Hydroirb Asp; Components: Hydrochlorothiazide (12.5 mg) + Irbesartan (150 mg) + atorvastatin $(40 \mathrm{mg})+100 \mathrm{mg}$ aspirin

(iii) Name: PolyPill Amloirb; Components: Amlodipine (5 mg) + Irbesartan (150 mg) + atorvastatin (40 mg)

(iv) Name: PolyPill Amloirb Asp; Components: Amlodipine (5mg) + Irbesartan (150mg) + atorvastatin (40 mg) + aspirin (100 mg)

(v) Name: PolyPill Perindap; Components: Perindopril (4 mg) + indapamide (1.25 mg) + atorvastatin (40 mg 
(vi) Name: PolyPill Perindap Asp; Components: Perindopril (4 mg) + indapamide (1.25 mg) + atorvastatin (40 mg) + aspirin (100 mg)

(vii) Name: PolyPill Peramlo; Components: Perindopril (4 mg) + amlodipine $(5 \mathrm{mg})+$ atorvastatin (40 mg)

(viii) Name: PolyPill Peramlo Asp; Components:Perindopril (4 mg) + amlodipine (5 mg) + atorvastatin (40 mg) + aspirin (100 mg)

(3) Pharmacy Adherence Support Service (PASS): This intervention involves supporting patients with their "medication journey" by a trained pharmacist. Patients who have been prescribed a Polypill or a new CVD preventative medication will be referred by the GP to a partner Pharmacist who will firstly administer the Morisky Medication Adherence Scale (MMAS-8) for assessing medication adherence in patients presenting with new CVD preventative medication prescriptions. In patients with an MMAS score $\geq 6$, pharmacists will offer and provide to patients the PASS. PASS, is a customised adherence programme which involves a structured clinical interview (approximately 20 minutes) focused on: (i) understanding how the patient actually 'uses' their medications; (ii) understanding patient beliefs about their medications; and (iii) capturing patient-reported barriers to adherence. The structured interview is based on a modified version of the Brief Medication Questionnaire 1 (BMQ1), which will be used to systematically review and collect adherence data. Depending on the individualised recommendations, pharmacists may see enrolled patients at approximately 2 weeks (telephone discussion, 5 minutes), and during scheduled pharmacy visits at approximately 1, 3, 6 and 12 months after enrolment, to coincide with prescription refills (patients may however present each month for a regular refill of their medications). Adherence issues and barriers to medication taking will be reviewed at each visit (10 minutes). An electronic software (PASS Application) has been developed to deliver the MMAS-8 and the PASS via a Tablet/Ipad provided to Pharmacists.

The use of HealthTracker will be monitored centrally by the research team. The use of PASS will be monitored by Project Officers who will contact and visit pharmacies regularly. Fidelity measures (e.g. number of times a recommendation was clicked or the PASS intervention was delivered) will be collected throughout the study.

Outcomes

Primary outcomes:

Proportion of high-risk participants who were not on full treatment at baseline achieving recommended target (i) BP and (ii) LDL-C target levels, at the end of the study. This is a composite primary outcome. These levels will be extracted from the general practice software systems using a general practice data auditing tool known as Clinical Audit Tool (CAT). Data is de-identified prior to extraction.

\section{Definitions:}

- High CVD risk: either (i) history of CVD (diagnosis of coronary heart disease, ischaemic stroke, peripheral vascular disease); (ii) presence of any guideline-stipulated clinically high-risk conditions (diabetes and age $>60$ years, diabetes and albuminuria, stage $3 B$ chronic kidney disease (CKD), or extreme risk factor elevations - systolic $B P \geq 180 \mathrm{mmHg}$, diastolic $B P \geq 110 \mathrm{mmHg}$, total cholesterol > $7.5 \mathrm{mmol}$ ); or (3) a calculated 5-year CVD risk of > 15\% using the 1991 Anderson Framingham equation. In the TORPEDO study, this comprised $27 \%$ of the study population.

- BP and LDL-C target levels: BP $\leq 140 / 90 \mathrm{mmHg}$ in general or people with CKD; $\leq 130 / 80 \mathrm{mmHg}$ in all people with diabetes; $\leq 130 / 80 \mathrm{mmHg}$ if albuminuria (UACR greater than $2.5 \mathrm{mg} / \mathrm{mmol}$ in men and $>3.5 \mathrm{mg} / \mathrm{m}$ in women); and LDL-C $<2.0 \mathrm{mmol} / \mathrm{L}$ in all high-risk individuals.

Secondary outcomes:

1. Proportion of high-risk participants who were not on full treatment at baseline achieving recommended target BP levels at study end;

Note: not composite. Data for will be extracted from the general practice software systems using CAT. 
2. Proportion of under-treated high-risk patients achieving recommended BP or LDL-C targets. Note: not composite. Data will be extracted from the general practice software systems using CAT. Under-treated includes participants at high risk of a CV event, not on full treatment at baseline. Full treatment: at least 1 BP-lowering drug and a statin for participants without established CVD; for those with CVD, full treatment will additionally require at least 1 antiplatelet drug.

3. Proportion of all high-risk participants achieving BP and LDL-C targets. Data will be extracted from the general practice software systems using CAT.

4. Proportion of participants achieving BP and LDL-C targets and prescribed antiplatelet (if relevant). Data will be extracted from the general practice software systems using CAT.

5. Risk factor measurement and mean levels. Data will be extracted from the general practice software systems using CAT. Risk factor measurement is calculated by HealthTracker. High CVD risk is defined as either (i) history of CVD (diagnosis of coronary heart disease, ischaemic stroke, peripheral vascular disease); (ii) presence of any guideline-stipulated clinically high-risk conditions (diabetes and age $>60$ years, diabetes and albuminuria, stage3B chronic kidney disease (CKD), or extreme risk factor elevations - systolic BP greater than or equal to $180 \mathrm{mmHg}$, diastolic BP $\geq 110$ $\mathrm{mmHg}$, total cholesterol $>7.5 \mathrm{mmol}$ ); or (3) a calculated 5-year CVD risk of > 15\% using the $1991 \mathrm{An}$ derson Framingham equation. In the TORPEDO study, this comprised $27 \%$ of the study population.

6. Treatment intensity in high-risk participants. Proportion of high-risk participants who receive a dose escalation or addition to their prescribed medication during the intervention period. De-identified data will be extracted from the general practice software systems using CAT.

7. Polypill prescriptions - will be assessed from the number of consent forms signed for the polypill and the supply of polypills.

8. Participation in pharmacy adherence support programmes. Will be assessed from the number of consent forms for the PASS.

9. Proportion of non-high-risk participants receiving either BP-lowering or statin and or anti-platelet therapy (looking at all the therapies individually and combined). Assessed by the number of new BP-lowering, statin and anti-platelet medication prescriptions in non-high risk participants.

Starting date $1 / 03 / 2016$

Contact information Prof Anushka Patel

The George Institute for Global Health Level 10, King George V (KGV)

Building Missenden Rd Camperdown NSW 2050, Australia

Phone+61 299934500

Fax+61 299934501

Email apatel@georgeinstitute.org

Notes ACTRN12616000233426

\section{ACTRN12616000422426}

Study name

Text4Heart Partnership: a text messaging programme to enhance self-management of cardiovascular disease.

Methods

RCT

Participants will be randomised via a central randomisation service accessed by computer at the time of allocation. 
Participants

A documented diagnosis of an acute coronary syndrome (including myocardial infarction, unstable angina) or percutaneous coronary revascularisation procedure, are 18 years or older, eligible for cardiac rehabilitation. 18 years to 80 years, both men and women.

Exclusion: Untreated ventricular tachycardia, severe heart failure, life-threatening co-existing disease with life expectancy $<1$ year, and significant exercise limitations other than cardiovascular disease.

Text4Heart is a self-management programme involving a personalised automated package of text messages via mobile phone to increase and maintain positive lifestyle changes, including stopping smoking, eating a heart-healthy diet, engaging in regular exercise behaviour, and decreasing stress. The programme will be delivered over 24 weeks. Messages focus on providing participants with key behaviour change strategies to initiate and maintain the respective behaviours.

Additional features include prompting and support to undertake the behaviour. Intervention messages were developed according to New Zealand clinical guidelines for the management of coronary heart disease, and are based on Social Cognitive Theory principles.

Each participant in the intervention group will receive at minimum the basic heart health CR program, consisting of 5 messages per week for 6 months. The general heart health messages provide overall advice and support on undertaking lifestyle change, including, taking medication, being physically active, eating healthy, and reducing alcohol consumption. One message per week on each topic is delivered or the entire six months.

Messages are sent to participants at times that suit them and will be personalised to participant's name (or nickname, and their sex). Participants can also choose their preferred time for receiving messages. The intervention will be predominantly unidirectional; however if participants choose to text questions to the team, these will be answered within 24 hours. Participants will be instructed that the messages are for general heart health issues and that all emergency issues should be managed as per normal procedures. All participants will be offered brief training at enrolment on how to read a text message and how to delete or save messages.

Participants will be able to request additional text messages based on the suboptimal behaviour (see below) they wish to modify (identified at their baseline assessment).

1. How to start and maintain a regular exercise program

2. How to start and maintain a heart-healthy diet

3. How to reduce stress and increase relaxation

4. How to stop smoking

These modules involve 1 - 2 additional messages per week for 12 weeks. After 12 weeks, participants can choose an new module for the remaining 12 weeks. Each message is sent once.

Using the gateway company we will monitor the number of messages sent and received. Particpants in the intervention group will also complete questions on adherence to the intervention (number of messages received and read).

The intervention is completely automated and no person delivers the intervention. However. all intervention content was developed by specialists in their respective fields with more than 5 years of experience each (including cardiology, nursing, exercise/physical activity, diet, psychology, smoking cessation). Apart from the messages, no intervention materials are provided to participants.

Participants in the control arm will be offered the standard outpatient CR programme provided by each hospital, which involves support and education provision to discharged patients, with supervised exercise offered at all 3 participating hospitals for those wishing to participate (Phase 2 CR usually of 6 - 12 weeks duration). During Phase 3 participants are encouraged to continue with their lifestyle changes and join a cardiac club. Heart Guide Aotearoa is also offered at the discretion of cardiac nurses. Given the proven effectiveness of CR, it would be unethical not to offer usual CR to 
all participants; therefore the Intervention arm participants will be advised that they are able to access the usual CR programme in addition to the mHealth intervention, if they wish to do so.

\section{Outcomes}

\section{PRIMARY OUTCOMES}

Proportion of participants adhering to medication at 24 weeks. The medication adherence measure in this trial will be prescription record-assessed adherence, defined as: a dispensed medication ratio of $80 \%$ for each of the classes of medications consistent with guideline recommended therapy (e.g. antiplatelet, statin, and blood pressure-lowering therapy, ACE-inhibitor and/or a beta blocker).

\section{SECONDARY OUTCOMES:}

- Adherence to recommended lifestyle behaviours will be measured using a composite health behaviour score adapted from the EPIC-Norfolk Prospective Population Study.

- Individual lifestyle risk factors (physical activity, fruit and vegetable consumption, smoking and alcohol intake).

- Self-report medication adherence measured using the Morisky 8-item medication adherence questionnaire.

- Participant engagement with the intervention measured via text message responses and an exit interview.

- Cost effectiveness will be assessed: The cost of delivering the intervention will be collected over the trial period., including text message service and per message costs, and health service staff time for facilitation of the programme and recruitment. Any changes in health service utilisation observed between intervention and control groups will lead to an estimation of the costs of those changes with assistance of the Waitemata District Health Board Funding Team information analysts. Health related quality of life (HRQOL) will be assessed using the EQ-5D to determine change in HRQOL and cost-effectiveness.

\begin{tabular}{ll}
\hline Starting date & 18/04/2016 \\
\hline Contact information & Prof Ralph Maddison \\
& National Institute for Health Innovation \\
& University of Auckland, Private Bag 92019, Auckland 1142, New Zealand \\
& Phone +6421470710 \\
& Email r.maddison@auckland.ac.nz \\
\hline Notes & Registered 23/03/2016; ACTRN12616000422426 \\
\hline
\end{tabular}

\section{Thom 2014}

\section{Study name}

Use of a Multidrug Pill In Reducing cardiovascular Events (UMPIRE): rationale and design of a randomised controlled trial of a cardiovascular preventive polypill-based strategy in India and Europe

\begin{tabular}{ll}
\hline Methods & Randomised open-label blinded end point (PROBE) \\
\hline Participants & This trial was designed to include 2000 participants \\
& CVD or a calculated 5-year CVD risk of $15 \%$ or higher \\
& Participants with high cardiovascular risk. \\
Inclusion criteria: \\
- Aged 18 yrs+ and able to give informed consent; \\
- High cardiovascular risk, defined as either:
\end{tabular}


Thom 2014 (Continued)

Interventions
- Established atherothrombotic CVD, defined as: A history of coronary heart disease (myocardial infarction, stable or unstable angina pectoris, or coronary revascularisation procedure); or A history of ischaemic cerebrovascular disease (ischaemic stroke or transient ischaemic attack); or A history of peripheral vascular disease (peripheral revascularisation procedure or amputation due to vascular disease); or

- a 5 -year risk of $15 \%$ (calculated using the Framingham risk equation as adjusted by the New Zealand Guidelines Group);

- The trial physician considers that each of the polypill components are indicated at the doses in the polypill.

Exclusion criteria:

- Contraindication to or known intolerance of any of the components of the polypill;

- The trial physician considers that changing a participant's cardiovascular medications would put the participant at risk (e.g. symptomatic heart failure, severe renal insufficiency, a history of resistant hypertension);

- A known situation where medication might be altered for a significant length of time (e.g. planned surgery);

- Unlikely to complete the trial, adhere to the trial procedures or attend study visits.

\section{CONTROL GROUP:}

"Participants who were randomised to usual care continued to be treated at the discretion of their routine treating doctor, in a manner consistent with current guideline-indicated cardiovascular medications. Beyond giving advice to follow current CVD prevention guidelines, no attempt was made to influence the format of "usual care."

\section{INTERVENTION GROUP:}

"Participants who were randomised to the polypill strategy were prescribed one of two polypill formulations, at the discretion of the trial investigator..... The polypill was taken orally, once daily with the dose timing left to the discretion of both the physician and the participant."

\section{Outcomes}

Adherence to treatment; changes in CV outcomes (BP and LDL cholesterol)

Primary outcomes:

1. Adherence to indicated medications (defined as self-reported current use of antiplatelet, any statin and a combination of 2 or more blood pressure-lowering therapy) at the end of the trial. 2. A change in systolic blood pressure from baseline to the end of the trial.

3. A change in LDL-cholesterol from the baseline measurement to the end of the trial.

Secondary outcomes:

a. Self-reported current use of antiplatelet, statin and combination of 2 or more blood pressure-lowering therapy at 12 months;

b. dispensing of statin and 2 types of blood pressure-lowering agents over the course of the trial;

c. reasons for stopping cardiovascular medications (all visits);

d. serious adverse events (between baseline and 28 days after the end of trial visit);

e. quality of life (baseline, 12 months and end of trial);

f. changes in diastolic blood pressure, total cholesterol and other lipid fractions (HDL-cholesterol,triglycerides) and creatinine, from baseline through 12 months, and the end of the follow-up period;

g. cardiovascular events, defined as: 
Thom 2014 (Continued)

- all coronary heart disease events including death from CHD, otherwise unexplained sudden death, non-fatal myocardial infarction, coronary artery bypass graft, percutaneous transluminal coronary angioplasty (with or without stenting) and hospitalisation for unstable angina;

- all heart failure-related events leading to death or requiring a hospital admission;

- all cerebrovascular disease events, including: death from cerebrovascular disease, non-fatal stroke, transient ischaemic attack and sub-arachnoid haemorrhage;

- all peripheral arterial events, including: death due to peripheral vascular disease, new symptomatic claudication, amputation due to ischaemia, aortic dissection, leg ulceration due to arterial insufficiency, and peripheral arterial revascularisation procedures (such as carotid endarterectomy or stent, open repair or stenting of an aortic aneurysm or dissection, or limb revascularisation).

\begin{tabular}{ll}
\hline Starting date & not reported \\
\hline Contact information & $\begin{array}{l}\text { Simon Thom, International Centre for Circulatory Health, National Heart and Lung Institute, Imper- } \\
\text { ial College of London, 59 North Wharf Road, London, W2 1LA, UK. } \\
\text { Email: s.thom@imperial.ac.uk }\end{array}$ \\
\hline Notes & $\begin{array}{l}\text { Funding: This work was supported by the European Commission, 7th framework programme un- } \\
\text { der the theme Health-2009-3.1-4: Improved treatment of chronic diseases in developed countries } \\
\text { (grant number 241849). }\end{array}$ \\
\hline
\end{tabular}

\section{DATA AND ANALYSES}

\section{Comparison 1. Intensified patient care vs usual care}

\begin{tabular}{|c|c|c|c|c|}
\hline Outcome or subgroup title & No. of studies & $\begin{array}{l}\text { No. of partici- } \\
\text { pants }\end{array}$ & Statistical method & Effect size \\
\hline $\begin{array}{l}1.1 \text { Medication adherence at } \leq 6 \\
\text { months }\end{array}$ & 7 & 11204 & $\begin{array}{l}\text { Odds Ratio (M-H, Random, } \\
95 \% \mathrm{Cl})\end{array}$ & $1.93[1.29,2.88]$ \\
\hline $\begin{array}{l}1.2 \text { Medication adherence at }>6 \\
\text { months }\end{array}$ & 3 & 663 & $\begin{array}{l}\text { Odds Ratio (M-H, Random, } \\
95 \% \mathrm{Cl})\end{array}$ & $2.87[1.91,4.29]$ \\
\hline $\begin{array}{l}1.3 \text { Reduction in total serum choles- } \\
\text { terol at } \leq 6 \mathrm{mos}(\mathrm{mg} / \mathrm{dL})\end{array}$ & 4 & 430 & $\begin{array}{l}\text { Mean Difference (IV, Ran- } \\
\text { dom, } 95 \% \mathrm{CI} \text { ) }\end{array}$ & $17.15[1.17,33.14]$ \\
\hline $\begin{array}{l}\text { 1.4 Reduction in total serum choles- } \\
\text { terol at }>6 \mathrm{mos}(\mathrm{mg} / \mathrm{dL})\end{array}$ & 2 & 127 & $\begin{array}{l}\text { Mean Difference (IV, Ran- } \\
\text { dom, } 95 \% \mathrm{CI} \text { ) }\end{array}$ & $\begin{array}{l}17.57[14.95 \\
20.19]\end{array}$ \\
\hline $\begin{array}{l}\text { 1.5 Reduction in LDL-C at } \leq 6 \text { months } \\
(\mathrm{mg} / \mathrm{dL})\end{array}$ & 3 & 333 & $\begin{array}{l}\text { Mean Difference (IV, Ran- } \\
\text { dom, } 95 \% \mathrm{CI} \text { ) }\end{array}$ & $19.51[8.51,30.51]$ \\
\hline $\begin{array}{l}\text { 1.6 Reduction in LDL-C }>6 \text { months } \\
(\mathrm{mg} / \mathrm{dL})\end{array}$ & 1 & & $\begin{array}{l}\text { Mean Difference (IV, Ran- } \\
\text { dom, } 95 \% \mathrm{CI} \text { ) }\end{array}$ & $\begin{array}{l}\text { Totals not select- } \\
\text { ed }\end{array}$ \\
\hline $\begin{array}{l}\text { 1.7 Attrition rate sensitivity analysis } \\
\text { (medication adherence at } \leq 6 \text { months) }\end{array}$ & 6 & 6656 & $\begin{array}{l}\text { Odds Ratio (M-H, Random, } \\
95 \% \mathrm{Cl})\end{array}$ & $2.22[1.41,3.49]$ \\
\hline
\end{tabular}


Analysis 1.1. Comparison 1: Intensified patient care vs usual care, Outcome 1: Medication adherence at $\leq 6$ months

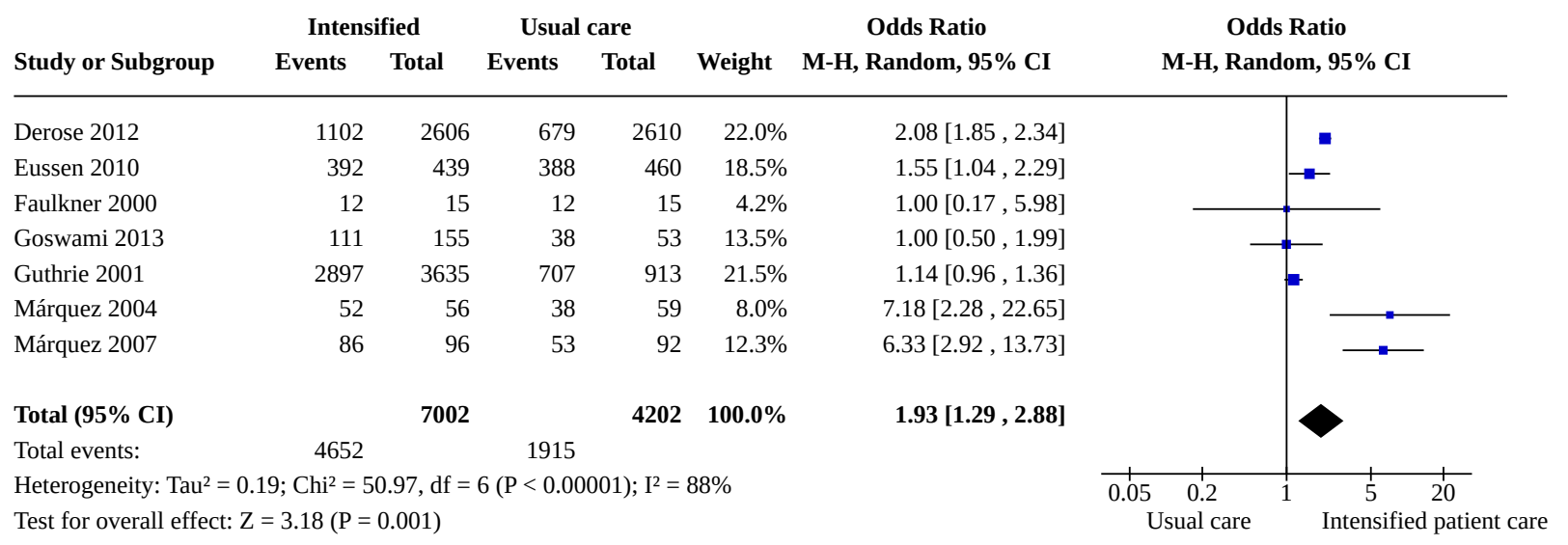

Analysis 1.2. Comparison 1: Intensified patient care vs usual care, Outcome 2: Medication adherence at $>6$ months

\begin{tabular}{|c|c|c|c|c|c|c|c|}
\hline \multirow[b]{2}{*}{ Study or Subgroup } & \multicolumn{2}{|c|}{ Intensified } & \multicolumn{2}{|c|}{ Usual care } & \multicolumn{2}{|r|}{ Odds Ratio } & Odds Ratio \\
\hline & Events & Total & Events & Total & Weight & M-H, Random, 95\% CI & M-H, Random, 95\% CI \\
\hline
\end{tabular}

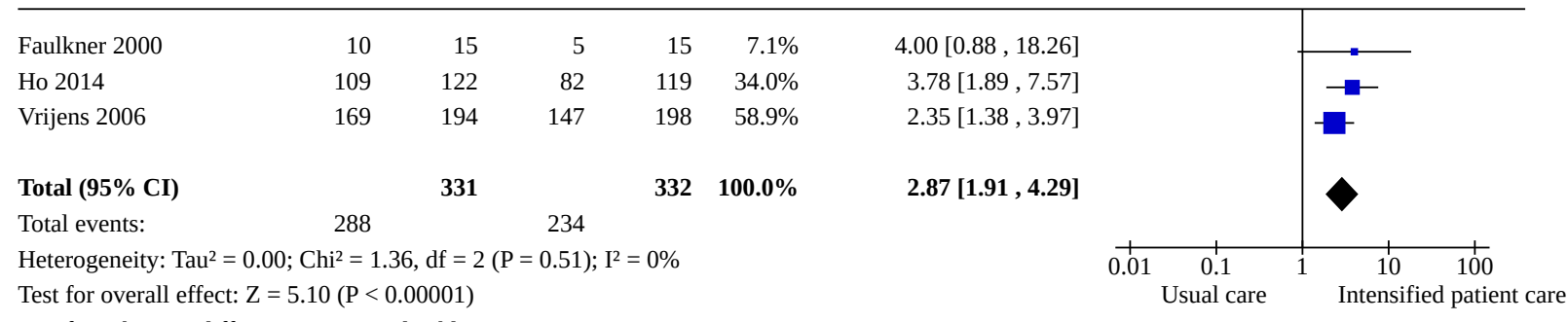

Test for subgroup differences: Not applicable

Analysis 1.3. Comparison 1: Intensified patient care vs usual care, Outcome 3: Reduction in total serum cholesterol at $\leq 6 \mathrm{mos}(\mathrm{mg} / \mathrm{dL})$

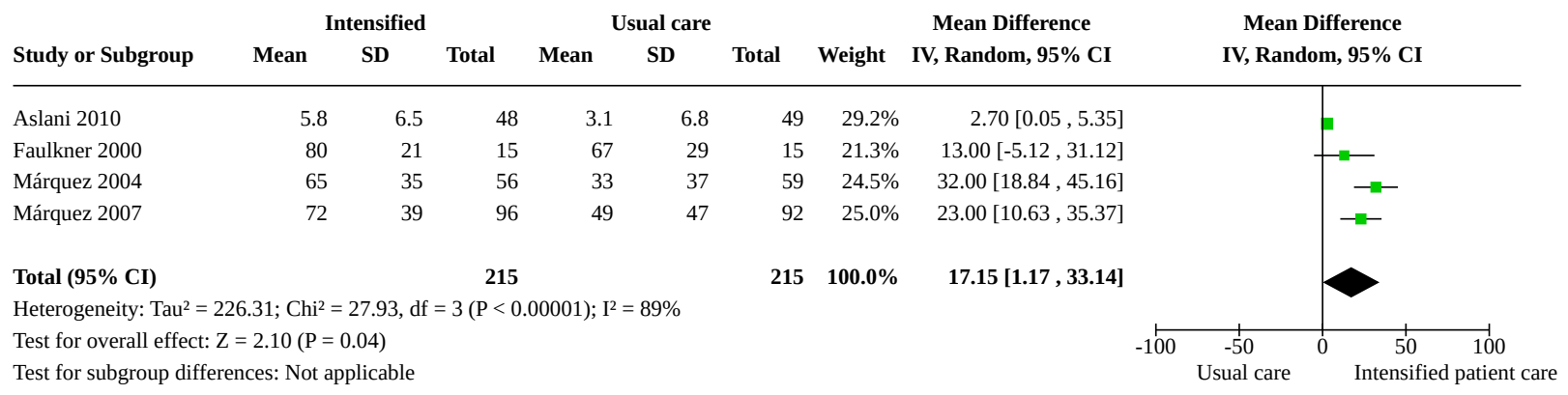


Analysis 1.4. Comparison 1: Intensified patient care vs usual care, Outcome 4: Reduction in total serum cholesterol at $>6 \mathrm{mos}(\mathrm{mg} / \mathrm{dL})$

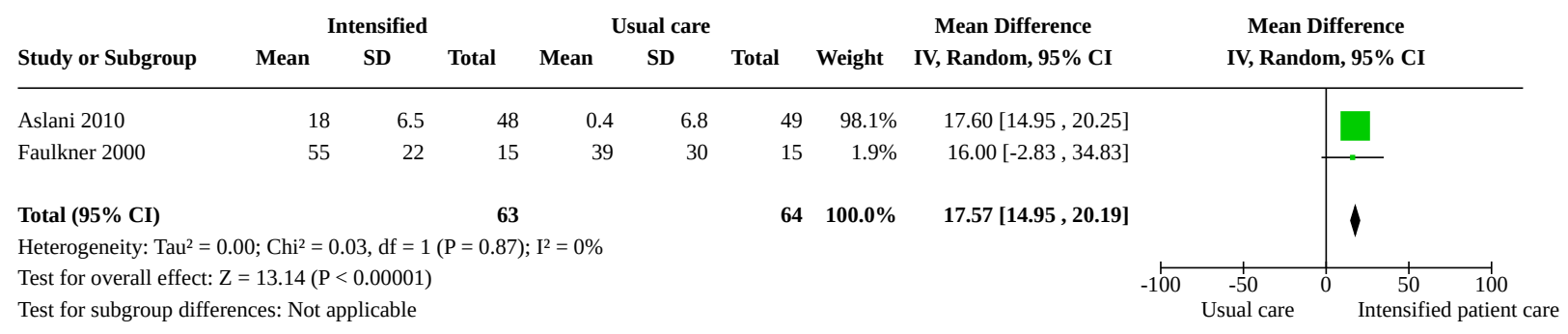

\section{Analysis 1.5. Comparison 1: Intensified patient care vs usual care, Outcome 5: Reduction in LDL-C at $\leq 6$ months $(\mathrm{mg} / \mathrm{dL}$ )}

\begin{tabular}{|c|c|c|c|c|c|c|c|c|c|}
\hline & & ensif & & & ual $c$ & & & Mean Difference & Mean Difference \\
\hline tudy or Subgroup & Mean & SD & Total & Mean & SD & Total & Weight & IV, Random, 95\% CI & IV, Random, 95\% CI \\
\hline
\end{tabular}

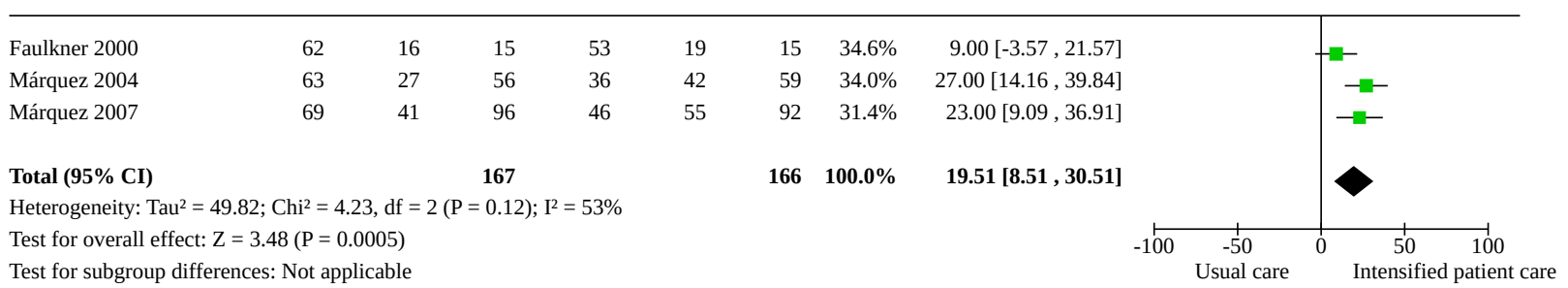

Analysis 1.6. Comparison 1: Intensified patient care vs usual care, Outcome 6: Reduction in LDL-C $>6$ months $(\mathrm{mg} / \mathrm{dL})$

\begin{tabular}{|c|c|c|c|c|c|c|c|c|c|c|}
\hline \multirow{3}{*}{$\begin{array}{l}\text { Study or Subgroup } \\
\text { Faulkner } 2000\end{array}$} & \multicolumn{3}{|c|}{ Intensified } & \multicolumn{3}{|c|}{ Usual care } & \multirow{2}{*}{$\begin{array}{c}\text { Mean Difference } \\
\text { IV, Random, 95\% CI }\end{array}$} & \multirow{2}{*}{\multicolumn{3}{|c|}{$\begin{array}{c}\text { Mean Difference } \\
\text { IV, Random, 95\% CI }\end{array}$}} \\
\hline & Mean & SD & Total & Mean & SD & Total & & & & \\
\hline & 47 & 18 & 15 & 29 & 18 & 15 & $18.00[5.12,30.88]$ & & & - \\
\hline & & & & & & & & -100 & $\begin{array}{c}1 \\
-50 \\
\text { Usual care }\end{array}$ & $\begin{array}{cc} & 1 \\
0 & 50 \\
& \text { Intensifi }\end{array}$ \\
\hline
\end{tabular}

Analysis 1.7. Comparison 1: Intensified patient care vs usual care, Outcome 7: Attrition rate sensitivity analysis (medication adherence at $\leq 6$ months)

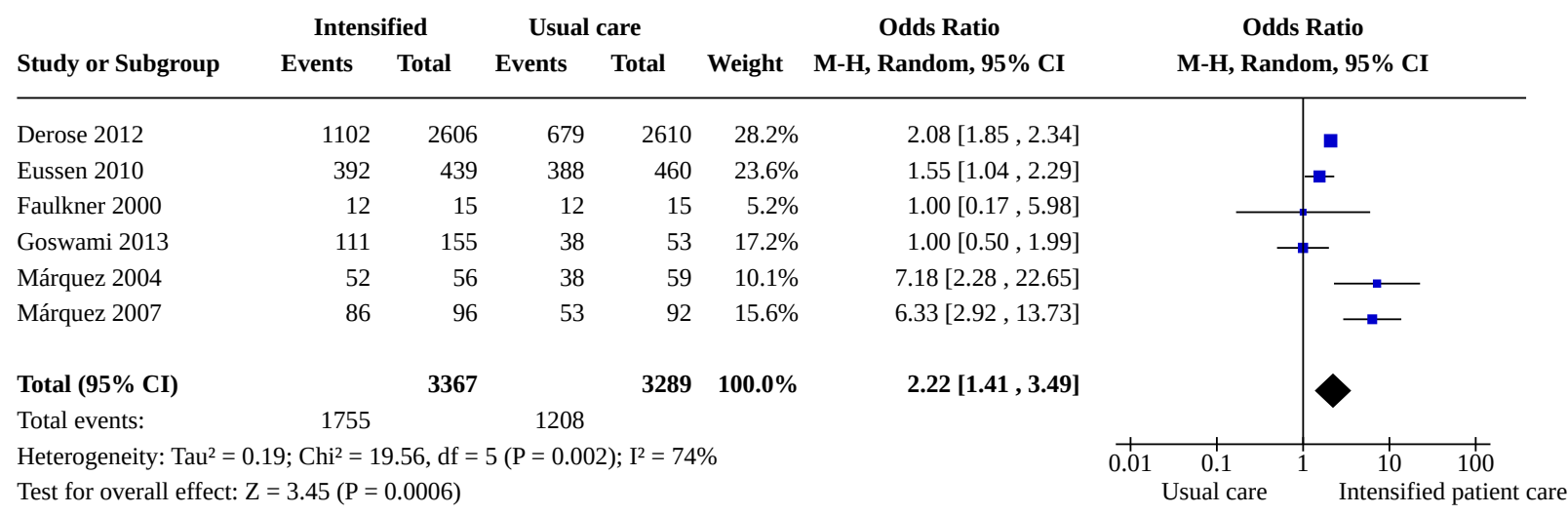


ADDITIONAL TABLES

Table 1. Matrix of comparisons in included studies

Intervention

\begin{tabular}{|c|c|c|c|c|c|c|c|}
\hline $\begin{array}{l}\text { Compara- } \\
\text { tor inter- } \\
\text { vention }\end{array}$ & $\begin{array}{l}\text { 1) simplifica- } \\
\text { tion of drug } \\
\text { regimen }\end{array}$ & $\begin{array}{l}\text { 2) patient ed- } \\
\text { ucation and } \\
\text { information }\end{array}$ & $\begin{array}{l}\text { 3) intensified patient } \\
\text { care }^{1}\end{array}$ & $\begin{array}{l}\text { 4) com- } \\
\text { plex behav- } \\
\text { ioural ap- } \\
\text { proaches } 2\end{array}$ & $\begin{array}{l}\text { 5) decision } \\
\text { support } \\
\text { systems }^{3}\end{array}$ & $\begin{array}{l}\text { 6) admin- } \\
\text { istrative } \\
\text { improve- } \\
\text { ments } 4\end{array}$ & $\begin{array}{l}\text { 7) pharma- } \\
\text { cy-led in- } \\
\text { tervention }\end{array}$ \\
\hline
\end{tabular}

1) simplification of drug N/A

regimen

2) patient education and N/A

information

N/A

3) intensified patient

care $^{1}$

\begin{tabular}{|c|c|c|}
\hline $\begin{array}{l}\text { 4) complex behavioural } \\
\text { approaches }^{2}\end{array}$ & $\mathrm{~N} / \mathrm{A}$ & $\begin{array}{l}\text { Kooy 2013; } \\
\text { Pladevall } \\
2014\end{array}$ \\
\hline $\begin{array}{l}\text { 5) decision support sys- } \\
\text { tems } 3\end{array}$ & & $\mathrm{~N} / \mathrm{A}$ \\
\hline
\end{tabular}

6) administrative im-

$\mathrm{N} / \mathrm{A}$

provements 4

7) pharmacy-led inter-

vention

8) usual care/placebo

Brown 1997;
Castellano
2014;
Patel 2015;
PILL 2011;
Selak 2014;
Sweeney 1991;
Thom 2013

Gujral 2014; $\quad$ Aslani 2010; Derose 2012;

Márquez

1998

Park 2013;

Eussen 2010; Fang 2015;

Faulkner 2000;

Poston 1998;

Goswami 2013;

Powell 1995;

Guthrie 2001 Ho 2014;

Willich 2009

Kardas 2013; Ma 2010; 


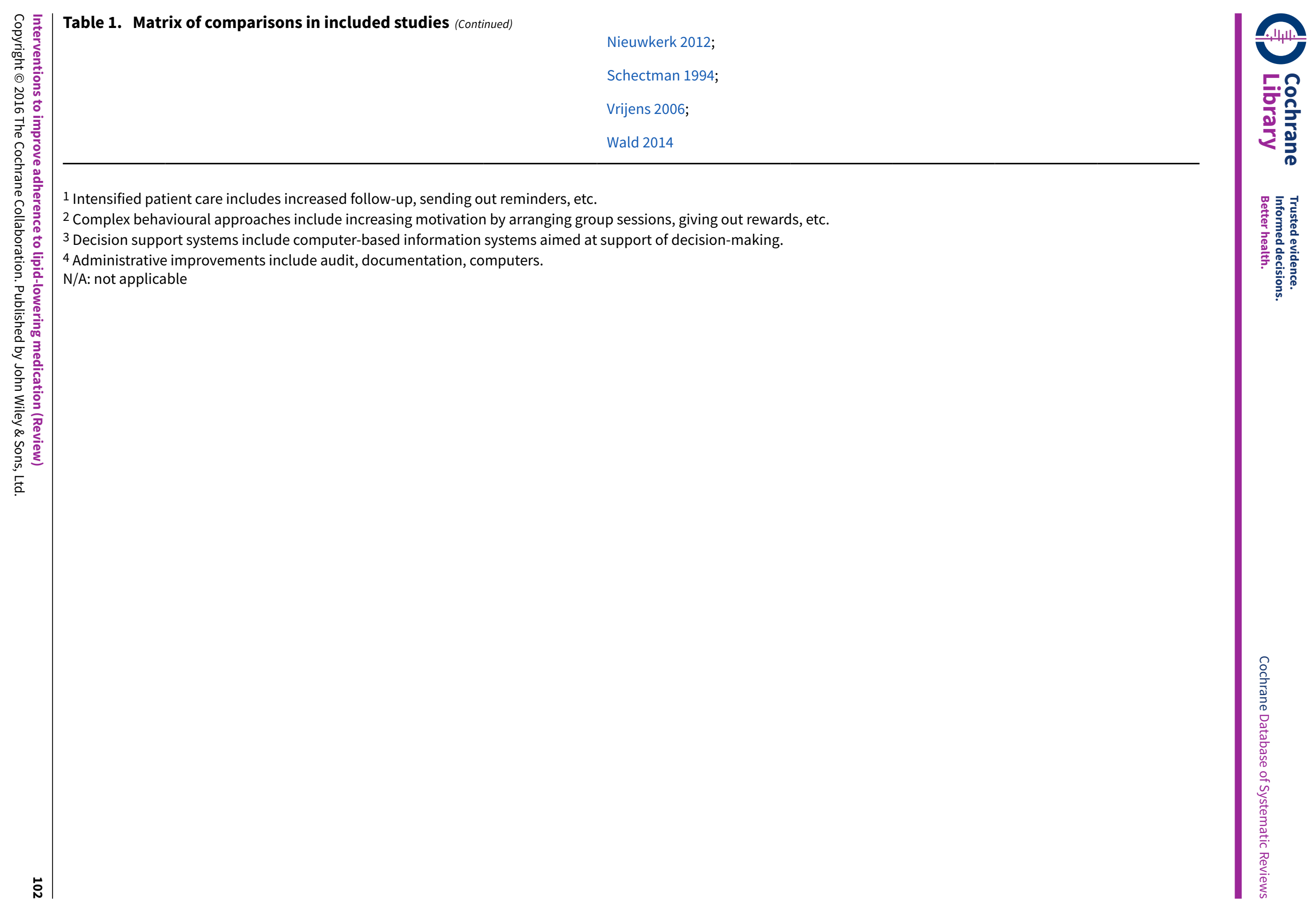


Table 2. Intensified vs usual care: Medication adherence outcomes for pooled studies

\begin{tabular}{|c|c|c|c|}
\hline Study & Intervention & Effective $Y / N$ & Results \\
\hline Faulkner 2000 & Regular phone calls & $\mathrm{Y}$ & $\begin{array}{l}24 \% \text { absolute difference ( } 63 \% \text { in intervention } \\
\text { group vs 39\% in control group; } P<0.05 \text { reported; } \\
n=30 \text { ) }\end{array}$ \\
\hline Márquez 2004 & Regular phone calls & $Y$ & $\begin{array}{l}29 \% \text { absolute difference ( } 93 \% \text { in intervention } \\
\text { group vs } 64 \% \text { in control group; } P<0.001 \text { reported; } \\
n=115 \text { ) }\end{array}$ \\
\hline Vrijens 2006 & $\begin{array}{l}\text { Regular review by the community } \\
\text { pharmacist }\end{array}$ & $Y$ & $\begin{array}{l}6.5 \% \text { difference }(95.9 \% \text { in the intervention group } \\
\text { vs } 89.4 \% \text { in the control group; } P<0.001 \text { reported; } \\
n=392)\end{array}$ \\
\hline
\end{tabular}

Derose $2012 \quad$ Automated telephone calls fol- $\quad$ Y Statins were dispensed to 42.3\% of intervention
lowed 1 week later by letters for participants and $26.0 \%$ of control participants continued nonadherence (absolute difference 16.3\%; $P=0001 ; n=5216$ )

\begin{tabular}{|c|c|c|c|}
\hline Márquez 2007 & $\begin{array}{l}\text { Simple calendar reminder of } \\
\text { medication taking given to pa- } \\
\text { tient at time of their first pre- } \\
\text { scription }\end{array}$ & $\mathrm{Y}$ & $\begin{array}{l}32 \% \text { difference ( } 90 \% \text { in intervention group vs } 58 \% \\
\text { in control group; } \mathrm{P}<0.005 \text { reported; } \mathrm{n}=186 \text { ) }\end{array}$ \\
\hline Guthrie 2001 & Telephone and postal reminders & $\mathrm{N}$ & $\begin{array}{l}79.7 \% \text { in intervention group vs } 77.4 \% \text { in control } \\
\text { group; P value non-significant; } n=4548\end{array}$ \\
\hline Schectman 1994 & Telephone and postal reminders & $\mathrm{N}$ & $\begin{array}{l}88 \% \text { in intervention group vs } 82 \% \text { in control } \\
\text { group; } P=0.32 ; n=162\end{array}$ \\
\hline Aslani 2010 & $\begin{array}{l}\text { Individualised adherence support } \\
\text { service delivered at baseline and } \\
3,6,9 \text { months to address issues } \\
\text { identified from a questionnaire. } \\
\text { Interventions included coun- } \\
\text { selling and advice about the dis- } \\
\text { ease, medicine, medicine use, ad- } \\
\text { herence and lifestyle measures. }\end{array}$ & $\mathrm{Y}$ & $\begin{array}{l}\text { Main effect } F_{2,178}=4.3 ; P<0.05 ; \text { contrast } F_{1,89} \\
=5.7 ; P<0.05 ; \text { the intervention group reported } \\
\text { that, compared with the control group, they were } \\
\text { more liable to alter the dose of their medicine at } \\
\text { the third reading compared to the second reading } \\
\left(F_{1,89}=4.97 ; P<0.05\right)(n=142)\end{array}$ \\
\hline Eussen 2010 & $\begin{array}{l}\text { Community pharmacy-based } \\
\text { pharmaceutical care programme }\end{array}$ & $\mathrm{Y}$ & $\begin{array}{l}\text { Lower rate of discontinuation within } 6 \text { months af- } \\
\text { ter initiating therapy versus usual care (HR } 0.66 \text {; } \\
95 \% \mathrm{Cl} 0.46 \text { to } 0.96 ; \mathrm{n}=899 \text { ); no difference be- } \\
\text { tween groups at } 12 \text { months (HR } 0.84 ; 95 \% \mathrm{Cl} 0.65 \\
\text { to } 1.10 \text { ) }\end{array}$ \\
\hline Goswami 2013 & $\begin{array}{l}\text { Integrated intervention pro- } \\
\text { gramme (nurse counselling, ad- } \\
\text { herence tip sheet, copay relief } \\
\text { card, opportunity to enrol in } 12- \\
\text { week cholesterol management } \\
\text { programme) }\end{array}$ & $\mathrm{N}$ & $\begin{array}{l}\mathrm{HR} 0.66 ; 95 \% \mathrm{Cl} 0.46 \text { to } 0.96 \text {; No significant dif- } \\
\text { ference between groups in discontinuation at } 12 \\
\text { months (HR } 0.84 ; 95 \% \mathrm{Cl} 0.65 \text { to } 1.10)(\mathrm{n}=208)\end{array}$ \\
\hline Kardas 2013 & $\begin{array}{l}\text { Educational counselling at each } \\
\text { visit (every } 8 \text { weeks) and asked to } \\
\text { adopt a routine evening activity } \\
\text { of choice for a reminder }\end{array}$ & $\mathrm{Y}$ & $\begin{array}{l}\text { Mean } \pm \text { SD MPR was } 95.4 \pm 53.7 \% \text { and } 81.7 \pm \\
31.0 \%, \text { for intervention and control group, respec- } \\
\text { tively }(P<0.05 ; n=196)\end{array}$ \\
\hline
\end{tabular}


Table 2. Intensified vs usual care: Medication adherence outcomes for pooled studies (Continued)

\begin{tabular}{|c|c|c|c|}
\hline Ma 2010 & $\begin{array}{l}\text { Pharmacist-delivered telephone } \\
\text { counselling calls post-hospital } \\
\text { discharge }\end{array}$ & $\mathrm{N}$ & $\begin{array}{l}\text { The continuous multiple interval (CMA) for statin } \\
\text { medication use was } 0.88(S D=0.3) \text { in the } \mathrm{PI} \text { con- } \\
\text { dition (referring to the participant being } 88 \% \text { ad- } \\
\text { herent to their statins medication), and } 0.90(\mathrm{SD}= \\
0.3 \text { ) in the usual care condition }(\mathrm{P}=0.51)(\mathrm{n}=559)\end{array}$ \\
\hline Nieuwkerk 2012 & $\begin{array}{l}\text { Nurse-led cardiovascular risk-fac- } \\
\text { tor counselling }\end{array}$ & $Y$ & $\begin{array}{l}\text { Statin adherence was significantly higher }(P< \\
0.01) \text { and anxiety was significantly lower }(P<0.01) \\
\text { in the intervention group }(n=181)\end{array}$ \\
\hline Ho 2014 & $\begin{array}{l}\text { Pharmacist-led counselling, pa- } \\
\text { tient education, teamwork with } \\
\text { participant's primary physician, } \\
\text { and voice messaging }\end{array}$ & $Y$ & $\begin{array}{l}89.3 \% \text { in the intervention group were adherent vs } \\
73.9 \% \text { in the usual care group }(P=0.003)(n=241)\end{array}$ \\
\hline Fang 2015 & $\begin{array}{l}\text { Short message service (SMS) and } \\
\text { SMS plus Micro Letter (ML) }\end{array}$ & $\mathrm{Y}$ & $\begin{array}{l}\text { SMS and SMS }+ \text { ML groups had better cumulative } \\
\text { adherence after } 6 \text { months than the phone group. } \\
\text { The SMS + ML group had better cumulative adher- } \\
\text { ence than the SMS group }(n=271)\end{array}$ \\
\hline Wald 2014 & $\begin{array}{l}\text { Texts sent daily for } 2 \text { weeks, alter- } \\
\text { nate days for } 2 \text { weeks and week- } \\
\text { ly thereafter for } 22 \text { weeks using } \\
\text { an automated computer pro- } \\
\text { gramme }\end{array}$ & $\mathrm{Y}$ & $\begin{array}{l}\text { improvement in adherence affecting } 16 \text { per } 100 \\
\text { participants }(95 \% \mathrm{Cl} 7 \text { to } 24), \mathrm{P}=0.001(\mathrm{n}=301)\end{array}$ \\
\hline
\end{tabular}

\section{APPENDICES}

\section{Appendix 1. Search strategies 2003}

\section{CENTRAL on The Cochrane Library}

\#1 compliance

\#2 non-compliance

\#3 noncompliance

\#4 adher*

\#5 PATIENT COMPLIANCE

\#6 TREATMENT REFUSAL

\#7 PATIENT DROPOUTS

\#8 nonadherence*

\#9 non-adherence ${ }^{\star}$

\#10 nonadherence

\#11 (refusal or refuse ${ }^{\star}$ )

\#12 (improv* near (follow next up*))

\#13 (improv* near follow-up*)

\#14 dropout ${ }^{\star}$

\#15 (drop next out*)

\#16 (abandon* near treatment ${ }^{\star}$ )

\#17 (stop* near treatment ${ }^{\star}$ )

\#18 (patient near attitude*)

\#19 (patient near acceptance)

\#20 ATTITUDE TO HEALTH

\#21 PATIENT SATISFACTION

\#22 (patient next satisfaction)

\#23 COUNSELING

\#24 PATIENT CARE

\#25 HEALTH BEHAVIOR 
\#26 PATIENT EDUCATION

\#27 BEHAVIOR THERAPY

\#28 NURSE PRACTITIONERS

\#29 PHARMACISTS

\#30 counsel* $^{*}$

\#31 nurse*

\#32 pharmacist $^{*}$

\#33 (patient next education*)

\#34 (pharmacy or pharmacies)

$\# 35$ (\#1 or \#2 or \#3 or \#4 or \#5 or \#6 or \#7 or \#8 or \#9 or \#10 or \#11)

$\# 36$ (\#12 or \#13 or \#14 or \#15 or \#16 or \#17 or \#18 or \#19 or \#20 or \#21 or \#22)

$\# 37$ (\#23 or \#24 or \#25 or \#26 or \#27 or \#28 or \#29 or \#30 or \#31 or \#32 or \#33 or \#34)

\#38 (\#35 or \#36 or \#37)

\#39 HYPERLIPIDEMIA

\#40 ANTILIPEMIC AGENTS

\#41 hypercholesterol ${ }^{\star}$

\#42 hypercholesterol*

\#43 hyperlipid*

\#44 statin*

\#45 antilipid $^{*}$

\#46 hyperlip*

\#47 dyslip*

\#48 (lipid next lowering)

\#49 (cholesterol next lowering)

\#50 antilipemic

\#51 hypocholesterolemic

\#52 (hydroxymethylglutaryl near inhibitor ${ }^{\star}$ )

\#53 atorvastatin

\#54 cerivastatin

\#55 pravastatin

\#55 simvastatin

(\#39 or \#40 or \#41 or \#42 or \#43 or \#44 or \#45 or \#46 or \#47 or \#48)

(\#49 or \#50 or \#51 or \#52 or \#53 or \#54 or \#55 or \#55)

(\#56 or \#57)

(\#38 and \#58)

\section{MEDLINE (on Ovid)}

1. $\exp$ HYPERLIPIDEMIA/

2. exp Antilipemic Agents/

3. hypercholesterol\$.tw.

4. hyperlipid\$.tw.

5. statin\$.tw.

6. antilipid\$.tw.

7. hyperlip?emia.tw.

8. dyslip?emia.tw.

9. lipid lowering.tw.

10. or/1-9

11. exp Patient Compliance/

12. Treatment Refusal/

13. Patient Dropouts/

14. exp Attitude to Health/

15. Patient Satisfaction/

16. (adher\$ or non-adherence $\$$ or nonadherence\$).tw.

17. (compliance\$ or noncompliance or non-compliance\$).tw.

18. (refusal or refuse\$).tw.

19. (improv\$ adj5 (follow-up or follow up)).tw.

20. (dropout\$ or drop-out\$ or drop out\$).tw.

21. (patient\$ adj3 (attitude\$ or acceptance $\$$ or satisfaction)).tw.

22. (treatment\$ adj3 (stop\$ or abandon\$)).tw.

23. or/11-22

24. exp Counseling/ 
25. patient care/

26. Case Management/

27. Health Behavior/

28. exp Patient Education/

29. exp Behavior Therapy/

30. (behavi\$ adj3 (modif\$ or therap\$ or adjust\$)).tw.

31. Patient Care Planning/

32. Nurse Practitioners/

33. Pharmacists/

34. counsel\$.tw.

35. patient education\$.tw.

36. (patient $\$$ adj3 educat\$).tw.

37. ((nurse $\$$ or pharmac\$) adj3 (led\$ or manage\$ or program\$ or based)).tw.

38. or/24-37

39. 23 or 38

40. 10 and 39

\section{Embase (on Ovid)}

1 exp hyperlipidemia/

2 exp antilipemic agents/

3 hypercholesterol\$.tw.

4 hyperlipid\$.tw.

5 statin\$.tw.

6 antilipid\$.tw.

7 hyperlip?emia.tw.

8 dyslip?emia.tw.

9 lipid lowering.tw.

10 or/1-9

11 exp Counseling/

12 patient care/

13 Health Behavior/

14 exp Patient Education/

15 exp Behavior Therapy/

16 behavior modification/

17 (behavi\$ adj3 (modif\$ or therap\$ or adjust\$)).tw.

18 Nurse Practitioners/

19 Pharmacists/

20 (nurse adj3 (led\$ or manage\$ or program\$)).tw.

21 counsel\$.tw.

22 nurse based.tw.

23 (nurse adj3 based).tw.

24 patient education\$.tw.

25 (patient\$ adj3 educat\$).tw.

26 ((nurse\$ or pharmac\$) adj3 (led\$ or manage\$ or program\$ or based)).tw.

27 or $/ 11-26$

28 (adher\$ or nonadherence\$ or non-adherence\$).tw.

29 (compliance\$ or noncompliance\$ or non-compliance\$).tw.

30 (refusal or refuse\$).tw.

31 (improv\$ adj5 (follow-up or follow up)).tw.

32 (dropout $\$$ or drop-out\$ or drop-out\$).tw.

33 (patient\$ adj3 (attitude\$ or acceptance or satisfaction)).tw.

34 (treatment\$ adj3 (stop\$ or abandon\$)).tw.

35 patient compliance/

36 Patient Attitude/

37 Illness Behavior/

38 patient satisfaction/

39 or/28-38

4010 and 39

\section{CINAHL (on Ovid)}

1 exp Patient Compliance/ 
2 exp Treatment Refusal/

3 exp Patient Dropouts/

4 exp Attitude to Health/

5 exp Patient Satisfaction/

6 (adher\$ or nonadherence or non-adherence\$).tw.

7 (compliance\$ or noncompliance or non-compliance\$).tw.

8 (refusal or refuse\$).tw.

9 (improv\$ adj5 (follow-up or follow up)).tw.

10 (dropout\$ or drop-out\$ or drop-out\$).tw.

11 (patient\$ adj3 (attitude $\$$ or acceptance $\$$ or satisfaction)).tw.

12 (treatment\$ adj3 (stop\$ or abandon\$)).tw.

13 or/1-12

14 exp hyperlipidemia/

15 exp antilipemic agents/

16 hypercholesterol\$.tw.

17 hyperlipid\$.tw.

18 statin\$.tw.

19 antilipid\$.tw.

20 hyperlip?emia.tw.

21 dyslip?emia.tw.

22 lipid lowering.tw.

23 or/ $14-22$

24 exp Counseling/

25 patient care/

26 Case Management/

27 Health Behavior/

28 exp Patient Education/

29 exp Behavior Therapy/

30 (behavi\$ adj3 (modif\$ or therap\$ or adjust\$)).tw.

31 Nurse Practitioners/

32 Pharmacists/

33 (nurse adj3 (led\$ or manage\$ or program\$)).tw.

34 counsel\$.tw.

35 nurse based.tw.

36 (nurse adj3 based).tw.

37 patient education $\$ . t w$.

38 (patient\$ adj3 educat\$).tw.

39 ((nurse $\$$ or pharmac\$) adj3 (led\$ or manage\$ or program $\$$ or based)).tw.

40 or/24-39

4113 and 23

4223 and 40

4342 not 41

44 Randomized controlled trials/

45 clinical trial.pt.

46 exp Clinical trials/

47 (clin\$ adj25 trial\$).ti,ab. (5610)

48 ((singl\$ or doubl\$ or trebl\$ or tripl\$) adj (blind\$ or mask\$)).ti,ab.

49 placebos.sh.

50 placebo\$.ti,ab.

51 random\$.ti,ab.

52 exp evaluation studies/

53 prospective studies.sh.

54 (control\$ or prospectiv\$ or volunteer\$).ti,ab.

55 or $/ 44-54$

5643 and 55

\section{PsycINFO}

\#45 \#44 not \#34(67 records)

\#44 ((educat $\left.{ }^{\star}\right)$ or (pharmacist* or pharmacy or pharmacies) or ("Health-Behavior" in DE) or (nurse*) or (counsel*) or ("Pharmacists-" in DE) or ("Cognitive-Therapy" in DE) or (explode "Counseling-" in DE)) and ((CLINICAL-TRIAL in PT:PY) or (random*) or (clinical trial*) or (controlled study) or ((double-blind)or (double blind)) or ("Placebo-" in DE) or (placebo*) or (clinical ${ }^{\star}$ stud $\left.^{\star}\right)$ or ((single-blind) or 
(single blind) or (triple-blind) or (triple blind)) or ((comparative stud $\left.{ }^{\star}\right)$ or (control ${ }^{\star}$ stud $\left.\left.\left.^{\star}\right)\right)\right)$ and $\left(\left(\right.\right.$ lipid $\left.^{\star}\right)$ or $\left(\left(\right.\right.$ antilipid $\left.^{\star}\right)$ or $\left(\right.$ statin $\left.^{\star}\right)$ or (hypercholesterol $^{\star}$ ) or (hyperlipid*) or (hyperlipidemi $\left.{ }^{\star}\right)$ or (antilipemic ${ }^{\star}$ ) or (lipid lower $\left.{ }^{\star}\right)$ ) or (cholesterol)) (75 records) \#43 (educat ${ }^{\star}$ ) or (pharmacist* or pharmacy or pharmacies) or ("Health-Behavior" in DE) or (nurse*) or (counsel ${ }^{\star}$ ) or ("Pharmacists-" in DE) or ("Cognitive-Therapy" in DE) or (explode "Counseling-" in DE)(363511 records)

\#42 educat* ${ }^{\star} 290103$ records)

\#41 "Health-Behavior" in DE(5756 records)

\#40 counsel $^{\star}(73170$ records)

\#39 pharmacist $^{\star}$ or pharmacy or pharmacies(3150 records)

\#38 nurse (19261 records)

\#37 "Pharmacists-" in DE(153 records)

\#36 "Cognitive-Therapy" in DE(7875 records)

\#35 explode "Counseling-" in DE(28948 records)

Searches and results below from saved search history adherence_statins 181202

\#34 (((lipid $\left.{ }^{\star}\right)$ or $\left(\left(\right.\right.$ antilipid $\left.^{\star}\right)$ or $\left(\right.$ statin $\left.^{\star}\right)$ or (hypercholesterol $\left.{ }^{\star}\right)$ or (hyperlipid $\left.{ }^{\star}\right)$ or (hyperlipidemi $\left.{ }^{\star}\right)$ or $\left(\right.$ antilipemic $\left.^{\star}\right)$ or $\left(\right.$ lipid lower $\left.\left.^{\star}\right)\right)$ or (cholesterol)) and ((adhere* or nonadhere* or non-adhere*) or ("Treatment-Compliance" in DE) or ("Treatment-Refusal" in DE) or ("Treatment-Dropouts" in DE) or (compliance* or noncompliance* or non-compliance*) or ("Client-Attitudes" in DE))) and (((CLINICALTRIAL in PT:PY) or (random*) or (clinical trial $\left.{ }^{\star}\right)$ or (controlled study) or ((double-blind)or (double blind)) or ("Placebo-" in DE) or (placebo*) or (clinical ${ }^{\star}$ stud $\left.^{\star}\right)$ or ((single-blind) or (single blind) or (triple-blind) or (triple blind)) or ((comparative stud $\left.{ }^{\star}\right)$ or (control ${ }^{\star}$ stud $\left.\left.\left.^{\star}\right)\right)\right)$ and ((adhere ${ }^{\star}$ or nonadhere* or non-adhere ${ }^{\star}$ ) or ("Treatment-Compliance" in DE) or ("Treatment-Refusal" in DE) or ("Treatment-Dropouts" in $\mathrm{DE})$ or (compliance* or noncompliance* or non-compliance*) or ("Client-Attitudes" in DE)))(13 records)

\#33 ((CLINICAL-TRIAL in PT:PY) or (random*) or (clinical trial*) or (controlled study) or ((double-blind)or (double blind)) or ("Placebo-" in $\mathrm{DE})$ or $\left(\right.$ placebo $\left.^{\star}\right)$ or $\left(\right.$ clinical $^{\star}$ stud $\left.^{\star}\right)$ or ((single-blind) or (single blind) or (triple-blind) or (triple blind)) or ((comparative stud $\left.{ }^{\star}\right)$ or $\left(\right.$ control $^{\star}$ stud $\left.\left.^{\star}\right)\right)$ ) and ((adhere* or nonadhere ${ }^{\star}$ or non-adhere $\left.{ }^{\star}\right)$ or ("Treatment-Compliance" in DE) or ("Treatment-Refusal" in DE) or ("TreatmentDropouts" in DE) or (compliance* or noncompliance* or non-compliance*) or ("Client-Attitudes" in DE))(1674 records)

\#32 ((lipid $\left.{ }^{\star}\right)$ or $\left(\left(\right.\right.$ antilipid $\left.^{\star}\right)$ or $\left(\right.$ statin $\left.^{\star}\right)$ or $\left(\right.$ hypercholesterol $\left.{ }^{\star}\right)$ or $\left(\right.$ hyperlipid $\left.{ }^{\star}\right)$ or (hyperlipidemi $\left.{ }^{\star}\right)$ or $\left(\right.$ antilipemic $\left.^{\star}\right)$ or $\left(\right.$ lipid lower $\left.\left.^{\star}\right)\right)$ or (cholesterol)) and ((adhere* or nonadhere* or non-adhere*) or ("Treatment-Compliance" in DE) or ("Treatment-Refusal" in DE) or ("Treatment-Dropouts" in DE) or (compliance* or noncompliance* or non-compliance*) or ("Client-Attitudes" in DE))(101 records)

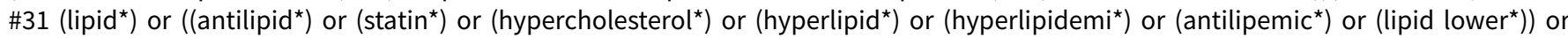
(cholesterol)(3874 records)

\#30 lipid*(1612 records)

\#29 cholesterol(1438 records)

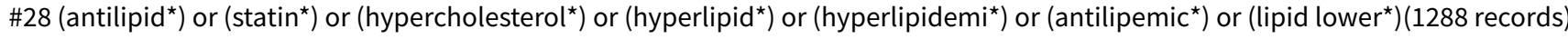

\#27 antilipid ${ }^{\star}$ (2 records)

\#26 statin*(1082 records)

\#25 hypercholesterol ${ }^{\star}(104$ records)

\#24 hyperlipid ${ }^{\star}$ (82 records)

\#23 hyperlipidemi*(77 records)

\#22 anti-lipemic ${ }^{\star}(0$ records)

\#21 antilipaemic ${ }^{\star}(0$ records)

\#20 antilipemic* (2 records)

\#19 lipid lower ${ }^{\star}$ (31 records)

\#18 (CLINICAL-TRIAL in PT:PY) or (random*) or (clinical trial $\left.{ }^{\star}\right)$ or (controlled study) or ((double-blind)or (double blind)) or ("Placebo-" in $\mathrm{DE})$ or $\left(\right.$ placebo $\left.^{\star}\right)$ or $\left(\right.$ clinical $^{\star}$ stud $\left.^{\star}\right)$ or ((single-blind) or (single blind) or (triple-blind) or (triple blind)) or ((comparative stud $\left.{ }^{\star}\right)$ or $\left(\right.$ control $^{\star}$ stud $\left.\left.^{\star}\right)\right)(75728$ records)

\#17 (comparative stud ${ }^{\star}$ ) or (control ${ }^{*}$ stud $\left.^{\star}\right)$ (12663 records)

\#16 (single-blind) or (single blind) or (triple-blind) or (triple blind)(467 records)

\#15 clinical $^{*}$ stud $^{\star}$ (4476 records)

\#14 placebo*(14487 records)

\#13 "Placebo-" in DE(1117 records)

\#12 (double-blind)or (double blind)(7946 records)

\#11 controlled study(2167 records)

$\# 10$ clinical trial ${ }^{\star}(4185$ records)

\#9 random ${ }^{\star}$ (45203 records)

\#8 CLINICAL-TRIAL in PT:PY(3367 records)

\#7 (adhere* or nonadhere ${ }^{\star}$ or non-adhere ${ }^{\star}$ ) or ("Treatment-Compliance" in DE) or ("Treatment-Refusal" in DE) or ("Treatment-Dropouts" in DE) or (compliance* or noncompliance* or non-compliance*) or ("Client-Attitudes" in DE)(22439 records)

\#6 "Client-Attitudes" in DE(6128 records)

\#5 compliance or noncompliance $^{\star}$ or non-compliance ${ }^{\star}(11645$ records)

\#4 "Treatment-Dropouts" in DE(1339 records)

\#3 "Treatment-Refusal" in DE(272 records)

\#2 "Treatment-Compliance" in DE(4478 records)

\#1 adhere* or nonadhere* or non-adhere*(5154 records) 


\section{Appendix 2. Search strategies 2008}

\section{CENTRAL on The Cochrane Library}

\#1 compliance in All Text 15244

\#2 non-compliance in All Text 732

\#3 noncompliance in All Text 650

\#4 adher* in All Text 5424

\#5 MeSH descriptor PATIENT COMPLIANCE this term only 5704

\#6 MeSH descriptor TREATMENT REFUSAL explode trees 1, 2, 3 and 4262

\#7 MeSH descriptor PATIENT DROPOUTS explode tree 11110

\#8 nonadherence* in All Text 128

\#9 non-adherence* in All Text 153

\#10 nonadherence in All Text 193

\#11 (refusal in All Text or refuse* in All Text) 2838

\#12 (improv* in All Text near/6 follow next up* in All Text) 3078

\#13 (improv* in All Text near/6 follow-up* in All Text) 3078

\#14 dropout* in All Text 4183

\#15 drop next out ${ }^{\star}$ in All Text 3551

\#16 (abandon* in All Text near/6 treatment* in All Text) 89

\#17 (stop* in All Text near/6 treatment* in All Text) 1695

\#18 (patient in All Text near/6 attitude* in All Text) 841

\#19 (patient in All Text near/6 acceptance in All Text) 5057

\#20 MeSH descriptor ATTITUDE TO HEALTH explode trees 1 and 215902

\#21 MeSH descriptor PATIENT SATISFACTION explode trees 1, 2 and 35527

\#22 patient next satisfaction in All Text 8166

\#23 MeSH descriptor COUNSELING explode trees 1, 2, 3 and 41819

\#24 MeSH descriptor PATIENT CARE this term only 84

\#25 MeSH descriptor HEALTH BEHAVIOR this term only 1155

\#26 MeSH descriptor PATIENT EDUCATION explode trees 1, 2 and 34159

\#27 MeSH descriptor BEHAVIOR THERAPY explode tree 16162

\#28 MeSH descriptor NURSE PRACTITIONERS this term only 240

\#29 MeSH descriptor PHARMACISTS this term only 260

\#30 counsel* $^{*}$ in All Text 6676

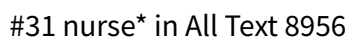

\#32 pharmacist* in All Text 1431

\#33 patient next education* in All Text 5406

\#34 (pharmacy in All Text or pharmacies in All Text) 6169

\#35 (\#1 or \#2 or \#3 or \#4 or \#5 or \#6 or \#7 or \#8 or \#9 or \#10 or \#11) 22017

$\# 36$ (\#12 or \#13 or \#14 or \#15 or \#16 or \#17 or \#18 or \#19 or \#20 or \#21 or \#22) 31158

$\# 37$ (\#23 or \#24 or \#25 or \#26 or \#27 or \#28 or \#29 or \#30 or \#31 or \#32 or \#33 or \#34) 30095

\#38 (\#35 or \#36 or \#37) 63870

\#39 MeSH descriptor Hyperlipidemias explode all trees 3699

\#40 MeSH descriptor ANTILIPEMIC AGENTS explode trees 1 and 23500

\#41 hypercholesterol* in All Text 3505

\#42 hypercholesterol* in All Text 3505

\#43 hyperlipid* in All Text 2339

\#44 statin* in All Text 2174

\#45 antilipid* in All Text 24

\#46 hyperlip* in All Text 2956

\#47 dyslip* in All Text 960

\#48 lipid next lowering in All Text 1499

\#49 cholesterol next lowering in All Text 1074

\#50 antilipemic in All Text 1194

\#51 hypocholesterolemic in All Text 201

\#52 (hydroxymethylglutaryl in All Text near/6 inhibitor* in All Text) 1648

\#53 atorvastatin in All Text 1042

\#54 cerivastatin in All Text 159

\#55 cerivastatin in All Text 159

\#56 pravastatin in All Text 1118

\#57 simvastatin in All Text 1352

$\# 58$ (\#39 or \#40 or \#41 or \#42 or \#43 or \#44 or \#45 or \#46 or \#47 or \#48) 9122

\#59 (\#49 or \#50 or \#51 or \#52 or \#53 or \#54 or \#55 or \#56 or \#57) 5039

Interventions to improve adherence to lipid-lowering medication (Review) 
\#60 (\#58 or \#59) 9857

\#61 (\#38 and \#60)

\section{MEDLINE (on Ovid) Search Strategy}

1 exp Patient Compliance/

2 exp Treatment Refusal/

3 exp Patient Dropouts/

4 exp Attitude to Health/

5 exp Patient Satisfaction/

6 (adher\$ or nonadherence\$ or non-adherence\$).tw.

7 (compliance $\$$ or noncompliance or non-compliance\$).tw.

8 (refusal or refuse\$).tw.

9 (improv\$ adj5 (follow-up or follow up)).tw.

10 (dropout $\$$ or drop-out\$ or drop-out\$).tw.

11 (patient $\$$ adj3 (attitude or acceptance or satisfaction)).tw.

12 (treatment\$ adj3 (stop\$ or abandon\$)).tw.

13 or/1-12

14 exp hyperlipidemias/

15 exp antilipemic agents/

16 hypercholesterol\$.tw.

17 hyperlipid\$.tw.

18 statin\$.tw.

19 antilipid\$.tw.

20 hyperlip?emia.tw.

21 dyslip?emia.tw.

22 lipid lowering.tw.

23 or/14-22

24 exp Counseling/

25 patient care/

26 Case Management/

27 Health Behavior/

28 exp Patient Education as topic/

29 exp Behavior Therapy/

30 (behavi\$ adj3 (modif\$ or therap\$ or adjust\$)).tw.

31 Patient Care Planning/

32 Nurse Practitioners/

33 Pharmacists/

34 counsel\$.tw.

35 (patient\$ adj3 educat\$).tw.

36 ((nurse $\$$ or pharmac\$) adj3 (led\$ or manage or program\$ or based)).tw.

37 or/24-36

3813 or 37

3923 and 38

40 randomized controlled trial.pt.

41 controlled clinical trial.pt.

42 Randomized controlled trials/

43 random allocation/

44 double blind method/

45 single-blind method/

46 or/ $40-45$

47 exp animal/ not humans/

4846 not 47

49 clinical trial.pt.

50 exp Clinical Trials as Topic/

51 (clin\$ adj25 trial\$).ti,ab.

52 ((singl\$ or doubl\$ or trebl\$ or tripl\$) adj (blind\$ or mask\$)).ti,ab.

53 placebos/

54 placebo\$.ti,ab.

55 random $\$ . t i, a b$.

56 research design/

57 or/49-56 
5857 not 47

5958 not 48

60 comparative study.pt.

61 exp evaluation studies/

62 follow up studies/

63 prospective studies/

64 (control\$ or prospectiv\$ or volunteer\$).ti,ab.

65 or/60-64

6665 not 47

6766 not (48 or 59)

6848 or 59 or 67

6939 and 68

\section{Embase (on Ovid) Search Strategy}

1 exp hyperlipidemia/ (50430)

2 exp antilipemic agents/ (89586)

3 hypercholesterol\$.tw. (17607)

4 hyperlipid\$.tw. (13218)

5 statin\$.tw. (12121)

6 antilipid\$.tw. (204)

7 hyperlip?emia.tw. (780)

8 dyslip?emia.tw. (132)

9 lipid lowering.tw. (6704)

10 or/1-9 (130007)

11 exp Counseling/ (43762)

12 patient care/ (74967)

13 Health Behavior/ (14692)

14 exp Patient Education/ (25230)

15 exp Behavior Therapy/ (20055)

16 behavior modification/ (5038)

17 (behavi\$ adj3 (modif\$ or therap\$ or adjust\$)).tw. (14313)

18 Nurse Practitioners/ (1889)

19 Pharmacists/ (20352)

20 (nurse adj3 (led\$ or manage\$ or program\$)).tw. (1389)

21 counsel\$.tw. (34358)

22 nurse based.tw. (69)

23 (nurse adj3 based).tw. (243)

24 patient education\$.tw. (4966)

25 (patient\$ adj3 educat\$).tw. (10362)

26 ((nurse $\$$ or pharmac\$) adj3 (led\$ or manage $\$$ or program $\$$ or based)).tw. (12664)

27 or/11-26 (220705)

28 (adher\$ or nonadherence or non-adherence\$).tw. (61485)

29 (compliance or noncompliance $\$$ or non-compliance\$).tw. (49358)

30 (refusal or refuse\$).tw. (13142)

31 (improv\$ adj5 (follow-up or follow up)).tw. (5243)

32 (dropout\$ or drop-out\$ or drop-out\$).tw. (5828)

33 (patient\$ adj3 (attitude\$ or acceptance $\$$ or satisfaction)).tw. (16597)

34 (treatment\$ adj3 (stop\$ or abandon\$)).tw. (4287)

35 patient compliance/ (42443)

36 Patient Attitude/ (18868)

37 Illness Behavior/ (2265)

38 patient satisfaction/ (32812)

39 or/28-38 (206979)

4027 or $39(403016)$

41 controlled clinical trial/ (43683)

42 random\$.tw. (365568)

43 randomized controlled trial/ (155932)

44 follow-up.tw. (329440)

45 double blind procedure/ (68699)

46 placebo\$.tw. (104515)

47 placebo/ (111476) 
48 factorial\$.ti,ab. (7516)

49 (crossover\$ or cross-over\$).ti,ab. (37689)

50 (double\$ adj blind\$).ti,ab. (81434)

51 (singl\$ adj blind\$).ti,ab. (7084)

52 assign\$.ti,ab. (101847)

\section{CINAHL (on Dialog Datastar)}

1 PATIENT-COMPLIANCE\#.DE.

2 TREATMENT-REFUSAL\#.DE.

3 PATIENT-DROPOUTS.DE.

4 PATIENT-SATISFACTION.DE.

5 ADHER\$6 OR NONADHER\$6 OR NON-ADHER\$

6 COMPLIANCE\$ OR NONCOMPLIANCE\$ OR NON-COMPLIANCE\$

7 REFUSAL OR REFUSE $\$ 47$

8 IMPROV\$5 NEAR (FOLLOW-UP OR FOLLOW ADJ UP)

9 (DROPOUT\$2 OR DROP-OUT\$2).TI,AB

10 (PATIENT\$4 NEAR (ATTITUDE\$4 OR ACCEPTANCE\$4 OR SATISFACTION)).TI,AB.

11 (TREATMENT\$2 NEAR (STOP\$2 OR ABANDON\$5)).TI,AB.

121 OR 2 OR 3 OR 4 OR 5 OR 6 OR 7 OR 8 OR 9 OR 10 OR

13 HYPERLIPIDEMIA\#.W..DE.

14 ANTILIPEMIC-AGENTS\#.DE.

15 HYPERCHOLESTEROL\$.TI,AB.

16 HYPERLIPID\$.TI,AB.

17 STATIN\$.TI,AB.

18 ANTILIPID\$.TI,AB.

19 HYPERLIPAEMIA OR HYPERLIPEMIA

20 (DYSLIPEMIA OR DISLIPEMIAS).TI,AB.

21 (DYSLIPAEMIA\$2 OR DISLIPAEMIA\$2).TI,AB.

22 (LIPID ADJ LOWER\$5).TI,AB.

2313 OR 14 OR 15 OR 16 OR 17 OR 18 OR 19 OR 20 OR 21 OR 22

24 COUNSELING\#.W..DE.

25 PATIENT-CARE\#.DE.

26 CASE-MANAGEMENT.DE.

27 Health-Behavior\#.DE.

28 Patient-Education\#.DE.

29 Behavior-Therapy\#.DE.

31 (behavi\$5 NEAR (modif\$7 OR therap\$5 OR adjust\$5)).TI,AB.

32 Nurse-Practitioners\#.DE.

33 Pharmacists\#.W..DE.

36 (nurse NEAR (led\$2 OR manage\$5 OR program\$2)).TI,AB.

3724 OR 25 OR 26 OR 27 OR 28 OR 29 OR 31 OR 32 OR 33 OR 36

38 Clinical-Trials\#.DE.

39 PT=CLINICAL-TRIAL

41 clin\$5 SAME trial\$2.TI,AB.

42 ((singl\$4 OR doubl\$ OR trebl\$4 OR tripl\$4) ADJ (blind\$4 OR mask\$4)).TI,AB.

43 (placebo\$2 OR random\$6).TI,AB.

44 Evaluation-Research\#.DE.

45 (control\$2 OR volunteer\$2).TI,AB.

4638 OR 39 OR 41 OR 42 OR 43 OR 44 OR 45

4723 AND

4823 AND 37

4947 OR 48

5049 AND 46

\section{PscINFO (on Ovid)}

1 (adhere $^{\star}$ or nonadher ${ }^{\star}$ or non-adher $\left.{ }^{\star}\right)$.tw.

2 exp treatment compliance/

3 exp Treatment Refusal/

4 exp Treatment Dropouts/

5 (compliance* or noncompliance $^{\star}$ or non-compliance).tw.

6 exp Client Attitudes/ 
7 or/1-6

8 treatment outcome clinical trial.md.

9 random*.tw.

10 clinical trial ${ }^{\star}$. tw.

11 controlled study.tw.

12 placebo*.tw.

13 clinical $^{\star}$ stud ${ }^{\star}$. tw

14 ((double ${ }^{\star}$ or single or triple $^{\star}$ or treble $\left.{ }^{\star}\right)$ and (blind ${ }^{\star}$ or mask or sham ${ }^{\star}$ or dummy)).mp. [mp=title, abstract, heading word, table of contents, key concepts]

15 (comparative stud $^{\star}$ or control ${ }^{\star}$ stud $\left.{ }^{\star}\right)$.tw.

16 or/8-15

17 anti!lipemic.mp. [mp=title, abstract, heading word, table of contents, key concepts]

18 anti!lipaemic.tw.

19 lipid lower ${ }^{\star}$. tw.

20 hyperlipid $^{*}$. tw.

21 statin ${ }^{\star}$.tw.

22 hypercholesterol ${ }^{*}$. tw.

23 antilipid $^{*}$. tw.

24 lipid $^{\star}$. tw.

25 cholesterol.tw.

26 or/ $17-25$

277 and 26

287 and 16 and 26

\section{Appendix 3. Search strategies 2016}

\section{CENTRAL}

\#1 compliance

\#2 non-compliance

\#3 noncompliance

\#4 adher $^{*}$

\#5 MeSH descriptor: [Patient Compliance] explode all trees

\#6 MeSH descriptor: [Treatment Refusal] this term only

\#7 MeSH descriptor: [Patient Dropouts] this term only

\#8 nonadherence*

\#9 non-adherence

\#10 nonadherence

\#11 (refusal or refuse ${ }^{\star}$ )

\#12 (improv* near/6 follow next up*)

\#13 (improv* near/6 follow-up*)

\#14 dropout*

\#15 drop next out*

\#16 (abandon* near/6 treatment ${ }^{\star}$ )

\#17 (stop* near/6 treatment*)

\#18 (patient near/6 attitude*)

\#19 (patient near/6 acceptance)

\#20 MeSH descriptor: [Attitude to Health] explode all trees

Interventions to improve adherence to lipid-lowering medication (Review) 
\#21 MeSH descriptor: [Patient Satisfaction] explode all trees

\#22 patient next satisfaction

\#23 MeSH descriptor: [Counseling] explode all trees

\#24 MeSH descriptor: [Patient Care] this term only

\#25 MeSH descriptor: [Health Behavior] this term only

\#26 MeSH descriptor: [Patient Education as Topic] explode all trees

\#27 MeSH descriptor: [Behavior Therapy] explode all trees

\#28 MeSH descriptor: [Nurse Practitioners] this term only

\#29 MeSH descriptor: [Pharmacists] this term only

\#30 counsel $^{*}$

\#31 nurse*

\#32 pharmacist* $^{\star}$

\#33 patient next education*

\#34 (pharmacy or pharmacies)

\#35 comply or complian*

\#36 abandon* near/6 medicat*

\#37 end ${ }^{\star}$ near/6 medicat*

\#38 stop* near/6 medicat*

\#39 patient ${ }^{\star}$ near/6 satisf*

$\# 40 \# 1$ or \#2 or \#3 or \#4 or \#5 or \#6 or \#7 or \#8 or \#9 or \#10 or \#11

$\# 41 \# 12$ or \#13 or \#14 or \#15 or \#16 or \#17 or \#18 or \#19 or \#20 or \#21 or \#22

$\# 42 \# 23$ or \#24 or \#25 or \#26 or \#27 or \#28 or \#29 or \#30 or \#31 or \#32 or \#33 or \#34

\#43 \#40 or \#41 or \#42

\#44 MeSH descriptor: [Hyperlipidemias] explode all trees

\#45 MeSH descriptor: [Hypolipidemic Agents] explode all trees

\#46 hypercholesterol ${ }^{*}$

\#47 hyperlipid*

\#48 statin*

\#49 antilipid*

\#50 hyperlip*

\#51 dyslip*

\#52 lipid next lowering

\#53 cholesterol next lowering

\#54 antilipemic

\#55 hypocholesterolemic 
\#56 (hydroxymethylglutaryl near/6 inhibitor ${ }^{\star}$ )

\#57 atorvastatin

\#58 cerivastatin

\#59 pravastatin

\#60 simvastatin

\#61 hypolipidemic

\#62 antilipemic*

\#63 antihyperlipidemic ${ }^{*}$

\#64 antihyperlipemic*

\#65 bezafibrate

\#66 butoxamine

\#67 clofenapate

\#68 clofibrate

\#69 clofibric next acid

\#70 colestipol

\#71 fenofibrate

\#72 gemfibrozil

\#73 halofenate

\#74 meglutol

\#75 nafenopin

\#76 niacin

\#77 niceritrol

\#78 pyridinolcarbamate

\#79 triparanol

\#80 rosuvastatin

\#81 lovastatin

$\# 82 \# 44$ or \#45 or \#46 or \#47 or \#48 or \#49 or \#50 or \#51 or \#52 or \#53 or \#54 or \#55 or \#56

$\# 83 \# 57$ or \#58 or \#59 or \#60 or \#61 or \#62 or \#63 or \#64 or \#65 or \#66 or \#67 or \#68

$\# 84 \# 69$ or \#70 or \#71 or \#72 or \#73 or \#74 or \#75 or \#76 or \#77 or \#78 or \#79 or \#80 or \#81

\#85 \#82 or \#83 or \#84

$\# 86$ \#43 and \#85

\section{MEDLINE Ovid}

1. exp Patient Compliance/

2. exp Treatment Refusal/

3. exp Patient Dropouts/

Interventions to improve adherence to lipid-lowering medication (Review) 
4. $\exp$ Attitude to Health/

5. exp Patient Satisfaction/

6. (adher\$ or nonadherence\$ or non-adherence\$).tw.

7. (compliance\$ or noncompliance\$ or non-compliance\$).tw.

8. (refusal or refuse\$).tw.

9. (improv\$ adj5 (follow-up or follow up)).tw.

10. (dropout\$ or drop-out\$ or drop-out\$).tw.

11. (patient\$ adj3 (attitude\$ or acceptance\$ or satisfaction)).tw.

12. (treatment\$ adj3 (stop\$ or abandon\$)).tw.

13. exp Counseling/

14. patient care/

15. Case Management/

16. Health Behavior/

17. exp Patient Education as topic/

18. exp Behavior Therapy/

19. (behavi\$ adj3 (modif\$ or therap\$ or adjust\$)).tw.

20. Patient Care Planning/

21. Nurse Practitioners/

22. Pharmacists/

23. counsel\$.tw.

24. (patient\$ adj3 educat\$).tw.

25. ((nurse\$ or pharmac\$) adj3 (led\$ or manage\$ or program\$ or based)).tw.

26. ((stop or end $^{\star}$ or abandon $\left.{ }^{\star}\right)$ adj3 (treat* or medicat $\left.\left.{ }^{\star}\right)\right)$.tw.

27. or/1-26

28. exp hyperlipidemias/

29. exp Hypolipidemic Agents/

30. hypercholesterol\$.tw.

31. hyperlipid\$.tw.

32. statin\$.tw.

33. antilipid\$.tw.

34. hyperlip?emia.tw.

35. dyslip?emia.tw.

36. lipid lowering.tw.

37. hypolipidemic.tw.

38. antilipemic ${ }^{\star}$. tw. 
39. antihyperlipidemic*.tw.

40. antihyperlipemic ${ }^{\star}$. tw.

41. bezafibrate.tw.

42. butoxamine.tw.

43. clofenapate.tw.

44. clofibrate.tw.

45. clofibric acid.tw.

46. colestipol.tw.

47. fenofibrate.tw.

48. gemfibrozil.tw.

49. halofenate.tw.

50. meglutol.tw.

51. nafenopin.tw.

52. niacin.tw.

53. niceritrol.tw.

54. pyridinolcarbamate.tw.

55. simvastatin.tw.

56. triparanol.tw.

57. rosuvastatin.tw.

58. lovastatin.tw.

59. or $/ 28-58$

60.27 and 59

61. randomized controlled trial.pt.

62. controlled clinical trial.pt.

63. randomized.ab.

64. placebo.ab.

65. drug therapy.fs.

66. randomly.ab.

67. trial.ab.

68. groups.ab.

69.61 or 62 or 63 or 64 or 65 or 66 or 67 or 68

70. exp animals/ not humans.sh.

71.69 not 70

72. 60 and 71

73. $\left(\left(2008^{\star}\right.\right.$ or $2009^{\star}$ or $2010^{\star}$ or $2011^{\star}$ or $2012^{\star}$ or $2013^{\star}$ or $2014^{\star}$ or $2015^{\star}$ or $\left.2016^{\star}\right)$ not $\left(200801^{\star}\right.$ or $\left.\left.200802^{\star}\right)\right)$.ed. 
74.72 and 73

\section{Embase Ovid}

1. (adher\$ or nonadherence $\$$ or non-adherence\$).tw.

2. (compliance\$ or noncompliance\$ or non-compliance\$).tw.

3. (refusal or refuse\$).tw.

4. (improv\$ adj5 (follow-up or follow up)).tw.

5. (dropout\$ or drop-out\$ or drop-out\$).tw.

6. (patient\$ adj3 (attitude\$ or acceptance\$ or satisfaction)).tw.

7. (treatment\$ adj3 (stop\$ or abandon\$)).tw.

8. patient compliance/

9. patient attitude/

10. illness behavior/

11. patient satisfaction/

12. exp counseling/

13. patient care/

14. Health Behavior/

15. patient education/

16. exp behavior therapy/

17. behavior modification/

18. (behavi\$ adj3 (modif\$ or therap\$ or adjust\$)).tw.

19. nurse practitioner/

20. pharmacist/

21. (nurse adj3 (led\$ or manage\$ or program\$)).tw.

22. counsel\$.tw.

23. nurse based.tw.

24. (nurse adj3 based).tw.

25. patient education\$.tw.

26. (patient\$ adj3 educat\$).tw.

27. ((nurse\$ or pharmac\$) adj3 (led\$ or manage\$ or program\$ or based)).tw.

28. exp patient attitude/

29. ((stop or end $^{\star}$ or abandon $\left.{ }^{\star}\right)$ adj3 $\left(\right.$ treat $^{\star}$ or medicat $\left.\left.^{\star}\right)\right)$.tw.

30. or/1-29

31. exp hyperlipidemia/

32. exp antilipemic agent/

33. exp antilipemic agent/

Interventions to improve adherence to lipid-lowering medication (Review) 
34. hypercholesterol\$.tw.

35. hyperlipid\$.tw.

36. statin\$.tw.

37. antilipid\$.tw.

38. hyperlip?emia.tw.

39. dyslip?emia.tw.

40. lipid lowering.tw.

41. hypolipidemic.tw.

42. antilipemic*.tw.

43. antihyperlipidemic*.tw.

44. antihyperlipemic ${ }^{\star}$. tw.

45. bezafibrate.tw.

46. butoxamine.tw.

47. clofenapate.tw.

48. clofibrate.tw.

49. clofibric acid.tw.

50. colestipol.tw.

51. fenofibrate.tw.

52. gemfibrozil.tw.

53. halofenate.tw.

54. meglutol.tw.

55. nafenopin.tw.

56. niacin.tw.

57. niceritrol.tw.

58. pyridinolcarbamate.tw.

59. simvastatin.tw.

60. triparanol.tw.

61. rosuvastatin.tw.

62. lovastatin.tw.

63. or/31-62

64.30 and 63

65. random\$.tw.

66. factorial\$̣.tw.

67. crossover\$.tw.

68. cross over\$.tw. 
69. cross-over\$.tw.

70. placebo\$.tw.

71. (doubl\$ adj blind\$).tw.

72. (singl\$ adj blind\$).tw.

73. assign\$.tw.

74. allocat\$.tw.

75. volunteer\$.tw.

76. crossover procedure/

77. double blind procedure/

78. randomized controlled trial/

79. single blind procedure/

80.65 or 66 or 67 or 68 or 69 or 70 or 71 or 72 or 73 or 74 or 75 or 76 or 77 or 78 or 79

81. (animal/ or nonhuman/) not human/

82. 80 not 81

83.64 and 82

84. $\left(\left(2008^{\star}\right.\right.$ or $2009^{\star}$ or $2010^{\star}$ or $2011^{\star}$ or $2012^{\star}$ or $2013^{\star}$ or $2014^{\star}$ or $2015^{\star}$ or $\left.2016^{\star}\right)$ not $\left(200801^{\star}\right.$ or $\left.\left.200802^{\star}\right)\right)$.dd.

85.83 and 84

\section{PsycINFO Ovid}

1. (adhere ${ }^{\star}$ or nonadher ${ }^{\star}$ or non-adher $\left.{ }^{\star}\right)$.tw.

2. treatment compliance/

3. treatment refusal/

4. treatment dropouts/

5. (compliance ${ }^{\star}$ or noncompliance ${ }^{\star}$ or non-compliance).tw.

6. exp client attitudes/

7. (refusal or refuse\$).tw.

8. (improv\$ adj5 (follow-up or follow up)).tw.

9. (dropout\$ or drop-out\$ or drop-out\$).tw.

10. (patient\$ adj3 (attitude\$ or acceptance\$ or satisfaction)).tw.

11. (treatment\$ adj3 (stop\$ or abandon\$)).tw.

12. (behavi\$ adj3 (modif\$ or therap\$ or adjust\$)).tw.

13. counsel\$.tw.

14. (patient\$ adj3 educat\$).tw.

15. ((nurse $\$$ or pharmac\$) adj3 (led\$ or manage $\$$ or program $\$$ or based)).tw.

16. ((stop* or end ${ }^{\star}$ or abandon $\left.{ }^{\star}\right)$ adj3 (treat* or medicat $\left.\left.{ }^{\star}\right)\right)$.tw.

17. or/1-16 
18. anti!lipemic.mp.

19. anti!lipaemic.tw.

20. lipid lower ${ }^{\star}$. tw.

21. hyperlipid ${ }^{*}$. tw.

22. statin ${ }^{\star}$. tw.

23. hypercholesterol ${ }^{\star}$. tw.

24. antilipid.tw.

25. lipid*.tw.

26. cholesterol.tw.

27. hyperlip?emia.tw.

28. dyslip?emia.tw.

29. hypolipidemic.tw.

30. antilipemic ${ }^{\star} . t w$.

31. antihyperlipidemic ${ }^{\star} . t w$.

32. antihyperlipemic ${ }^{\star} . t w$.

33. bezafibrate.tw.

34. butoxamine.tw.

35. clofenapate.tw.

36. clofibrate.tw.

37. clofibric acid.tw.

38. colestipol.tw

39. fenofibrate.tw.

40. gemfibrozil.tw.

41. halofenate.tw.

42. meglutol.tw.

43. nafenopin.tw.

44. niacin.tw.

45. niceritrol.tw.

46. pyridinolcarbamate.tw.

47. simvastatin.tw.

48. triparanol.tw.

49. rosuvastatin.tw.

50. lovastatin.tw.

51. or/18-50

52. 17 and 51

Interventions to improve adherence to lipid-lowering medication (Review) 
53. random\$.tw.

54. factorial\$.tw.

55. crossover\$.tw.

56. cross-over\$.tw.

57. placebo\$.tw.

58. (doubl\$ adj blind\$).tw.

59. (singl\$ adj blind\$).tw.

60. assign\$.tw.

61. allocat\$.tw.

62. volunteer\$.tw.

63. control*.tw.

64. "2000".md.

65. or/53-64

66.52 and 65

$67 .\left(\left(2008^{\star}\right.\right.$ or $2009^{\star}$ or $2010^{\star}$ or $2011^{\star}$ or $2012^{\star}$ or $2013^{\star}$ or $2014^{\star}$ or $2015^{\star}$ or $\left.2016^{\star}\right)$ not $\left(200801^{\star}\right.$ or $\left.\left.200802^{\star}\right)\right)$.up.

68.66 and 67

\section{CINAHL}

\section{S56 S54 AND S55}

S55 EM 20080330-20160203

\section{S54 S35 AND S53}

S53 S36 or S37 or S38 or S39 or S40 or S41 or S42 or S43 or S44 or S45 or S46 or S47 or S48 or S49 or S50 or S51 or S52

S52 TX cross-over*

S51 TX crossover*

S50 TX volunteer ${ }^{\star}$

S49 (MH "Crossover Design")

S48 TX allocat*

S47 TX control ${ }^{\star}$

S46 TX assign*

S45 TX placebo*

S44 (MH "Placebos")

S43 TX random*

S42 TX (doubl* N1 mask ${ }^{\star}$ )

S41 TX (singl ${ }^{*}$ N1 mask ${ }^{\star}$ )

S40 TX (doubl* N1 blind ${ }^{\star}$ )

S39 TX (singl ${ }^{\star}$ N1 blind*) 
S38 TX (clinic* N1 trial?)

S37 PT clinical trial

S36 (MH "Clinical Trials+")

S35 S22 AND S34

S34 S12 OR S33

S33 S23 OR S24 OR S25 OR S26 OR S27 OR S28 OR S29 OR S30 OR S31 OR S32

S32 nurse N4 (led ${ }^{\star}$ or manage* or program*)

S31 (MH "Pharmacists")

S30 (MH "Nurse Practitioners")

S29 behavi ${ }^{\star}$ N4 (modif* or therap* or adjust ${ }^{\star}$ )

S28 (MH "Behavior Therapy")

S27 (MH "Patient Education")

S26 (MH "Health Behavior")

S25 (MH "Case Management")

S24 (MH "Patient Care")

S23 (MH "Counseling+")

S22 S13 OR S14 OR S15 OR S16 OR S17 OR S18 OR S19 OR S20 OR S21

S21 lipid* N2 lower*

S20 dyslipemia* or dislipemia*

S19 hyperlipaemia or hyperlipemia

S18 antilipid* $^{*}$

S17 statin* or rosuvastatin or lovastatin

S16 hyperlipid*

S15 hypercholesterol ${ }^{*}$

S14 (MH "Antilipemic Agents+")

S13 (MH "Hyperlipidemia+")

S12 S1 OR S2 OR S3 OR S4 OR S5 OR S6 OR S7 OR S8 OR S9 OR S10 OR S11

S11 treatment* N3 (stop* or abandon ${ }^{\star}$ )

S10 patient ${ }^{\star}$ N6 (attitude* or acceptance* or satisfaction)

S9 dropout* or drop-out*

S8 improv* N5 (follow-up or "follow up")

S7 resusal or refuse*

S6 compliance* or noncompliance* or non-compliance*

S5 adher* or nonadher* or non-adher*

S4 (MH "Patient Satisfaction")

Interventions to improve adherence to lipid-lowering medication (Review) 
S3 (MH "Patient Dropouts")

S2 (MH "Treatment Refusal")

S1 (MH "Patient Compliance+")

\section{FEE D B A C K}

\section{Conclusions and methods, November 2017}

\section{Summary}

In their Cochrane Systematic Review, Van Driel et al. reported statistically significant improvement of medication adherence and reductions in total cholesterol and LDL-C with intensified patient care. They concluded that healthcare systems that are able to implement such interventions "may well be successful in decreasing the burden of cardiovascular disease in the populations whom they serve through improved adherence to statin medications." We are not convinced of this statement as it makes several potentially invalid assumptions. Firstly, a clear unidirectional association between achieving lower LDL-C targets (as would be achieved by improved adherence to lipidlowering medications) and a decreased risk of mortality, is not apparent in the current body of evidence. Although two recent metaanalyses by Silverman et al. and Koskinas et al. have shown an association between lower LDL-C levels and risk of major vascular events, a systematic review by Ravnskov et al. suggested an inverse association between LDL-C and mortality in the elderly. Given the results of the latter study, more intensive LDL-C lowering does not necessarily translate to improved clinical outcomes, and may in fact be associated with harm in certain populations. Furthermore, there are examples of interventions that reduce LDL-C and do not result in clinical benefit (e.g. ezetimibe), and drugs that increase LDL-C but have benefit for cardiovascular outcomes (e.g. empagliflozin). We believe that measurement of LDL-C lowering is not a good surrogate for cardiovascular benefit due to these conflicting observations amongst studies.

With the evidence mentioned above, we believe that investigating clinical outcomes would have been more relevant than assessing LDL$\mathrm{C}$ lowering in this review. However, the included studies did not report any usable data for health outcome indications (e.g. all-cause mortality, cardiovascular events), adverse effects or costs/resource use, and Van Driel et al. assessed the included studies in their review to have a low risk of reporting bias. The Cochrane Handbook states, "in many systematic reviews, only a few eligible studies can be included in a meta-analysis for a specific outcome because the necessary information [is] not reported by the other studies. While that outcome may not have been assessed in some studies, there is almost always a risk of biased reporting for some studies. Review authors need to consider whether an outcome was collected but not reported or simply not collected". It is unclear whether van Driel et al. have determined if relevant and important clinical outcomes such as mortality were collected but not reported or simply not collected in the included studies. Without such information, we believe that at the very least, the risk of bias is unclear.

We also believe that performing a per-protocol analysis instead of an intention to treat analysis may result in misleading effect estimates that do not accurately represent the true effect of adherence interventions. Per-protocol analyses represent an ideal scenario where patients are under close observation by study investigators and may be more motivated to adhere to study treatments. In a real-world scenario, patients are not monitored so closely and may be less motivated than patients included in RCTs. As a result, adherence to interventions may be lower than in RCTs. An intention to treat analysis may be a more accurate representation of the true effect of these adherence interventions in real life, since it would include data from those who deviate from study protocols. By focusing on participants who are adherent to their lipid-lowering therapy, the effect size of these interventions is overestimated.

\section{Reply}

Thank you for your thoughtful feedback on our review. The points you raise are very pertinent. We discussed these issues extensively within the author team when working on the review.

We fully agree that cholesterol levels are merely surrogate markers of the burden of cardiovascular disease in the population. They are also surrogate outcomes of trials aimed at reducing cardiovascular outcomes in individuals. Ideally, studies would collect data on clinical outcomes such as morbidity or mortality. Unfortunately, none of the studies included in this review report these outcomes. This may be explained by the fact that the focus of the trials was on improving medication adherence (primary outcome in the majority of included studies). The cholesterol markers were measured as an indicator of adherence to the lipid-lowering drug, not as a marker of effectiveness of the drug. Therefore, we don't think that this is highly suspicious of reporting bias. Most studies were simply not designed to track morbidity and mortality outcomes. This of course, shows the limitations of the available evidence. As clinicians we would be most interested in knowing if encouraging and monitoring our patients to be compliant with the treatments we prescribe, is worthwhile on outcomes that matter to patients (and not just lipid levels). Our review doesn't give a straightforward answer. We can only say that these interventions seem to improve adherence to treatment which is reflected in cholesterol levels. These in turn are linked (albeit not directly) to cardiovascular outcomes.

Your point regarding the per-protocol analysis is valid. We may be painting a more ideal picture with this kind of analysis. In the real world, without the careful follow up of a clinical trial, patients are often much less adherent to their medications. Moreover, we know that people who participate in trials are usually better motivated than those who choose not to. However, an intention to treat (ITT) analysis which considers all those lost to follow up as treatment failures (in this case non-adherent), will seriously underestimate the effect. If the per protocol (PP) analysis provides a 'best case scenario', the ITT analysis portrays the 'worst case'. In this review we have chosen to report the 
PP analysis as the interventions are complex and mostly pragmatic (set in the 'messiness' of real world health systems, which means that even the follow up of participants in the trials is messy). We considered that PP would at least reveal the potential of these interventions (as it is unlikely that there would be much impact in ITT analysis). We describe this in our methods section.

We are in the process of updating the searches for this review and will include these reflections if an update to our review is published. Thank you for taking the time to comment on our review and its findings.

\section{Contributors}

Candy Lee, Karen Ng, Shalini Singla, Marco Yeung (Comment contributors)

Mieke van Driel (Author)

Bill Cayley (Feedback Editor, Cochrane Heart)

Nicole Martin (Managing Editor, Cochrane Heart)

WHAT'S NEW

\begin{tabular}{lll}
\hline Date & Event & Description \\
\hline 26 March 2021 & Amended & $\begin{array}{l}17 \text { new studies have been identified with the latest search in Feb- } \\
\text { ruary 2019. They have been assessed as not changing the find- } \\
\text { ings of the review. The review is therefore considered up-to-date. } \\
\text { For a list of these 17 studies, please contact cochrane.heart@u- } \\
\text { cl.ac.uk. }\end{array}$ \\
\hline
\end{tabular}

\section{H I S T O R Y}

Protocol first published: Issue 3, 2003

Review first published: Issue 4, 2004

\begin{tabular}{lll}
\hline Date & Event & Description \\
\hline 23 March 2018 & Feedback has been incorporated & Feedback and reply added. \\
\hline February 2016 & New search has been performed & New searches run and incorporated. \\
\hline 10 July 2015 & $\begin{array}{l}\text { New citation required and conclusions } \\
\text { have changed }\end{array}$ & 16 new studies included. Conclusions changed. \\
\hline 7 March 2015 & New search has been performed & $\begin{array}{l}\text { Searches up-to-date to 14 January 2015. New author team and } \\
\text { updated review format. }\end{array}$ \\
\hline 15 January 2013 March 2009 & Review declared as stable & Authors no longer wish to update. \\
\hline hew citation required but conclusions & $\begin{array}{l}\text { Change of authors. } \\
\text { have not changed }\end{array}$ & $\begin{array}{l}\text { New search has been performed } \\
\text { the search was updated to March 2008. Randomised controlled } \\
\text { identified and included in the review. The conclusion has not } \\
\text { changed significantly. }\end{array}$ \\
\hline
\end{tabular}




\begin{tabular}{lll}
\hline Date & Event & Description \\
\hline 1 August 2004 & $\begin{array}{l}\text { New citation required and conclusions } \\
\text { have changed }\end{array}$ & Substantive amendment
\end{tabular}

\section{CONTRIBUTIONS OF AUTHORS}

Mieke van Driel led the review team and provided oversight, statistical expertise, manuscript writing, and gave direction to the group.

Michael Morledge was involved with the selection of studies, data extraction, assessment of risk of bias in included studies, pooling of data, manuscript writing, and data analysis.

Robin Ulep was involved with the selection of included studies, data extraction, assessment of risk of bias in included studies, pooling of data, manuscript writing, and data analysis.

Johnathon Shaffer assisted with selection of studies, data extraction, and manuscript writing.

Phillipa Davies was part of the original author team and for this update assisted with proofreading and manuscript writing.

Richard Deichmann assisted with management of the project, guidance of study team, study inclusion, and manuscript writing.

\section{DECLARATIONS OF INTEREST}

Mieke $L$ van Driel declares that there is no conflict of interest.

Michael D Morledge declares that there is no conflict of interest.

Robin Ulep declares that there is no conflict of interest.

Johnathon P Shaffer declares that there is no conflict of interest.

Philippa Davies declares that there is no conflict of interest.

Richard Deichmann declares that there is no conflict of interest.

\section{SOURCES OF SUPPORT}

\section{Internal sources}

- Academic Unit of Primary Health Care, University of Bristol, UK

- South West Deanery, Bristol, UK

- Tayside Centre for General Practice, University of Dundee, UK

- Ochsner Health System, New Orleans, LA, USA

\section{External sources}

- No sources of support supplied

\section{DIFFERENCES BETWEEN PROTOCOLANDREVIEW}

The protocol for this review was published in 2003 (Schedlbauer 2003). The initial review was published in 2004 (Schedlbauer 2004 ) and the previous update in 2010 (Schedlbauer 2010).

A novel type of intervention, i.e. "large scale pharmacy-led automated telephone call" was introduced in Fischer 2014 and added to the list of interventions to be considered in this review.

Pooling of the results warranted sensitivity analysis to assess heterogeneity in this version of the review. Also, in this review we compared the results of pooling with a random-effects model to those using a fixed-effect model when statistical heterogeneity was low $(12<40 \%)$ in order to assess the robustness of the effect estimate.

We also added a sensitivity analysis to assess the impact of high study attrition rates on the overall effect estimate where relevant. We added a Summary of Findings table with GRADE assessments. 


\section{N D EX TERMS}

\section{Medical Subject Headings (MeSH)}

Cardiovascular Diseases [prevention \& control]; Cholesterol [blood]; Cholesterol, LDL [blood]; Hypolipidemic Agents [*therapeutic use]; *Medication Adherence [statistics \& numerical data]; Randomized Controlled Trials as Topic; Reminder Systems

\section{MeSH check words}

Adult; Humans 